\title{
RELAÇÕES INTERSETORIAIS DA ECONOMIA ACREANA E SUA INSERÇÃO NA ECONOMIA BRASILEIRA: UMA ANÁLISE INSUMO-PRODUTO
}

\section{LANA MIRIAN SANTOS DA SILVA}

\author{
Dissertação apresentada à Escola Superior de \\ Agricultura "Luiz de Queiroz", Universidade de \\ São Paulo, para obtenção do título de Mestre em \\ Ciências, Área de Concentração: Economia \\ Aplicada.
}

P I R A C I C A B A

Estado de São Paulo - Brasil

Maio - 2004 


\title{
RELAÇÕES INTERSETORIAIS DA ECONOMIA ACREANA E SUA INSERÇÃO NA ECONOMIA BRASILEIRA: UMA ANÁLISE INSUMO-PRODUTO
}

\section{LANA MIRIAN SANTOS DA SILVA}

Engenheiro Florestal

Orientador: Prof. Dr. LUIZ CARLOS ESTRAVIZ RODRIGUEZ

\author{
Dissertação apresentada à Escola Superior de \\ Agricultura "Luiz de Queiroz", Universidade de \\ São Paulo, para obtenção do título de Mestre em \\ Ciências, Área de Concentração: Economia \\ Aplicada.
}

P I R A C I C A B A

Estado de São Paulo - Brasil

Maio - 2004 


\section{Dados Internacionais de Catalogação na Publicação (CIP) DIVISÃO DE BIBLIOTECA E DOCUMENTAÇÃO - ESALQ/USP}

Silva, Lana Mirian Santos da

Relações intersetoriais da economia acreana e sua inserção na economia brasileira: uma análise insumo-produto / Lana Mirian Santos da Silva. - - Piracicaba, 2004. $165 \mathrm{p}$.

Dissertação (mestrado) - - Escola Superior de Agricultura Luiz de Queiroz, 2004. Bibliografia.

1. Desenvolvimento econômico 2. Economia 3. Insumo-produto 4. Integração econômica 5. Política públicas 6 . Relação Intersetorial I. Título

CDD 339.23

"Permitida a cópia total ou parcial deste documento, desde que citada a fonte - O autor" 


\section{DEDICATÓRIA}

Ao grande e eterno amor da minha vida que mesmo passando por momentos difíceis, de "escuridão" e dor, teve a serenidade de me incentivar, apoiar e demonstrar todo seu amor e fé. A você, querido e amado PAI (José Nicolau da Silva), dedico esse singelo trabalho!!

E, também, à minha querida e amada MÃE (Gidalci Santos da Silva) por sua força, alegria, fé e por suas orações, sem os quais esse trabalho não teria chegado ao fim!

E, aos meus maninhos maravilhosos, grandes exemplos na minha vida:

JANÚBIA, RUI, JONISI, KELLY e RENATO. 


\section{AGRADECIMENTOS}

“Em tudo daí graças. O pai assim diz. Em tudo dai graças pois serás mais feliz!...."

Agradecer significar reconhecer que a caminhada só foi possível devido ao apoio, orações, incentivo e orientação de inúmeras pessoas dentre as quais faço questão de destacar:

A DEUS, a quem TUDO é possível e porque...

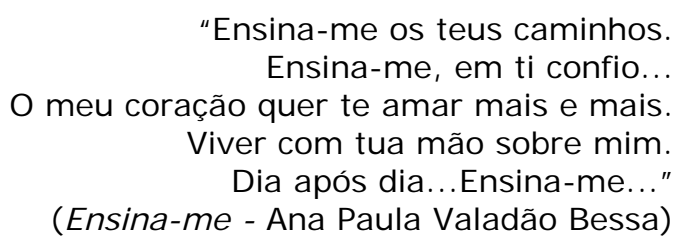

... e, por ter me dado:

Uma bela e grande FAMILÍA:

José Nicolau da Silva e Gidalci Santos da Silva - meus pais; Janúbia, Rui, Jonisi, Kelly e Renato - meus irmãos e irmãs;

Natal, Elide, Paulo e Claudinei - meus cunhados e cunhada;

Erich, Ricardo, Letícia, Bruno, Alexandre - meus sobrinhos e sobrinha;

Elezeni da Silva Guerra - minha grande tia! e

Joana e Esther - minhas avós 
Inúmeros AMIGOS, porque...

“Ser amigos é pra sempre como eterno é nosso Deus.

Como amigos nós diremos até breve e não adeus. Eu agora vou partir, sobre a mão do pai seguir.

Mas amigos nada vai nos separar...

Amigos nada vai nos separar..."

(Amigos - Eduardo e Silvana)

... e dentre os quais destaco:

Aqueles que ficarão eternamente no meu coração: Débora Pignatari Drucker, Margarida Garcia de Figueiredo, Tatiana Mahalen do Amaral, Eliza Harumi Takashiba, Daniela Andrade Medeiros, Marky Brito, Ana Schiling, Clariça Cacciamali, Rosangela Pontilli, Andréa Dorr, Greice Baltieri, Renata Ferrari, Ivo Rosa Filho, Jefferson Polizel, Daniela Bacchi.

Os amigos da Athena, pelo apoio principalmente na fase final dessa pesquisa: Milena, Adriele, Ivo, Tatiana, Alexandre, Melissa, Thiago e Silvana.

E aqueles que de tão amigos, se tornaram maninhos do coração: à minha super amiga de todas as horas Kerlyng Cecchini com quem tive o privilégio de trabalhar, estudar, ir ao cinema e compartilhar sonhos e anseios durante o primeiro ano do mestrado. Ao meu amigão Elvis Joacir França (Nanis) por seu jeito menino de ser, por seu carinho e atenção. E, ao meu também amigão, prof. Luiz Carlos, meu maninho mais velho. Grande exemplo pra mim!

Dois grandes ORIENTADORES:

Prof. Dr. Joaquim José Martins Guilhoto e Prof. Dr. Luiz Carlos estraviz Rodriguez

Ao primeiro, agradeço por ter aceitado essa florestal forasteira no seu grupo Projeções Econômicas do CEPEA sem o apoio do qual essa dissertação não teria sido concluída. Agradeço imensamente a sua atenção, cuidado e a paciência com que esclareceu todas as minhas dúvidas. E, também, por suas sugestões, críticas e por ter ajudado a acertar o rumo dessa dissertação!

Ao segundo, agradeço por fazer parte da minha formação desde o final da graduação, agradeço pelo incentivo, dicas, apoio e por suas terapias nos momentos mais difíceis em que pensei em largar tudo. Agradeço pela pessoa íntegra que o sr. é, pela habilidade que tens de ser mestre e amigo e pela paciência com que me orientou, sentando inúmeras vezes para discutirmos os rumos desse trabalho. 
Porque...

"Só é um mestre completo aquele que tem conhecimento para legar, altruísmo para transmitir, energia para incentivar a dedicação para perseverar face à indiferença “

(Antonio Ermírio de Moraes)

Dois PATROCINADORES: professor Joaquim José Martins Guilhoto e meu cunhado Paulo Sérgio Silva.

Toda a INFRA-ESTRUTURA necessária para o desenvolvimento dessa dissertação, localizada no Departamento de Ciências Florestais da ESALQ/USP.

E pelos FUNCIONÁRIOS e PROFESSORES do Departamento de Economia, Administração e Sociologia: Maielli, sr. Pedro, Ligiana, Álvaro, Marilena, Helena e Dna. Maria.

Aos FUNCIONÁRIOS do Departamento de Ciências Florestais: Margarete, sr. José, Jefferson, Evandro e Marialice.

Aos PROFESSORES Alexandre Lahóz Mendonça de Barros, Joaquim Bento de Souza Ferreira Filho e Silvia Helena Galvão de Miranda pelas críticas e sugestões dadas no seminário e na qualificação.

E, por fim, a todos que direta e indiretamente contribuíram para a realização dessa pesquisa e que por ventura não tiveram seus nomes registrados aqui. 


\section{SUMÁRIO}

Página

LISTA DE FIGURAS ………………………………………………………... ix

LISTA DE TABELAS ….......................................................................... xi

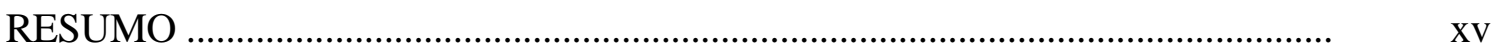

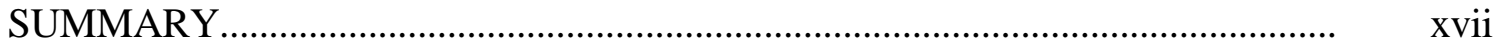

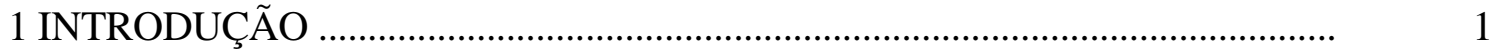

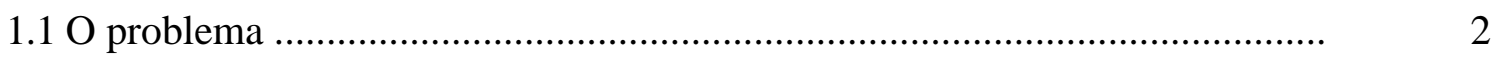

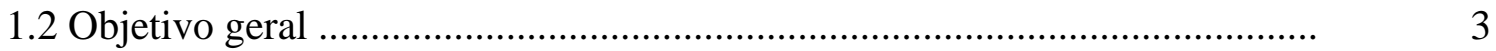

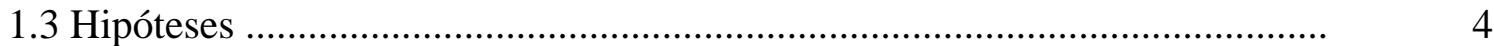

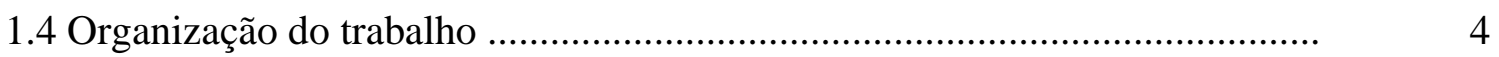

2 POLÍTICAS DESENVOLVIMENTISTAS PARA A REGIÃO NORTE:

UMA PERSPECTIVA HISTÓRICA …....................................................

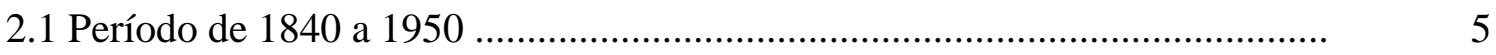

2.2 Período de 1960 até o presente …....................................................................

3 MATERIAL E MÉTODOS ….................................................................... 12

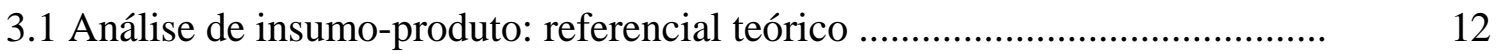

3.1.1 Leontief e os antecedentes históricos da teoria de insumo-produto ............. 12

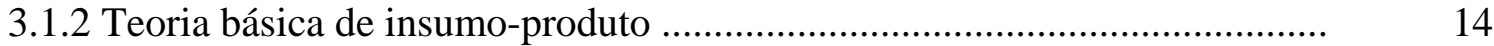

3.1.3 Hipóteses do modelo de insumo-produto .............................................. 18

3.1.4 Modelos de insumo-produto regionais e inter-regionais ........................... 20

3.1.5 Obtenção do sistema de Leontief ............................................................. 26

3.1.6 Estrutura produtiva, ligações interindustriais e setores-chave ................... 31 
3.2 O Estado do Acre como modelo para estudos de insumo-produto .............. 44

3.2.1 Aspectos históricos .......................................................................... 44

3.2.2 Características gerais ........................................................................ 46

3.2.3 Demografia .............................................................................. 48

3.2.4 Aspectos ambientais e hidrografia .................................................. 49

3.2.5 Os setores primário, secundário e terciário da economia acreana ....... 51

3.2.6 Exportações acreanas ........................................................................ 71

3.2.7 Obtenção dos dados e construção da matriz de insumo-produto interregional Acre vs. resto do Norte vs. resto do Brasil ....................................... 73

3.2.8 Produto interno bruto florestal acreano .................................................. 83

4 RESULTADOS E DISCUSSÃO ......................................................... 88

4.1 Índices de ligação de Hirschman-Rasmussen ............................................ 90

4.2 Campo de influência ................................................................................ 98

4.3 Índices puros de ligação .......................................................................... 101

4.3.1 Interação entre as regiões do sistema inter-regional ............................... 109

4.4 Multiplicadores tipo I e tipo II ............................................................... 111

4.5 Produtointerno bruto florestal acreano...................................................... 130

4.6 Aplicação dos resultados........................................................................ 134

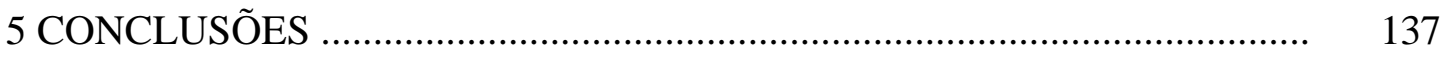

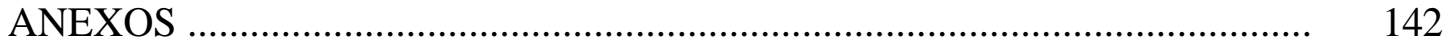

REFERÊNCIAS BIBLIOGRÁFICAS ......................................................... 160 


\section{LISTA DE FIGURAS}

Página

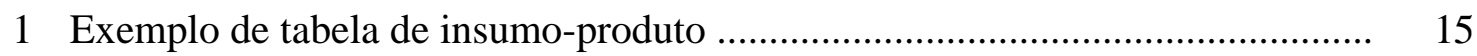

2 Esquema do sistema de insumo-produto .................................................. 27

3 Acre: localização, fronteiras nacionais e internacionais ............................... 46

4 Hidrografia, rodovias, projetos de assentamento e colonização, terras indígenas e unidades de conservação do Estado do Acre .............................. 50

5 Valor da produção de cada produto da extrativa vegetal do Acre - 1990 a 2002

66

6 Efetivos dos rebanhos, em mil cabeças, para o Acre no período de 1995 a 2002

7 Representação das matrizes de produção do sistema Amazônia Legal + resto do Brasil e das matrizes de produção do sistema Acre + resto do Norte + resto do Brasil

8 Consumo intermediário e valor adicionado do sistema Acre, resto do Norte e resto do Brasil

9 Agregação dos 90 setores da matriz de insumo-produto Brasil, 1999 para os 53 setores componentes do sistema inter-regional Acre vs. resto do Norte vs. sesto do Brasil 
10 Padrões médios de comportamento dos índices de Hirschman-Rasmussen do Acre, Resto do Norte e Resto do Brasil - 1999 ........................................... 91

11 Índices de ligações para frente de Hirschman-Rasmussen para as regiões Acre, resto do Norte e resto do Brasil - índices dependentes ......................... 93

12 Índices de ligações para trás de Hirschman-Rasmussen para as regiões Acre, resto do Norte e resto do Brasil - índices dependentes ................................ 94

13 Coeficientes setoriais com maior campo de influência para o Acre ................ 99

14 Coeficientes setoriais com maior campo de influência para o resto do Norte. 100

15 Coeficientes setoriais com maior campo de influência para o resto do Brasil 101

16 Índices puros de ligações normalizados para frente para as regiões Acre, resto do Norte e resto do Brasil - índices dependentes ................................ 105

17 Índices puros de ligações normalizados para trás para as regiões Acre, resto do Norte e resto do Brasil - índices dependentes ....................................... 106

18 Setores-chave consolidados no sistema inter-regional: critério do índice puro total de ligação maior que um e critério mais restritivo dos índices de

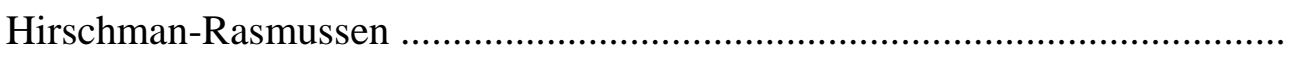

19 Participação (\%) dos estados da região Norte brasileira no PIB da região, 2000 


\section{LISTA DE TABELAS}

Página

1 Densidade demográfica do Acre de 1920 a 2000 ......................................... 49

2 Número de empresas e pessoal ocupado, por categorias de atividades, para o Acre de 1996 a 2001

3 Número de empresas e pessoal ocupado segundo as categorias de atividades “Agricultura, pecuária, silvicultura e exploração florestal” (A) e “Pesca” (B), para o Estado do Acre em 2001

4 Valor da produção e área plantada de lavouras temporárias para os anos de 1990 a 2002 - Brasil, Norte e Acre

5 Valor da produção e área plantada de lavouras permanentes para os anos de 1990 a 2002 - Brasil, Norte e Acre

6 Participação (\%) de cada tipo de produto extrativo dos grupos: alimentícios, borrachas e oleaginosos, no total produzido por esses três grupos, para o Estado do Acre, de 1990 a 2002

7 Produção total de extrativos dos grupos: alimentícios, borrachas e oleaginosos do Brasil, Norte e Acre, para o período de 1990 a 2002

8 Participação (\%) dos produtos extrativos lenha, madeira em tora e carvão vegetal, no total produzido, correspondente a soma desses três produtos, para o Estado do Acre, de 1990 a 2002 
9 Produtos de origem animal do estado do Acre -1990 a 2002 ......................... 68

10 Participação percentual das categorias C, D, E e F no número total de empresas e pessoal ocupado total - Acre, 2001

11 Exportações do Estado do Acre: total e de produtos florestais, para o período de 1996 a 2003

12 Cinco mais importantes setores, de acordo com os índices de ligações intersetoriais de Hirschman-Rasmussen

13 Setores-chave de acordo com o critério de McGilvray (1977)

14 Cinco mais importantes setores, de acordo com os índices puros totais normalizados

15 Cinco setores mais importantes, de acordo com os índices puros para trás e para frente normalizados

16 Produção das regiões: Acre, resto do Norte e resto do Brasil induzida pela demanda final da própria região e das outras regiões do sistema inter-regional, em bilhões de reais de 1999

17 Importância do Acre, resto do Norte e resto do Brasil na indução da produção do sistema inter-regional

18 Multiplicadores de produção setoriais para o Acre

19 Multiplicadores de produção para o resto do Norte

20 Multiplicadores de produção para o resto do Brasil

21 Setores que apresentaram maiores valores de multiplicadores de emprego do tipo I e do tipo II nas regiões: Acre, resto do Norte e resto do Brasil 
22 Número total de empregos gerados no Acre, resto do Norte e resto do Brasil, para a variação de um milhão de reais na demanda final.

23 Geração de empregos diretos, indiretos, induzidos e total no Acre, resto do Norte e resto do Brasil, para a variação de um milhão de reais da demanda final

24 Número de empregos diretos, indiretos, induzidos e total gerados pelos setores Extrativismo vegetal e silvicultura, Indústria da madeira, Indústria do mobiliário, Fabricação de celulose, pasta mecânica, papel, papelão e artefatos de papel, Indústria editorial e gráfica e Indústria da borracha de cada região do sistema inter-regional

25 Setores que apresentaram maiores valores de multiplicadores de renda do tipo I e do tipo II nas regiões: Acre, resto do Norte e resto do Brasil

26 Setores mais importantes na geração de renda direta e indireta em cada uma das regiões do sistema inter-regional

27 Participação (\%) das importações no valor da produção das regiões do sistema inter-regional no ano de 1999

28 Setores que apresentaram maiores valores de multiplicadores de importação do tipo I e do tipo II nas regiões: Acre, resto do Norte e resto do Brasil

29 Setores mais importantes na geração de importação direta e indireta em cada uma das regiões do sistema inter-regional

30 Produto Interno Bruto (R\$ milhão e \%) das macro regiões brasileiras e do Brasil para o ano 2000 
31 Número de empresas e pessoal ocupado segundo categorias de atividades C, D, E e F do Estado do Acre, para o ano 2001

32 Número de empresas e pessoal ocupado segundo categorias de atividades, G até O, para o Estado do Acre, para o ano 2001

33 Índices de ligação de Hirschman-Rasmussen para trás e para frente para o sistema inter-regional Acre, resto do Norte e resto do Brasil (1999) - índices dependentes

34 Índices de ligação de Hirschman-Rasmussen para trás e para frente para o sistema inter-regional Acre, resto do Norte e resto do Brasil (1999) - índices 149 dependentes

35 Índices puros de ligação totais para as regiões Acre, resto do Norte e resto do Brasil (1999) - índices dependentes

36 Índices puros de ligação para trás e para frente para o sistema inter-regional Acre, resto do Norte e resto do Brasil (1999) - índices dependentes

37 Multiplicador de emprego tipo I para o Acre, resto do Norte e resto do Brasil .

38 Multiplicador de emprego tipo II para o Acre, resto do Norte e resto do Brasil

39 Multiplicador de renda tipo I para o Acre, resto do Norte e resto do Brasil ...

40 Multiplicador de renda tipo II para o Acre, resto do Norte e resto do Brasil ..

41 Geração de renda direta e indireta no Acre, resto do Norte e resto do Brasil .

42 Geração de importações diretas e indiretas nos setores do Acre, resto do Norte e resto do Brasil 


\title{
RELAÇÕES INTERSETORIAIS DA ECONOMIA ACREANA E SUA INSERÇÃO NA ECONOMIA BRASILEIRA: UMA ANÁLISE INSUMO- PRODUTO
}

\author{
Autora: LANA MIRIAN SANTOS DA SILVA \\ Orientador: Prof. Dr. LUIZ CARLOS ESTRAVIZ RODRIGUEZ
}

\section{RESUMO}

Este estudo aplicou os princípios da teoria insumo-produto para analisar a importância relativa dos setores primários e, em especial, do setor florestal para a economia acreana, bem como a sua dependência com relação às regiões resto do Norte e resto do Brasil. Os resultados decorrentes desta análise também permitiram caracterizar a estrutura produtiva do Acre, os seus setores-chave e o efeito multiplicador de cada setor econômico em termos de produção, emprego, renda e importação. Através dos resultados obtidos, a hipótese inicialmente formulada de que os setores primários juntamente com os setores relacionados ao comércio e serviços constituem a base da economia acreana pôde ser confirmada. Destaca-se também o fato de os setores Extrativismo vegetal e silvicultura, Indústria da madeira, Indústria do mobiliário, Fabricação de celulose, papel, papelão e artefatos de papel, Indústria editorial e gráfica, e Indústria da borracha, constituintes do macro-setor florestal, não exercerem de fato papel chave na economia acreana, apesar do impacto positivo destes na geração de 
empregos diretos. Se utilizados os índices de Hirschman-Rasmussen, esse papel chave é exercido pelos setores Metalurgia básica, Indústria têxtil, Outros metalúrgicos, Comunicações, Indústria de alimentos, Químicos diversos, Serviços industriais de utilidade pública, e Instituições financeiras. Se utilizados os índices puros, surgem como setores-chave para a economia acreana os setores Comércio, Saúde pública, Construção civil, Serviços prestados às empresas e Outros administração pública. Em termos de efeito multiplicador de produção, emprego, renda e importação, os setores relacionados a Abate de animais merecem destaque nessas quatro categorias. Industria têxtil e Metalurgia básica se destacam pelo efeito multiplicador da produção; Elementos químicos e Comunicações, pelo efeito multiplicador de emprego; Metalurgia básica e Automóveis, caminhões, ônibus e peças pelo efeito multiplicador da renda, e Saúde mercantil e Indústria da madeira destacaram-se pelo efeito multiplicador de importações. Através da decomposição da produção total de cada região (Acre, resto do Norte e resto do Brasil) em produção induzida pela demanda final da própria região e produção induzida pela demanda final das demais regiões do sistema, constata-se uma baixa ligação entre todas as regiões do sistema inter-regional. No entanto, uma variação na demanda final dos setores do Acre afeta mais a produção da economia do resto do Brasil do que do resto do Norte. A matriz de insumo-produto construída neste trabalho permitiu a estimação do PIB florestal acreano em $\mathrm{R} \$ 17,78$ milhões, o que corresponde a 1,15\% do PIB total acreano. Os resultados aqui apresentados servirão como marco de comparação para as futuras relações inter-setoriais e inter-regionais decorrentes das grandes transformações pelas quais o estado do Acre passará em breve, quando estiver então efetivamente integrado via rodoviária aos países vizinhos e ao Pacífico. 


\title{
INTERSECTORIAL RELATIONSHIPS OF THE ACREAN ECONOMY AND ITS INSERTION INTO THE BRAZILIAN ECONOMY: AN INPUT-OUTPUT ANALYSIS
}

\author{
Author: LANA MIRIAN SANTOS DA SILVA \\ Adviser: Prof. Dr. LUIZ CARLOS ESTRAVIZ RODRIGUEZ
}

\section{SUMMARY}

This study applied input-output principles to the analysis of the relative importance of the primary sectors and specially the forest sector to the Acrean economy, as well as its dependency towards the Rest of the Northern region and the Rest of the Brazilian region. The results also allowed for the characterization of the productive structure of the state of Acre, its key sectors and multiplier effects of each economic sector in terms of production, employment, income and imports. The initially formulated hypothesis that the primary sector and the commerce and services sector form the basis of the Acrean economy was confirmed. The hypothesis that the forest macro-sector, formed by the Plant Extractive, Silviculture, Wood Mills, Furniture Industry, Pulp, Paper and Similar, Editorial and Printing, and Rubber Industry sectors, is a key sector was not confirmed. Its role as one of the most important direct employers was confirmed though. The Hirschman-Rasmussen indices point to the following key-sectors: Basic Metal Industry, Other Metals Textiles, Communications, Food Industry, 
Chemicals, Industrial Services for Public Utilities, and Finance. The pure index reveal the following sectors as the most important: Commerce, Public Health, Construction, Enterprise Services, and Other Public Management Services. The most important sectors in terms of production, employment, income and import multipliers, simultaneously, are the sectors dealing with the Meat and Food Industry. Individually, the most important sectors in terms of production are the Textiles and Basic Metal Industry; of employment are the Chemical and Communication sectors; of income are the Basic Metals and Automotive sectors; and of import are the Health and Wood Industry. A weak link among all regions is observed when production in each region (Acre, rest of the Northern, and rest of Brazil) is decomposed into production induced by internal demand and production induced by external demand. Meanwhile, when demand varies in Acrean sectors, production is more affected in the Rest of Brazil region than in the Rest of the Northern region. The Acrean Forest Growth Product estimated by the input-output matrix calculated in this study is $\mathrm{R} \$ 17,78$ million, which represents $1,15 \%$ of the total Acrean Growth Product. This study contributes with data that will allow comparisons of present and future inter-sector and inter-regional relationships; especially after the Acrean economy becomes integrated to neighbor countries and to Pacific ports by new roads. 


\section{INTRODUÇÃO}

Um dos pontos que mais chamam a atenção em todo o processo histórico dos estados que compõem a Amazônia brasileira é a extrema interferência do Estado tanto em questões relacionadas à ocupação dessas áreas quanto nas estratégias voltadas ao desenvolvimento econômico e social local.

Em períodos recentes, os governos estaduais têm procurado estruturar suas ações de modo a conhecer as limitações físicas, edafoclimáticas e econômicas do ente governado para assim propor ações específicas. Essas ações procuram também maior integração com as demais regiões do país e a melhoria das atividades econômicas internas, explorando as eventuais vantagens comparativas e aptidões estaduais nos setores (primário, secundário e terciário) da economia.

Assim, a tendência de investir em estratégias que promovam o desenvolvimento setorial, integrado de forma intra e inter-regional, induz à necessidade de se determinar quais os impactos sobre a economia do incentivo a um determinado setor em detrimento dos demais, bem como a forma como os diferentes setores e regiões se relacionam entre si.

Na teoria econômica um dos instrumentos que permite esse tipo de análise é a matriz insumo-produto desenvolvida por Wassily Leontief no final dos anos 20 que permite a análise do fluxo de bens e serviços de um setor da economia para outro.

A matriz insumo-produto permite uma detalhada caracterização da economia de um país, região ou estado; o cálculo do PIB por setores e per capita; a análise dos graus de influência de setores-chave e a deteç̧ão dos setores prioritários para investimento. 
Além de ser uma poderosa ferramenta de análise de cenários para as equipes de planejamento.

A proposta desenvolvida por Leontief possibilita, também, a análise do comportamento de alguns parâmetros da economia como a produção, o emprego, e as relações intersetoriais dadas as ações estabelecidas no planejamento de curto e longo prazo, de modo a tratar essas desigualdades sob uma nova ótica, levando em conta a geografia econômica do País e os fluxos de bens, serviços e pessoas.

\subsection{O problema}

Em alguns estados brasileiros, principalmente da região Norte, procura-se estimular o desenvolvimento regional através do fomento à atividade florestal, quer seja de base (através de planos de manejo sustentável, de uso comunitário, da introdução de plantios etc) ou de transformação (desenvolvimento de pólos madeireiros, serrarias, fábricas de compensados, de processamento de produtos não madeireiros como o palmito, castanha etc).

Nessas regiões, onde a atividade econômica se concentra em segmentos do setor primário como a pecuária e a produção de grãos, qual seria o impacto da destinação mais concentrada de recursos públicos para um segmento concorrente como o florestal? O estado do Acre, nesse sentido, pode ser considerado um interessante estudo de caso. O atual governo, assumidamente auto-intitulado o "governo da floresta", procura avaliar os impactos dessa opção.

E, além disso, encontra-se em um importante momento de sua história econômica pelo fato de estar passando por intensas transformações em sua economia local por conta da integração econômica, comercial e cultural do Estado com os países andinos, através das suas principais vias de acesso rodoviário (BR-364 e BR-317) permitindo, assim, o acesso aos portos do Pacífico. 


\subsection{Objetivo geral}

O presente trabalho, utilizando o estado do Acre como estudo de caso, tem por objetivo construir um Modelo de Insumo-Produto do tipo inter-regional envolvendo três regiões: o Estado do Acre (AC), a região Norte sem o estado do Acre - que ao longo desse trabalho será chamada de resto do Norte (RNO) e, a região denominada de resto do Brasil (RBR) que corresponde ao Brasil sem a região Norte. Esse modelo interregional foi utilizado na obtenção de respostas para as seguintes perguntas:

(i) Os setores primários constituem a base da economia acreana?

(ii) O setor florestal é dentre os setores primários o mais importante?

(iii) A economia acreana depende de quais estados ou regiões brasileiras?

Dentro dessa perspectiva, pretende-se:

1. Coletar e sistematizar os dados para a elaboração da Matriz Insumo-Produto Interregional Acre vs. resto do Norte vs. resto do Brasil;

2. Analisar a estrutura produtiva do estado do Acre, identificando os setores-chave para implementação de políticas públicas;

3. Avaliar a dependência externa do estado do Acre, com relação aos demais estados que compõem as regiões resto do Norte e resto do Brasil;

4. Estimar o impacto de variações na demanda final dos setores sobre a produção, renda emprego e importação;

5. Calcular o Produto Interno Bruto Florestal Acreano. 


\subsection{Hipóteses}

(i) Os setores ligados à agricultura, juntamente com os setores relacionados ao comércio e outros serviços, constituem a base da economia acreana;

(ii) O setor florestal acreano pode ser um indutor mais eficiente, em termos de capacidade de geração de produção, de emprego, de renda e de importação, do que alguns setores de base industrial como a indústria de alimentos e de abate de animais;

(iii) A economia acreana é menos dependente da região Norte, e mais dependente dos demais estados brasileiros.

\subsection{Organização do trabalho}

Este trabalho é dividido em cinco partes: essa introdução, onde são apresentados o problema, os objetivos e as hipóteses que o norteiam; a seção dois, onde apresenta-se um resgate histórico das principais políticas desenvolvimentistas para a região Norte e para o Acre especificamente, que será utilizado como estudo de caso. $\mathrm{Na}$ seção três, é realizada uma descrição detalhada da Teoria de Insumo-Produto, que será tomada como referencial teórico para as análises estruturais e de impacto da economia acreana e, também, uma caracterização do estado do Acre e um detalhamento da construção do modelo inter-regional de insumo-produto e do cálculo do PIB Florestal acreano. Na seção quatro, por sua vez, os principais resultados obtidos da aplicação da teoria de insumo-produto, referentes à análise estrutural e à identificação dos setoreschave para a economia acreana e ao valor do PIB Florestal do Acre são apresentados. E, a última seção concentra as principais conclusões desse trabalho e sugestões de trabalhos futuros. 


\section{POLÍTICAS DESENVOLVIMENTISTAS PARA A REGIÃO NORTE - UMA PERSPECTIVA HISTÓRICA}

\subsection{Período de 1840 a 1950}

A inserção da região amazônica na economia nacional teve início em 1840, com a descoberta da borracha. O grande interesse internacional pelo látex extraído da Hevea brasiliensis, naturalmente abundante na região, influenciou marcantemente todo o processo de colonização, ocupação e desenvolvimento da região. No entanto, dado o caráter extrativista da atividade, não foi possível competir com os seringais Asiáticos da Malásia e Ceilão e a atividade entra em colapso em 1910.

De acordo com Miranda Neto (1991), a criação do Plano de Defesa da Borracha e da Superintendência de Defesa da Borracha pelo Poder Público em 1912 são as primeiras manifestações de intervenção do Estado na região. O objetivo dessa intervenção era assegurar à Amazônia condições de voltar ao mercado internacional com o mais importante produto regional de exportação, a borracha, bem como melhorar as condições econômicas e sociais da região.

A situação financeira precária do País, a escassez de capital privado, a escassez de técnicos qualificados e a falta de um mercado interno desenvolvido levaram esse Plano a não atingir seus objetivos. 
Trinta anos se passaram entre a primeira e a segunda intervenção governamental na região, ambas em 1912 e 1942, respectivamente. Durante esse período, os fluxos demográficos para a região praticamente deixaram de existir e houve uma nova tentativa de desenvolver a economia local a partir do extrativismo da castanha, que não apresentou a mesma relevância econômica que a borracha.

Assim, em 1942, aconteceria a segunda intervenção governamental na região, com a celebração dos chamados “Acordos de Washington” entre Brasil e EUA. Esses acordos tinham o objetivo de implementar uma ação conjunta que permitisse o rápido crescimento da produção de borracha na América Latina, especialmente no Brasil, uma vez que os seringais asiáticos estavam sob o domínio dos japoneses. Por essa razão, foram incentivados os fluxos migratórios de outras regiões do país, especialmente da Região Nordeste, para a Amazônia. Cabe destacar que o Acre concentrou nesse período a maioria dos 65 mil imigrantes da região Norte (Brasil, et al., 2002; Mendes,2002).

Moraes (2003) destaca que as principais contribuições da exploração da borracha para a economia brasileira foram: a expansão territorial do Brasil, por meio da conquista do Acre, o reforço à industrialização do Sul, a contribuição fiscal e o aumento das exportações.

Em suma, de 1912 a 1945 a intervenção do Estado na Amazônia teve como objetivo quase que exclusivamente recuperar a economia da borracha. Mas, uma vez que a relação da região com o restante da economia brasileira ainda permanecia profundamente marginal, as estratégias adotadas para a região após esse período visaram, principalmente, a sua integração ao restante do país.

Na década de 50, um novo modelo econômico passou a vigorar no país, o de substituição de importações. Com o objetivo de aumentar a produção industrial do país esse modelo tinha na expansão do mercado interno a principal forma de escoamento da produção. Datam dessa década a criação da Superintendência do Plano de Valorização Econômica da Amazônia (SPVEA), em 1953, a criação da Zona Franca de Manaus (ZFM), em 1957, que efetivamente só foi implantada em 1967, a implantação da rodovia Belém-Brasília, em 1958 e, posteriormente, da Brasília-Acre, que ligaram a Região Norte ao Centro-Sul do Brasil (Becker, 2002; Brasil et al., 2002). 
Os objetivos da Valorização Econômica da Amazônia eram “a integração territorial, econômica e social da região Amazônica na unidade social, buscando, não somente, o progresso das áreas de mais fácil acesso e economicamente mais produtivas, como também a ocupação e desenvolvimento da Amazônia como um todo, especialmente as regiões de fronteira” (Brasil, 1954).

Como resultado do plano de valorização econômica da Amazônia (PVEA), a Região receberia investimentos nas mais variadas áreas: agricultura, indústria, pecuária, transporte, infra-estrutura e pesquisa. O planejamento seria organizado na forma de Planos Quinqüenais sucessivos, antecedidos, no primeiro ano, por um Programa de Emergência que abrangeria problemas de transporte, energia, comércio, saúde, comunicações, crédito, educação, recursos naturais e outros serviços considerados de interesse imediato, em face das condições econômico e social da região (Brasil, 1954).

As rodovias construídas no final da década de cinqüenta, durante o mandato do Presidente Juscelino Kubtschek, permitiram uma situação de igualdade entre a Amazônia e as outras regiões do país, no que se refere às ligações viárias com a capital (Brasil et al., 2002). Porém, a falta de continuidade política e de recursos financeiros fizeram com que os objetivos do PVEA não fossem alcançados.

As ações nas décadas de 40 e 50 permitiram que a Amazônia pudesse contar com os primeiros instrumentos de uma política brasileira de desenvolvimento econômico e social para a região: i) o Banco de Crédito da Amazônia (BCA) - antigo Banco de Crédito da Borracha (BCB), criado em 1942 e que posteriormente, em 1966, se tornaria Banco da Amazônia (BASA) e ii) a Superintendência do Plano de Valorização Econômica da Amazônia (SPVEA) - que mais tarde, na década de 60, seria transformada em Superintendência do Desenvolvimento da Amazônia (SUDAM) e esta, substituída, atualmente, pela ADA - Agência do Desenvolvimento da Amazônia (Mendes, 2002). 


\subsection{Período de 1960 até o presente}

Na segunda metade da década de 60 novas políticas governamentais são implantadas com fortes impactos na Amazônia. Nota-se, nesse período, um compromisso efetivo por parte do Governo Militar com a ocupação e o desenvolvimento da Amazônia, assim como com a sua integração à economia nacional.

A “Operação Amazônia” é proposta com o objetivo de desenvolver, ocupar e fortalecer economicamente a Região de modo a promover, de maneira definitiva, a sua integração à economia brasileira. Essa operação tinha como um dos seus aspectos mais importantes, a promoção de incentivos tributários especiais para as empresas privadas que se estabelecessem na Amazônia Ocidental (Amazonas, Acre, Rondônia e Roraima), com o intuito de implementar a criação de pólos de desenvolvimento e de povoamentos nas zonas fronteiriças pouco povoadas. Somente no final da década de 60 a Zona Franca de Manaus é efetivamente implementada (Brasil et al., 2002).

Os efeitos dessas transformações ocorridas na região sobre a população amazônica tornaram-se evidentes. De 1950 a 1970 a população amazônica passou de 3,43 milhões para 7,72 milhões, e a população rural apresentou um crescimento demográfico superior à média nacional.

De 1970 a 1975 o Governo Federal teve expressiva presença na Amazônia através da criação do Programa de Integração Nacional (PIN) - para financiamento da construção das rodovias Transamazônica e Santarém-Cuiabá. A rodovia Transamazônica foi idealizada para ligar a Amazônia ao Nordeste e dar uma solução aos problemas provenientes da seca no Nordeste, criando novas oportunidades de emprego (Moraes, 2003; Brasil et al., 2002).

Em 1971, criou-se o Programa de Redistribuição de Terras (PROTERRA), com a finalidade de completar a ação do PIN e cujo objetivo era facilitar a aquisição de terra, melhorar as condições de trabalho na área rural e promover o desenvolvimento da agroindústria na Amazônia e no Nordeste.

Uma característica marcante da década de 70 foi o fato de que o Estado aprofunda sua intervenção na Amazônia introduzindo uma modalidade de acumulação 
fundamentada na trilogia: capital público, capital privado nacional e capital privado internacional.

De acordo com Moraes (2003) e Brasil et al. (2002), as políticas públicas voltadas para a integração e ocupação da Amazônia sofreram profundas mudanças a partir de 1974, quando a política de desenvolvimento para a região passou a focalizar os projetos de larga escala, com a criação do POLAMAZÔNIA, Programa Especial de Pólos Agropecuários e Agrominerais da Amazônia.

O objetivo desse programa era criar 60 pólos sustentados para redirecionar os investimentos públicos e privados para áreas consideradas com potencial econômico. Essas novas prioridades foram expressas no II Plano de Desenvolvimento da Amazônia (PDA) para o período de 1975 a 1979. Com isso, o apoio político aos projetos de colonização é cessado, fazendo com que o Governo praticamente abandonasse seus projetos remanescentes de colonizar a Amazônia através do pequeno produtor e racionalizasse a ocupação econômica da região através de médias e grandes empresas (Brasil et al., 2002).

A década de 80, por sua vez, foi marcada por crises conjunturais e pelo esgotamento estrutural da capacidade de financiamento público bem como pelo abandono ou desaceleração de um conjunto de políticas setoriais e espaciais de desenvolvimento regional, o que produziu efeitos marcantes sobre a Amazônia, modificando o ritmo e as prioridades sociais e demográficas na região.

Nessa década, constatou-se que a ocupação com base nas grandes empresas favoreceu a especulação, o desperdício de recursos e a ausência de investimentos que propiciassem um efeito multiplicador sobre as atividades desenvolvidas. Conforme destaca Moraes (2003), todos os grandes empreendimentos incentivados pelo Governo Federal nesse período constituíram-se em verdadeiros enclaves, voltados unicamente para o mercado externo e sem um encadeamento efetivo com a economia regional.

Assim, desde meados da década da 80 a Amazônia vem passando por profundas transformações com relação às políticas públicas voltadas para o seu desenvolvimento econômico e social. 
O ano de 1985 marcou o esgotamento da política nacional-desenvolvimentista e da intervenção do Estado na economia e no território (Becker, 2001). A partir de então, as populações tradicionais da região iniciaram um forte movimento de resistência, através da criação do Conselho Nacional de Seringueiros, resgatando, assim, um modelo de desenvolvimento baseado na demanda de grupos locais e regionais com o intuito de melhorar as condições de vida. O mesmo aconteceu com grupos indígenas que se organizaram em associações para lutar pela defesa de seu território, por sua sobrevivência e pela preservação de sua cultura (Acre, 2000; Brasil et al., 2002 e Moraes, 2003).

Um ponto importante destacado por Mendes (2000), é que a preocupação em integrar a região com as demais partes do país levou a uma desintegração intra-regional da Amazônia. Um bom exemplo disso é o Acre que, após se libertar das casas aviadoras de Belém e Manaus (após o declínio da borracha), passou a depender diretamente de São Paulo.

Fruto dessa constatação, e buscando amenizar as desigualdades, cada vez maiores, entre as regiões brasileiras, especialmente entre o Norte e o Centro-Sul do país, surge a nova tendência do final da década de 90 e início dos anos 2000 que, Mendes (2002, p. 28) definiu como "novas medidas nacionais de vertebração do território e de atividades via Avança Brasil e Eixos Nacionais de Integração e Desenvolvimento (ENIDs)”.

De acordo com Nasser (2000), essa nova proposta (ENIDs) permitirá um novo recorte do território nacional, diferente do político-administrativo, que possibilita melhor análise da relação entre as regiões. O governo será considerado o indutor da realização de investimentos privados e da disseminação de investimentos por todo o país, tendo como objetivo a redução das desigualdades inter-regionais.

A estratégia adotada pelos ENIDs está focada na identificação de oportunidades de investimentos públicos e/ou privados, nas áreas de influência dos Eixos, em setores considerados essenciais ao desenvolvimento social e econômico: infra-estrutura (transporte, energia, telecomunicações e infra-estrutura hídrica), desenvolvimento social (educação, habitação, saúde e saneamento), informação e 
conhecimento (associados a atividades econômicas e a projetos de infra-estrutura) e meio ambiente (gestão de recursos hídricos, florestas e outros). 


\section{MATERIAL E MÉTODOS}

\subsection{Análise de insumo-produto: referencial teórico}

Para alcançar os objetivos descritos anteriormente, o presente trabalho utilizou a Teoria de Insumo-Produto desenvolvida pelo economista Wassily Leontief no final dos anos 20. Dessa forma, inicialmente, serão apresentadas as influências que levaram Leontief ao desenvolvimento dessa teoria. Logo em seguida, será apresentada a Teoria Básica de Insumo-Produto; os Modelos de Insumo-Produto Regionais e Inter-regionais; os indicadores que são geralmente utilizados em análises de estruturas produtivas e, por último, a forma como são construídas as matrizes de insumo-produto e a metodologia adotada para a estimativa do PIB Florestal Acreano.

\subsubsection{Leontief e os antecedentes históricos da teoria de insumo-produto}

Wassily Leontief nasceu em 1906 em São Petersburgo, Rússia. Foi um brilhante estudante de filosofia, matemática e economia na Universidade de Leningrado. Seu primeiro artigo sobre Insumo-Produto foi publicado no final dos anos 20 trabalho este em que construiu um sistema de contabilidade experimental para a economia soviética com o intuito de medir não somente o volume da produção, mas também a distribuição da renda. Leontief procurava dessa forma, integrar a teoria econômica a uma base de dados cuidadosamente projetada.

Para tanto, desenvolveu descrições quantitativas da


estrutura econômica e mostrou como modelos de enorme relevância prática podem ser construídos e usados (Carter \& Petri, 1989). Em 1973 recebeu o prêmio Nobel por desenvolver uma teoria de planejamento econômico através da análise de um sistema do tipo Insumo-Produto.

Assim como Leontief tem influenciado inúmeros pesquisadores dos mais diversos países, a teoria por ele desenvolvida teve influência direta, principalmente, de dois pesquisadores que o antecederam: François Quesnay (1694-1774) e Léon Walras (1834-1910).

O primeiro, François Quesnay, demonstrou, em sua principal obra "Tableau économique", publicada em 1758, a relação entre diferentes classes e setores econômicos, e o fluxo de pagamentos entre elas. Assim, no sistema econômico proposto por Quesnay, a sociedade achava-se dividida em três classes: a classe produtiva, a classe estéril e a classe dos proprietários.

$\mathrm{Na}$ primeira classe, encontravam-se os arrendatários capitalistas e assalariados que desenvolviam suas atividades na agricultura e cujo trabalho era produtivo (como criador do produto líquido).

A classe estéril era constituída por todos aqueles que exerciam sua atividade à margem da agricultura e cujo trabalho não era produtivo, porque não produzia excedente. Na concepção de Quesnay, tanto a indústria como o comércio eram considerados estéreis.

Já a classe dos proprietários de terras correspondia aquela em que não se desenvolvia qualquer atividade econômica e apenas se tinha o direito à percepção dessa renda (produto líquido) - o rei, sua corte, o conjunto de funcionários públicos e a igreja faziam parte dessa classe. Assim, todos esses percebem uma porção da renda, quer por serem proprietários (como é o caso do rei e da igreja), quer por terem o direito de arrecadar impostos (o rei) ou o dízimo (a igreja).

Quesnay é considerado o precursor do pensamento fisiocrata, o criador dos conceitos de equilíbrio econômico, capital fixo e capital circulante, e da noção de que o capital deve constituir uma reserva de riqueza a ser acumulada antes da produção. 
Léon Walras, por sua vez, ficou conhecido por sua exposição matemática muito compreensiva do equilíbrio econômico geral, descrita em sua principal obra "Elements of Pure Economics" (1874-77). Dedicou boa parte de seus estudos à teoria da determinação dos preços, baseado no regime hipotético do livre mercado e da concorrência perfeita, sempre buscando demonstrar seus descobrimentos em forma de proposições matemáticas. Pretendia com isso, esboçar o modo como se poderia alcançar uma solução de equilíbrio em todos os mercados, simultaneamente, ou seja, seu objetivo era formular um processo mediante o qual fosse possível estabelecer um equilíbrio geral, levando em conta a inter-relação de todas as atividades econômicas.

Com base nas teorias desenvolvidas por Quesnay e Walras, Leontief desenvolveu uma estrutura analítica, denominada Insumo-Produto. Para tanto, introduziu simplificações importantes ao modelo Walrasiano permitindo, assim, que fosse aplicada à teoria de equilíbrio geral (Miller \& Blair, 1985). Segundo Moretto (2000), Leontief apresentou uma teoria geral de produção baseada na noção de interdependência econômica.

\subsubsection{Teoria básica de insumo-produto}

A base do sistema analítico de Leontief é a matriz ou tabela de insumo-produto (Figura 1) construída a partir de dados econômicos observados para uma região geográfica específica (país, estado, cidade etc). 


\begin{tabular}{|c|c|c|c|c|c|c|c|c|c|c|c|c|c|}
\hline \multicolumn{13}{|c|}{ COMPRAS (i) } & \multirow{2}{*}{$\begin{array}{c}\text { TOTAL } \\
\text { PRODUTO } \\
\left(\mathrm{X}_{i}\right)\end{array}$} \\
\hline \multicolumn{8}{|c|}{ DEMANDA INTERMEDIÁRIA } & \multicolumn{5}{|c|}{ DEMANDA FINAL* } & \\
\hline \multirow{5}{*}{\multicolumn{2}{|c|}{ 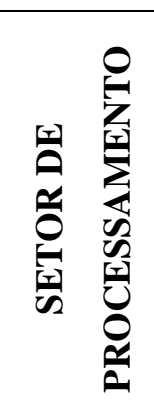 }} & \multirow{5}{*}{\begin{tabular}{l}
$\approx$ \\
\multirow{2}{\infty}{} \\
$\sum_{1}^{\infty}$
\end{tabular}} & & $\mathrm{S}_{1}$ & $\mathrm{~S}_{2}$ & $\mathrm{~S}_{3}$ & $\overline{\Sigma_{i}}$ & $\mathrm{E}$ & $\mathrm{C}$ & $\mathrm{G}$ & I & $\overline{\Sigma_{i}}$ & \\
\hline & & & $\mathrm{S}_{1}$ & $\mathrm{X}_{11}$ & $\mathrm{X}_{12}$ & $\mathrm{X}_{13}$ & $W_{1}$ & $\mathrm{E}_{1}$ & $\mathrm{C}_{1}$ & $\mathrm{G}_{1}$ & $\mathrm{I}_{1}$ & $Y_{1}$ & \\
\hline & & & $\mathrm{S}_{2}$ & $\mathrm{X}_{21}$ & $\mathrm{X}_{22}$ & $\mathrm{X}_{23}$ & $W_{2}$ & $\mathrm{E}_{2}$ & $\mathrm{C}_{2}$ & $\mathrm{G}_{2}$ & $\mathrm{I}_{2}$ & $Y_{2}$ & \\
\hline & & & $\mathrm{S}_{3}$ & $\mathrm{X}_{31}$ & $\mathrm{X}_{32}$ & $\mathrm{X}_{33}$ & $W_{3}$ & $\mathrm{E}_{3}$ & $\mathrm{C}_{3}$ & $\mathrm{G}_{3}$ & $\mathrm{I}_{3}$ & $Y_{3}$ & \\
\hline & & & $\Sigma_{j}$ & $U_{1}$ & $U_{2}$ & $U_{3}$ & $\begin{array}{c}\Sigma_{j} U_{j}=\Sigma_{i} W_{i} \\
U=W\end{array}$ & $\Sigma_{i} E_{i}$ & $\Sigma_{i} C_{i}$ & $\Sigma_{i} G_{i}$ & $\Sigma_{i} I_{i}$ & $\Sigma_{i} Y_{i}$ & $\Sigma_{i} X_{i}=X$ \\
\hline \multirow{3}{*}{ 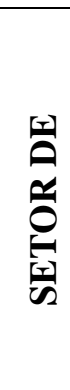 } & \multirow{3}{*}{ 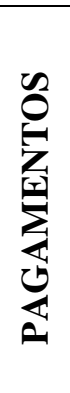 } & \multirow{2}{*}{\multicolumn{2}{|c|}{$\begin{array}{c}\text { Impostos (T) } \\
\text { Importações } \\
\text { (M) }\end{array}$}} & $\mathrm{T}_{1}$ & $\mathrm{~T}_{2}$ & $\mathrm{~T}_{3}$ & $\Sigma_{j} T_{j}=T_{P}$ & $\mathrm{~T}_{\mathrm{E}}$ & $\mathrm{T}_{\mathrm{C}}$ & $\mathrm{T}_{\mathrm{G}}$ & $\mathrm{T}_{\mathrm{I}}$ & $\sum$ & $\mathrm{T}$ \\
\hline & & & & $\mathrm{M}_{1}$ & $\mathrm{M}_{2}$ & $\mathrm{M}_{3}$ & $\Sigma_{j} M_{j}=M_{P}$ & & $\mathrm{M}_{\mathrm{C}}$ & $\mathrm{M}_{\mathrm{G}}$ & $\mathrm{M}_{\mathrm{I}}$ & $\sum$ & M \\
\hline & & \multicolumn{2}{|c|}{$\begin{array}{c}\text { Valor } \\
\text { Adicionado } \\
\text { (VA) }\end{array}$} & $\mathrm{VA}_{1}$ & $\mathrm{VA}_{2}$ & $\mathrm{VA}_{3}$ & $\Sigma_{j} V A_{j}=V A$ & & & & & & \\
\hline \multicolumn{4}{|c|}{ TOTAL INSUMO $\left(\mathrm{X}_{j}\right)$} & $\mathrm{X}_{1}$ & $\mathrm{X}_{2}$ & $\mathrm{X}_{3}$ & $\Sigma_{j} X_{j}=X$ & & & & & & \\
\hline
\end{tabular}

Figura 1 - Exemplo de tabela de insumo-produto.

Fonte: adaptado de Miernyk (1974), Montoya Rodriguez (1998), Silveira (2000) e Guilhoto (2001)

* E = Exportações; $\mathrm{C}=$ Famílias; $\mathrm{G}=$ Governo e I = Investimento 
A Matriz de Insumo-Produto corresponde, portanto, a um esquema de organização das informações sobre a atividade econômica da região estudada, uma vez que descreve o fluxo de bens e serviços entre todos os setores individuais da economia nacional, para um período de tempo, geralmente fixado em um ano (Bacha, 1999; Leontief, 1986; Silveira, 2000).

As linhas da tabela mostram como o produto de cada setor da economia é distribuído entre os outros setores. Isto é, mostra a demanda intermediária constituída pelas vendas do setor $i$ para os outros setores $j\left(\mathrm{X}_{i j}\right)$, e a demanda final constituída pelo consumo das famílias (C), por investimentos privados (I), pelos gastos do governo (G) e pelas exportações $(\mathrm{E})$.

Assim, temos que a soma da demanda intermediária com a demanda final resulta no produto total ou vendas da indústria i. Matematicamente, temos:

$$
\begin{aligned}
& X_{i}=\sum_{j=1}^{n} X_{i j}+C_{i}+I_{i}+G_{i}+E_{i} \\
& i=1,2, \ldots, n
\end{aligned}
$$

As colunas mostram como cada setor obtêm dos outros setores os insumos necessários para o desenvolvimento de sua atividade econômica. Ou seja, contabiliza as compras de insumos intermediários produzidos pela própria indústria $\mathrm{j}$, e por todas as outras indústrias, bem como, outros insumos não industriais de produção requeridos no processo produtivo que correspondem às partes componentes do setor pagamentos: impostos $(\mathrm{T})$, importações $(\mathrm{M})$ e valor adicionado $^{1}(\mathrm{VA})$ - remuneração do trabalho, capital e terra. Assim, do somatório das colunas temos:

$$
\begin{aligned}
& X_{j}=\sum_{i=1}^{n} X_{i j}+T_{j}+M_{j}+V A_{j} \\
& j=1,2, \ldots, n
\end{aligned}
$$

\footnotetext{
${ }^{1}$ Valor adicionado (VA) é o acréscimo de valor a um bem devido à utilização de serviços de fatores de produção na elaboração desse bem. Os pagamentos aos serviços prestados pelos fatores de produção adicionam valor aos bens intermediários, definindo o valor do bem ou serviço final (Bacha, 1999).
} 
Somando-se os totais de cada linha $\left(\mathrm{X}_{i}\right)$ ou os de cada coluna $\left(\mathrm{X}_{\mathrm{j}}\right)$, temos a Produção Total da Economia (X). De modo que, igualando-se as duas expressões, obtemos:

$$
\sum_{i}\left[\sum_{j=1}^{n} X_{i j}+C_{i}+I_{i}+G_{i}+E_{i}\right]=\sum_{j}\left[\sum_{i=1}^{n} X_{i j}+T_{j}+M_{j}+V A_{j}\right]
$$

e, portanto,

$$
T+V A=C+I+G+(E-M) \Rightarrow R N B=P N B
$$

Assumindo-se que os fluxos interindustriais de $i$ para $j$, para um dado período de tempo, dependem do produto total do setor $j$, os coeficientes técnicos $\left(a_{i j}\right)$ podem ser definidos pela seguinte equação:

$$
X_{i j}=a_{i j} \cdot X_{j} \rightarrow a_{i j}=\frac{X_{i j}}{X_{j}}
$$

sendo que, o coeficiente $a_{i j}$ representa a proporção fixa do produto do setor $i$ utilizado como insumo produtivo na produção do setor $j$. O conjunto dos coefícientes técnicos $\left(a_{i j}\right)$ constitui a matriz tecnológica (A).

A soma da produção do setor $i$ que é consumida pelas famílias $\left(\mathrm{C}_{i}\right)$, com a que é investida $\left(\mathrm{I}_{i}\right)$, com a que é consumida pelo governo $\left(\mathrm{G}_{i}\right)$ e com a que é exportada $\left(\mathrm{E}_{i}\right)$ apresentada em (1) corresponde à demanda final da produção do setor $i\left(Y_{i}\right)$. Dessa forma, substituindo-se $\left(\mathrm{C}_{i}+\mathrm{I}_{i}+\mathrm{G}_{i}+E_{i}\right)$ por $Y_{i}$ e $X_{i j}$ por $a_{i j} X_{j}$ na equação (1), temos:

$$
\begin{aligned}
& \sum_{j=1}^{n} a_{i j} \cdot X_{j}+Y_{i}=X_{i} \\
& i=1,2, \ldots, n
\end{aligned}
$$


A equação (4) pode ser expressa em termos matriciais como:

$$
A X+Y=X
$$

sendo que,

$A$ é a matriz de coeficientes técnicos diretos de insumos de ordem $(n \times n)$; $X$ e $Y$ são vetores coluna de ordem $(n \times 1)$.

Fazendo as devidas manipulações algébricas na equação (5), temos que a produção total $(\mathrm{X})$ necessária para satisfazer a demanda final $\left(Y_{i}\right)$, determinada exógenamente, é dada por:

$$
X=[I-A]^{-1} Y
$$

onde,

$[I-A]^{-1}$ corresponde à matriz de coeficientes técnicos de insumos diretos e indiretos, ou à matriz inversa de Leontief. A equação (6) completa é também chamada de modelo de Leontief.

Fazendo $\mathrm{B}=[I-A]^{-1}$, temos que cada elemento $b_{i j}$ deve ser interpretado como sendo a produção total do setor $i$ que é necessária para produzir uma unidade de demanda final do setor $j$.

\subsubsection{Hipóteses do modelo de insumo-produto}

Leontief, ao desenvolver o modelo de insumo-produto, estabeleceu algumas hipóteses com relação ao comportamento do sistema econômico no modelo. É relevante destacar que algumas dessas hipóteses são alvo de críticas, mas estas são amenizadas a partir do momento em que se considera que a realidade, principalmente a econômica, não pode ser analisada considerando-se todos os seus componentes simultaneamente. E, 
para que isso seja possível, em geral lança-se mão dos métodos de modelagem que, por sua própria definição já pressupõe o "modelo" como uma simplificação da realidade.

Sendo assim, Feijó et al. (2001) destacam que as hipóteses adotadas por Leontief podem ser resumidas em Homogeneidade e Proporcionalidade. A primeira relaciona-se à questão de que no modelo de Leontief cada setor produz um único produto e cada produto é produzido por um único setor, ou seja, o modelo não leva em conta a possibilidade de haver produção secundária (um setor produzindo mais que um produto). Já a proporcionalidade está relacionada ao fato de que os insumos consumidos por cada atividade são uma função somente do nível de produção dessa atividade.

No entanto, uma vez que esses modelos são construídos a partir do maior número de informações disponíveis, eles se prestam a uma série de análises estruturais e comparativas entre economias, ao cálculo do PIB setorial, à análise e determinação de clusters, à introdução do meio ambiente como setor importante da economia etc. Fatos esses que fazem do instrumental de insumo-produto um dos mais utilizados nos últimos tempos.

Conforme destacam Miller \& Blair (1985), Considera (1997), Bêrni (2000), Silveira, (2000) e Guilhoto (2003), a análise de insumo-produto é um dos métodos mais amplamente utilizados atualmente, justamente pelo fato de congregar informações estatísticas sobre produção, consumo intermediário, distribuição da renda gerada, comércio exterior, salários, impostos etc. Essas informações permitem uma descrição quantitativa da estrutura econômica e, portanto, uma reconstituição do funcionamento e das relações setoriais de um sistema econômico. São, por isso, utilizadas para examinar uma ampla variedade de problemas econômicos, tratando desde análises estruturais até questões relativas ao planejamento. 


\subsubsection{Modelos de insumo-produto regionais $\mathrm{e}$ inter-regionais ${ }^{2}$}

O Modelo de Insumo-Produto desenvolvido por Leontief foi uma importante ferramenta utilizada pelos americanos durante a Segunda Guerra Mundial. Inicialmente, todas as análises eram feitas em nível Nacional com o intuito de avaliar o impacto, sobre os setores individuais da economia americana, de uma mudança na produção decorrente do fim da guerra, por exemplo.

Mais recentemente, houve uma demanda por modelos que extrapolassem a esfera nacional e pudessem contemplar peculiaridades regionais, seja para um grupo de Estados, um Estado individual, um país, ou área metropolitana. Dessa forma, o modelo de insumo-produto, para ser implementado, necessitaria de algumas modificações para refletir as particularidades regionais.

Uma economia regional apresenta duas características básicas que influenciam um estudo de insumo-produto regional. A primeira delas se refere ao fato de que a estrutura de produção de uma determinada região não necessariamente é igual à estrutura de produção nacional. A segunda concentra-se na tendência observada de que quanto menor for a área econômica considerada no estudo, mais dependente do comércio com outras regiões essa área se torna, tanto para vendas da produção regional quanto para compra de insumos necessários para a produção.

Assim, como uma primeira iniciativa de obtenção das matrizes regionais, foram

estimadas porcentagens de oferta para cada setor, em uma determinada região $\left(p_{j}^{R}\right)$, da seguinte forma:

$$
p_{j}^{R}=\frac{\left(X_{j}^{R}-E_{j}^{R}\right)}{\left(X_{j}^{R}-E_{j}^{R}+M_{j}^{R}\right)}
$$

onde,

$X_{\mathrm{j}}^{\mathrm{R}}$ corresponde a produção regional total do setor $j$;

\footnotetext{
${ }^{2}$ Este sub-item está inteiramente baseado no capítulo 3 de Miller e Blair (1985)
} 
$E_{\mathrm{j}}^{\mathrm{R}}$ corresponde às exportações do bem $j$ da região $R$;

$M_{\mathrm{j}}^{\mathrm{R}}$ corresponde às importações do bem $j$ pela região $R$.

O numerador corresponde, portanto, a quantidade localmente produzida do bem $j$ que está disponível para compra na região $R$; o denominador corresponde à quantidade total do bem $j$ (produzida localmente e importada) que está disponível na região $R$. Assim, $p_{j}^{R}$ determina quanto da demanda total do bem $j$ é atendida pela produção interna da região $\mathrm{R}$.

A matriz de coeficientes técnicos regional $\left(A^{R}\right)$ é obtida por meio da multiplicação de cada elemento da i-ésima linha da matriz de coefícientes técnicos nacional $(A)$ por $p_{j}^{R}$. Assumindo-se, nesse caso, que a tecnologia de produção da região é igual à nacional.

Em termos matriciais, temos que $P$ corresponde ao vetor coluna formado pelos n percentuais obtidos na equação (7) e $P$ corresponde ao vetor $P$ diagonalizado. Assim, é obtida a matriz $A^{R}$ de coeficientes técnicos de insumos regionais por meio da seguinte expressão: $A^{R}=\hat{P} \cdot A$. E, se tivermos o vetor de demanda final $\left(Y^{R}\right)$, poderemos então encontrar a produção total regional $\left(X^{R}\right)$ como:

$$
X^{R}=(I-\hat{P} \cdot A)^{-1} Y^{R}
$$

Miller \& Blair (1985) destacam que ao pré-multiplicarmos $A$ por $\hat{P}$, estamos alterando os elementos de cada linha da matriz nacional uniformemente, o que é uma hipótese extremamente forte. Se, por exemplo, os setores produtores de avião, equipamentos de cozinha e barcos usam alumínio como insumo, a matriz $A^{R}$ indicará que os três setores compram a mesma proporção de alumínio da região $R$, importando o restante das demais regiões.

Assim, quando utilizamos o percentual de oferta regional não estamos levando em consideração as especificidades técnicas de cada região, nem a parcela de insumos que cada setor compra de outra região. 
Como solução para essas questões pode-se utilizar uma tabela de insumoproduto censitária, específica para uma determinada região. De modo que, se considerarmos somente $a_{i j}^{L L}$ (coeficiente de insumo regional), podemos calcular os impactos de uma variação da demanda final da região $L$ de uma forma mais precisa, mas que, por outro lado, demanda um volume maior de dados:

$$
X^{L}=\left(I-A^{L L}\right)^{-1} Y^{L}
$$

Uma forma alternativa consiste em além de obtermos o coeficiente de insumo regional $\left(\mathrm{a}_{\mathrm{ij}}^{L L}\right)$, obtermos o coeficiente de comércio $\left(\mathrm{a}_{\mathrm{ij}}{ }^{M L}\right)$ :

$$
\begin{aligned}
& a_{i j}^{L L}=z_{i j}^{L L} / X_{j}^{L} \\
& a_{i j}^{M L}=Z_{i j}^{M L} / X_{j}^{L}
\end{aligned}
$$

onde,

$\mathrm{z}_{\mathrm{ij}}{ }^{L L}=$ fluxo monetário da venda do bem do setor $i$ localizado na região $L$ para o setor $j$, também situado na região $L$;

$\mathrm{Z}_{\mathrm{ij}}{ }^{M L}=$ fluxo monetário da venda do bem do setor $i$ localizado na região $M$ para o setor $j$ situado na região $L$;

$X_{j}^{L}=$ produção total do setor $i$ da região $L\left(X_{j}^{L}\right)$.

Podemos, a partir desses dois coeficientes, então, calcular o coeficiente técnico regional $\left(a_{i j}{ }^{L}\right)$, pela soma de $a_{i j}{ }^{L L}$ e $a_{i j}{ }^{M L}$ e derivarmos a matriz de produção total regional $(X)$ da seguinte forma:

$$
X=\left(I-\hat{P} \cdot A^{L}\right)^{-1} Y^{L}
$$


No entanto, quando se utiliza o coeficiente técnico regional não há distinção quanto à origem do insumo. Por isso, lança-se mão da matriz $P$ diagonalizada e, quando pré-multiplicamos $A^{L}$ por $P$, obtemos um estimador de $A^{L L}$.

Modelos como os representados pelas equações (8), (9) e (12) não captam um efeito muito importante denominado efeito feedback inter-regional. Esse efeito pode ser ilustrado da seguinte forma: dado um aumento na demanda de uma determinada região, $J$, por um bem $i$ qualquer, estimula-se a produção desse bem $i$ na própria região $J$. No entanto, os setores de $J$ demandarão diversos tipos de insumos para a fabricação de $i$. Esses insumos poderão vir da própria região, $J$, ou de outra região, $M$, por exemplo. A região $M$, por sua vez, utiliza, na produção dos insumos requeridos por $J$, uma certa quantidade de insumos provenientes da região $J$, o que propicia um novo aumento na produção de $J$. Essa nova demanda "para trás" da região $M$ por insumos de $J$ é chamada de efeito feedback inter-regional. Esse efeito não é captado pelos modelos anteriores, pelo fato de as relações inter-regionais não fazerem parte dos mesmos.

Essa questão é resolvida por meio da utilização de Modelos de Insumo-Produto Inter-regionais, também chamados de Modelo de Isard (Isard, 1951).

A estrutura básica dos modelos inter-regionais pode ser descrita da seguinte forma: dada uma economia formada por duas regiões $(L$ e $M)$. A região $L$ apresenta três setores produtivos enquanto que a $M$ apresenta 2 setores. Os fluxos intra-regionais $z_{\mathrm{ij}}{ }^{L} \mathrm{e}$ $z_{\mathrm{ij}}{ }^{M M}$, e inter-regionais $z_{\mathrm{ij}}{ }^{M L}$ e $\mathrm{z}_{\mathrm{ij}}{ }^{L M}$, são conhecidos, assim como $X_{j}^{L}$ e $X_{j}^{M}$. A partir desses dados podemos calcular os coeficientes de insumo para ambas as regiões $\left(a_{i j}{ }^{L L}\right.$ e $\left.a_{i j}{ }^{M M}\right)$ e os coeficientes de comércio interregional $\left(a_{i j}{ }^{M L}\right.$ e $\left.a_{i j}{ }^{L M}\right)$, da mesma forma como apresentado nas equações (10) e (11). E, finalmente, podemos expressar a relação entre a produção total e seu destino para cada setor das duas regiões da seguinte forma:

$$
\begin{aligned}
& X_{1}^{L}=a_{11}^{L L} X_{1}^{L}+a_{12}^{L L} X_{2}^{L}+a_{13}^{L L} X_{3}^{L}+a_{11}^{L M} X_{1}^{M}+a_{12}^{L M} X_{2}^{M}+Y_{1}^{L} \\
& X_{2}^{L}=a_{21}^{L L} X_{1}^{L}+a_{22}^{L L} X_{2}^{L}+a_{23}^{L L} X_{3}^{L}+a_{21}^{L M} X_{1}^{M}+a_{22}^{L M} X_{2}^{M}+Y_{2}^{L} \\
& X_{3}^{L}=a_{31}^{L L} X_{1}^{L}+a_{32}^{L L} X_{2}^{L}+a_{33}^{L L} X_{3}^{L}+a_{31}^{L M} X_{1}^{M}+a_{32}^{L M} X_{2}^{M}+Y_{3}^{L} \\
& X_{1}^{M}=a_{11}^{M L} X_{1}^{L}+a_{12}^{M L} X_{2}^{L}+a_{13}^{M L} X_{3}^{L}+a_{11}^{M M} X_{1}^{M}+a_{12}^{M M} X_{2}^{M}+Y_{1}^{M} \\
& X_{2}^{M}=a_{21}^{M L} X_{1}^{L}+a_{22}^{M L} X_{2}^{L}+a_{23}^{M L} X_{3}^{L}+a_{21}^{M M} X_{1}^{M}+a_{22}^{M M} X_{2}^{M}+Y_{2}^{M}
\end{aligned}
$$


Se movermos todos os termos envolvendo $X^{L}$ e $X^{M}$ para o lado esquerdo, podemos representar as equações anteriores da seguinte forma:

$$
\begin{aligned}
& \left(1-a_{11}^{L L}\right) X_{1}^{L}+a_{12}^{L L} X_{2}^{L}+a_{13}^{L L} X_{3}^{L}+a_{11}^{L M} X_{1}^{M}+a_{12}^{L M} X_{2}^{M}=Y_{1}^{L} \\
& a_{21}^{L L} X_{1}^{L}+\left(1-a_{22}^{L L}\right) X_{2}^{L}+a_{23}^{L L} X_{3}^{L}+a_{21}^{L M} X_{1}^{M}+a_{22}^{L M} X_{2}^{M}=Y_{2}^{L} \\
& a_{31}^{L L} X_{1}^{L}+a_{32}^{L L} X_{2}^{L}+\left(1-a_{33}^{L L}\right) X_{3}^{L}+a_{31}^{L M} X_{1}^{M}+a_{32}^{L M} X_{2}^{M}=Y_{3}^{L} \\
& a_{11}^{M L} X_{1}^{L}+a_{12}^{M L} X_{2}^{L}+a_{13}^{M L} X_{3}^{L}+\left(1-a_{11}^{M M}\right) X_{1}^{M}+a_{12}^{M M} X_{2}^{M}=Y_{1}^{M} \\
& a_{21}^{M L} X_{1}^{L}+a_{22}^{M L} X_{2}^{L}+a_{23}^{M L} X_{3}^{L}+a_{21}^{M M} X_{1}^{M}+\left(1-a_{22}^{M M}\right) X_{2}^{M}=Y_{2}^{M}
\end{aligned}
$$

Representando matricialmente temos:

a) a matriz completa de coeficientes, $A$, desse modelo inter-regional de duas regiões será composta por 4 sub-matrizes $A^{L L}(3 \times 3), A^{L M}(3 \times 2), A^{M L}(2 \times 3)$ e $A^{M M}(2 \times 2)$ :

$$
A=\left[\begin{array}{ll}
A^{L L} & A^{L M} \\
A^{M L} & A^{M M}
\end{array}\right]
$$

b) o vetor de demanda final (Y) será formado pelos vetores $Y^{L}(3 \times 1)$ e $Y^{M}(2 \times 1)$ :

$$
Y=\left[\begin{array}{l}
Y^{L} \\
Y^{M}
\end{array}\right]
$$

c) o vetor de produção total será formado pelos vetores $X^{L}(3 \times 1)$ e $X^{M}(2 \times 1)$ :

$$
X=\left[\begin{array}{l}
X^{L} \\
X^{M}
\end{array}\right]
$$


d) matriz identidade

$$
I=\left[\begin{array}{ll}
I & 0 \\
0 & I
\end{array}\right]
$$

Assim, o sistema insumo-produto inter-regional completo pode ser representado por:

$$
\begin{aligned}
& (I-A) X=Y \\
& \left\{\left[\begin{array}{cc}
I & \mathbf{0} \\
\mathbf{0} & I
\end{array}\right]-\left[\begin{array}{ll}
A^{L L} & A^{L M} \\
A^{M L} & A^{M M}
\end{array}\right]\right\} \cdot\left[\begin{array}{l}
X^{L} \\
X^{M}
\end{array}\right]=\left[\begin{array}{l}
Y^{L} \\
Y^{M}
\end{array}\right] \\
& \left(I-A^{L L}\right) X^{L}-A^{L M} X^{M}=Y^{L} \\
& -A^{M L} X^{L}+\left(I-A^{M M}\right) X^{M}=Y^{M}
\end{aligned}
$$

Para identificar o efeito feedback, Miller \& Blair (1985), assumem que há variação somente na demanda final da região $L$, portanto, $Y^{M}=0$. Dessa forma, se isolarmos $X^{M}$ da equação (17) e substituirmos a expressão resultante na equação (16), temos:

$$
\begin{aligned}
& X^{M}=\left(I-A^{M M}\right)^{-1} A^{M L} X^{L} \\
& \left(I-A^{L L}\right) X^{L}-A^{L M}\left(I-A^{M M}\right)^{-1} A^{M L} X^{L}=Y^{L}
\end{aligned}
$$

Se compararmos a expressão obtida em (19), para duas regiões, com a equivalente para uma única região, $\left\{\left(I-A^{L L}\right)^{-1} X^{L}=Y^{L}\right\}$, constatamos que a expressão (19) apresenta um termo a mais, a expressão $\left\{A^{L M}\left(I-A^{M M}\right) A^{M L} X^{L}\right\}$, que corresponde ao efeito feedback inter-regional. 
Analisando separadamente cada componente dessa expressão podemos entender melhor esse efeito. $\mathrm{O}$ termo $X^{L}$ representa o aumento na produção da região $L$ que, por sua vez, provoca um aumento na produção de insumos na região $M$, capturado pelo termo $\left(A^{M L} X^{\mathrm{L}}\right)$, fazendo com que a região $M$ aumente a sua produção para suprir o aumento de demanda na região $L$. As relações internas da região como um todo geram um aumento na produção em $M$ causado pelo aumento da produção em $L$ \{ $I$ $\left.A^{M M}\right) A^{M L} X^{L}$ \} e, como $M$ também demandará insumos de $L$, multiplicamos a variação na produção da região $M$ por $A^{L M}$.

\subsubsection{Obtenção do sistema de Leontief}

O sistema originalmente definido por Leontief define duas matrizes como sendo a base do sistema como um todo: a matriz de consumo intermediário setor por setor (Z) e a matriz de demanda final por setor (Y). De acordo com Guilhoto (2003), existem duas formas de se obter o sistema de Leontief a partir das matrizes de Produção e de Uso. A escolha de uma dessas formas se baseia no tipo de hipótese feita com relação ao modo de produção e participação das indústrias no mercado de produtos.

Segundo esse autor, se assumirmos que o mix de produção de um dado setor pode ser alterado, mas esse setor mantém a sua participação constante no mercado dos bens que produz, a forma adotada para obtenção do sistema de Leontief é a que considera a hipótese da tecnologia baseada na indústria. Por outro lado, se assumirmos que o mix de produção de um dado setor não pode ser alterado, mas a sua participação no mercado dos bens que produz pode ser alterada, a hipótese considerada é a da tecnologia baseada no produto. Cada uma dessas tecnologias pode ser aplicada de modo a gerar o sistema de Leontief sob diferentes enfoques: produto $\mathrm{x}$ produto; produto $\mathrm{x}$ setor; setor x produto e setor x setor.

Assim, conforme destacam Miller \& Blair (1985) e Guilhoto (2003), pelo fato de a hipótese da tecnologia baseada no produto ser mais restritiva e, em geral, aplicada a 
poucos setores da economia, a hipótese da tecnologia baseada na indústria é em geral mais realista e a mais utilizada, sendo mais utilizado o enfoque setor x setor.

A Figura 2 representa o sistema de Insumo-Produto, que será usado como referência para a derivação do enfoque setor x setor baseado na indústria, e que usa as Tabelas de Recursos (V) e Usos (U) disponibilizadas pelo IBGE.

\begin{tabular}{|c|c|c|c|c|}
\hline & Produtos & Setores & Demanda Final & Produção Total \\
\hline Produtos & & $U$ & $E$ & $Q$ \\
\hline Setores & $V$ & $Z$ & $Y$ & $X$ \\
\hline Importações & & $M$ & & \\
\hline $\begin{array}{c}\text { Impostos Indiretos } \\
\text { Líquidos }\end{array}$ & & $T$ & & \\
\hline Valor Adicionado & & $W$ & & \\
\hline Produção Total & $Q^{\prime}$ & $X^{\prime}$ & & \\
\hline
\end{tabular}

Figura 2 - Esquema do sistema de insumo-produto.

Fonte: Miller \& Blair (1985); Guilhoto (2003)

Assim, considerando uma economia onde existam $n$ setores e $m$ produtos, temse que:

$V$ é a matriz de produção de dimensão $n \times m$, onde o elemento $v_{i j}$ corresponde ao bem $j$ produzido pelo setor $i$;

$U$ é a matriz de uso de dimensão $m \times n$, onde o elemento $u_{i j}$ é o valor do produto $i$ utilizado pelo setor $j$ em seu processo de produção;

$Z$ é a matriz de uso de dimensão $n \times n$, onde o elemento $z_{i j}$ é o valor do setor $i$ utilizado pelo setor $j$ em seu processo de produção;

$E$ é o vetor de demanda final por produto, de dimensão $m \times 1$; 
$Y$ é o vetor de demanda final por setor, de dimensão $n \times 1$;

$M$ é o vetor de importações totais realizadas em cada setor, de dimensão $1 x n$;

$T$ é o vetor do total dos impostos indiretos líquidos pagos em cada setor, de dimensão $1 \times n$;

$W$ é vetor do total do valor adicionado à produção gerado em cada setor, de dimensão $1 \times n$

$Q$ é o vetor de produção total, por produto, de dimensão $m \times 1$;

$X$ é o vetor de produção total, por setor, de dimensão $n x 1$.

Para a aplicação da tecnologia baseada na indústria, são definidas, inicialmente, duas matrizes de transformação: B, que transforma as informações obtidas por setor em informações por produto e D, que transforma as informações obtidas por produto em informações por setor. Assim, temos que:

$$
\begin{aligned}
& B=U(\hat{X})^{-1} \\
& D=V(\hat{Q})^{-1}
\end{aligned}
$$

e,

$$
b_{i j}=\frac{u_{i}}{X_{j}}
$$




$$
d_{i j}=\frac{v_{i j}}{Q_{j}}
$$

Assim, $B$ representa a matriz de coeficientes técnicos de cada setor em relação a cada produto utilizado como insumo. A matriz $D$ determina, por sua vez, a proporção, para cada produto, dos setores que o produzem. Vale destacar que essa proporção será fixa.

Da definição de $D$, temos que:

$$
V=D \hat{Q}
$$

e, sabendo que:

$$
X=V .1
$$

onde 1 é um vetor coluna cujos elementos são todos iguais a 1.

Substituindo-se a equação (22) em (23), tem-se:

$$
X=D \hat{Q}_{i}=D Q
$$

Considerando-se o esquema apresentado no Quadro 1, temos que:

$$
Q=U_{i}+E
$$

Segundo a equação (20), $U=B X$, logo:

$$
Q=B X+E
$$


Essa equação mostra a produção total de cada produto, que é obtida pela soma do produto total por setor $(X)$ pré-multiplicado pela matriz que representa quanto cada setor utiliza de cada produto no seu processo de produção $(B)$, com a demanda final por produto.

Assim, pré-multiplicando ambos os lados da equação (26) por $D$ tem-se:

$$
D Q=D B X+D E
$$

Da equação (24) temos que $X=D Q$ e, uma vez que a matriz $D$, assumindo a hipótese da tecnologia baseada na indústria, é uma matriz de proporções que redefine a produção por produto em produção por setor tem-se que $Y=D E, \operatorname{logo}, E=D^{-1} Y$. Assim,

$$
X=D B X+Y
$$

Isolando os termos $\mathrm{X}$ do lado esquerdo da equação (28) e colocando $\mathrm{X}$ em evidência, temos o enfoque setor $(X)$ por setor $(Y)$ com a tecnologia baseada na indústria, equação (29).

$$
X=(I-D B)^{-1} Y
$$

Esse enfoque é o que mais se aproxima do modelo original de Leontief e, portanto, é o padrão que se costuma utilizar para transformar as matrizes de usos e recursos, fornecidas pelas Contas Nacionais, no modelo de Leontief.

A matriz $D B$, nesse caso, é equivalente à matriz $A$ de coeficientes técnicos de Leontief, e a matriz $(I-D B)^{-1}$ é equivalente à matriz inversa de Leontief, $(I-A)^{-1}$. 


\subsubsection{Estrutura produtiva, ligações interindustriais e setores-chave}

O objetivo desta seção é descrever os métodos geralmente utilizados na análise da estrutura produtiva, na identificação dos setores-chave e nas análises de impacto de uma economia.

Em geral, poucos são os setores que tem real importância para uma economia, ou seja, poucos são os setores que apresentam muitas ligações com os demais setores da economia. A teoria de insumo-produto, através dos cálculos dos Índices de HirschmanRasmussen, do Campo de Influência, da Matriz Intensidade e dos Índices Puros de Ligações nos permite a determinação desses setores denominados, então, como setoreschave da economia.

Uma outra forma de analisar uma economia é determinando como esta se comporta frente a uma variação na demanda final por produtos de setores específicos, podendo esses ser os setores-chave ou qualquer outro setor para o qual se queira quantificar esse impacto. Essa análise, na teoria de insumo-produto, é feita através do cálculo dos multiplicadores de produção, renda, emprego e importação.

A seguir serão descritos os métodos empregados no cálculo desses indicadores.

\section{Índices de ligação de Hirschman-Rasmussen}

Os índices de Hirschman-Rasmussen são calculados a partir da matriz inversa de Leontief $B=[I-A]^{-1}$. Os índices de ligações para trás $\left(\mathrm{U}_{\mathrm{j}}\right)$, determinam o quanto um setor demanda dos outros (equação 30); já os índices de ligações para frente $\left(\mathrm{U}_{\mathrm{i}}\right)$ determinam o quanto este setor é demandado pelos outros (equação 31).

$$
U_{j}=\left[B_{* j} / n\right] / B^{*}
$$




$$
U_{i}=\left[B_{*_{i}} / n\right] / B^{*}
$$

onde,

$\mathrm{B}^{*}$ corresponde à média de todos os elementos da inversa de Leontief $(\mathrm{B})$ :

$$
B^{*}=\frac{\sum_{i=1}^{n} \sum_{j=1}^{n} b_{i j}}{n^{2}}
$$

$\mathrm{B}_{*_{\mathrm{j}}}$ corresponde à soma de uma coluna típica de B:

$$
B_{* j}=\sum_{i=1}^{n} b_{i j}
$$

$\mathrm{B} *_{\mathrm{i}}$ corresponde à soma de uma linha típica de $\mathrm{B}$ :

$$
B_{* i}=\sum_{j=1}^{n} b_{i j}
$$

Através desses índices, temos o grau de encadeamento dos setores da economia para trás, como demandante de insumos dos demais setores da economia, e para frente, como ofertante de insumos para os demais setores da economia. Assim, os setores que apresentam esses índices maiores que a unidade tanto para frente como para trás indicam setores acima da média e, portanto, setores-chave para o crescimento da economia.

Guilhoto et al. (1994), levantam um problema dos índices de HirschmanRasmussen que se refere ao fato de os mesmos não considerarem os diferentes níveis de produção de cada setor da economia, destacando que "apesar de avaliarem a importância de um dado setor em termos dos seus impactos no sistema como um todo, é difícil 
visualizar os principais elos de ligações dentro da economia, ou seja, quais seriam os coeficientes que, se alterados, teriam um maior impacto no sistema como um todo" (Guilhoto et al., 1994 p. 296).

\section{Campo de influência}

Para resolver essa limitação dos índices de Hirschman-Rasmussen, esses autores propõem o uso do conceito de Campo de Influência, desenvolvido por Sonis e Hewings (1989, 1995). Esse conceito descreve como se distribuem as mudanças dos coeficientes diretos no sistema econômico como um todo permitindo, dessa forma, determinar quais as relações entre os setores que seriam mais importantes dentro do processo produtivo.

Assim, conforme destaca Silveira (2000), pode-se identificar quais setoreschave apresentarão maior sensibilidade, se ocorrerem pequenas mudanças nos coeficientes de produção, que poderão afetar o resto da economia regional.

O campo de influência requer a matriz de coeficientes técnicos de produção (A $\left.=\left|a_{\mathrm{ij}}\right|\right)$ e a matriz de variações incrementais nos coeficientes diretos de insumo $(\mathrm{E}=$ $\left.\left|\varepsilon_{\mathrm{ij}}\right|\right)$. As correspondentes matrizes inversas de Leontief são dadas por $B=[I-A]^{-1}=$ $\left|b_{\mathrm{ij}}\right|$ e $B(\varepsilon)=[I-A-\varepsilon]^{-1}=\mid b_{\mathrm{ij}}(\varepsilon)$. $\mid$. Assim, caso a variação tecnológica seja pequena e só ocorra num coeficiente direto, isto é:

$$
\begin{cases}\varepsilon_{i j}=\varepsilon & i=i_{1}, j=j_{1} \\ \varepsilon_{i j}=0 & i \neq i_{1}, j \neq j_{1}\end{cases}
$$

o campo de influência desta variação pode ser obtido pela expressão (32):

$$
F\left(\varepsilon_{i j}\right)=\frac{\left[B\left(\varepsilon_{i j}\right)-B\right]}{\varepsilon_{i j}}
$$


onde,

$\mathrm{F}\left(\varepsilon_{\mathrm{ij}}\right)$ é uma matriz ( $\mathrm{n} \times \mathrm{n}$ ) do campo de influência do coeficiente $\mathrm{a}_{\mathrm{ij}}$.

Para se identificar quais são os coeficientes que possuem o maior campo de influência, associa-se a cada matriz $\mathrm{F}\left(\varepsilon_{\mathrm{ij}}\right)$ um valor que é dado por:

$$
S_{i j}=\sum_{k=l}^{n} \sum_{l=1}^{n}\left[f_{k l}\left(\varepsilon_{i j}\right)\right]^{2}
$$

logo, os coeficientes diretos que apresentarem os maiores valores de $\mathrm{S}_{\mathrm{ij}}$ serão aqueles com o maior campo de influência dentro da economia como um todo.

O enfoque do campo de influência, conforme destaca Guilhoto (2003), constitui-se em uma análise complementar à dos índices de ligações de HirschmanRasmussen, uma vez que os principais elos de ligações dentro da economia determinados através do campo de influência estariam associados aos setores que apresentam os maiores índices de ligações tanto para trás, como para frente.

\section{Índices puro de ligação (enfoque GHS)}

O fato de os índices de ligações de Hirschman-Rasmussen não considerarem os níveis de produção de cada setor analisado levou alguns autores como Cella (1984) e Clements (1990) a tentarem resolver ou minimizar essa deficiência. No entanto, o enfoque desses autores também vem sendo aprimorado e, a abordagem de índices puros de ligações utilizada no presente trabalho será aquela desenvolvida por Guilhoto, Sonis e Hewings (1996).

A idéia que está por trás do índice puro de ligações está relacionada à determinação da importância de um determinado setor na geração de produção na economia, ou seja, tem-se uma economia funcionando com um determinado número de setores, retira-se um setor ( $j$, por exemplo) e faz-se a análise de como a economia se 
comporta sem ele. A diferença entre o comportamento da economia com e sem o setor $j$ nos fornece a contribuição desse setor para a economia em questão.

Seguindo a abordagem de Guilhoto et al. (1996), temos que o cálculo dos índices puros de ligação inicia-se pela definição de uma matriz A, que contém os coeficientes de insumos diretos do setor destacado $j$ e do resto da economia, que é decomposta da seguinte forma:

$$
A=\left[\begin{array}{cc}
A_{j j} & A_{j r} \\
A_{r j} & A_{r r}
\end{array}\right]=\left[\begin{array}{cc}
A_{j j} & A_{j r} \\
A_{r j} & 0
\end{array}\right]+\left[\begin{array}{cc}
0 & 0 \\
0 & A_{r r}
\end{array}\right]=A_{j}+A_{r}
$$

onde,

$A_{\mathrm{jj}}$ e $\mathrm{A}_{\mathrm{rr}}$ são, respectivamente, matrizes de insumos diretos do setor $j$ e do resto da economia;

$\mathrm{A}_{\mathrm{rj}}$ é a matriz de insumos diretos comprados pelo setor $j$ do resto da economia; $\mathrm{A}_{\mathrm{jr}}$ é a matriz de insumos diretos comprados pelo resto da economia do setor $j$; $\mathrm{A}_{\mathrm{j}}$ corresponde ao setor $\mathrm{j}$ isolado do resto da economia; $\mathrm{e}$ $\mathrm{A}_{\mathrm{r}}$ corresponde ao restante da economia.

A partir da matriz A, definida na equação (34), chega-se à matriz inversa de Leontief (B) da seguinte forma:

$$
B=(I-A)^{-1}=\left(\begin{array}{ll}
B_{j j} & B_{j r} \\
B_{r j} & B_{r r}
\end{array}\right)=\left(\begin{array}{cc}
\Delta_{j j} & 0 \\
0 & \Delta_{r r}
\end{array}\right) \cdot\left(\begin{array}{ll}
\Delta_{j} & 0 \\
0 & \Delta_{r}
\end{array}\right) \cdot\left(\begin{array}{ll}
I & A_{j r} \Delta_{r} \\
A_{r j} \Delta_{j} & I
\end{array}\right)
$$

onde seus elementos são representados por:

$\Delta_{\mathrm{j}}=\left(\mathrm{I}-\mathrm{A}_{\mathrm{jj}}\right)^{-1}$ que representa a interação do setor $\mathrm{j}$ com ele mesmo;

$\Delta_{\mathrm{r}}=\left(\mathrm{I}-\mathrm{A}_{\mathrm{rr}}\right)^{-1}$ que representa a interação do restante da economia com ele mesmo; 
$\Delta_{\mathrm{jj}}=\left(\mathrm{I}-\Delta_{\mathrm{j}} \mathrm{A}_{\mathrm{jr}} \Delta_{\mathrm{r}} \mathrm{A}_{\mathrm{rj}}\right)^{-1}$ representa quanto o setor $j$ tem que produzir para o restante da economia para que ela atenda às suas necessidades; e

$\Delta_{\mathrm{rr}}=\left(\mathrm{I}-\Delta_{\mathrm{r}} \mathrm{A}_{\mathrm{rj}} \Delta_{\mathrm{j}} \mathrm{A}_{\mathrm{jr}}\right)^{-1}$ representa quanto o restante da economia vai tem que produzir para o setor $j$ para que ele atenda às suas necessidades.

A partir da equação (35) e do modelo de Leontief apresentado na equação (6), é possível derivar um conjunto de índices de ligações que permitem: i) ordenar os setores em termos de sua importância no valor da produção gerada e ii) verificar como o processo de produção acontece na economia. Dessa forma, substituindo a equação (35) na (6), tem-se:

$$
\left(\begin{array}{l}
X_{j} \\
X_{r}
\end{array}\right)=\left(\begin{array}{cc}
\Delta_{j j} & 0 \\
0 & \Delta_{r r}
\end{array}\right) \cdot\left(\begin{array}{cc}
\Delta_{j} & 0 \\
0 & \Delta_{r}
\end{array}\right) \cdot\left(\begin{array}{ll}
I & A_{j r} \Delta_{r} \\
A_{r j} \Delta_{j} & I
\end{array}\right) \cdot\left(\begin{array}{l}
Y_{j} \\
Y_{r}
\end{array}\right)
$$

Realizando a multiplicação do lado direito da equação (36), obtém-se:

$$
\left(\begin{array}{l}
X_{j} \\
X_{r}
\end{array}\right)=\left(\begin{array}{cc}
\Delta_{j j} & 0 \\
0 & \Delta_{r r}
\end{array}\right) \cdot\left(\begin{array}{l}
\Delta_{j} Y_{j}+\Delta_{j} A_{j r} \Delta_{r} Y_{r} \\
\Delta_{r} A_{r j} \Delta_{j} Y_{j}+\Delta_{r} Y_{r}
\end{array}\right)
$$

O índice puro de ligação para trás (PBL) e o índice puro de ligação para frente (PFL) são dados por:

$$
\begin{aligned}
& P B L=\Delta_{r} A_{r j} \Delta_{j} Y_{j} \\
& P F L=\Delta_{j} A_{j r} \Delta_{r} Y_{r}
\end{aligned}
$$


O PBL (índice puro de ligação para trás) representa o impacto do valor da produção total do setor $j$ sobre o resto da economia, desconsiderando a demanda de insumos que o setor gera internamente, bem como as demandas da economia como um todo para o setor $j$ e a demanda do setor $j$ para a economia como um todo. Já o PFL (índice puro de ligação para frente) representa o impacto do valor da produção total do resto da economia sobre o setor $j$.

O índice puro total das ligações é a soma dos dois índices, expressos em valores correntes:

$$
P T L=P B L+P F L
$$

O cálculo dos índices puros de ligações desenvolvidos por Guilhoto, Sonis e Hewings (1996), segundo Silveira (2000, p. 90), consiste em um procedimento alternativo para a compreensão da estrutura da economia, permitindo separar os impactos de um setor específico do resto da economia. Esse modelo considera além das abordagens tradicionais de identificação dos setores-chave (como os índices de Rasmussen-Hirschman), abordagens alternativas desenvolvidas por outros autores como Cella $(1984,1986)$ e Clements (1990) e explora, também, o papel das ligações internas e externas para identificar as fontes de mudanças em uma economia.

Além da obtenção dos índices puros para trás e para frente esse enfoque permite a decomposição do nível de produção total na região $j$ e no resto da economia em quatro componentes. Assim, partindo da expressão (41) temos:

$$
\left(\begin{array}{l}
X_{j} \\
X_{r}
\end{array}\right)=\left(\begin{array}{l}
\Delta_{i j} \Delta_{j} Y_{j}+\Delta_{i j} \Delta_{j} A_{j r} \Delta_{r} Y_{r} \\
\Delta_{r r} \Delta_{r} A_{r j} \Delta_{j} Y_{j}+\Delta_{r r} \Delta_{r} Y_{r}
\end{array}\right)=\left(\begin{array}{l}
X_{j}^{j}+X_{j}^{r} \\
X_{r}^{j}+X_{r}^{r}
\end{array}\right)
$$

onde, $X_{j j}$ fornece o valor da produção total da região $j$ decorrente da demanda final da região $j$; $\mathrm{X}_{\mathrm{jr}}$ fornece o valor da produção total da região $j$ decorrente da demanda final do resto da economia $(r)$; 
$\mathrm{X}_{r j}$ fornece o valor da produção total do resto da economia que é devido à demanda final da região $j$;

$\mathrm{X}_{r r}$ fornece o nível de produção total do resto da economia que é devido à demanda final do resto da economia $(r)$.

\section{Análises de impacto}

A partir do modelo básico de Leontief definido na equação 6 pode-se mensurar o impacto que mudanças nos componentes da demanda final (Y) - consumo da administração pública $(\mathrm{G})$, consumo das famílias $(\mathrm{F})$, investimentos (I) e exportações (X) - teriam sobre a produção total, emprego, importações, impostos, salários, valor adicionado etc. Se representarmos as mudanças nos componentes da demanda final por $\Delta \mathrm{Y}$, temos que a expressão (42) nos fornece os impactos sobre o volume de produção $(\Delta \mathrm{X})$ :

$$
\Delta X=(I-A)^{-1} \cdot \Delta Y
$$

Guilhoto (2003), chamou de $\Delta \mathrm{V}$ o impacto sobre as variáveis emprego, importações, impostos, salários, valor adicionado etc. E, de $v_{i}$, os coeficientes de emprego, de importações etc., que são obtidos dividindo-se, para cada setor, o valor utilizado dessas variáveis na produção total pela produção total do setor correspondente (equação 43).

$$
v_{i}=V_{i} / X_{i}
$$




\section{Multiplicadores}

A partir da equação (43) e da inversa de Leontief, $\mathrm{B}=[I-A]^{-1}$, é possível estimar, para cada setor da economia, o quanto é gerado direta e indiretamente de emprego, importações, impostos, salários, valor adicionado etc., para cada unidade monetária produzida para a demanda final. De acordo com Miller \& Blair (1985), são usados mais freqüentemente três tipos de multiplicadores: de produção, de emprego e de renda. No presente trabalho serão obtidos, além desses três multiplicadores, também o multiplicador de importação.

O Multiplicador de Produção do setor $j$ é definido como o valor total da produção gerada em todos os setores da economia, decorrente de uma alteração em uma unidade monetária na demanda final total com relação à produção do setor $j$.

Assim, pode-se expressar o Multiplicador de Produção tipo I $\left(M P_{j}\right)$ do setor $j$ da seguinte forma:

$$
M P_{j}=\sum_{i=1}^{n} b_{i j}
$$

onde,

$j$ representa um determinado setor da economia e

$b_{i j}$ são os elementos da matriz inversa de Leontief.

Para o multiplicador tipo II $\left(M \overline{P_{j}}\right)$, calcula-se a matriz inversa de Leontief $\bar{B}=(I-\bar{A})^{-1}$, cujos coeficientes são $\bar{b}_{i j}$, e é obtida a partir da matriz $\bar{A}$ de coeficientes técnicos, onde o consumo das famílias é endogenizado.

$$
M \overline{P_{j}}=\sum_{i=1}^{n} \overline{b_{i j}}
$$


O Multiplicador de Emprego para um determinado setor $j$ representa o número de empregos gerados em todos os setores da economia (relacionados direta e indiretamente com o setor $j$ ) para cada emprego gerado diretamente no setor $j$. $\mathrm{O}$ multiplicador de emprego tipo I $\left(M E_{j}\right)$ pode ser expresso como:

$$
M E_{j}=G E_{j} / C E_{j}
$$

onde,

$G E_{j}$ corresponde ao número total de empregos gerados, direta e indiretamente, para cada aumento unitário da demanda final por produtos do setor $j$ (equação 45.1).

$C E_{j}$ corresponde ao número de empregos gerados diretamente no setor $j$ por unidade monetária produzida neste setor.

$$
G E_{j}=\sum_{i=1}^{n} C E_{i} \cdot b_{i j}
$$

em que,

$C E_{i}$ refere-se ao coeficiente direto de emprego do i-ésimo setor, ou seja, corresponde ao número de empregos diretos gerados no i-ésimo setor por unidade monetária produzida neste setor. Esse coeficiente é obtido através da equação 45.2.

$$
C E_{i}=P O_{i} / X_{i}
$$

sendo:

$\mathrm{PO}_{i}$ o número de pessoas ocupadas no i-ésimo setor e $X_{i}$ a produção total do i-ésimo.

O multiplicador de emprego tipo II $\left(M \overline{E_{j}}\right)$ é calculado da seguinte forma: 


$$
M \overline{E_{j}}=G \overline{E_{j}} / C E_{j}
$$

sendo $G \bar{E}_{j}$ o número total de empregos gerados, direta e indiretamente, para cada aumento unitário da demanda final por produtos do setor $j$ (equação 46.1), calculado a partir do coeficiente direto de emprego (CE), definido anteriormente, e dos elementos da inversa de Leontief, considerando o consumo doméstico das famílias endogenamente $\left(\bar{b}_{i j}\right)$,

$$
G \overline{E_{j}}=\sum_{i=1}^{n} C E_{j} \cdot \bar{b}_{i j}
$$

De acordo com Casimiro Filho (2002), os multiplicadores de emprego permitem determinar o impacto de variações na demanda final sobre o produto que, por sua vez, leva a variações no emprego. A variação no emprego conduz a uma variação na renda e, conseqüentemente, na demanda do consumidor.

O Multiplicador de Renda do setor $j$ pode ser definido como a renda gerada, em todos os setores da economia, para cada unidade monetária de renda obtida em um determinado setor devido ao seu aumento de produção necessário para atender a variação em uma unidade de sua demanda final. Dessa forma, o Multiplicador de renda do tipo I $\left(M R_{j}\right)$ é obtido da seguinte forma:

$$
M R_{j}=\sum_{i=1}^{n}\left(r_{n+1, i} \cdot b_{i j}\right) / r_{n+1, j}
$$

onde:

$r_{n+1}$ é um elemento da linha correspondente ao coeficiente da remuneração das famílias e $b_{i j}$ são os elementos da matriz inversa de Leontief. 
E o multiplicador do tipo II $\left(M \bar{R}_{j}\right)$ é calculado da seguinte forma:

onde:

$$
M \bar{R}_{j}=\sum_{i=1}^{n}\left(r_{n+\mathbf{1}, i} \cdot \bar{b}_{i j}\right) / r_{n+\mathbf{1}, j}
$$

$r_{n+1}$ é um elemento da linha correspondente ao coeficiente da remuneração das famílias e $\bar{b}_{i j}$ são os elementos da matriz inversa de Leontief, considerando o consumo das famílias endogenamente.

Já o Multiplicador de Importações do setor $j$ representa o aumento nas importações de todos os setores da economia resultante de um aumento de uma unidade monetária de demanda final do setor $j$. Assim, pode-se expressar o Multiplicador de importações do tipo I como:

$$
M I_{j}=\sum_{i=\mathbf{1}}^{n}\left(\beta_{n+\mathbf{1}, i} \cdot b_{i j}\right) / \beta_{n+\mathbf{1}, j}
$$

onde:

$\beta_{n+1}$ é um elemento da linha correspondente ao coeficiente de importações e $b_{i j}$ são os elementos da matriz inversa de Leontief.

Já o multiplicador tipo II pode ser expresso como:

$$
M \overline{I_{j}}=\sum_{i=1}^{n}\left(\beta_{n+1, i} \cdot \bar{b}_{i j}\right) / \beta_{n+1, j}
$$

onde, $\beta_{n+1}$ é um elemento da linha correspondente ao coeficiente de importações e $\bar{b}_{i j}$ são os elementos da matriz inversa de Leontief, considerando o consumo das famílias endogenamente.

Vale ressaltar que no caso dos multiplicadores do tipo I (ou simples), o efeito multiplicativo se restringe à demanda de insumos intermediários. Isto implica na 
desconexão do setor demanda final da matriz das inter-relações tecnológicas dos setores produtivos.

Os tipos básicos de transações que constituem as atividades da demanda final da matriz de insumo-produto são: consumo (ou compras) das famílias, gastos do governo, investimento privado bruto doméstico (formação bruta de capital fixo) e exportações.

Os multiplicadores do tipo II representam uma forma alternativa de análise que a matriz de insumo-produto nos permite realizar. No cálculo desse tipo de multiplicador, o consumo das famílias é endogenizado, ou seja, uma linha e uma coluna são acrescentadas à matriz original de modo que as vendas e compras desse setor passem a fazer parte das inter-relações tecnológicas dos setores da matriz.

A idéia que está por trás da endogenização das famílias é a seguinte: as famílias (consumidores) recebem renda devido ao pagamento por seu insumo "trabalho" empregado no processo produtivo dos setores da economia. Essa renda, por sua vez, é gasta comprando produtos dos mais variados setores. Assim, se houver um aumento na produção de algum setor da economia, haverá um aumento na quantidade do insumo trabalho necessário para atender a esse aumento de produção, o que implica em um aumento na renda das famílias que, por sua vez, levará a uma mudança (aumento, nesse exemplo) nos gastos das famílias com a sua cesta de consumo. Com isso, temos que embora as famílias tendem a comprar bens para o seu consumo "final", a quantidade por elas comprada está relacionada com a sua renda que, por sua vez, depende da produção de cada setor (Miller \& Blair, 1985).

O processo de endogenização do consumo das famílias consiste em levar em consideração, na matriz de insumo-produto original (que dá origem aos multiplicadores tipo I), essas relações do setor famílias como comprador e vendedor de insumos para os demais setores. Tal como anteriormente, a linha "famílias" acrescida à matriz original mostra como o insumo trabalho é utilizado no processo produtivo dos diversos setores da economia. Ou seja, representa o fluxo de renda e salários recebidos pelas famílias dos n setores no pagamento por seus serviços. Já a coluna, mostra a estrutura de compras ou 
de consumo do setor "famílias", ou seja, representa o fluxo monetário das famílias para os setores, na compra de bens e serviços dos n setores da economia.

O efeito da endogenização sobre os valores dos multiplicadores, segundo Miller \& Blair (1985), refere-se ao fato de que os multiplicadores tipo II são maiores que os do tipo I. Isso se deve ao fato de que com a endogenização, gera-se produção nos setores da economia devido ao efeito renda ou induzido. E assim, um aumento nas produções setoriais torna-se necessário para satisfazer o aumento no consumo das famílias, decorrente do aumento nos salários (renda).

\subsection{O Estado do Acre como modelo para estudos de insumo-produto}

\subsubsection{Aspectos históricos}

O Acre foi incorporado ao Brasil em dezessete de novembro de 1903 por conta de um acordo internacional com a Bolívia, o "Tratado de Petrópolis" constituindo, assim, o primeiro Território Federal do Brasil (Acre (2000); Freitas (2002)).

O período que antecedeu à inclusão do Acre, como território federal brasileiro, foi um tanto conflituoso uma vez que, como a Constituição de 1889 não contemplava a possibilidade de criação de Territórios Federais pela União, o Estado do Amazonas queria incorporar a porção de terra correspondente ao Acre ao seu território estadual.

O amparo legal para a criação de Territórios Federais só viria a aparecer na Constituição de 1934, que considerou esses territórios como partes integrantes da Nação Brasileira e, ainda contemplou, nos seus artigos subseqüentes, que à União competiria a sua administração bem como a cobrança de impostos e o fato de que outros territórios nacionais, além do Acre, poderiam vir a pertencer à União.

A partir de então, os Territórios Federais passaram a constituir projetos de uma política de governo cujo objetivo principal era a ocupação de espaços vazios na Amazônia. 
Vale destacar que, embora pudessem eleger dois Deputados Federais, os Governadores e Prefeitos dos Territórios Federais eram sempre pessoas indicadas e que, em geral, desconheciam a região a ser governada (Freitas, 2002). Nesses territórios não havia Poder Legislativo e Judiciário e havia uma submissão dos seus orçamentos ao Governo Federal uma vez que era Brasília quem definia suas receitas.

Em 1943 o Brasil era composto pelos seguintes Territórios Federais: Acre, Amapá, Guaporé, Rio Branco, Roraima, Fernando de Noronha, Ponta Porã e Iguaçu. Mas a Constituição de 1946 extinguiu os territórios de Iguaçu e Ponta Porã, devido a fortes pressões de Estados fortes como Santa Catarina e Paraná.

Devido às suas localizações distintas e distantes, cada território federal procurou desenvolver suas vocações econômicas na época. O Acre e Guaporé se voltaram mais para a produção de borracha, Rio Branco para a pecuária e Amapá para a mineração. No entanto, a fraca economia local excluía esses Territórios do acesso a uma economia mais dinâmica e, por isso, o Governo Federal era a única possibilidade inicial de promover o desenvolvimento dos territórios.

Em 1962 o Acre foi transformado em Estado. Guaporé passou a ser Rondônia e tornou-se estado em 1982. Roraima e Amapá esperaram até 1988 para tanto. Já Fernando de Noronha foi incorporado ao estado de Pernambuco em 1988.

O ano de 1988 é o marco da consolidação da questão territorial e de ocupação na Amazônia uma vez que, nesse ano, os últimos territórios federais tornaram-se Estados. Assim, o Governo Federal transferiu a responsabilidade para o governante estadual. A partir de então, cada Estado passou a tentar identificar as suas vantagens comparativas de modo a atingir mais autonomia e garantir o seu desenvolvimento econômico.

Becker (2002) analisa as diferentes estratégias adotadas pelos diferentes Estados e destaca que, em tempos recentes, cada Estado adotou estratégias diferentes para a consolidação do seu povoamento e desenvolvimento local. Por exemplo, os Estados do Mato Grosso, Tocantins e parte dos estados do Pará, Maranhão, Roraima e Rondônia, têm um modelo de ocupação extensivo baseado na agropecuária; o Amazonas tem um modelo de ocupação pontual, fundamentado na concentração industrial na Zona 
Franca de Manaus; já os estados do Acre e Amapá optaram por modelos baseados na utilização conservacionista da floresta.

\subsubsection{Características gerais}

Situado no extremo sudoeste da Amazônia brasileira, entre as latitudes de $07^{\circ} 07^{\prime} \mathrm{S}$ e $11^{\circ} 08^{\prime} \mathrm{S}$, e as longitudes $66^{\circ} 30^{\prime} \mathrm{W}$ e $74^{\circ} \mathrm{W}$ GR, o Estado do Acre faz fronteiras nacionais com os Estados do Amazonas e Rondônia e internacionais com o Peru e a Bolívia (Figura 3).

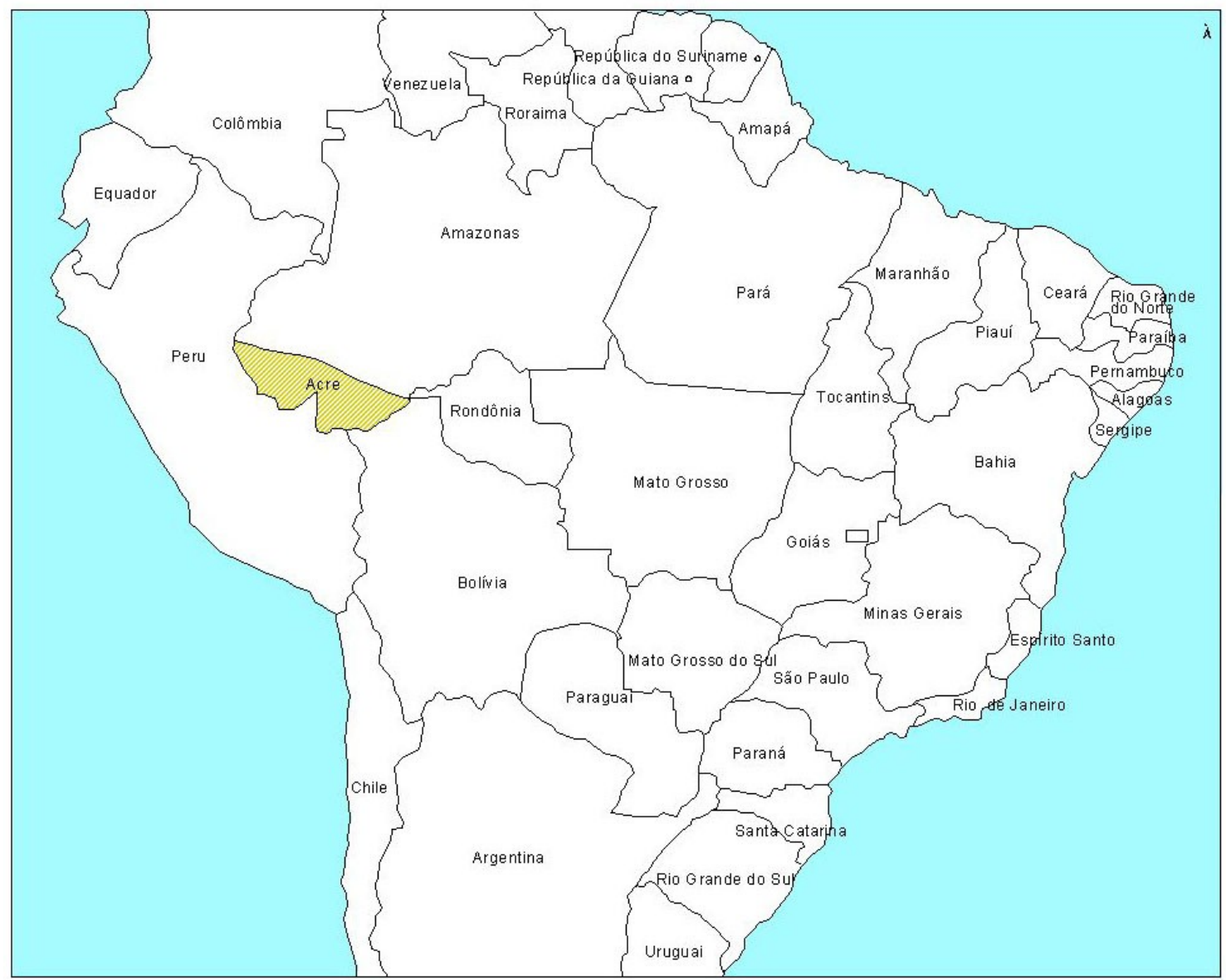

Figura 3 - Acre: localização, fronteiras nacionais e internacionais.

Fonte: IBGE (2000) 
O clima do estado é quente e úmido, com duas estações bem definidas: a seca, que vai de maio a outubro e a chuvosa, que vai de novembro a abril. A precipitação pluviométrica anual varia entre $1600 \mathrm{~mm}$ e $2750 \mathrm{~mm}$ e a temperatura média anual está em torno de $24,5^{\circ} \mathrm{C}$, sendo que a máxima fica em torno de $32^{\circ} \mathrm{C}$ e a mínima varia de local para local, de acordo com a maior ou menor exposição aos sistemas extratropicais.

Os tipos de solos predominantes são: os Argissolos, em 64\% do território, seguido pelos Cambissolos (24,2\%) e Gleissolos (7,4\%). Estes solos, de origem sedimentar, abrigam, basicamente, dois tipos de florestas: Tropical Densa e Tropical Aberta, de grande heterogeneidade florística e grande valor econômico para o estado (Acre, 2000).

O Zoneamento Ecológico-Econômico dividiu o estado do Acre em seis Grupos de Aptidão Agroflorestal dependendo do tipo de solo predominante no estado, da fertilidade natural desses, do excesso ou deficiência de água, da susceptibilidade à erosão e dos impedimentos ao uso de implementos agrícolas além, dos graus de limitação que venham a existir após a utilização de práticas agrícolas inerentes aos sistemas de manejo.

Os seis grupos de aptidão agroflorestal são:

1. produção intensiva de grãos;

2. culturas perenes, espécies frutíferas e florestais em monocultivos;

3. exploração de culturas perenes e espécies florestais e frutíferas em sistemas agroflorestais;

4. pastagem com ênfase para sistemas agrossilvipastoris;

5. sem aptidão agroflorestal, com restrições moderadas para atividades florestais e conseqüente circulação de veículos ; e

6. sem aptidão agroflorestal, indicado para preservação da flora e fauna.

Essa classificação resulta na seguinte distribuição: 44,3\% das terras do Acre enquadram-se no grupo $2 ; 41,0 \%$ no grupo $3 ; 10,6 \%$ no grupo $4 ; 2,0 \%$ estão no grupo 1 ; $1,4 \%$ estão no grupo 5 ; e $0,7 \%$ no grupo 6 . 


\subsubsection{Demografia}

Segundo o Censo Demográfico do IBGE (2003), a população do Acre corresponde a 557.526 habitantes que estão distribuídos em uma superfície territorial de $153.149,9 \mathrm{Km}^{2}$ (1,8\% do território nacional), o que resulta em uma densidade demográfica de 3,65 habitantes por quilômetro quadrado.

Essa população reside, em sua maioria, na área urbana $(66,42 \%)$ e está distribuída entre homens e mulheres nas proporções 50,4\% e 49,6\%, respectivamente (IBGE, 2000).

A Tabela 1 permite analisar a evolução da densidade demográfica do estado desde 1920. De acordo com esses dados, podemos observar que houve uma diminuição do número de habitantes por quilometro quadrado de 1920 para 1940. Isso reflete o fato dos ciclos econômicos, principalmente, terem exercido influência negativa no que se refere aos fluxos migratórios para o Estado.

Após o primeiro colapso da borracha, em 1912, a Amazônia passou por um período de involução econômica que levou os seringalistas a se deslocarem para outras regiões.

$\mathrm{O}$ aumento no número de habitantes por quilômetro quadrado observado de 1940 para 1950 deveu-se ao segundo ciclo da borracha que incentivou a migração da mão-de-obra para a região amazônica, especialmente para o Acre, como alternativa ao serviço militar durante a Segunda Guerra Mundial (os chamados "Soldados da Borracha").

O aumento na densidade demográfica de 1950 para 1960 teve a influência da construção da rodovia Belém-Acre que, embora precária, amenizou o isolamento do Estado com relação ao Centro-Sul brasileiro. 
Tabela 1. Densidade demográfica do Acre de 1920 a 2000.

\begin{tabular}{ccc}
\hline Ano & $\begin{array}{c}\text { Densidade Demográfica } \\
\text { (habitantes/Km2) }\end{array}$ & $\begin{array}{c}\text { População } \\
\text { (habitantes) }\end{array}$ \\
\hline 1920 & 0,61 & 92.379 \\
1940 & 0,52 & 79.768 \\
1950 & 0,75 & 114.755 \\
1960 & 1,05 & 160.208 \\
1970 & 1,43 & 215.299 \\
1980 & 2,01 & 301.276 \\
1991 & 2,74 & 417.718 \\
2000 & 3,65 & 557.226 \\
\hline
\end{tabular}

Fonte: IBGE (2003)

A respeito desses períodos, um recente zoneamento ecológico-econômico do estado do Acre (Acre, 2000) destaca que a partir de 1940 a população cresceu a taxas elevadas: $3,7 \%$ na década de quarenta, $3,3 \%$ na de cinqüenta e $3,1 \%$ na de sessenta. No entanto, esse mesmo trabalho mostra que houve um saldo migratório negativo nas décadas de cinqüenta e sessenta.

O incremento populacional da década de setenta refletiu a entrada de uma frente agropecuária especulativa no Acre. Na década seguinte, começaram os projetos de colonização do Instituto Nacional de Colonização e Reforma Agrária (INCRA), para alocar as populações extrativistas que foram expulsas do meio rural pelos pecuaristas e os migrantes de outros estados que se dirigiam para o estado e para a Amazônia. A demografia das décadas seguintes (80 e 90) teve estreita relação com as melhorias ocorridas nas vias de acesso ao estado: BR-364 (Cuiabá - Rio Branco), na década de oitenta e das rodovias BR-317 (Rio Branco - Xapuri) e BR-364 (Rio Branco - Cruzeiro do Sul), na década de noventa (Acre, 2000).

\subsubsection{Aspectos ambientais e hidrografia}

Somente a partir da década de sessenta, com o surgimento dos empreendimentos agropecuários como mola propulsora de desenvolvimento local, a preocupação ambiental tornou-se uma questão em pauta na região. De fato, nesse 
momento inicial não houve, por parte desses empreendimentos, qualquer preocupação com os impactos ambientais e sociais decorrentes de sua implantação desordenada.

Dessa constatação, resultaram duas ações que contribuíram para a proteção do território acreano e da sua hidrografia: a demarcação das Terras indígenas, protegendo $13,9 \%$ do território e a criação de Áreas de conservação, protegendo 15,6\%. Posteriormente, na década de oitenta, foram criadas também as Reservas Extrativistas Chico Mendes e Alto Juruá (Figura 4).

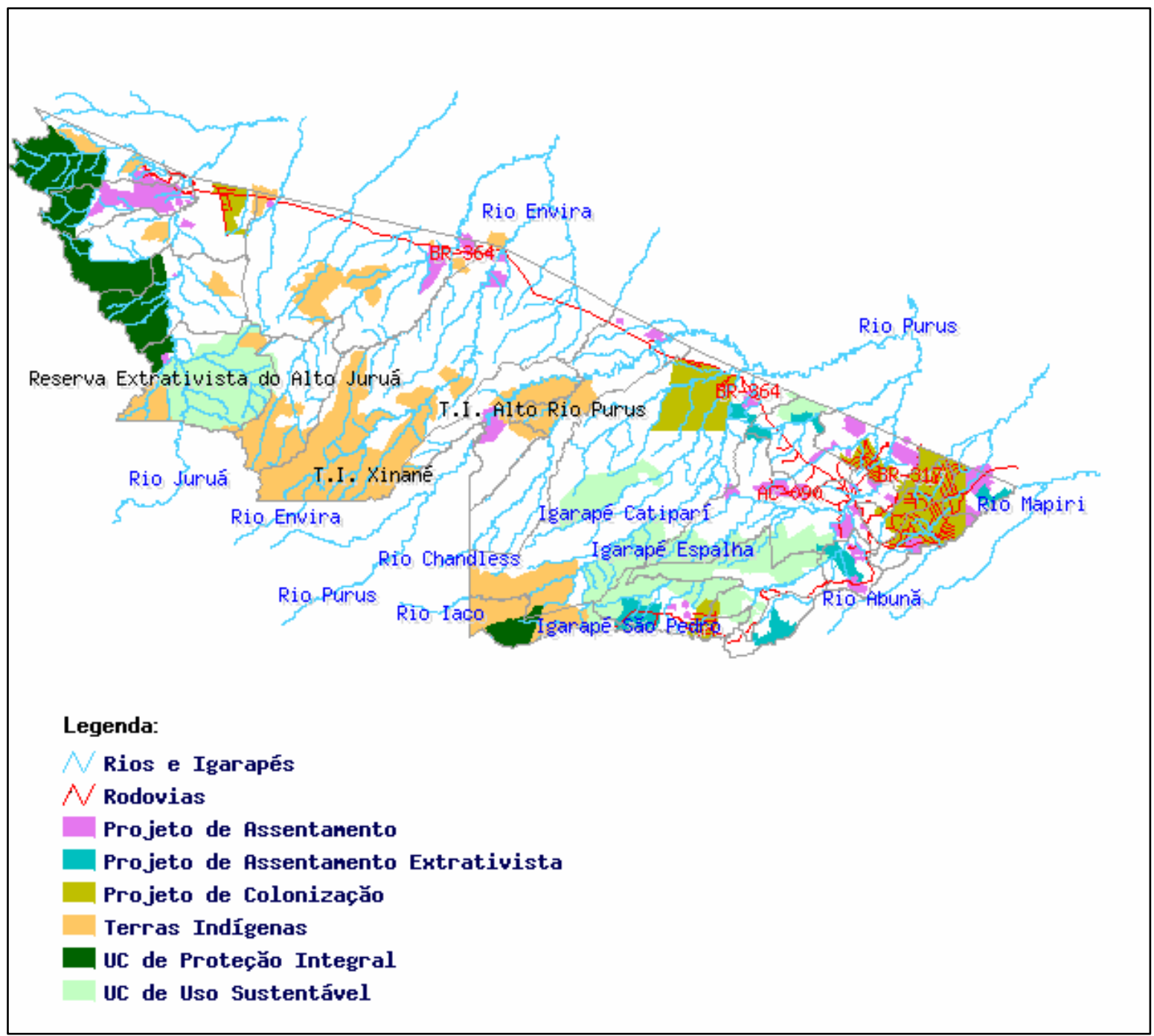

Figura 4 - Hidrografia, rodovias, projetos de assentamento e colonização, terras indígenas e unidades de conservação do Estado do Acre.

Fonte: Sistema Estadual de Informação Ambiental - SEIAM (2000) 
A complexa rede hidrográfica do estado, apresentada na Figura 4, é formada pelas bacias do Juruá e do Purus que, por sua vez, são compostas pelos seguintes cursos d'água: o Rio Purus e o Rio Acre, localizados na parte central do Estado; os rios Gregório, Muru, Envira e Jurupari, à noroeste; e o rio Juruá e seus afluentes a oeste (Acre, 2000).

Com base na distribuição dos principais rios, o Acre foi divido, politicamente, em cinco regiões de desenvolvimento - Alto Acre, Baixo Acre, Purus, Tarauacá/Envira e Juruá - que correspondem às microrregiões estabelecidas pelo IBGE.

\subsubsection{Os setores primário, secundário e terciário da economia acreana}

O Instituto Brasileiro de Geografia e Estatística (IBGE) disponibiliza uma série de informações, obtidas por meio de pesquisas específicas, que permitem uma descrição detalhada dos Setores Primário, Secundário e Terciário do Estado do Acre.

Esta seção apresenta alguns dados do Zoneamento Ecológico-Econômico do Acre (ZEE-AC) complementados por pesquisas do IBGE que contemplassem um período não analisado no mesmo, ou seja, optou-se por analisar o período de 1990 a 2002 uma vez que, em geral, o ZEE-AC termina suas análises em 1991 ou 1996.

Assim, as seguintes pesquisas foram utilizadas nesta caracterização setorial:

a) Produção Agrícola Municipal para obter informações a respeito da agricultura (lavouras temporárias e permanentes);

b) Produção Extrativa Vegetal para caracterizar o extrativismo vegetal de produtos alimentícios, borrachas, carvão vegetal, lenha, madeira e oleaginosas do Acre;

c) Pesquisa Pecuária Municipal que fornece informações sobre os produtos de origem animal do estado; 
d) Cadastro Central de Empresas $^{3}$ para descrever o tipo de unidade empresarial que predomina no estado - para o período de 1996 a 2001.

O Cadastro Central de Empresas disponibiliza informações referentes ao número de empresas e pessoal ocupado por atividades as quais são agrupadas, de acordo com a Classificação Nacional de Atividade Econômicas (CNAE), nas seguintes categorias: A) Agricultura, pecuária, silvicultura e exploração florestal; B) Pesca; C) Indústrias extrativas; D) Indústrias de transformação; E) Produção e distribuição de eletricidade, gás e água; F) Construção; G) Comércio; reparação de veículos automotores, objetos pessoais e domésticos; H) Alojamento e alimentação; I) Transporte, armazenagem e comunicações; J) Intermediação financeira; K) Atividades imobiliárias, aluguéis e serviços prestados às empresas; L) Administração pública, defesa e seguridade social; M) Educação; N) Saúde e serviços sociais; O) Outros serviços coletivos, sociais e pessoais; P) Serviços domésticos; e Q) Organismos internacionais e outras instituições extraterritoriais.

De maneira geral, pode-se dizer que a atividade predominante no estado é a de "Comércio; reparação de veículos automotores, objetos pessoais e domésticos" (categoria G) que passou de 3.265 empresas em 1996 para 4.901 em 2001 (Tabela 2). No entanto, a participação relativa dessa atividade no total de empresas (soma de todas as categorias A até O) vem caindo anualmente. Isto é, em 1996 o número total de empresas no estado era igual a 5.197 sendo que $62,82 \%$ delas pertenciam a esta categoria $(G)$ e 9,08\% pertenciam à categoria "Indústria de transformação" (D). Nos anos seguintes, a participação do comércio no total de empresas caiu para $62,49 \%$, em 1997; para 61,27\% em 1998; para 57,83\%, em 1999; para 56,08\% em 2000 e para $56,51 \%$ em 2001 .

3 Essa pesquisa apresenta informações a respeito das unidades empresariais com registro no CNPJ, abrangendo as entidades empresariais, órgãos da administração pública e entidades privadas sem fins lucrativos. 
A categoria formada pelas atividades relacionadas à indústria de transformação manteve sua participação no total de empresas, em 1997. Em 1998 sua participação caiu para 8,69\% do total; em 1999 houve um ligeiro aumento da sua participação, para 9,13\%; em 2000, sua participação no número total de empresas do ano caiu para $8,51 \%$ e, em 2001, sua participação ficou em torno dos 8,53\%.

"Outros serviços coletivos, sociais e pessoais" passou de 326 empresas (ou 6,27\% do total), em 1996, para 955 (ou 11,01\%), em 2001, ganhando participação relativa ao longo do período.

"Atividades imobiliárias, aluguéis e serviços prestados às empresas" também apresentou um aumento de participação de 1996 (4,37\% do total) para 2001 (5,28\%). Já a participação do número de empresas pertencentes ao grupo F, "Construção", no total de cada ano caiu de 5,08\% em 1996 para 4,76\% em 2001.

Cabe destacar que até 1998 os dois ramos de atividades mais representativos no estado, em termos de número de empresas, eram o G (Comércio; reparação de veículos automotores, objetos pessoais e domésticos) e o D (Indústria de transformação). De 1999 em diante, a categoria "Outros serviços coletivos, sociais e pessoais" (O) assumiu o segundo lugar, a "Indústria de transformação" passou para a terceira posição e a categoria "Comércio" permaneceu em primeiro lugar.

Com relação ao número de pessoas ocupadas, houve uma alteração importante com relação às categorias que mais empregavam em 1996 em relação às de 2001. Em 1996 a categoria "Administração pública, defesa e seguridade social” empregava $72,79 \%$ do total, enquanto que "Comércio; reparação de veículos automotores, objetos pessoais e domésticos" empregava 10,26\% e a "Indústria de transformação" 3,49\%. No ano 2001, essas três categorias continuaram sendo as que mais empregavam no estado, no entanto houve uma alteração significativa da suas respectivas participações no total de pessoas ocupadas. Assim, temos que "Administração pública, defesa e seguridade social” empregou 54,78\% do total de pessoas do ano (74.732); "Comércio; reparação de veículos automotores, objetos pessoais e domésticos" empregou 17,53\% e a "Indústria de transformação" 4,95\%. 
Por fim, temos que, ao contrário do número de empresas, que aumentou de 5.197 em 1996 para 8.673 em 2001, o pessoal ocupado total apresentou uma queda de 86.186 pessoas em 1996 para $74.732 \mathrm{em} 2001$.

Tabela 2. Número de empresas e pessoal ocupado, por categorias de atividades, para o Acre de 1996 a 2001.

\begin{tabular}{|c|c|c|c|c|c|c|c|c|c|c|c|c|}
\hline \multirow{2}{*}{ Categorias* } & \multicolumn{6}{|c|}{ Número de Empresas (Unidade) } & \multicolumn{6}{|c|}{ Pessoal ocupado total (Pessoas)** } \\
\hline & 1996 & 1997 & 1998 & 1999 & 2000 & 2001 & 1996 & 1997 & 1998 & 1999 & 2000 & 2001 \\
\hline A & 67 & 61 & 67 & 77 & 107 & 89 & 251 & 1.170 & 227 & 272 & 607 & 662 \\
\hline $\mathrm{B}$ & 1 & 1 & 2 & 4 & 4 & 2 & $\mathrm{X}$ & $\mathrm{X}$ & $\mathrm{X}$ & 8 & 4 & $\mathrm{X}$ \\
\hline $\mathrm{C}$ & 8 & 10 & 11 & 8 & 14 & 16 & 33 & 31 & 21 & 15 & 54 & 35 \\
\hline $\mathrm{D}$ & 472 & 522 & 529 & 599 & 646 & 740 & 3.005 & 3.077 & 3.248 & 3.467 & 3.622 & 3.696 \\
\hline E & 3 & 5 & 6 & 6 & 6 & 7 & 600 & 744 & 715 & 773 & 673 & 710 \\
\hline $\mathrm{F}$ & 264 & 282 & 298 & 306 & 352 & 413 & 2.003 & 1.884 & 1.610 & 1.873 & 2.519 & 3.215 \\
\hline G & 3.265 & 3.592 & 3.730 & 3.794 & 4.258 & 4.901 & 8.840 & 9.741 & 10.222 & 10.616 & 11.276 & 13.104 \\
\hline $\mathrm{H}$ & 251 & 264 & 257 & 288 & 312 & 360 & 1.007 & 1.083 & 1.077 & 1.221 & 1.338 & 1.452 \\
\hline I & 92 & 108 & 100 & 126 & 143 & 155 & 1.904 & 1.969 & 1.909 & 1.974 & 2.149 & 2.015 \\
\hline $\mathrm{J}$ & 21 & 18 & 27 & 37 & 39 & 182 & 675 & 586 & 186 & 242 & 250 & 284 \\
\hline $\mathrm{K}$ & 227 & 272 & 319 & 369 & 424 & 458 & 1.976 & 2.309 & 2.191 & 1.994 & 2.136 & 2.458 \\
\hline $\mathrm{L}$ & 70 & 71 & 64 & 62 & 118 & 74 & 62.733 & 36.586 & 27.632 & 33.402 & 32.641 & 40.936 \\
\hline M & 72 & 103 & 107 & 123 & 158 & 200 & 648 & 13.488 & 16.310 & 1.721 & 1.798 & 1.877 \\
\hline $\mathrm{N}$ & 58 & 70 & 80 & 98 & 108 & 121 & 896 & 5.656 & 1.410 & 1.441 & 1.826 & 1.891 \\
\hline $\mathrm{O}$ & 326 & 369 & 491 & 664 & 904 & 955 & 1.615 & 1.634 & 1.716 & 1.834 & 2.338 & 2.397 \\
\hline Total & 5.197 & 5.748 & 6.088 & 6.561 & 7.593 & 8.673 & 86.186 & 79.958 & 68.474 & 60.853 & 63.231 & 74.732 \\
\hline
\end{tabular}

Fonte: IBGE (2004a)

* Categorias: A) Agricultura, pecuária, silvicultura e exploração florestal; B) Pesca; C) Indústrias extrativas; D) Indústrias de transformação; E) Produção e distribuição de eletricidade, gás e água; F) Construção; G) Comércio; reparação de veículos automotores, objetos pessoais e domésticos; H) Alojamento e alimentação; I) Transporte, armazenagem e comunicações; J) Intermediação financeira; K) Atividades imobiliárias, aluguéis e serviços prestados às empresas; L) Administração pública, defesa e seguridade social; M) Educação; N) Saúde e serviços sociais; O) Outros serviços coletivos, sociais e pessoais; P) Serviços domésticos; e Q) Organismos internacionais e outras instituições extraterritoriais.

** Os dados com menos de 3 (três) informantes estão desidentificados com o caracter X. 


\subsubsection{O setor primário}

A partir do que foi apresentado na Introdução e na seção "Políticas desenvolvimentistas para a região Norte: uma perspectiva histórica" deste trabalho, pode-se observar que a economia acreana sempre foi fundamentada no extrativismo vegetal e, mais especificamente, em apenas um produto, a borracha. Após o declínio da borracha, houve a tentativa de tornar a castanha o seu substituto. No entanto, essa não apresentou a mesma relevância econômica tanto no mercado interno quanto no externo.

De acordo com dados oficiais do Governo do Acre (Acre, 2000), após a segunda crise da borracha houve uma reestruturação do setor primário do estado (agropecuária e extrativismo) decorrente da desestruturação da economia da borracha. Ainda segundo essa fonte de informações, na década de 70 e início dos anos 80, a agropecuária e o extrativismo tiveram sua participação relativa na composição do PIB do Acre diminuída drasticamente, passando de $40,8 \%$ para $16,7 \%$.

As informações referentes ao número de empresas e pessoal ocupado nesse setor estão contidas na Tabela 3 que detalha a distribuição dessas variáveis entre as subcategorias que compõe a agricultura, pecuária, produção mista e silvicultura e exploração florestal.

Empresas relacionadas à subcategoria "Pecuária" ocorreram em maior número no estado, em 2001, correspondendo a 57,69\% do total de empresas da categoria A (Agricultura, pecuária, silvicultura e exploração florestal), cujo total de empresas era igual a 78, excluindo-se as atividades relacionadas ao setor terciário. A pecuária também liderou a quantidade de pessoas ocupadas, 61,86\%, ficando a atividade "Silvicultura e exploração florestal" em segundo lugar, em número de empresas, e em terceiro em número de pessoas ocupadas. O setor "Agricultura" mereceu destaque nesse ano com relação ao número de empresas e o setor "Produção mista" se destacou em relação a pessoal ocupado (Tabela 3). 
Tabela 3. Número de empresas e pessoal ocupado segundo as categorias de atividades “Agricultura, pecuária, silvicultura e exploração florestal" (A) e "Pesca" (B), para o Estado do Acre em 2001.

\begin{tabular}{lcccc}
\hline \multicolumn{1}{c}{ Categorias } & $\begin{array}{c}\text { Número de } \\
\text { empresas } \\
\text { (Unidade) }\end{array}$ & $\begin{array}{c}\text { Participação no } \\
\text { total de } \\
\text { empresas } \\
\text { de cada } \\
\text { categoria } \\
\text { (\%) }\end{array}$ & $\begin{array}{c}\text { Pessoal } \\
\text { ocupado } \\
\text { (PO) total } \\
\text { (Pessoas) }\end{array}$ & $\begin{array}{c}\text { Participação no PO } \\
\text { total de cada categoria } \\
\text { (\%) }\end{array}$ \\
\hline $\begin{array}{l}\text { A Agricultura, pecuária, } \\
\text { silvicultura e exploração } \\
\text { florestal: } \\
\text { Agricultura }\end{array}$ & 78 & 100,00 & 388 & 100,00 \\
$\begin{array}{l}\text { Pecuária } \\
\text { Produção Mista }\end{array}$ & 13 & 16,67 & 46 & 11,86 \\
$\begin{array}{l}\text { Silvicultura e } \\
\text { Exploração florestal }\end{array}$ & 45 & 57,69 & 240 & 61,86 \\
B Pesca & 14 & 7,69 & 55 & 14,18 \\
\hline
\end{tabular}

Fonte: IBGE (2004a)

\section{Agricultura}

A agricultura no Acre caracteriza-se por suprir, fundamentalmente, a demanda interna (subsistência), o que se reflete na sua pouca expressividade tanto em nível regional como brasileiro (Tabela 4).

Em geral, as análises dessa atividade se dão por meio da sua subdivisão em lavouras temporárias e permanentes. As Tabelas 4 e 5 apresentam os dados referentes ao valor da produção (expressos em mil Reais de 2002) e área plantada (em mil hectares) das lavouras temporárias e permanentes, respectivamente. Com o objetivo de permitir uma melhor comparação, esses dados são apresentados para o Acre e também para a região Norte e para o Brasil. 
Tabela 4. Valor da produção e área plantada de lavouras temporárias para os anos de 1990 a 2002 - Brasil, Norte e Acre.

\begin{tabular}{ccccccc}
\hline \multirow{2}{*}{ Ano } & \multicolumn{2}{c}{ Valor da produção* $(1.000 \mathrm{R} \$)$} & \multicolumn{2}{c}{ Área Plantada (mil hectares) } \\
\cline { 2 - 7 } & BRASIL & NORTE & ACRE & BRASIL & NORTE & ACRE \\
\hline 1990 & 17.196 .826 & 762.617 & 50.427 & $45.980,738$ & $1.505,923$ & 96,393 \\
1991 & 14.793 .514 & 672.206 & 51.385 & $44.755,350$ & $1.517,785$ & 118,355 \\
1992 & 14.932 .760 & 531.372 & 48.021 & $45.422,845$ & $1.775,606$ & 104,020 \\
1993 & 10.889 .534 & 600.894 & 38.813 & $42.970,397$ & $1.732,201$ & 111,641 \\
1994 & 38.345 .599 & 1.855 .141 & 162.356 & $46.758,724$ & $1.944,764$ & 117,045 \\
1995 & 35.071 .093 & 1.909 .260 & 157.303 & $45.960,271$ & $1.974,329$ & 107,648 \\
1996 & 34.004 .829 & 1.468 .826 & 52.734 & $41.215,129$ & $1.765,484$ & 65,915 \\
1997 & 37.105 .987 & 1.362 .915 & 47.752 & $42.433,428$ & $1.779,360$ & 68,512 \\
1998 & 38.887 .373 & 1.603 .432 & 104.177 & $42.442,966$ & $1.909,927$ & 75,309 \\
1999 & 38.342 .090 & 1.665 .148 & 128.108 & $44.459,394$ & $2.074,390$ & 81,922 \\
2000 & 41.895 .683 & 1.575 .374 & 141.926 & $45.573,754$ & $2.053,739$ & 93,973 \\
2001 & 47.229 .598 & 1.616 .484 & 105.717 & $45.371,768$ & $1.822,772$ & 91,952 \\
2002 & 58.119 .547 & 1.758 .157 & 116.038 & $48.128,388$ & $1.792,936$ & 97,794 \\
\hline
\end{tabular}

Fonte: IBGE (2004b)

* Valores corrigidos pelo IPCA, ano base 2002

Observando os dados apresentados na Tabela 4 nota-se que o Valor da Produção (VP) de lavouras temporárias apresentou um aumento significativo de 1990 para 2002, tanto no Brasil (cujo VP de 2002 correspondeu a 3,38 vezes o de 1990) como na região Norte e no Acre, em que o VP de 2002 correspondeu a mais do que o dobro do VP de 1990. Cabe destacar que esse aumento de VP foi acompanhado, nas três regiões, de um aumento na área plantada. 
Analisando o período como um todo (1990 a 2002), observa-se uma queda significativa no valor da produção (VP) e área plantada no Acre, nos anos de 1993, 1996 e 1997. A região Norte apresentou o mesmo comportamento de queda observado para o VP do Acre de 1996 e 1997 porém, com um aumento progressivo desse valor nos anos subseqüentes. O Brasil como um todo apresentou um aumento gradativo nessas variáveis ao longo do período analisado (Tabela 4).

Dentre as lavouras temporárias, destacaram-se, no Acre, com relação ao valor da produção, em 2002, a mandioca (60,38\% do total), o milho (13,29\%), o arroz $(12,38 \%)$ e feijão $(7,63 \%)$.

Quando observadas as duas variáveis em questão, valor da produção e área plantada, para as lavouras permanentes (Tabela 5), percebe-se que houve uma oscilação muito grande no VP dessas lavouras, no período analisado, tanto no Brasil quanto na região Norte e no Acre. No entanto, para o Acre e Brasil, o aumento no VP dessas lavouras, de 1990 para 2002, foi mais expressivo do que para o Norte.

Tabela 5. Valor da produção e área plantada de lavouras permanentes para os anos de 1990 a 2002 - Brasil, Norte e Acre.

\begin{tabular}{ccccccc}
\hline \multirow{2}{*}{ Ano } & \multicolumn{2}{c}{ Valor da produção* $(1.000 \mathrm{R} \$)$} & \multicolumn{2}{c}{ Área Plantada (mil hectares) } \\
\cline { 2 - 7 } & BRASIL & NORTE & ACRE & BRASIL & NORTE & ACRE \\
\hline 1990 & 5.792 .514 & 412.999 & 8.020 & $7.171,708$ & 462,829 & 7,228 \\
1991 & 5.572 .375 & 452.930 & 6.967 & $6.997,728$ & 449,334 & 9,415 \\
1992 & 4.903 .101 & 302.779 & 6.172 & $6.850,734$ & 481,836 & 9,183 \\
1993 & 4.772 .997 & 303.551 & 5.611 & $6.256,355$ & 470,094 & 9,375 \\
1994 & 16.835 .779 & 1.260 .990 & 22.176 & $6.056,306$ & 468,904 & 8,154 \\
1995 & 12.098 .256 & 1.156 .498 & 32.596 & $5.892,839$ & 475,942 & 12,265 \\
1996 & 10.786 .993 & 912.872 & 15.452 & $5.606,685$ & 427,311 & 7,774 \\
1997 & 11.819 .873 & 847.844 & 16.917 & $5.868,977$ & 408,923 & 8,201
\end{tabular}


Tabela 5. Valor da produção e área plantada de lavouras permanentes para os anos de 1990 a 2002 - Brasil, Norte e Acre.

\begin{tabular}{ccccccc}
\hline \multirow{2}{*}{ Ano } & \multicolumn{2}{c}{ Valor da produção* $(1.000 \mathrm{R} \$)$} & \multicolumn{2}{c}{ Área Plantada (mil hectares) } \\
\cline { 2 - 7 } & BRASIL & NORTE & ACRE & BRASIL & NORTE & ACRE \\
\hline 1998 & 13.712 .673 & 933.334 & 19.351 & $6.066,108$ & 420,889 & 7,904 \\
1999 & 13.727 .804 & 1.169 .159 & 23.176 & $6.241,300$ & 495,413 & 9,865 \\
2000 & 12.820 .871 & 1.079 .197 & 26.393 & $6.245,371$ & 539,540 & 11,194 \\
2001 & 13.386 .165 & 818.759 & 23.704 & $6.265,399$ & 556,054 & 10,652 \\
2002 & 16.293 .130 & 1.103 .967 & 25.984 & $6.395,369$ & 543,622 & 15,345 \\
\hline
\end{tabular}

Fonte: IBGE (2004b)

* Valores corrigidos pelo IPCA, ano base 2001

A área plantada de lavouras permanentes no Brasil se mantém relativamente estável entre aproximadamente 6 e 7 milhões de hectares, do quais a região Norte contribui com áreas que flutuam entre 408 e 556 mil hectares aproximadamente. Já no Acre a área plantada com essas culturas permanentes mais que dobrou de 1990 para 2002.

Dentre as principais lavouras permanentes do Acre, destacaram-se, em 2002, a banana $(51,07 \%)$, o palmito $(15,05 \%)$, a laranja $(7,47 \%)$, o café $(6,38 \%)$, a borracha $(4,61 \%)$ e o mamão $(4,51 \%)$.

Documentos oficiais do Estado (Acre, 2000) destacam que, entre 1975 e 1996, a produção agrícola de lavouras temporárias no Acre passou de $40 \%$ para $47 \%$ do Valor Bruto Total (que engloba os setores agropecuária e extrativismo vegetal), assumindo o posto de atividade com maior valor relativo. Com relação às lavouras permanentes, 0 comportamento observado pelo autor, para o mesmo período, também foi de aumento da sua participação no valor bruto total (VBT). 


\section{Extrativismo vegetal e silvicultura}

O IBGE divide o extrativismo vegetal nos seguintes tipos de produtos: alimentícios (açaí, castanha de caju, castanha-do-pará, palmito, entre outros); aromáticos

(jaborandi, urucum, entre outros); borrachas (caucho e hevea); ceras (carnauba); fibras (buriti, carnauba e piaçava); gomas elásticas (balata, maçaranduba e sorva); carvão vegetal; lenha; madeira em tora; oleaginosas (babaçu, copaíba, pequi, entre outros); pinheiro brasileiro; e tanantes (angico, barbatimão e outros).

No Estado do Acre, no grupo dos produtos alimentícios destacam-se o açaí e a castanha-do-pará. De acordo com os dados fornecidos pelo IBGE, referentes a quantidade total de produtos extrativos alimentícios produzidos no estado, temos que quase $90 \%$ desse total corresponde a castanha-do-pará. Participação esta mantida durante todo o período em que o IBGE disponibiliza esses dados, ou seja, de 1990 a 2002.

Quando considerada a quantidade total de produtos alimentícios (açaí e castanha); borrachas (látex coagulado de hevea) e oleaginosos (óleo de copaíba e coquilho de licuri) produzidos no Acre, nota-se que, somadas as participações da castanha e do látex coagulado de hevea, a menor participação desses dois produtos no total produzido ocorreu em 1991, equivalente a $84,89 \%$, e a maior participação se deu em 1999, com 96,30\%. Ao longo do período, podemos dizer que de 1993 a 1997 houve um equilíbrio na produção de castanha e látex coagulado de hevea uma vez que a participação de cada um desses produtos na produção total de cada ano ficou ao redor dos 50\%. Já no período entre 1998 e 2001, a produção de castanha sofreu um aumento substancial, especialmente em 1999 e 2000, tornando a sua produção superior à produção de látex coagulado (Tabela 6). 
Tabela 6. Participação (\%) de cada tipo de produto extrativo dos grupos: alimentícios, borrachas e oleaginosos, no total produzido por esses três grupos, para o Estado do Acre, de 1990 a 2002.

\begin{tabular}{cccccc}
\hline \multirow{2}{*}{ Ano } & \multicolumn{4}{c}{ Participação (\%) dos diferentes produtos } & \multirow{2}{*}{$\begin{array}{c}\text { Total produzido } \\
\text { no total produzido em cada ano }\end{array}$} \\
\cline { 2 - 4 } & Açaí & Castanha-do-Pará & Hevea & Oleaginosos & \\
\hline 1990 & 0,99 & 52,47 & 35,52 & 11,03 & 33.348 \\
1991 & 1,12 & 46,88 & 38,01 & 13,99 & 31.208 \\
1992 & 1,46 & 45,30 & 40,91 & 12,32 & 24.625 \\
1993 & 1,56 & 51,66 & 43,46 & 3,32 & 23.198 \\
1994 & 1,83 & 54,34 & 41,81 & 2,02 & 20.306 \\
1995 & 2,10 & 51,68 & 44,09 & 2,12 & 18.123 \\
1996 & 1,96 & 48,50 & 47,19 & 2,35 & 7.955 \\
1997 & 2,32 & 49,29 & 46,52 & 1,87 & 6.853 \\
1998 & 6,03 & 56,50 & 36,30 & 1,17 & 6.421 \\
1999 & 3,13 & 75,25 & 21,04 & 0,57 & 12.774 \\
2000 & 3,74 & 71,48 & 24,15 & 0,63 & 11.536 \\
2001 & 6,11 & 66,85 & 27,03 & 0,01 & 8.861 \\
2002 & 8,89 & 73,49 & 17,60 & 0,02 & 9.082 \\
\hline
\end{tabular}

Fonte: IBGE (2004c)

A significativa redução na quantidade total de produtos extrativos dos grupos alimentícios (considerando nesse grupo apenas açaí e castanha-do-pará), borrachas (apenas látex coagulado) e oleaginosos (apenas copaíba e licuri) apresentada na Tabela 6, para o estado do Acre pode ser observada, também, na Tabela 7 que trás as produções totais apenas desses produtos para as regiões Brasil, Norte e Acre para o período de 1990 a 2002. 
Tabela 7. Produção total de extrativos dos grupos: alimentícios, borrachas e oleaginosos do Brasil, Norte e Acre, para o período de 1990 a 2002.

\begin{tabular}{cccc}
\hline & \multicolumn{3}{c}{ Produção total $(\mathrm{t})$ de produtos extrativos dos grupos: alimentícios, } \\
Ano & Brasil & Norte & Acre \\
\cline { 2 - 4 } & 617.334 & 262.366 & 33.348 \\
1991 & 645.348 & 241.027 & 31.208 \\
1992 & 628.476 & 236.664 & 24.625 \\
1993 & 565.631 & 166.302 & 23.199 \\
1994 & 528.145 & 177.264 & 20.306 \\
1995 & 535.806 & 184.700 & 18.124 \\
1996 & 488.085 & 157.126 & 7.955 \\
1997 & 514.259 & 162.699 & 6.853 \\
1998 & 511.059 & 169.030 & 6.421 \\
1999 & 496.584 & 164.377 & 12.774 \\
2000 & 502.115 & 174.212 & 11.537 \\
2001 & 500.554 & 167.276 & 8.861 \\
2002 & 552.910 & 173.239 & 9.082 \\
\hline
\end{tabular}

Fonte: IBGE (2004c)

Através desses dados tem-se que a produção de extrativos no Acre, em 2002, correspondeu a apenas $27,23 \%$ do total produzido em 1990 . No Brasil a produção de 2002 correspondeu a 89,56\% da produção de 1990. Já na região Norte a produção de 2002 correspondeu a $66,03 \%$ da de 1990 . 
De acordo com o estudo de zoneamento ecológico-econômico do Acre (Acre, 2000), a partir de 1989 houve uma queda acentuada na produção extrativista de borracha decorrente do final do PROBOR III $^{4}$, em 1987, e da extinção da SUDHEVEA e do Conselho Nacional da Borracha.

A ineficácia das políticas com relação à borracha, ocorridas de 1990 até 1997, resultou na promulgação da Lei Federal $n^{0} 9.479$ de 12/08/97 que dispõe sobre a concessão de subvenção econômica aos produtores de borracha natural, com o objetivo de incentivar a comercialização da produção nacional. Essa subvenção econômica corresponde ao subsídio, de no máximo $\mathrm{R} \$ 0,90$ por quilo de borracha natural beneficiada, que deveria ser dado aos produtores decorrente da diferença entre os preços de referência das borrachas naturais e os produtos congêneres no mercado internacional, acrescidas as despesas de nacionalização.

Em 1999, o Estado do Acre criou o subsídio estadual para a borracha, através da Lei $\mathrm{n}^{0} 1.277$, de 13/01/99 (a Lei Chico Mendes), equivalente a $\mathrm{R} \$ 0,40$ por quilo de borracha natural bruta.

Ambas ações apontam para um provável reaquecimento dessa atividade uma vez que sinalizam a elevação dos preços pagos aos produtores nos próximos anos. No entanto, ainda existe uma série de pontos a serem melhorados para que a borracha produzida no Acre seja competitiva no mercado. Dentre essas melhorias destacam-se como essenciais as transformações necessárias na infra-estrutura de transporte e comunicação do estado.

Além dos subsídios à produção de borracha, o Governo do Estado do Acre, juntamente com a Secretaria Executiva de Florestas e Extrativismo (SEFE) criou o "Programa de Desenvolvimento de Cadeias Produtivas" que envolve os produtos

\footnotetext{
${ }^{4}$ No Brasil, foram três os Programas de Incentivos à Produção de Borracha Natural (PROBOR) sendo que o último deles PROBOR III tinha a meta de plantar 250 mil ha de Hevea brasiliensis. No entanto, a escassa liberação de recursos, a extinção da Superintendência da Borracha (SUDHEVEA), encarregada de viabilizar o programa, e o infestamento dos plantios com o fungo Microcyclus ulei causador do mal-dasfolhas, fizeram com que a meta originalmente estabelecida não fosse atingida e com que o programa fosse extinto em 1987.
} 
tradicionais (borracha e castanha) além, de outros potenciais. Através desse programa, uma série de planos de manejo, de estudos de cadeias produtivas e a elaboração de um conjunto de políticas públicas têm sido desenvolvidos com vistas à exploração racional, beneficiamento no próprio Estado e a comercialização desses produtos (Acre, 2000).

Esse programa corresponde a uma parceria entre a iniciativa privada, 0 governo, o BASA, os produtores e as ONGs. Dentre as ações efetivas já realizadas temos o "Programa do Couro Vegetal", desenvolvido em parceira com Associações de seringueiros e a empresa Tree Tap, com sede no Rio de Janeiro, que melhorou as lâminas de tecido emborrachado com látex de seringueira tradicionalmente elaborado pelos seringueiros e que servem para a confecção de roupas, bolsas e mochilas. Nessa parceira, o governo e o BASA viabilizam o treinamento das comunidades; a empresa Tree Tap participa no treinamento e garante a compra da produção e as comunidades entram com a mão-de-obra e matéria-prima.

Outro projeto como esse, denominado "Projeto do Solado de Borracha" vem sendo desenvolvido em parceira com a WWF (World Wildlife Found) e pretende apoiar o beneficiamento nos locais de extração do látex, de modo a abreviar a cadeia produtiva e remunerar melhor o seringueiro.

Para a castanha, estão sendo instaladas duas usinas de beneficiamento no Estado, buscando, assim, viabilizar o beneficiamento e a comercialização do produto.

Através da análise dos demais produtos extrativos apresentados na Tabela 6 tem-se que a produção de oleaginosos (constituído, no Acre, basicamente por óleo de copaíba) apresentou uma queda progressiva no período analisado, chegando a um produção irrisória em 2002. Já o açaí, apresentou um certo aumento de 1990 para 2002 no entanto, ainda não se pode inferir sobre a sua participação efetiva na pauta de produtos extrativos produzidos pelo Acre.

Com relação aos outros três produtos extrativos representativos no estado do Acre: carvão vegetal, lenha e madeira em tora, observa-se o aumento da participação da madeira em tora originária do extrativismo em relação ao total produzido (lenha + madeira em tora + carvão) anualmente e uma queda da participação da lenha, isto é, em 1990, do total de $1.215 .855 \mathrm{~m}^{3}$ produzidos, $24,8 \%$ (ou $301.509 \mathrm{~m}^{3}$ ) corresponderam a 
madeira em tora ao passo que a lenha participou com $75 \%$ (ou $911.751 \mathrm{~m}^{3}$ ) desse total. Já em 2002, dos $796.234 \mathrm{~m}^{3}$ totais produzidos, 36,1\% (ou $287.306 \mathrm{~m}^{3}$ ) corresponderam ao produto madeira em tora e $66,2 \%$ (ou $505.539 \mathrm{~m}^{3}$ ) corresponderam a lenha (Tabela 8 ).

Tabela 8. Participação (\%) dos produtos extrativos lenha, madeira em tora e carvão vegetal, no total produzido, correspondente a soma desses três produtos, para o Estado do Acre, de 1990 a 2002.

\begin{tabular}{ccccc}
\hline & \multicolumn{3}{c}{ Participação (\%) } & $\begin{array}{c}\text { Total produzido } \\
\text { (metros cúbicos) }\end{array}$ \\
\cline { 2 - 5 } & Lenha & Madeira em tora & Carvão vegetal & \\
\hline 1990 & 75,0 & 24,8 & 0,2 & 1.215 .855 \\
1991 & 73,6 & 26,2 & 0,2 & 1.164 .399 \\
1992 & 76,3 & 23,5 & 0,2 & 1.217 .816 \\
1993 & 71,6 & 28,2 & 0,2 & 1.266 .629 \\
1994 & 71,1 & 28,7 & 0,2 & 1.299 .582 \\
1995 & 72,8 & 27,1 & 0,2 & 1.187 .513 \\
1996 & 58,1 & 41,2 & 0,7 & 530.265 \\
1997 & 59,9 & 39,4 & 0,7 & 542.728 \\
1998 & 69,1 & 30,4 & 0,5 & 659.650 \\
1999 & 67,9 & 31,6 & 0,5 & 665.344 \\
2000 & 68,2 & 31,3 & 0,5 & 661.110 \\
2001 & 66,2 & 33,4 & 0,4 & 727.397 \\
2002 & 63,5 & 36,1 & 0,4 & 796.234 \\
\hline
\end{tabular}

Fonte: IBGE (2004c)

Embora as participações relativas de cada um dos produtos no total anual tenham variado bastante no período analisado, ao observarmos os totais de produtos extrativos apresentados nas Tabelas 6 e 8 (últimas colunas dessas tabelas), nota-se uma queda significativa (de 1990 para 2002) nas quantidades totais de produtos extrativos produzidos. 
Quando analisamos o comportamento destes produtos com relação ao valor da produção (em R \$ de 2002), temos que ocorrem as mesmas particularidades destacadas para quantidade produzida (Figura 5).

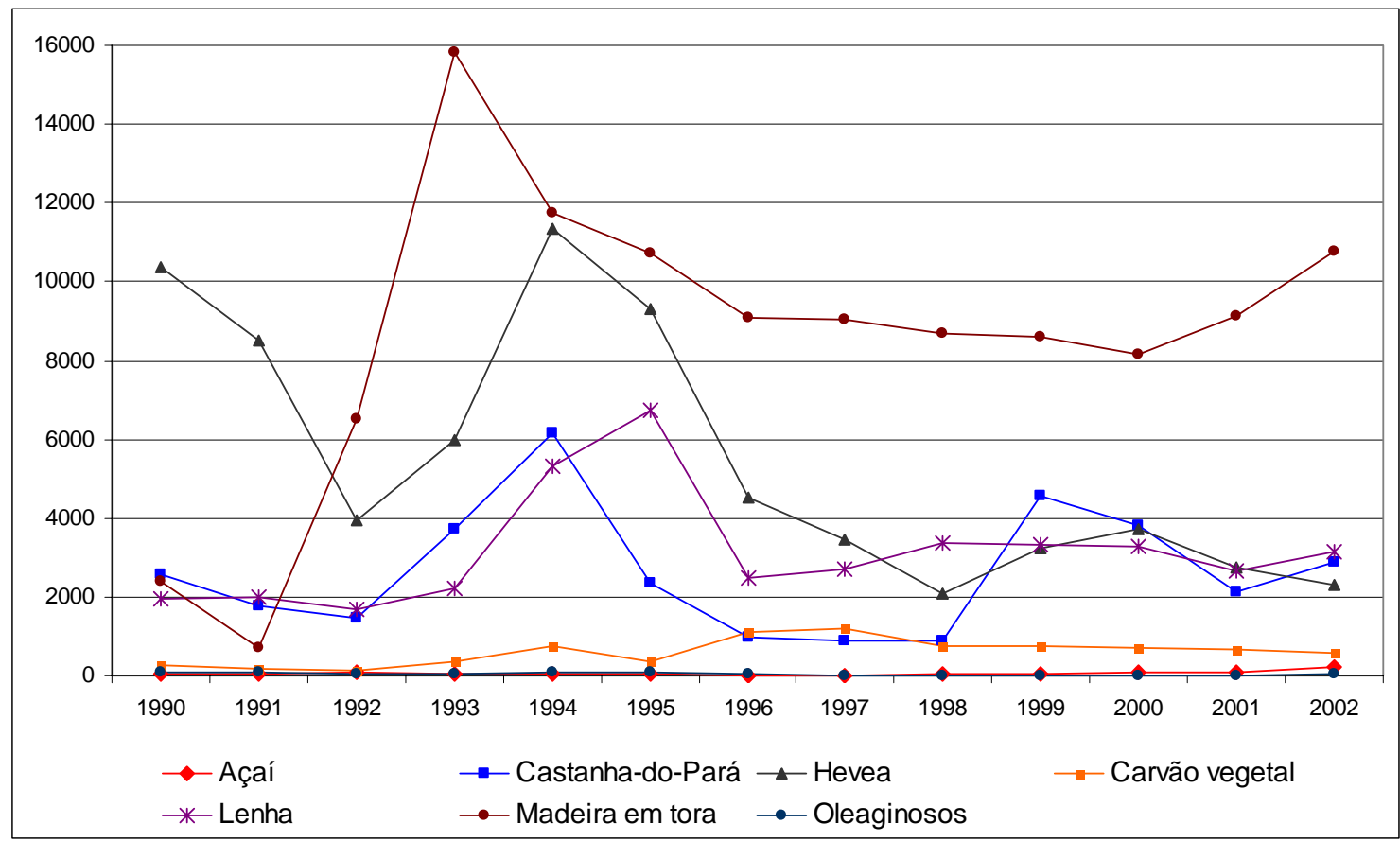

Figura 5 - Valor da produção de cada produto da extrativa vegetal do Acre - 1990 a 2002.

Fonte: IBGE (2004c)

\section{Pecuária}

De acordo com informações oficiais do Governo na Acre, publicadas no zoneamento ecológico-econômico, o rebanho bovino do estado do Acre cresceu, entre 1970 e 1996, mais de $1000 \%$ sendo o maior crescimento do mesmo verificado no período entre 1985 e 1996 (Acre, 2000).

A Figura 6 representa a evolução, no período de 1990 até 2002, do número de cabeças dos rebanhos bovinos, aves, suínos e outros (ovino, eqüino, caprino, muar, 
bubalino, asinino e coelhos). Observa-se que o rebanho bovino mais que quadruplicou no período analisado, passando de 400.085 cabeças em 1990 para 1.817 .467 cabeças em 2002. Aves apresentou uma leve oscilação no período, permanecendo, em 2002, com 1.491.054 cabeças contra as 1.577 .298 cabeças em 1990. O rebanho suíno teve um pequeno aumento de 3.045 cabeças de 1990 para 2002. Já a última categoria, formada pelo os demais tipos de rebanhos, teve seu efetivo de rebanho mais que dobrado de 1990 (41.289 cabeças) para 2002 (90.236 cabeças).

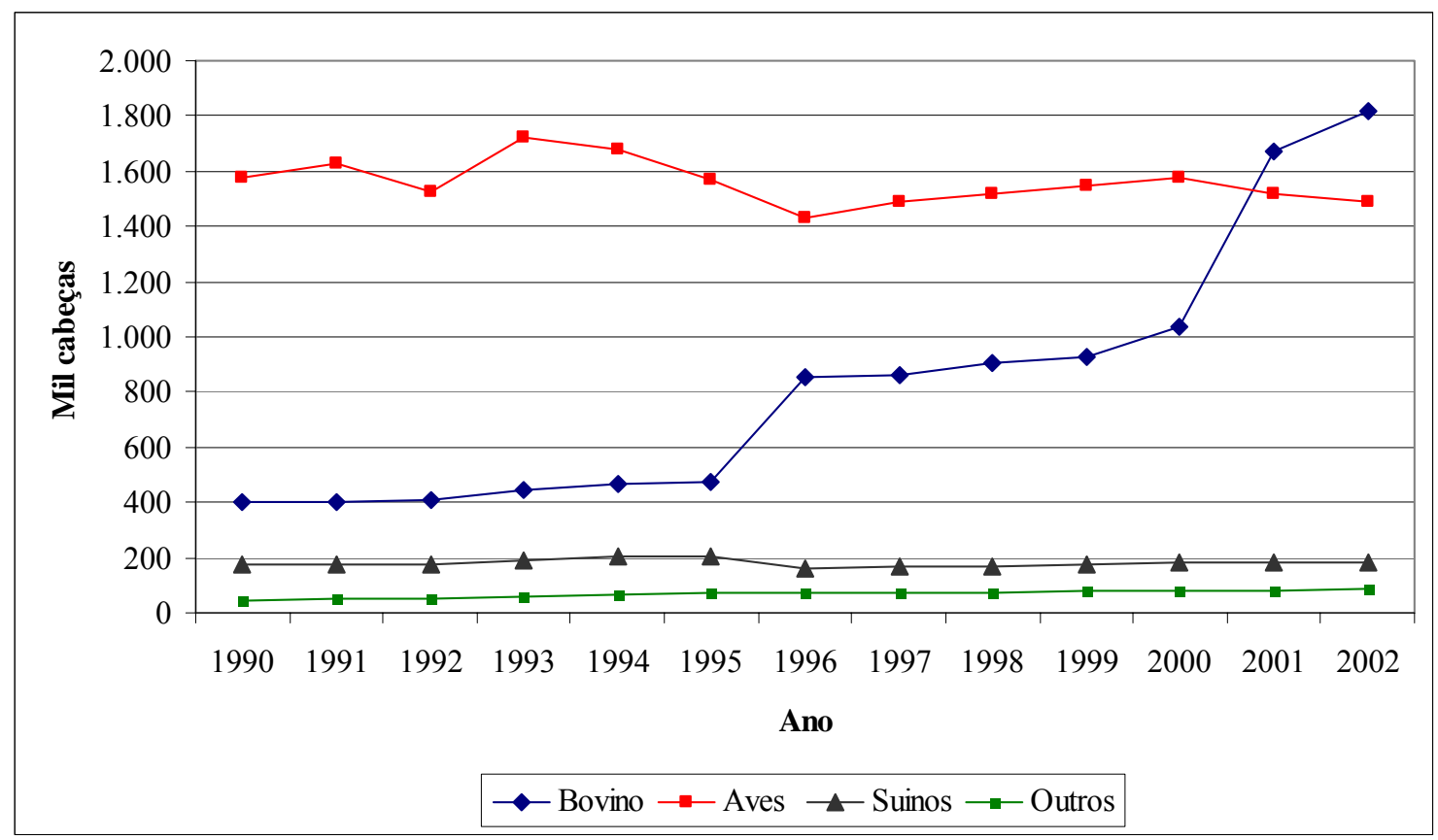

Figura 6 - Efetivos dos rebanhos, em mil cabeças, para o Acre no período de 1995 a 2002.

Fonte: IBGE (2004d)

O aumento desses rebanhos e, em especial, do rebanho bovino refletiu-se positivamente na produção de leite do Estado, que aumentou 4,8 vezes em 2002 quando comparada à produção de 1995. Ovos e Mel também são produtos importantes para o estado embora suas produções ainda não sejam tão expressivas (Tabela 9). 
Tabela 9. Produtos de origem animal do estado do Acre - 1990 a 2002.

\begin{tabular}{cccc}
\hline Ano & $\begin{array}{c}\text { Leite } \\
\text { (Mil litros) }\end{array}$ & $\begin{array}{c}\text { Ovos de Galinha } \\
\text { e Codorna } \\
\text { (Mil dúzias) }\end{array}$ & $\begin{array}{c}\text { Mel de Abelha } \\
\text { (Quilograma) }\end{array}$ \\
\hline 1990 & 21.430 & 4.299 & 1.235 \\
1991 & 22.294 & 3.597 & 732 \\
1992 & 20.660 & 3.936 & 0 \\
1993 & 30.125 & 4.803 & 0 \\
1994 & 30.299 & 4.477 & 0 \\
1995 & 29.696 & 3.374 & 0 \\
1996 & 31.356 & 1.826 & 0 \\
1997 & 31.831 & 1.840 & 1.300 \\
1998 & 32.850 & 2.008 & 1.500 \\
1999 & 36.625 & 2.096 & 1.800 \\
2000 & 40.804 & 2.018 & 3.305 \\
2001 & 85.773 & 2.349 & 3.300 \\
2002 & 103.848 & 2.452 & \\
\hline
\end{tabular}

Fonte: IBGE (2004d)

\subsubsection{O setor secundário}

$\mathrm{Na}$ Tabela 2, apresentada na seção 3.2.5, percebe-se que as categorias "Comércio; reparação de veículos automotores, objetos pessoais e domésticos” (G); "Outros serviços coletivos, sociais e pessoais"(O) e "Indústria de transformação" (D) foram as que se destacaram no ano de 2001 em termos de número de empresas, com participações equivalentes a, respectivamente, 56,51\%; 11,01\% e 8,53\%. Com relação a Pessoal ocupado, a "Administração pública, defesa e seguridade social” (L); "Comércio; reparação de veículos automotores, objetos pessoais e domésticos" (G) e a "Indústria de 
transformação" (D) se destacaram com, respectivamente, 54,78\%; 17,53\% e 4,95\% de participação no total de pessoas ocupadas em 2001.

Os dados mostrados a seguir permitem detalhar melhor os tipos de empresas que predominaram no estado do Acre, nas categorias "Indústrias extrativas" (C); "Indústrias de Transformação" (D); "Produção e distribuição de eletricidade, gás e água" (E) e "Construção" (F) que fazem parte do setor secundário e cujos dados não incluem informações referente aos outros setores (primário e terciário), como ocorre para as categorias $\mathrm{A}$ e $\mathrm{B}$, já ressaltado anteriormente.

Considerando-se a soma do número de empresas e pessoal ocupado nas quatro categorias C, D, E e F, observa-se a categoria D (Indústria de transformação) participou com 62,93\% (ou 740 empresas) do número total de empresas (1.176) e com 48,28\% do pessoal ocupado total (7.656). A segunda categoria importante nesse ano, "Construção", conforme pode ser observado na Tabela 10, teve uma participação no número total de empresas igual a $35,12 \%$ e no pessoal ocupado total igual a $41,99 \%$.

Tabela 10. Participação percentual das categorias $C, D, E$ e $F$ no número total de empresas e pessoal ocupado total - Acre, 2001.

\begin{tabular}{ccccc}
\hline Categorias* & $\begin{array}{c}\text { Número de } \\
\text { empresas } \\
\text { (Unidade) }\end{array}$ & $\begin{array}{c}\text { Participação no total } \\
\text { de empresas } \\
\text { de cada categoria }\end{array}$ & $\begin{array}{c}\text { Pessoal } \\
\text { ocupado } \\
(\text { PO) total } \\
(\%)\end{array}$ & $\begin{array}{c}\text { Participação no PO } \\
\text { total de cada } \\
\text { categoria } \\
(\%)\end{array}$ \\
\hline C & 16 & 1,36 & 35 & 0,46 \\
D & 740 & 62,93 & 3.696 & 48,28 \\
E & 7 & 0,60 & 710 & 9,27 \\
F & 413 & 35,12 & 3.215 & 41,99 \\
Total & 1.176 & 100,00 & 7.656 & 100,00 \\
\hline
\end{tabular}

Fonte: IBGE (2004a)

* C) Indústrias extrativas; D) Indústrias de transformação; E) Produção e distribuição de eletricidade, gás e água; F) Construção 
Analisando, cada categoria separadamente, tem-se que todas as empresas que pertencem à categoria $\mathrm{C}$ (Indústrias extrativas) correspondem a empresas de extração de pedra, areia e argila. Na categoria E (Produção e distribuição de eletricidade, gás e água), formada por 7 empresas, predominaram empresas de Captação, tratamento e distribuição de água $(71,43 \%)$ seguida das empresas de Produção e distribuição de energia elétrica, com 28,57\%, Tabela 31 (Anexo).

Com relação as 413 empresas do ramo Construção $(\mathrm{F})$, aquelas relacionadas à Construção de edifícios e obras de engenharia civil representam 76,76\% (317 empresas) e as de Obras de acabamento 9,69\% (40 empresas).

Os dados referentes a "Indústria de transformação" (D) estão subdivididos em 21 sub-categorias, conforme Tabela 31 (Anexo). Dentre estas sub-categorias, destacamse: "Fabricação de produtos alimentícios e bebidas" (25,68\%); "Fabricação de produtos de madeira" (18,92\%); "Fabricação de móveis e indústrias diversas" (14,32\%); "Edição, impressão e reprodução de gravações" (9,59\%) e "Fabricação de produtos de minerais não metálicos" (7,57\%), totalizando $76,08 \%$ das empresas dessa categoria no estado do Acre.

\subsubsection{O setor terciário}

Conforme já foi ressaltado no item 3.2.5, das categorias que mais se destacaram com relação ao número de empresas, no ano 2001, duas pertencem ao setor terciário: “Comércio; reparação de veículos automotores, objetos pessoais e domésticos” (G), com $56,51 \%$ e "Outros serviços coletivos, sociais e pessoais" (O), com 11,01\%. A Tabela 32 (Anexo) apresenta um detalhamento das categorias que compõem esse setor e permitenos identificar, dentro dessas duas categorias mais importantes para 2001, as subcategorias que mais participaram relativamente do número total de empresas de cada uma das categorias individualmente.

Assim, na categoria $\mathrm{G}$ pode-se destacar o "Comércio varejista e reparação de objetos pessoais e domésticos" como a subcategoria que apresenta o maior número de 
empresas desse ramo de atividade, 4.035 ou, 82,33\% do total de 4.901 empresas referente à categoria $\mathrm{G}$.

$\mathrm{Na}$ categoria $\mathrm{O}$, destacaram-se as "Atividades associativas" (de organizações empresariais, patronais, profissionais, sindicais e outras), com uma participação relativa equivalente a $77,17 \%$ das 955 empresas que fazem parte desta categoria.

Outras subcategorias que também se destacaram foram: Restaurantes e outros estabelecimentos de serviços de alimentação (pertencente à categoria H); Transporte terrestre (pertencente à I), Intermediação financeira, exclusive seguros e previdência privada (pertencentes à $\mathrm{J}$ ); Serviços prestados principalmente às empresas $(\mathrm{K})$; Administração do estado e da política econômica e social (L); Educação pré-escolar e fundamental $(\mathrm{M})$ e Atividades de atenção à saúde $(\mathrm{N})$, Tabela 32 (Anexo).

Em termos de Pessoal ocupado (PO), "Administração pública, defesa e seguridade social" e "Comércio; reparação de veículos automotores, objetos pessoais e domésticos" foram as que mais se destacaram em 2001, com uma participação de $54,78 \%$ e 17,53\%, respectivamente, no total de todas as categorias (ver Tabela $32 \mathrm{em}$ Anexo). As subcategorias mais representativas nessas duas categorias foram: Administração do estado e da política econômica e social (92,74\% do total da categoria L) e Comércio varejista e reparação de objetos pessoais e domésticos (72,33\% do total da categoria $\mathrm{G})$.

Além dessas, as subcategorias Atividades de atenção à saúde (77,01\%); Serviços prestados principalmente às empresas (participando com 67,49\% do PO da categoria K); Atividades associativas $(61,16 \%$ da categoria $\mathrm{O})$ e Restaurantes e outros estabelecimentos de serviços de alimentação (com 66,87\% da categoria $\mathrm{H}$ ) foram as que mais se destacaram com relação a pessoal ocupado.

\subsubsection{Exportações acreanas}

Com relação às exportações, a Tabela 11 trás o valor das exportações acreanas divulgado pela Secretaria de Comércio Exterior - SECEX. 
Tabela 11. Exportações do Estado do Acre: total e de produtos florestais, para o período de 1996 a 2003.

\begin{tabular}{|c|c|c|c|c|c|c|c|c|}
\hline \multirow{2}{*}{ Exportação } & \multicolumn{8}{|c|}{ Ano } \\
\hline & 1996 & 1997 & 1998 & 1999 & 2000 & 2001 & 2002 & 2003 \\
\hline $\begin{array}{c}\text { Valor Total } \\
\text { (em R\$ milhões de 2003) }\end{array}$ & 3,99 & 0,34 & 1,47 & 3,28 & 3,72 & 16,77 & 12,13 & 12,35 \\
\hline \multicolumn{9}{|l|}{ Valor dos Produtos } \\
\hline $\begin{array}{c}\text { Florestais } \\
\text { (em R\$ milhões de 2003) }\end{array}$ & 3,98 & 0,24 & 1,40 & 2,54 & 2,58 & 3,63 & 10,58 & 9,41 \\
\hline \multicolumn{9}{|l|}{ Participação dos Produtos } \\
\hline Florestais Exportados no & 99,66 & 70,90 & 95,23 & 77,52 & 69,38 & 21,64 & 87,18 & 76,24 \\
\hline Total de Exportações (\%) & & & & & & & & \\
\hline
\end{tabular}

Fonte: Brasil (2004)

O que chama mais a atenção nessa tabela é a grande importância do setor florestal na pauta de exportações do Estado do Acre. Como pode ser observado, com exceção do ano de 2001, a exportação de produtos florestais ultrapassou a casa dos $69 \%$ nos demais anos. A pauta de exportação acreana dos anos de 1996 e 1998 foi quase que na sua totalidade formada por produtos florestais. Nos outros anos, houve uma certa oscilação da participação dos produtos florestais no total exportado permanecendo, no ano de 2003 , na casa dos $76,24 \%$.

A baixa participação dos produtos florestais no valor total exportado pelo estado no ano 2001 deve-se ao fato de que, nesse ano, 69,58\% das exportações do Acre foram de couro/pele, inteiro/meio, de bovino, "wet blue". No entanto, nos anos posteriores não houve exportação desses produtos.

Dentre os produtos florestais exportados nesse período destacam-se: castanhado-pará, fresca ou seca, com e sem casca; taninos; adesivos a base de borracha; madeiras de diversas espécies serradas, cortadas em folhas e compensadas; armações e cabos de madeira de ferramentas e escovas; janelas; portas; papéis, cartões e artefatos de papel; móveis para cozinha e quartos; e outros móveis. 


\subsubsection{Obtenção dos dados e construção da matriz de insumo-produto inter-regional Acre vs. resto do Norte vs. resto do Brasil}

No Brasil, o órgão oficial responsável pela construção das Matrizes Nacionais de Insumo-Produto (MIPs) é o Instituto Brasileiro de Geografia e Estatística (IBGE). De 1970 a 1990 essas matrizes foram elaboradas com periodicidade qüinqüenal e, a partir de 1990, a periodicidade passou a ser anual. No entanto, devido à defasagem de tempo para a divulgação das mesmas, o último ano para o qual o instituto elaborou a MIP foi 1996.

Essa defasagem na divulgação das MIPs deve-se ao fato de que as mesmas são elaboradas a partir dos dados das Contas Nacionais do Brasil (CN) que, por sua vez, são divulgados em sua versão definitiva com 3 anos de defasagem, e que se somam aos 3 anos para a divulgação das MIPs. O resultado é uma defasagem de pelo menos 6 anos.

Em 1993 foi publicado, pelas Nações Unidas, a terceira versão do Sistema de Contas Nacionais (SCN/93), centrado nas Contas Econômicas Integradas - construídas por setores institucionais (empresas, famílias e administrações públicas) e de onde são derivados os principais agregados macroeconômicos - e nas Tabelas de Recursos e Usos (TRUs) - que são a base para a construção da matriz de insumo-produto (Feijó et al (2001); Guilhoto et al. (2002)).

Segundo Feijó (2001), nas Tabelas de Recursos e Usos as unidades produtivas são classificadas segundo as atividades econômicas permitindo visualizar as relações de troca entre os diversos setores. As TRUs são divididas em: Tabela de Recursos de Bens e Serviços, onde encontramos a Oferta Total de Bens e Serviços da economia (produção e importação); Tabela de Usos de Bens e Serviços que apresenta o Consumo Intermediário e a Demanda Final (exportação, consumo final e formação bruta de capital), totalizando a demanda da economia; e nos Componentes do Valor Adicionado por setor de atividade.

A Tabela de Recursos apresenta o formato produto x setor. Da soma dos quadrantes A1 (produção dos setores de atividades) e A2 (importação) obtemos o quadrante A que corresponde à oferta total de bens e serviços. 
A Tabela de Usos de Bens e Serviços também apresenta o formato produto $\mathrm{x}$ setor e fornece o destino da produção de cada setor de atividade para Consumo Intermediário (CI) e Demanda Final (DF) - exportação, consumo da administração pública, consumo das famílias, formação bruta de capital fixo e variação de estoque. Assim, ao somarmos CI com DF obtemos a Demanda total da economia. Além dessas informações, essa tabela ainda apresenta os componentes do Valor Adicionado: remunerações, excedente operacional bruto, outros impostos sobre a produção, outros subsídios à produção, valor da produção e pessoal ocupado.

O sistema inter-regional envolvendo as regiões Acre, Resto do Norte e Resto do Brasil utilizado no presente trabalho foi construído a partir das informações do modelo de insumo-produto elaborado por Guilhoto et al.(2002) para o ano de 1999 para os nove Estados da Amazônia Legal - Acre, Amapá, Amazonas, Pará, Rondônia, Roraima, Tocantins, Maranhão, Mato Grosso - e o Resto do Brasil. Esse sistema foi construído com uma abertura de 90 grupos de atividades econômicas (setores) e 141 grupos de produtos.

A base para a obtenção desse sistema de dez regiões foi a matriz de insumoproduto da economia brasileira para o ano de 1999 (MIP_BR99), elaborada por Guilhoto et al. (2001b) a partir da versão preliminar das TRUs divulgadas pelo Instituto Brasileiro de Geografia e Estatística. Tal procedimento justifica-se, uma vez que a última versão disponível da matriz de insumo-produto geral da economia brasileira elaborada pelo IBGE refere-se ao ano de 1996.

Em linhas gerais, o procedimento adotado para a obtenção do sistema interregional Acre, Resto do Norte, Resto do Brasil consistiu na regionalização da matriz Brasil, obtendo-se assim as matrizes para as macro regiões (para maiores detalhes, ver Guilhoto, 2001 e 2002).

Essa regionalização aconteceu em duas etapas: primeiramente, foi aberta a Matriz de Produção (P x S). Para tanto foi realizado o levantamento do valor da produção por produto de cada um dos setores da MIP-BR99 que seriam abertos. E, posteriormente, foi aberta a Matriz de Uso ( $\mathrm{S}$ x P), primeiro nos setores e depois nos produtos tomando-se como base a estrutura da matriz de produção. 
A abertura da MIP foi realizada de maneira bastante criteriosa e, nesse processo, foi utilizado o maior número de informações disponíveis para a economia e sua estrutura produtiva, garantindo, assim, a confiabilidade do resultado final. Nessa etapa, lançou-se mão das inúmeras pesquisas realizadas pelo IBGE quais sejam: Produção Agrícola Municipal (PAM); Produção Extrativa Vegetal (PEV); Silvicultura; Pesquisa Industrial Anual (PIA); Censo Agropecuário; Pesquisa de Orçamentos Familiares; Pesquisa Anual de Comércio; Pesquisa Anual de Serviços; Pesquisa Pecuária Municipal, entre outras. Alem dessas pesquisas, foram utilizados dados do Ministério da Agricultura, relativos a pesca; dados de exportações disponibilizados pelo Sistema ALICE-SECEX, entre outros. Todas as informações levantadas foram para o ano de 1999.

Além disso, foram realizados três ajustes para i) garantir a consistência por linhas e colunas; ii) garantir a consistência interna e minimizar a variação de estoques; e iii) garantir a consistência interna de totais por linhas e por colunas.

Assim, a Matriz Insumo-Produto para o Brasil (90 setores por 141 produtos) serviu de base para a estimação das Matrizes Insumo-Produto Regionais (Norte, Nordeste, Centro-Oeste, Sudeste e Sul).

A partir das matrizes regionais foram obtidas as matrizes estaduais. A regionalização, nesse caso, também ocorreu primeiramente na matriz de produção e posteriormente na matriz de uso. Para tanto, lançou-se mão das Contas Regionais, publicada pelo IBGE, que apresenta informações relacionadas ao quanto cada região e cada Estado participa na produção de 15 setores disponibilizados pelas contas. O ajuste feito nessa etapa é para que se mantenha, nas novas matrizes macro-regionais e estaduais estimadas, a mesma participação nacional apresentada nas contas regionais.

Com base nas matrizes estaduais obteve-se o sistema inter-regional composto pelos nove estados da Amazônia Legal e pelo resto do Brasil. Dessa forma, a partir das matrizes de produção (90 setores por 141 produtos) e de uso (141 produtos e 90 setores) dessas dez regiões, chegou-se às matrizes de produção e uso para as três regiões consideradas no presente trabalho. O procedimento adotado na obtenção dessas matrizes consistiu nas seguintes etapas: 
1) Obtenção da Matriz de Produção das três regiões: Acre, Resto do Norte e Resto do Brasil

O procedimento adotado consistiu na soma das matrizes de produção (90 setores por 141 produtos) dos estados da Amazônia Legal e resto do Brasil de modo a obter as matrizes de produção do Acre, do resto do Norte e do resto do Brasil (Figura 7). Em resumo,

\begin{tabular}{|c|c|}
\hline \multicolumn{2}{|c|}{ Matriz Amazônia Legal + resto do Brasil } \\
\hline 1 & Acre \\
\hline 2 & Amapá \\
\hline 3 & Amazonas \\
\hline 4 & Pará \\
\hline 5 & Rondônia \\
\hline 6 & Roraima \\
\hline 7 & Tocantins \\
\hline 8 & Maranhão \\
\hline 9 & Mato Grosso \\
\hline 10 & Resto do Brasil \\
\hline
\end{tabular}

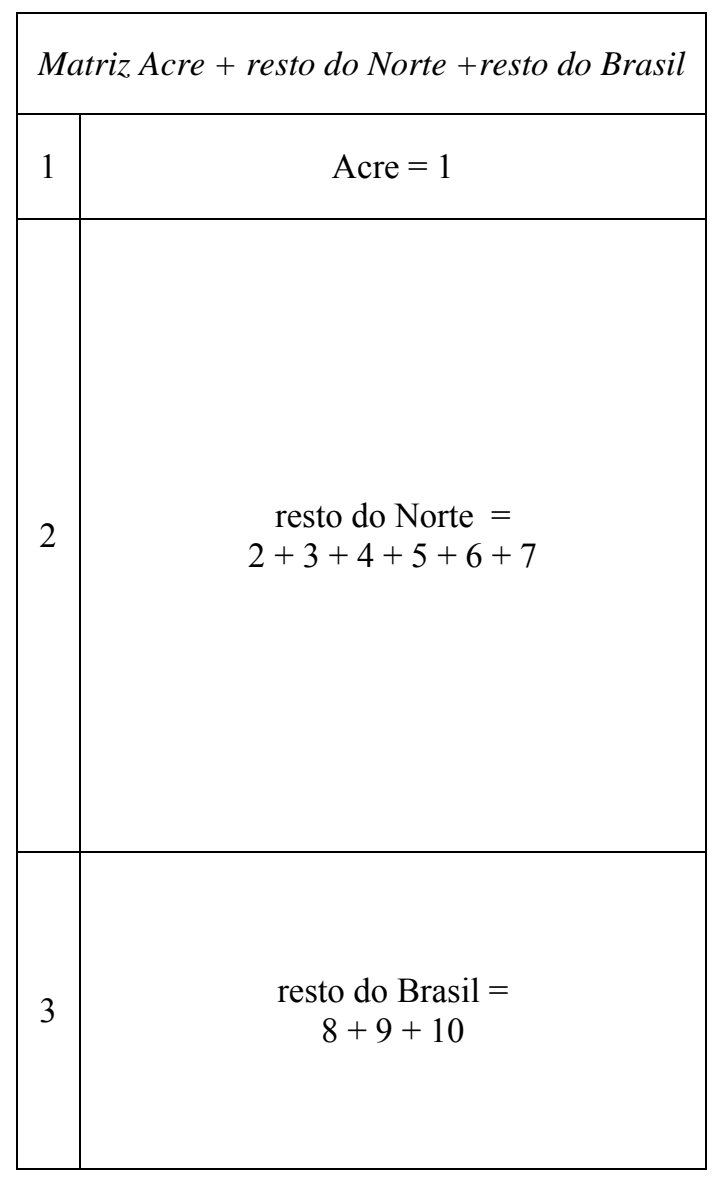

Figura 7 - Representação das matrizes de produção do Sistema Amazônia Legal + resto do Brasil e das matrizes de produção do Sistema Acre + resto do Norte + resto do Brasil. 
2) Construção da matriz de Consumo intermediário e Valor Adicionado

O sistema para os nove estados da Amazônia Legal e Resto do Brasil é composto por cem sub-matrizes de Consumo Intermediário (CI) de 141 produtos por 90 setores cada uma, e 10 sub-matrizes de Valor Adicionado (VA) de 25 variáveis $^{5}$ por 90 setores.

Cada matriz de CI representa as vendas de produtos de cada região (AC, AP, AM, PA, RO, RR, TO, MA, MT e RBR) para os setores da própria região e para os setores das outras nove regiões. Dessa forma, tal como no caso das matrizes de produção, as matrizes de consumo intermediário das três regiões, Acre, Resto do Norte e Resto do Brasil, utilizadas no presente trabalho, foram obtidas por meio da soma dos consumos intermediários (CIs) do Amapá, Amazonas, Pará, Rondônia, Roraima e Tocantins para compor o CI do Resto do Norte e, a soma dos CIs do Maranhão, Mato Grosso e Resto do Brasil para compor o CI do Resto do Brasil (Figura 8). Obtendo-se, dessa forma, nove sub-matrizes de 141 produtos por 90 setores cada.

O mesmo procedimento foi adotado para obtenção do Valor adicionado para o Acre, Resto do Norte e Resto do Brasil. O resultado final correspondeu a três submatrizes de 25 variáveis por 90 setores cada.

\footnotetext{
${ }^{5}$ As variáveis componentes do VA são: Produção nacional, Importação, Impostos de importação, ICM Nacional, ICM Importado, IPL Nacional, IPL Importação, Outros Impostos Indiretos Líquidos (IIL) Nacional, Outros IIL Importação, Consumo Intermediário, Remunerações, Salários, Contribuições sociais fictícias: Previdência oficial/FGTS e Previdência privada, Excedente operacional bruto (EOB), Rendimento de autônomos, EOB exclusive rendimentos de autônomos, Valor adicionado a custo de fatores, Outros impostos sobre a produção, Outros subsídios à produção, Valor adicionado a preço básico, Valor da Produção e Pessoal Ocupado.
} 


\begin{tabular}{|c|c|c|c|}
\hline & Acre (AC) & Resto do Norte (RN) & Resto do Brasil (RBR) \\
\hline AC & $\mathrm{CI}_{\mathrm{ACAC}}$ & $\begin{array}{c}\mathrm{CI}_{\mathrm{ACAP}}+\mathrm{CI}_{\mathrm{ACAM}}+\mathrm{CI}_{\mathrm{ACPA}}+\mathrm{CI}_{\mathrm{ACRO}}+ \\
\mathrm{CI}_{\mathrm{ACRR}}+\mathrm{CI}_{\mathrm{ACTO}}\end{array}$ & $\mathrm{CI}_{\mathrm{ACMA}}+\mathrm{CI}_{\mathrm{ACMT}}+\mathrm{CI}_{\mathrm{ACRBR}}$ \\
\hline $\mathbf{R N}$ & $\begin{array}{c}\mathrm{CI}_{\mathrm{APAC}}+\mathrm{CI}_{\mathrm{AMAC}}+ \\
\mathrm{CI}_{\mathrm{PAAC}}+\mathrm{CI}_{\mathrm{ROAC}}+ \\
\mathrm{CI}_{\mathrm{RRAC}}+\mathrm{CI}_{\mathrm{TOAC}}\end{array}$ & $\begin{aligned} \mathrm{CI}_{\mathrm{APAP}} & +\mathrm{CI}_{\mathrm{APAM}}+\mathrm{CI}_{\mathrm{APPA}}+\mathrm{CI}_{\mathrm{APRO}} \\
& +\mathrm{CI}_{\mathrm{APRR}}+\mathrm{CI}_{\mathrm{APTO}}+ \\
\mathrm{CI}_{\mathrm{AMAP}} & +\mathrm{CI}_{\mathrm{AMAM}}+\mathrm{CI}_{\mathrm{AMPA}}+\mathrm{CI}_{\mathrm{AMRO}} \\
& +\mathrm{CI}_{\mathrm{AMRR}}+\mathrm{CI}_{\mathrm{AMTO}}+ \\
\mathrm{CI}_{\mathrm{PAAP}} & +\mathrm{CI}_{\mathrm{PAAM}}+\mathrm{CI}_{\mathrm{PAPA}}+\mathrm{CI}_{\mathrm{PARO}}+ \\
& \mathrm{CI}_{\mathrm{PARR}}+\mathrm{CI}_{\mathrm{PATO}}+ \\
\mathrm{CI}_{\mathrm{ROAP}}+ & \mathrm{CI}_{\mathrm{ROAM}}+\mathrm{CI}_{\mathrm{ROPA}}+\mathrm{CI}_{\mathrm{RORO}} \\
& +\mathrm{CI}_{\mathrm{RORR}}+\mathrm{CI}_{\mathrm{ROTO}}+ \\
\mathrm{CI}_{\mathrm{RRAP}}+ & \mathrm{CI}_{\mathrm{RRAM}}+\mathrm{CI}_{\mathrm{RRPA}}+\mathrm{CI}_{\mathrm{RRRO}}+ \\
& \mathrm{CI}_{\mathrm{RRRR}}+\mathrm{CI}_{\mathrm{RRTO}}+ \\
\mathrm{CI}_{\mathrm{TOAP}}+ & \mathrm{CI}_{\mathrm{TOAM}}+\mathrm{CI}_{\mathrm{TOPA}}+\mathrm{CI}_{\mathrm{TORO}} \\
& +\mathrm{CI}_{\mathrm{TORR}}+\mathrm{CI}_{\mathrm{TOTO}}\end{aligned}$ & $\begin{array}{c}\mathrm{CI}_{\mathrm{APMA}}+\mathrm{CI}_{\mathrm{APMT}}+ \\
\mathrm{CI}_{\mathrm{APRBR}}+\mathrm{CI}_{\mathrm{AMMA}}+ \\
\mathrm{CI}_{\mathrm{AMMT}}+\mathrm{CI}_{\mathrm{AMRBR}}+ \\
\mathrm{CI}_{\mathrm{PAMA}}+\mathrm{CI}_{\mathrm{PAMT}}+ \\
\mathrm{CI}_{\mathrm{PARBR}}+\mathrm{CI}_{\mathrm{ROMA} A}+ \\
\mathrm{CI}_{\mathrm{ROMT}}+\mathrm{CI}_{\mathrm{RORBR}}+ \\
\mathrm{CI}_{\text {RRMA }}+\mathrm{CI}_{\mathrm{RRMT}}+ \\
\mathrm{CI}_{\mathrm{RRRBR}}+\mathrm{CI}_{\mathrm{TOMA}}+ \\
\mathrm{CI}_{\mathrm{TOMT}}+\mathrm{CI}_{\mathrm{TORBR}}\end{array}$ \\
\hline RBR & $\begin{array}{c}\mathrm{CI}_{\mathrm{MAAC}}+\mathrm{CI}_{\mathrm{MTAC}}+ \\
\mathrm{CI}_{\mathrm{RBRAC}}\end{array}$ & $\begin{array}{c}\mathrm{CI}_{\mathrm{MAAP}}+\mathrm{CI}_{\mathrm{MAAM}}+\mathrm{CI}_{\mathrm{MAPA}}+ \\
\mathrm{CI}_{\mathrm{MARO}}+\mathrm{CI}_{\mathrm{MARR}}+\mathrm{CI}_{\mathrm{MATO}}+ \\
\mathrm{CI}_{\mathrm{MTAP}}+\mathrm{CI}_{\mathrm{MTAM}}+\mathrm{CI}_{\mathrm{MTPA}}+ \\
\mathrm{CI}_{\mathrm{MTRO}}+\mathrm{CI}_{\mathrm{MTRR}}+\mathrm{CI}_{\mathrm{MTTO}}+ \\
\mathrm{CI}_{\mathrm{RBRAP}}+\mathrm{CI}_{\mathrm{RBRAM}}+\mathrm{CI}_{\mathrm{RBRPA}}+ \\
\mathrm{CI}_{\text {RBRRO }}+\mathrm{CI}_{\text {RBRRR }}+\mathrm{CI}_{\text {RBRTO }}\end{array}$ & $\begin{array}{c}\mathrm{CI}_{\mathrm{MAMA}}+\mathrm{CI}_{\mathrm{MAMT}}+ \\
\mathrm{CI}_{\mathrm{MARBR}}+\mathrm{CI}_{\mathrm{MTMA}}+ \\
\mathrm{CI}_{\mathrm{MTMT}}+\mathrm{CI}_{\mathrm{MTRBR}}+ \\
\mathrm{CI}_{\text {RBRMA }}+\mathrm{CI}_{\text {RBRMT }}+\mathrm{CI}_{\text {RBRRBR }}\end{array}$ \\
\hline VA & $\mathrm{VA}_{\mathrm{AC}}$ & $\begin{array}{l}\mathrm{VA}_{\mathrm{AP}}+\mathrm{VA}_{\mathrm{AM}}+\mathrm{VA}_{\mathrm{PA}}+ \\
\mathrm{VA}_{\mathrm{RO}}+\mathrm{VA}_{\mathrm{RR}}+\mathrm{VA}_{\mathrm{TO}}\end{array}$ & $\mathrm{VA}_{\mathrm{MA}}+\mathrm{VA}_{\mathrm{MT}}+\mathrm{VA}_{\mathrm{RBR}}$ \\
\hline
\end{tabular}

Figura 8 - Consumo intermediário e valor adicionado do sistema Acre, resto do Norte e resto do Brasil.

3) Obtenção do Dummy Financeira e da Demanda Final

A coluna de Dummy financeiro da matriz insumo-produto, segundo Feijó et al.(2001), representa um setor de atividade fictício criado para evitar que despesas que não se relacionam diretamente à produção sejam incluídas no Valor Adicionado Total.

Considera (1998, p. 36) destaca que “o tratamento das Instituições Financeiras na Conta produção das Contas Nacionais incorpora uma convenção adotada por todos os países que seguem as recomendações das Nações Unidas. Assim, para evitar que se chegue, nas atividades das instituições financeiras (exceto seguros), a um Valor 
Adicionado próximo de zero, ou negativo, imputa-se um Valor de Produção referente aos Serviços Financeiros, que é calculado como a diferença entre os Juros recebidos e os pagos. Os juros são, entretanto, tratados não como produção, e sim como uma operação de repartição da renda. Por isso, recomenda-se que essa diferença seja tratada da mesma forma. Com isso, é necessário retirar-se do somatório do Valor Adicionado Total o valor já imputado, de forma a se não contabilizar como Produto (Valor adicionado) um valor que não é obtido na Produção. Como a Renda que permite o pagamento (e recebimento) dos juros já foi computada quando da sua geração no processo de Produção, evita-se, assim, a dupla contagem".

O Dummy financeiro serve, então, para fazer o ajuste mencionado, ou seja, a ele é associado um valor de Consumo Intermediário equivalente ao valor imputado, e um Valor de Produção igual a zero. Assim, o Valor adicionado obtido é negativo (simétrico ao Consumo Intermediário), ajustando o total do Valor Adicionado da economia. Na matriz insumo-produto, o setor Dummy financeiro está colocado fora do domínio das atividades, porque, uma vez que possui Valor da Produção nulo, não seria possível o cálculo dos coeficientes técnicos.

As colunas correspondentes ao Dummy Financeiro e à Demanda Final do Acre, Resto do Norte e Resto do Brasil foram obtidas mediante o mesmo procedimento descrito anteriormente, ou seja, o Dummy do Acre é obtido diretamente. Para compor o Dummy do Resto do Norte realizou-se a soma dos dummys do Amapá, do Amazonas, do Pará, de Rondônia, de Roraima e do Tocantins e para compor o Dummy do Resto do Brasil, foram somados os dummys do Maranhão, do Mato Grosso e do Resto do Brasil. O mesmo foi realizado com a demanda final.

4) Agregação das matrizes de produção e uso

Por meio dos procedimentos descritos nas seções anteriores, chegou-se as matrizes de produção e uso para o sistema inter-regional Acre vs. Resto do Norte vs. Resto do Brasil. A matriz de produção de cada região composta por 90 setores e 141 produtos gerou um sistema inter-regional com 270 linhas (setores) e 141 colunas 
(produtos). Já a matriz de uso do sistema inter-regional apresenta 447 linhas (141 produtos para cada uma das três regiões e 25 variáveis componentes do valor adicionado) por 291 colunas das quais 270 correspondem ao consumo intermediário dos 90 setores para cada uma das três regiões e as 21 colunas restantes representam a colunas dummy financeiro (para o $\mathrm{AC}, \mathrm{RN}$ e RBR), consumo intermediário (soma das 270 colunas do consumo intermediário das 3 regiões), demanda final de cada região (Formação Bruta de Capital Fixo, Exportação, Variação de Estoques, Consumo da Administração Pública e Consumo das Famílias), demanda final (soma da demanda final das 3 regiões) e demanda total (soma do consumo intermediário e demanda final).

De posse das matrizes de produção e uso das três regiões, realizou-se um conjunto de procedimentos visando a obtenção da Matriz Inversa de Leontief. Inicialmente agregaram-se os setores das matrizes de produção e uso, reduzindo-os para 53 setores (Figura 9). Essa agregação justifica-se pelo fato dos setores componentes do setor florestal serem o foco do presente estudo.

Levando-se em consideração essa peculiaridade, o setor Silvicultura foi agregado ao setor Extrativismo Vegetal, compondo assim, o macro-setor "Extrativismo Vegetal e Silvicultura" e os setores Fabricação de Celulose e Pasta Mecânica e Fabricação de Papel, Papelão e Artefatos de Papel formaram o macro-setor "Fabricação de Celulose, Pasta Mecânica, Papel, Papelão e Artefatos de Papel”.

A Figura 9 apresenta as agregações setoriais realizadas para a construção do sistema inter-regional. 


\begin{tabular}{|c|c|c|c|}
\hline \multicolumn{2}{|r|}{ Setores Componentes da Matriz Brasil, 1999} & \multicolumn{2}{|r|}{$\begin{array}{l}\text { Agregação para o Sistema Inter-regional Acre vs. Resto } \\
\text { do Norte vs. Resto do Brasil }\end{array}$} \\
\hline 1 & Cana-de-açúcar & & \\
\hline 2 & Soja & & \\
\hline 3 & Milho & 1 & Agricultura \\
\hline 4 & Fruticultura & & \\
\hline 5 & Outras Culturas & & \\
\hline 6 & Aves & 2 & Aves \\
\hline 7 & Bovinos & 3 & Bovinos \\
\hline $\begin{array}{l}8 \\
9\end{array}$ & $\begin{array}{l}\text { Suínos } \\
\text { Outros Pecuária }\end{array}$ & 4 & Outros Pecuária \\
\hline $\begin{array}{l}10 \\
11\end{array}$ & $\begin{array}{l}\text { Extrativismo Vegetal } \\
\text { Silvicultura }\end{array}$ & 5 & Extrativismo Vegetal e Silvicultura \\
\hline 12 & Extrativismo Animal (Pesca) & 6 & Extrativismo Animal (Pesca) \\
\hline $\begin{array}{l}13 \\
14 \\
15 \\
16\end{array}$ & $\begin{array}{l}\text { Extrat. Mineral } \\
\text { Petróleo E Outros } \\
\text { Gás Natural } \\
\text { Carvão Mineral }\end{array}$ & 7 & Extrativa Mineral \\
\hline 17 & Mineral Ñ Metálico & 8 & Mineral não Metálico \\
\hline $\begin{array}{l}18 \\
19\end{array}$ & $\begin{array}{l}\text { Siderurgia } \\
\text { Metalurg. Não Ferrosos }\end{array}$ & 9 & Metalurgia Básica \\
\hline 20 & Outros Metalúrgicos & 10 & Outros Metalúrgicos \\
\hline $\begin{array}{l}21 \\
22\end{array}$ & $\begin{array}{l}\text { Máquinas E Implementos Agrícolas } \\
\text { Outras Máquinas e EQUIP. }\end{array}$ & 11 & Máquinas e Equipamentos \\
\hline 23 & Material Elétrico & 12 & Material Elétrico \\
\hline 24 & Equip. Eletrônicos & 13 & Equipamentos Eletrônicos \\
\hline 25 & Automóveis & & \\
\hline 26 & Caminhões e Ônibus & 14 & Automóveis, Caminhões, Ônibus e Peças \\
\hline 27 & Peças e Out. Veículos & & \\
\hline 28 & Indústria da Madeira & 15 & Indústria da Madeira \\
\hline 29 & Indústria do Mobiliário & 16 & Indústria do Mobiliário \\
\hline $\begin{array}{l}30 \\
31\end{array}$ & $\begin{array}{l}\text { Fabricação de Celulose e Pasta Mecânica } \\
\text { Fabricação de Papel, Papelão e Artefatos de Papel }\end{array}$ & 17 & $\begin{array}{l}\text { Fab. de Celulose, Pasta Mecânica, Papel, Papelão } \\
\text { e Artefatos de Papel }\end{array}$ \\
\hline 32 & Indústria Editorial e Gráfica & 18 & Indústria Editorial e Gráfica \\
\hline 33 & Ind. da Borracha & 19 & Indústria da Borracha \\
\hline
\end{tabular}

Figura 9 - Agregação dos 90 setores da matriz de insumo-produto Brasil, 1999 para os 53 setores componentes do sistema inter-regional Acre vs. resto do Norte vs. sesto do Brasil. 


\begin{tabular}{|c|c|c|c|}
\hline \multicolumn{2}{|c|}{ Setores Componentes da Matriz Brasil, 1999} & \multicolumn{2}{|r|}{$\begin{array}{c}\text { Agregação para o Sistema Inter-regional Acre vs. Resto } \\
\text { do Norte vs. Resto do Brasil }\end{array}$} \\
\hline $\begin{array}{l}34 \\
35\end{array}$ & $\begin{array}{l}\text { Álcool } \\
\text { Outros Elementos Químicos }\end{array}$ & 20 & Elementos Químicos \\
\hline 36 & Refino do Petróleo & & \\
\hline 37 & Adubos e Fertilizantes & 21 & Químicos Diversos \\
\hline 38 & Químicos Diversos & & \\
\hline 39 & Farmac. e Veterinária & 22 & Farmac. e Veterinária \\
\hline 40 & Artigos Plásticos & 23 & Artigos de Plástico \\
\hline 41 & Ind. Têxtil & 24 & Indústria Têxtil \\
\hline 42 & Artigos do Vestuário & 25 & Artigos do Vestuário \\
\hline 43 & Fabricação Calçados & 26 & Fabricação de Calçados \\
\hline $\begin{array}{l}44 \\
45\end{array}$ & $\begin{array}{l}\text { Indústria do Café } \\
\text { Benef. Outros Produtos Vegetais }\end{array}$ & 27 & Benef. de Produtos Vegetais \\
\hline 46 & Abate de Aves & 28 & Abate de Aves \\
\hline 47 & Abate de Bovinos & 29 & Abate de Bovinos \\
\hline 48 & Abate de Suínos e Outros & 30 & Abate de Suínos e Outros \\
\hline $\begin{array}{l}49 \\
50 \\
51 \\
52 \\
53 \\
54\end{array}$ & $\begin{array}{l}\text { Indústria de Laticínios } \\
\text { Fabricação de Açúcar } \\
\text { Fabricação de Óleos Vegetais } \\
\text { Rações } \\
\text { Outros Produtos Alimentares } \\
\text { Bebidas }\end{array}$ & 31 & Indústria de Alimentos \\
\hline 55 & Indústrias Diversas & 32 & Indústrias Diversas \\
\hline 56 & Prod. de Energia Elétrica Hidráulica & & \\
\hline 57 & Prod. de Energia Elétrica Óleo Combustível & & \\
\hline 58 & Prod. de Energia Elétrica Carvão & & \\
\hline 59 & Prod. Energia Óleo Diesel & & \\
\hline 60 & Prod. de Energia Elétrica Gás Natural & 33 & SIUP \\
\hline 61 & Prod. Energia Outras Fontes & & \\
\hline 62 & Distribuição de Energia Elétrica & & \\
\hline 63 & Saneamento e Abastecimento d'água & & \\
\hline 64 & Coleta e Tratamento de Lixo & & \\
\hline 65 & Construção Civil & 34 & Construção Civil \\
\hline
\end{tabular}

Figura 9 - Agregação dos 90 setores da matriz de insumo-produto Brasil, 1999 para os 53 setores componentes do sistema inter-regional Acre vs. resto do Norte vs. sesto do Brasil. 


\begin{tabular}{|c|c|c|c|}
\hline \multicolumn{2}{|r|}{ Setores Componentes da Matriz Brasil, 1999} & \multicolumn{2}{|r|}{$\begin{array}{c}\text { Agregação para o Sistema Inter-regional Acre vs. Resto } \\
\text { do Norte vs. Resto do Brasil }\end{array}$} \\
\hline 66 & Atacado & 35 & Comércio \\
\hline 67 & Comércio Varejista de Combustíveis & & \\
\hline 68 & Comércio Varejista de Veículos, Peças e Acessórios & & \\
\hline 69 & Supermercados & & \\
\hline 70 & Outros Comércios Varejistas & & \\
\hline 71 & Transporte Rodoviário & 36 & Transporte Rodoviário \\
\hline 72 & Transporte Aéreo & 37 & Transporte Aéreo \\
\hline 73 & Transporte Ferroviário & 38 & Transporte Ferroviário \\
\hline 74 & Transporte Aquaviário & 39 & Transporte Aquaviário \\
\hline 75 & Atividades Auxiliares dos Transportes & 40 & Atividades Auxiliares dos Transportes \\
\hline 76 & Serviços de Telefonia Móvel & 41 & Comunicações \\
\hline 77 & Serviços de Telefonia Fixa & & \\
\hline 78 & Correios & & \\
\hline 79 & Instituições Financeiras & 42 & Instituições Financeiras \\
\hline 80 & Saúde Mercantil & 43 & Saúde Mercantil \\
\hline 81 & Educação Mercantil & 44 & Educação Mercantil \\
\hline 82 & Serviços de Alojamento e Alimentação & 45 & Serviços de Alojamento e Alimentação \\
\hline 83 & Outros Serviços Prestados à Família & 46 & Outros Serviços Prestados à Família \\
\hline 84 & Serviços Prestados à Empresa & 47 & Serviços Prestados à Empresa \\
\hline 85 & Aluguel de Imóveis & 48 & Aluguel de Imóveis \\
\hline 86 & Saúde Pública & 49 & Saúde Pública \\
\hline 87 & Educação Pública & 50 & Educação Pública \\
\hline 88 & Segurança Pública & 51 & Segurança Pública \\
\hline 89 & Outros Administração Pública & 52 & Outros Administração Pública \\
\hline 90 & Serv. Privados Não Mercantis & 53 & Serv. Privados Não Mercantis \\
\hline
\end{tabular}

Figura 9 - Agregação dos 90 setores da matriz de insumo-produto Brasil, 1999 para os 53 setores componentes do sistema inter-regional Acre vs. resto do Norte vs. sesto do Brasil.

\subsubsection{Produto Interno Bruto florestal acreano}

Agregados macroeconômicos, segundo Rossetti (1997), é a expressão em geral empregada para designar os resultados da mensuração da atividade econômica como um 
todo. Refere-se a soma de todas as transações, realizadas por todos os agentes, na totalidade dos mercados.

O conceito básico a ser considerado no cálculo dos agregados nacionais é o de valor adicionado, que é derivado da concepção da produção como um processo de entradas-e-saídas. Defini-se a partir da dedução das entradas de insumos, das saídas da produção elaborada, equivalendo-se então, aos custos de processamento. O valor adicionado corresponde, portanto, aos pagamentos de fatores mobilizados pela empresa - trabalho (salários), capital (aluguéis, arrendamentos, juros e depreciações) e empresariedade (lucros), além dos custos tributários do processamento produtivo (tributos indiretos).

\section{Método de cálculo do produto interno bruto florestal da economia acreana}

O PIB florestal acreano foi calculado tomando como base a Matriz de InsumoProduto construída a partir da matriz estimada por Guilhoto et al. (2001) para o ano de 1999. O método utilizado para cálculo de PIB Florestal, a partir das informações contidas na matriz de insumo-produto, foi o desenvolvido por Furtuoso (1998) e aperfeiçoado por Guilhoto, Furtuoso e Silva (2002).

O procedimento adotado por esses autores para a estimativa do PIB do Agronegócio Brasileiro, e que será adaptado para o cálculo do PIB Florestal Acreano, utiliza o Valor Adicionado a preços de mercado (VAPM), que é obtido pela soma do valor adicionado a preços básicos $\left(\mathrm{VA}_{\mathrm{PB}}\right)$ com os impostos indiretos líquidos de subsídios sobre os produtos (IIL), subtraída da Dummy financeira (DuF). Ou seja:

$$
V A_{P M}=V A_{P B}+I I L-D u F
$$

O Cálculo do PIB Florestal inicia-se pela definição do Complexo Florestal que, por sua vez, é definido e mensurado em um grande setor denominado Extrativismo 
Vegetal e Silvicultura bem como pelos setores industriais que apresentam as maiores interligações setoriais com esse setor.

O valor total do PIB Florestal será dividido em: a) insumos, b) o próprio setor, c) processamento, e d) distribuição e serviços.

Assim, tem-se que o PIB Florestal tal como o PIB do Agronegócio estimado por Guilhoto et al. (2002) será composto pela soma dos PIBs de quatro agregados:

- Agregado I: insumos não florestais para o setor Extrativismo vegetal e Silvicultura;

- Agregado II: o setor florestal propriamente dito, representado pelo setor Extrativismo Vegetal e Silvicultura;

- Agregado III: composto pelas indústrias de base florestal;

- Agregado IV: referente à distribuição final.

Para o cálculo do PIB do Agregado I são utilizadas as informações disponíveis nas tabelas de insumo-produto referentes aos valores dos insumos adquiridos pela Extrativa vegetal e silvicultura. A coluna com os valores dos insumos são multiplicadas pelos respectivos coeficientes de valor adicionado (CVAi).

Os Coeficientes de Valor Adicionado por setor (CVAi) são obtidos por meio da divisão do Valor Adicionado a Preços de Mercado $\left(V A_{P M i}\right)$ pela Produção do Setor $\left(X_{i}\right)$ :

$$
C V A_{i}=\frac{V A_{P M_{i}}}{X_{i}}
$$

Elimina-se com isso, o problema de dupla contagem apresentado nos primeiros métodos desenvolvidos para cálculo do PIB, quando se levava em consideração os valores dos insumos e não o valor adicionado efetivamente gerado na produção desses. Dessa forma, tem-se então que o PIB do Agregado I da seguinte forma:

$$
P I B_{I}=\sum_{i}^{n} Z_{i} * C V A_{i}
$$


$k=$ setor Extrativismo vegetal e silvicultura (setor cinco da matriz);

$i=$ setores restantes da matriz;

$Z_{i}=$ valor total do insumo do setor i para o setor extrativismo vegetal e silvicultura;

$C V A_{i}=$ coeficiente de valor adicionado do setor $i$.

Para o Agregado II considera-se no cálculo o valor adicionado gerado pelo setor Extrativismo vegetal e silvicultura:

$$
P I B_{I I}=V A_{P M}
$$

Para o cálculo do PIB do Agregado III, há a necessidade de se definir a composição das Indústrias de Base Florestal. Para tanto, lança-se mão dos indicadores definidos por Guilhoto et al. (2002) que consistem:

a) na identificação dos principais setores demandantes de produtos florestais;

b) na determinação das participações dos insumos florestais no consumo intermediário dos setores industriais de base florestal; e

c) na delimitação das atividades econômicas que efetuam a primeira, segunda e terceira transformação das matérias-primas florestais.

Da análise desses indicadores determina-se quais os setores que farão parte da indústria de base florestal e, portanto, que entrarão no cálculo do PIB do Agregado III.

Assim, o PIB do Agregado III é estimado por meio do somatório dos valores adicionados pelos setores industriais de base florestal subtraídos dos valores adicionados desses setores que foram utilizados como insumos do Agregado II. Mais uma vez, essa subtração tem por objetivo eliminar a dupla contagem presente nas estimativas desenvolvidas anteriormente. Dessa forma, tem-se:

$$
P I B_{I I I}=\sum\left(V A_{P M_{q}}-Z_{q} * C V A_{q}\right)
$$

No caso do Agregado IV, referente à Distribuição final, considera-se para fins de cálculo o valor agregado dos setores relativos ao Transporte, Comércio e segmentos 
de Serviços. Do valor total obtido, destina-se ao complexo florestal apenas a parcela que corresponde à participação dos produtos do setor extrativismo vegetal e silvicultura e dos setores industriais de base florestal na demanda final de produtos. Assim, o PIB desse agregado é calculado da seguinte forma:

$$
\begin{aligned}
& D F D=D F G-I I L_{D F}-P I_{D F} \\
& M C=V A T_{P M}+V A C_{P M}+V A S_{P M} \\
& P I B_{I V}=M C * \frac{D F+\sum D F_{q}}{D F D}
\end{aligned}
$$

onde:

$\mathrm{DFG}=$ demanda final global;

$\mathrm{IIL}_{D F}=$ impostos indiretos líquidos pagos pela demanda final;

$\mathrm{PI}_{D F}=$ produtos importados pela demanda final;

$\mathrm{DFD}=$ demanda final doméstica;

$\mathrm{VAT}_{P M}=$ valor adicionado do setor transporte a preços de mercado;

$\mathrm{VAC}_{P M}=$ valor adicionado do setor comércio a preços de mercado;

$\mathrm{VAS}_{P M}=$ valor adicionado do setor serviços a preços de mercado;

$\mathrm{MC}=$ margem de comercialização;

$\mathrm{DF}_{k}=$ demanda final do setor extrativismo vegetal e silvicultura;

$\mathrm{DF}_{q}=$ demanda final dos setores agroindustriais;

$\mathrm{PIB}_{I V k}=\mathrm{PIB}$ do agregado IV para o setor extrativismo vegetal e silvicultura.

E, finalmente, para o cálculo do PIB total do Complexo Florestal

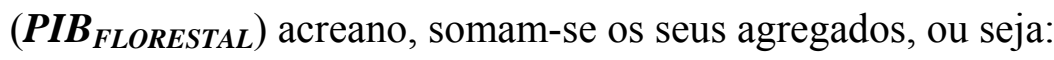

$$
P I B_{\text {FLORESTAL }}=P I B_{I}+P I B_{I I}+P I B_{I I I}+P I B_{I V}
$$




\section{RESULTADOS E DISCUSSÃO}

As análises conduzidas neste trabalho permitiram representar a economia acreana, e a sua importância dentro e fora do estado, sob a perspectiva das relações insumo-produto dessa economia.

As informações geradas por essa análise são apresentadas nesta seção e poderão apoiar a reestruturação político-administrativo, econômico, social e infra-estrutural pelas quais o estado do Acre vem passando.

Um dos pontos chave dessa reestruturação consiste no investimento em setores considerados de alto potencial para a economia do estado. Dentre esses setores, o florestal vem sendo apontado pelas autoridades locais como o de maior potencial, tendo em vista a vocação florestal do Estado, onde predomina, principalmente, a produção de madeira (serrada e em tora) e de produtos florestais não madeireiros como látex (borracha) e castanha, conforme já exposto na seção 3.2.5.1.

Nesta seção, de forma mais específica, são apresentados e discutidos os resultados de uma análise geral da estrutura produtiva da economia acreana, identificando as relações intersetoriais e, com isso, os setores-chave para desenvolvimento econômico do estado. Essa análise é complementada pela caracterização da importância dos setores em termos de geração de produção, emprego, renda e importação. Pretende-se com isso, identificar a real importância do setor florestal para a economia em questão. 
Assim, a análise dos resultados obtidos a partir da aplicação da teoria de insumo-produto, descrita na seção 3, é dividida da seguinte forma: identificação dos setores-chave por meio da análise conjunta dos índices de Hirschman-Rasmussen, campo de influência e índices puros de ligações; identificação dos setores importantes em termos de geração de emprego, de renda, de produção e de importação e, por último, são apresentados os resultados referentes ao cálculo do PIB florestal acreano.

Modelos inter-regionais como o utilizado no presente estudo permitem que sejam calculados índices de ligação de Hirschman-Rasmussen e índices puro de ligação através de três procedimentos. No primeiro, analisa-se cada economia de forma isolada, sem levar em consideração os efeitos inter-regionais sofridos pela mesma, ou seja, como se não houvesse relação entre as regiões. Nesse caso, uma matriz inversa de Leontief de dimensão 53 x 53 é obtida para cada região separadamente e os índices obtidos são classificados como índices independentes.

Nos outros dois procedimentos, os elos entre todas as regiões são levados em consideração de maneira que os índices englobam os efeitos inter-regionais e são obtidos a partir da matriz inversa de Leontief para o sistema total (159 x 159). No entanto, os índices podem também ser calculados através da inversa de Leotinef completa, ou da matriz inversa correspondente às relações da região com ela mesma, constituída de forma característica por um conjunto de matrizes na sua diagonal principal. Os índices obtidos por esses dois procedimentos são classificados como dependentes.

No presente trabalho, os índices de Hirschman-Rasmussen e puro de ligação são calculados dessas três formas. No entanto, como os objetivos do presente trabalho são analisar a estrutura produtiva da economia acreana, identificando os setores-chave dessa economia, e avaliar a dependência do estado com relação às outras duas regiões consideradas no presente trabalho (resto do Norte e resto do Brasil), foram descartados, na identificação dos setores-chave, os índices calculados a partir da inversa de Leontief para o sistema total. Isso se justifica pelo fato desses índices não permitirem efetivamente o atendimento dos citados objetivos, uma vez que, por ser muito pequeno o peso da economia acreana no sistema como um todo, fica difícil identificar efetivamente os setores mais importantes dessa economia. 
Índices calculados por meio desse procedimento permitem, contudo, que sejam analisados os padrões médios das ligações para frente e para trás dos diferentes setores da economia. Por isso, embora os índices obtidos por meio desse procedimento não tenham sido utilizados para a identificação dos setores-chave das economias formadas pelo Acre, resto do Norte e resto do Brasil, eles acabaram sendo utilizados na análise do padrão médio das ligações para frente e para trás dos diferentes setores pertencentes a essas economias.

Os outros dois procedimentos, independente e dependente (que leva em consideração as matrizes inversas de Leontief da diagonal principal do sistema total), resultaram em valores muito parecidos. Por isso, optou-se pelo emprego dos índices dependentes para a análise estrutural do sistema inter-regional e para a identificação dos setores-chave para as regiões Acre, resto do Norte e resto do Brasil. Dessa forma, a dependência entre as regiões é levada em consideração e é possível identificar a importância dos setores para cada uma das regiões separadamente.

\section{1 Índices de ligação de Hirschman-Rasmussen}

Conforme apresentado na seção 3, os índices de Hirschman-Rasmussen permitem identificar o grau de encadeamento entre os setores de uma economia para trás, como demandante de insumos dos demais setores da economia, e para frente, como ofertante de insumos para os demais setores da economia.

Dois são os critérios básicos para a determinação dos setores-chave para o crescimento de uma economia. O primeiro, proposto por Hirschman-Rasmussen, classifica como setores-chave aqueles que apresentam pelo menos um dos índices de ligação, para frente ou para trás, acima de um. O segundo critério, proposto por McGilvray (1977), considera um setor como chave se esse apresentar ambos os índices, para frente e para trás maiores do que um, simultaneamente.

A Tabela 33 (Anexo) apresenta os índices de ligação de Hirschman-Rasmussen para trás e para frente obtidos para o sistema inter-regional como um todo. Dessa tabela, 
foi obtida a Figura 10 que apresenta o padrão médio de comportamento dos índices de Hirschman-Rasmussen do Acre, resto do Norte e resto do Brasil, no sistema interregional.

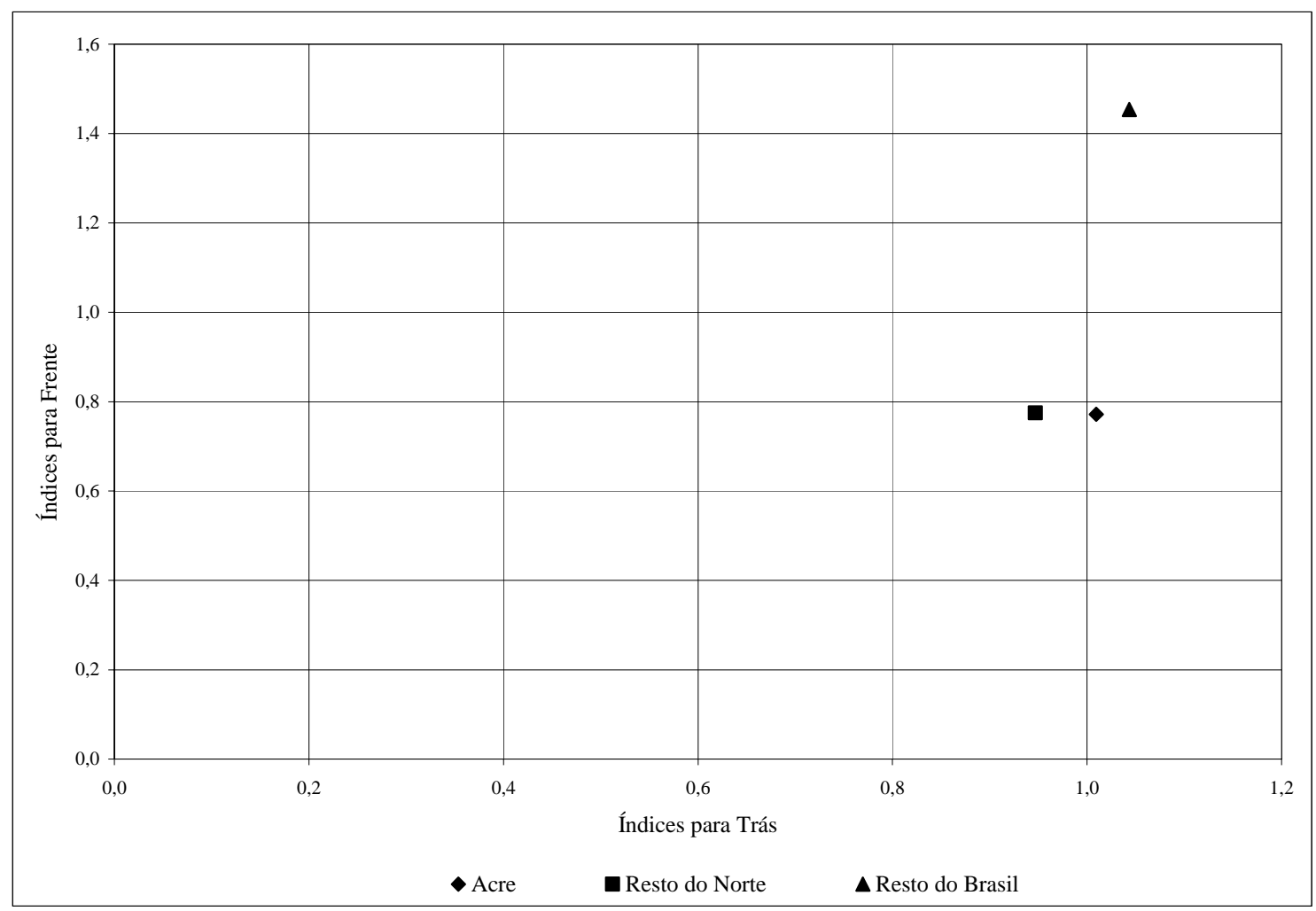

Figura 10 - Padrões médios de comportamento dos índices de Hirschman-Rasmussen do Acre, Resto do Norte e Resto do Brasil - 1999.

Através dessa figura podemos identificar três padrões bastante distintos dentro do sistema inter-regional: a) o Acre apresenta índice médio para frente igual a 0,771 e para trás igual a 1,010, o que sugere que os setores mais interligados nessa economia o são com os setores fornecedores de insumos; b) o resto do Norte apresenta índices médios para frente igual a 0,775 e para trás igual a 0,947, que refletem fracas ligações entre os setores domésticos; c) o resto do Brasil, apresenta uma estrutura setorial melhor articulada, tanto para frente $(1,454)$ como para trás $(1,044)$, em relação à média das regiões resto do Norte e Acre. 
A partir dessa constatação, e de uma análise de como variam os padrões de ligações intersetoriais em cada região, podem ser traçadas diretrizes básicas de políticas voltadas ao desenvolvimento dessas regiões. No Acre, a Figura 10 sugere que as políticas de desenvolvimento deveriam visar os setores com maior poder de ligações para trás. 


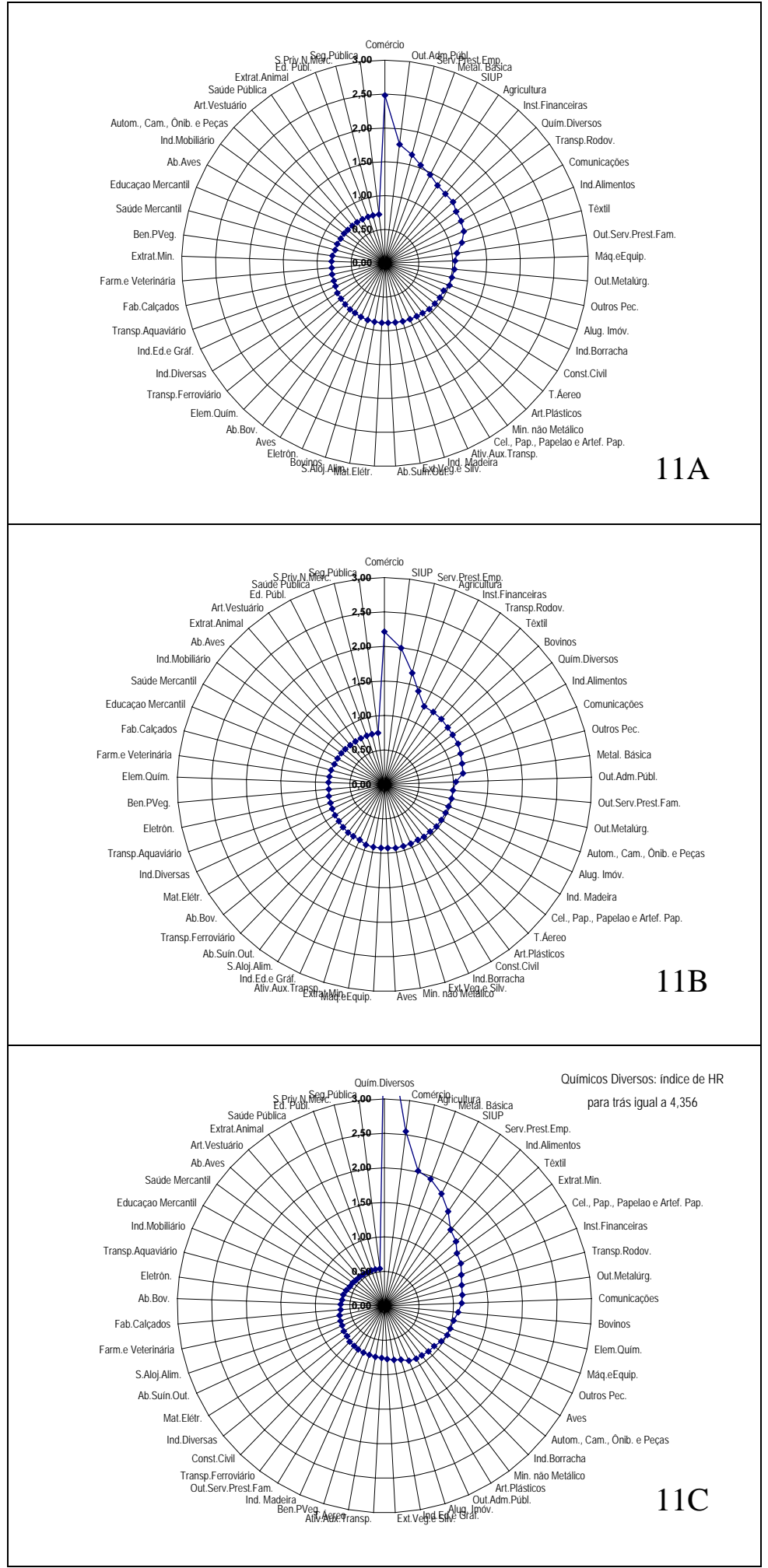

Figura 11 - Índices de ligações para frente de Hirschman-Rasmussen para as regiões Acre, resto do Norte e resto do Brasil - índices dependentes. 


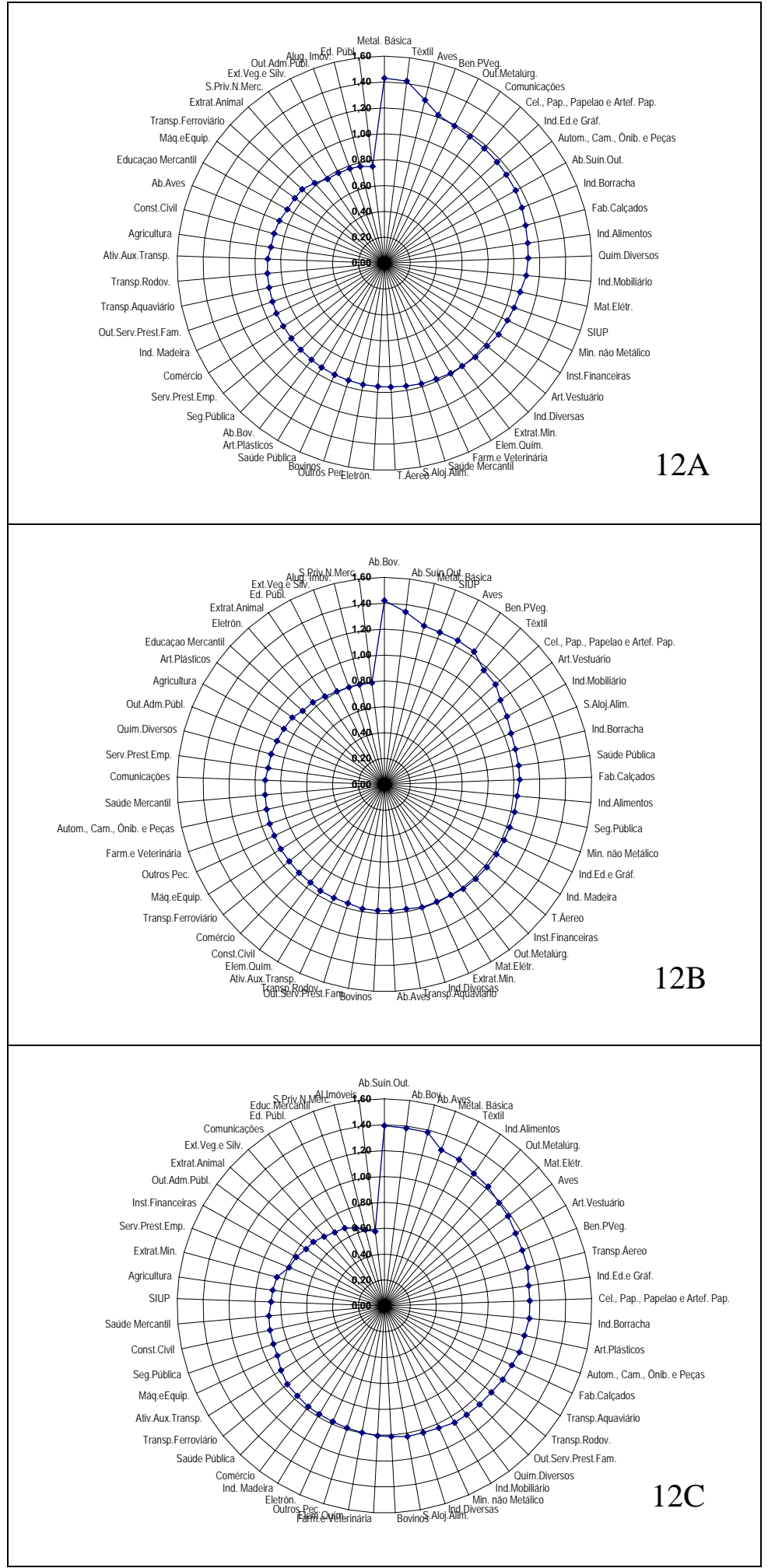

Figura 12 - Índices de ligações para trás de Hirschman-Rasmussen para as regiões Acre, resto do Norte e resto do Brasil - índices dependentes. 
Dessa forma, lançando mão dos índices dependentes para frente e para trás apresentados na Tabela 34 (Anexo) e nas Figuras 11A e 12A, definem-se os setores chave para a economia acreana. Pelo critério estabelecido por Hirschman-Rasmussen, que considera chave os setores com índices para trás ou para frente maiores do que um, encontram-se 38 setores-chave para o Acre: 17 com ligações para frente (Figura 11A) e 21 com ligações para trás (Figura 12A).

Dentre os setores com maiores ligações para frente, os cinco mais expressivos (Tabela 12) são: Comércio, Outros administração pública, Serviços prestados às empresas, Metalurgia básica e Serviços Industriais de Utilidade Pública (S.I.U.P.). Ao passo que, os setores Metalurgia básica, Indústria têxtil, Aves, Beneficiamento de produtos vegetais e Outros metalúrgicos são os que apresentam ligações mais fortes como setores demandantes de insumos (para trás) dos outros setores da economia (Tabela 12).

Tabela 12. Cinco mais importantes setores, de acordo com os índices de ligações intersetoriais de Hirschman-Rasmussen.

\begin{tabular}{|c|c|c|c|c|c|c|}
\hline \multirow[b]{2}{*}{ Setores } & \multicolumn{3}{|c|}{ Para Frente } & \multicolumn{3}{|c|}{ Para Trás } \\
\hline & Acre & $\begin{array}{l}\text { Resto } \\
\text { Norte }\end{array}$ & $\begin{array}{l}\text { Resto } \\
\text { Brasil }\end{array}$ & Acre & $\begin{array}{l}\text { Resto } \\
\text { Norte }\end{array}$ & $\begin{array}{l}\text { Resto } \\
\text { Brasil }\end{array}$ \\
\hline Comércio & 2,483 & 2,212 & 2,548 & & & \\
\hline Outros Administração Pública & 1,768 & & & & & \\
\hline Serviços Prestados à Empresa & 1,652 & 1,664 & & & & \\
\hline Metalurgia Básica & 1,541 & & 1,955 & 1,430 & 1,263 & 1,281 \\
\hline SIUP & 1,467 & 1,991 & 1,822 & & 1,250 & \\
\hline Agricultura & & 1,438 & 2,014 & & & \\
\hline Instituições Financeiras & & 1,270 & & & & \\
\hline Químicos diversos & & & 4,356 & & & \\
\hline Indústria Têxtil & & & & 1,418 & & 1,268 \\
\hline Aves & & & & 1,298 & 1,248 & \\
\hline Beneficiamento de Produtos Vegetais & & & & 1,217 & & \\
\hline Outros Metalúrgicos & & & & 1,189 & & \\
\hline Abate de Bovinos & & & & & 1,421 & 1,383 \\
\hline Abate de Suínos e Outros & & & & & 1,343 & 1,393 \\
\hline Abate de Aves & & & & & & 1,381 \\
\hline
\end{tabular}

É importante destacar que dentre os vinte e um setores com maiores índices para trás, nove apresentam relação direta com o setor primário acreano, seja ele 
agropecuário ou florestal. Dessa forma, os setores Aves e Abate de suínos e outros possuem relação direta com a pecuária acreana. Os setores Indústria têxtil, Beneficiamento de produtos vegetais e Indústria de alimentos são responsáveis pela transformação dos insumos de base agrícola em produtos de maior valor agregado. Já os setores relacionados ao setor florestal que merecem destaque como demandantes de insumos dos demais setores da economia acreana são: Fabricação de celulose, papel, papelão e artefatos de papel - que, no caso específico da economia acreana, contempla apenas empresas relacionadas a fabricação de papel, papelão liso, cartolina e cartão e relacionadas a fabricação de artefatos diversos envolvendo papel, papelão, cartolina e cartão - Indústria editorial e gráfica, Indústria da borracha e Indústria do mobiliário.

Já com relação aos setores acreanos ofertantes de insumos para os demais setores da economia, merecem destaque os seguintes: Agricultura, Indústria de alimentos, Indústria têxtil e Outros pecuária.

Dessas duas constatações, pode-se dizer que em termos de ligações intersetoriais para trás e para frente os setores de base primária acreanos apresentam destaque significativo quando comparados aos demais setores dessa economia.

Através do critério mais restrito de classificação dos setores-chave, estabelecido por McGilvray (1977), tem-se que o número de setores que atendem ao requerimento de índices para trás e para frente maiores do que um, simultaneamente, se reduz consideravelmente nas três regiões (Tabela 13). Dessa forma, a partir desse critério podem ser considerados chave para a economia acreana os setores: Metalurgia básica, Outros metalúrgicos, Químicos diversos, Indústria têxtil, Indústria de alimentos, S.I.U.P., Comunicações e Instituições Financeiras.

Conforme dito anteriormente, no caso do resto do Norte, a Figura 10 indica que as ligações médias para trás $(0,947)$ de seus setores predominam sobre as ligações médias para frente $(0,775)$. Uma análise mais detalhada dos índices dependentes obtidos para essa região, apresentados na Tabela 34 (Anexo) e nas Figuras 11B e 12B, permite identificar 36 setores como chave (22 com ligações para trás e 14 com ligações para frente), através do critério de Hirschman-Rasmussen. 
Tabela 13. Setores-chave de acordo com o critério de McGilvray (1977).

\begin{tabular}{|c|c|c|c|c|c|c|}
\hline \multirow[b]{2}{*}{ Setores } & \multicolumn{3}{|c|}{ Para Frente } & \multicolumn{3}{|c|}{ Para Trás } \\
\hline & Acre & $\begin{array}{l}\text { Resto } \\
\text { Norte }\end{array}$ & $\begin{array}{l}\text { Resto } \\
\text { Brasil }\end{array}$ & Acre & $\begin{array}{l}\text { Resto } \\
\text { Norte }\end{array}$ & $\begin{array}{l}\text { Resto } \\
\text { Brasil }\end{array}$ \\
\hline Metalurgia Básica & 1,541 & 1,149 & 1,955 & 1,430 & 1,263 & 1,281 \\
\hline Indústria Têxtil & 1,174 & 1,256 & 1,395 & 1,418 & 1,170 & 1,268 \\
\hline Outros Metalúrgicos & 1,028 & & 1,138 & 1,189 & & 1,221 \\
\hline Comunicações & 1,284 & & & 1,179 & & \\
\hline Indústria de Alimentos & 1,256 & 1,218 & 1,459 & 1,118 & 1,028 & 1,234 \\
\hline Químicos Diversos & 1,353 & & 4,356 & 1,111 & & 1,054 \\
\hline SIUP & 1,467 & 1,991 & & 1,059 & 1,250 & \\
\hline Instituições Financeiras & 1,359 & 1,270 & & 1,040 & 1,015 & \\
\hline $\begin{array}{l}\text { Fabricação de Celulose, Papel, } \\
\text { Papelão e Artefatos de Papel }\end{array}$ & & & 1,265 & & & 1,122 \\
\hline Transporte Rodoviário & & & 1,158 & & & 1,063 \\
\hline Bovinos & & & 1,071 & & & 1,010 \\
\hline
\end{tabular}

Dentre os setores com fortes ligações para frente, destacam-se: Comércio, S.I.U.P., Serviços prestados às empresas, Agricultura e Instituições financeiras. E, dentre os setores com fortes ligações para trás, os que mais se destacam são: Abate de bovinos, Abate de suínos e outros, Metalurgia básica, S.I.U.P. e Aves (Tabela 12).

Considerando a critério de mais restritivo (McGilvray, 1977), Metalurgia básica, Indústria têxtil, Indústria de alimentos, S.I.U.P. e Instituições Financeiras foram os setores considerados chave para o crescimento da economia da região resto do Norte (Tabela 13).

O resto do Brasil, por sua vez, teve um comportamento dos índices médios diferenciado do Acre e Resto do Norte. Ao contrário dessas duas regiões, o resto do Brasil apresentou índices médios tanto para trás como para frente maiores do que um. No entanto, a média dos índices de ligações para frente foi maior do que a média para trás (Tabela 33, Anexo), o que sugere que seria mais conveniente implantar políticas de desenvolvimento para região através de setores-chave com altos níveis de ligações para frente do que para trás.

Assim, seguindo o critério de Hirschman-Rasmussen, o Resto do Brasil apresenta 46 setores-chave, 28 com ligações para trás e 18 com ligações para frente (Tabela 34 em Anexo e Figuras 11C e 12C). Dessa forma, os setores que mais destacam como ofertantes de insumos para os demais setores da economia são: Químicos diversos, 
Comércio, Agricultura, Metalurgia básica e S.I.U.P. Como demandantes de insumos dos outros setores da economia: Abate de suínos e outros, Abate de aves, Abate de bovinos, Metalurgia básica e Indústria têxtil são os setores que mais se destacam (Tabela 12).

De acordo com o critério mais restrito, estabelecido por McGilvray (1977), os seguintes setores do resto do Brasil podem ser considerados chave: Metalurgia básica, Outros metalúrgicos, Fabricação de celulose, papel, papelão e artefatos de papel, Químicos diversos, Indústria têxtil, Indústria de alimentos, Bovinos e Transporte rodoviário (Tabela 13).

Logo, da análise dos índices de ligações dependentes de HirschmanRasmussen, constata-se que as três economias em questão são bastante diversificadas em termos de números de setores demandantes e ofertantes de insumos. Todavia, os setores Metalurgia básica, Indústria têxtil e Indústria de alimentos são setores-chave nas três regiões (pelo critério de McGilvray) e, portanto, podem ser classificados como os principais setores estimuladores da atividade econômica dessas regiões.

Cabe destacar que o setor metalurgia básica engloba, de acordo com a classificação do IBGE, as atividades relacionadas à siderurgia e metalurgia de metais não ferrosos. O estado do Acre participa apenas na atividade fundição enquanto que o resto do Norte e o resto do Brasil destacam-se, principalmente, nas atividades fundição e metalurgia de não ferrosos.

\subsection{Campo de influência}

É sabido que devido à estrutura do sistema de insumo-produto, mudanças em alguns coeficientes tendem a causar maiores alterações do que se essas mudanças se dessem em outros setores (Hewings et al. (1989).

Os índices de Hirschman-Rasmussen, conforme descrito na seção 3, não mostram os elos de ligações dentro da economia, ou seja, quais seriam os coeficientes que, se alterados, teriam um maior impacto no sistema como um todo. O conceito de Campo de influência, desenvolvido por Sonis e Hewings (1989 e 1995), supera essa 
limitação e complementa a análise dos índices de Hirschman-Rasmussen na medida em que os principais elos de ligação dentro da economia estariam associados aos setores que apresentam os maiores índices de ligações, tanto para frente, como para trás.

Assim, tem-se que as relações domésticas no caso da economia do estado do Acre foram dominadas pelos setores Metalurgia básica e Indústria têxtil, o que indica que variações nos coeficientes desses setores causam maiores mudanças na economia pelo fato desses se relacionarem com todos os setores da economia acreana (Figura 13).

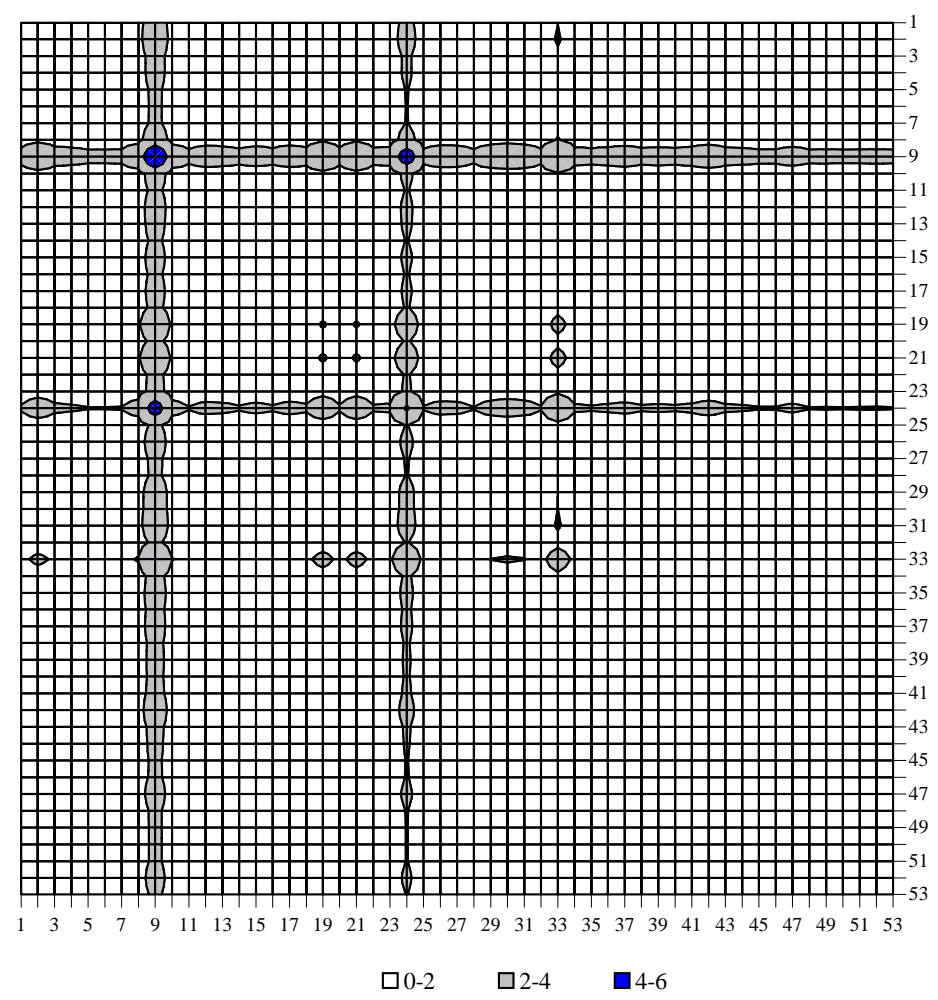

Figura 13 - Coeficientes setoriais com maior campo de influência para o Acre.

No caso do resto do Norte, se destacaram os setores S.I.U.P., Metalurgia básica e Indústria têxtil. No entanto, cabe destacar que desses três, S.I.U.P. foi o único setor que apresentou ligações com todos os setores da economia (Figura 14). 


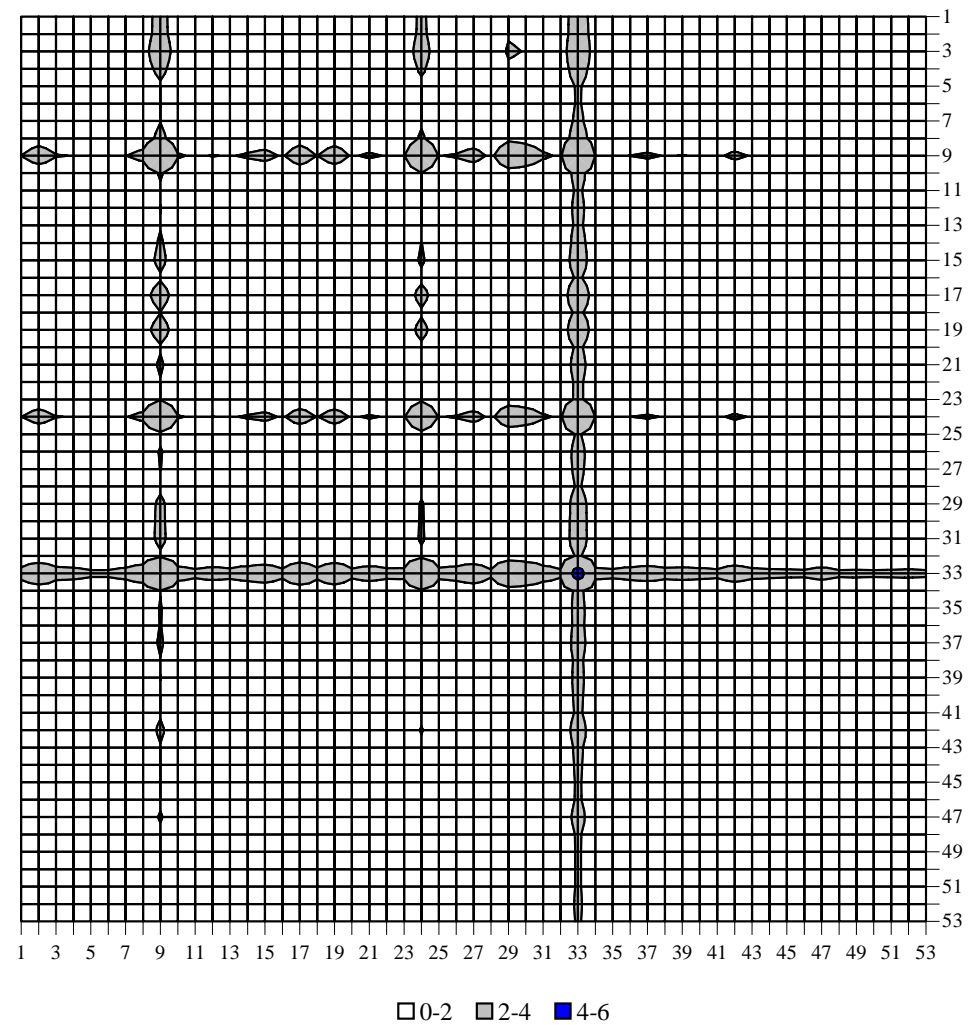

Figura 14 - Coeficientes setoriais com maior campo de influência para o resto do Norte.

O resto do Brasil apresentou um número maior de setores com capacidade de impactar sua economia (Figura 15), dentre os quais merecem destaque: Metalurgia básica, Químicos diversos, Indústria têxtil, S.I.U.P., Fabricação de celulose, pasta mecânica, papel, papelão e artefatos de papel e Indústria da borracha.

Esses setores, que já foram identificados como setores-chave pelos índices de Hirschman-Rasmussen em suas respectivas economias, devem ser considerados também, dentre os setores-chave, como os de maior capacidade intersetorial para afetar os sistemas econômicos. 


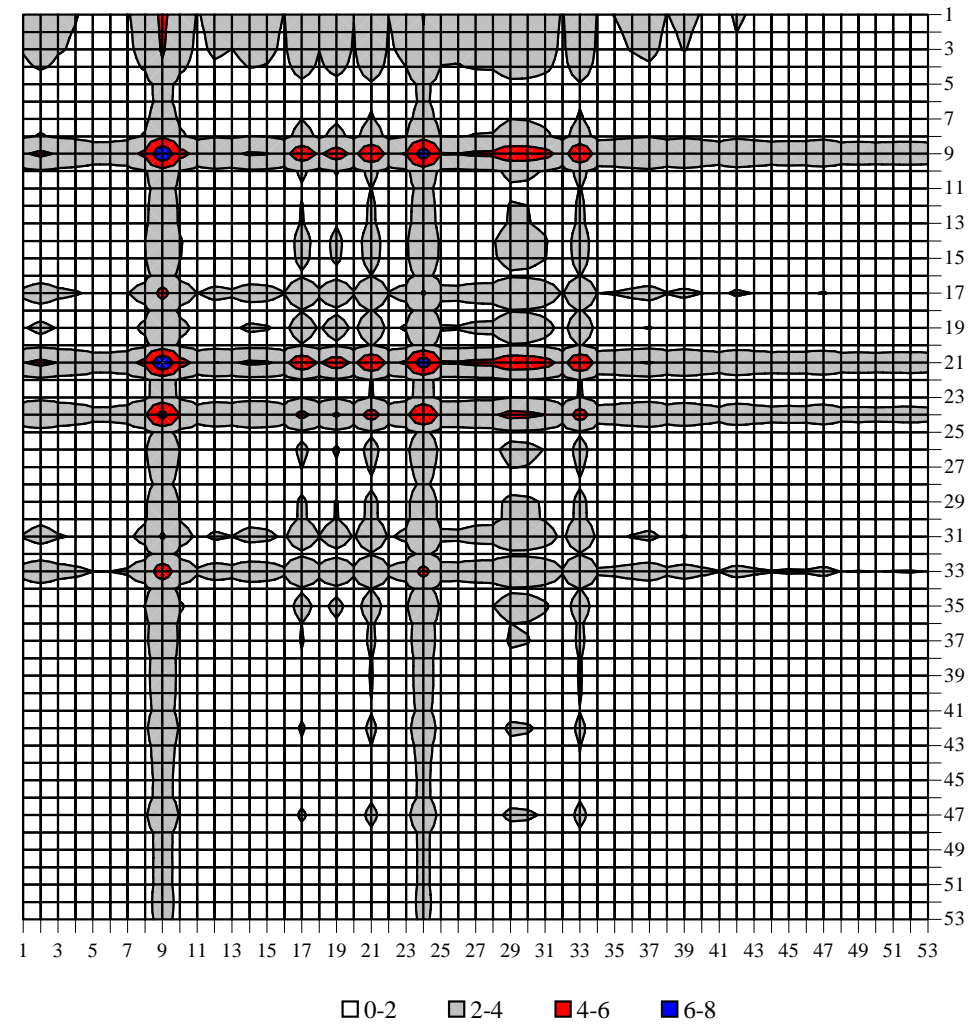

Figura 15 - Coeficientes setoriais com maior campo de influência para o resto do Brasil.

\section{3 Índices puros de ligação}

Os índices puros de ligações para frente revelam o impacto puro da produção total de todos os outros setores da economia sobre um determinado setor. Já os índices puros para trás apontam o impacto puro do valor da produção de um determinado setor sobre o restante da economia. Dessa forma, esses índices medem a importância econômica de um setor, em termos de valor da produção gerado pelo mesmo (Guilhoto et al., 1996).

A análise dos índices puros é complementar a análise dos índices de Hirschman-Rasmussen uma vez que os índices puros levam em consideração os diferentes níveis de produção em cada setor, o que não ocorre no caso dos de Hirschman-Rasmussen. Dessa forma, através da análise dos índices puros é possível 
determinar quais setores são importantes para essas regiões em termos de capacidade de interação inter e intra-setorial e de valor de produção.

Além dos índices puros para trás e para frente descritos anteriormente, é possível obter, também, os índices puros totais, que corresponde à soma dos índices para trás e para frente de cada região. Em geral, para facilitar a análise desses índices, realizase a normalização dos mesmos. Esse procedimento consiste na divisão de cada índice para trás, para frente ou total de uma determinada região pela média de cada um desses índices (para trás, para frente e total) para a região.

Nesta seção serão analisados os índices puros totais normalizados (Tabela 35, Anexo) e os índices para trás e para frente normalizados (Tabela 36, Anexo) obtidos para cada uma das três regiões consideradas no presente estudo. Nesse caso, o critério utilizado para a determinação dos setores-chave corresponde à identificação dos setores cujos valores desses índices sejam superiores a um, o que indica setores com capacidade acima da média de afetar a economia.

Com base nos dados apresentados na Tabela 35 (Anexo), temos que dezessete setores da economia acreana se destacaram como chave. Dentre esses, os principais foram: Comércio, Saúde pública, Construção civil, Serviços prestados às empresas e Outros administração pública (Tabela 14). Ou seja, houve uma alteração significativa em termos de setores-chave para a economia acreana quando se leva em consideração a produção total de cada setor, além das suas relações com os outros setores.

Para região resto do Norte, a Tabela 35 (Anexo) evidencia a presença de dezenove setores-chave para essa economia, dentre os quais destacam-se: Comércio, Construção civil, Serviços prestados às empresas, Outros administração pública e Indústria de alimentos (Tabela 14). 
Tabela 14. Cinco mais importantes setores, de acordo com os índices puros totais normalizados.

\begin{tabular}{lccc}
\hline \multirow{2}{*}{ Setores } & \multicolumn{3}{c}{ Índice puro total } \\
\cline { 2 - 4 } & Acre & Resto do Norte & Resto do Brasil \\
\hline Comércio & 5,766 & 5,619 & 5,427 \\
Saúde Pública & 5,572 & & \\
Construção Civil & 3,903 & 3,374 & 3,142 \\
Serviços Prestados às Empresas & 3,662 & 2,656 & 2,960 \\
Outros Administração Pública & 3,345 & 2,884 & 2,868 \\
Indústria de Alimentos & & 2,582 & \\
Instituições Financeiras & & & 3,360 \\
\hline
\end{tabular}

O resto do Brasil apresentou dezessete setores-chave (Tabela 35, Anexo), dentre os quais destacaram-se: Comércio, Construção civil, Serviços prestados às empresas, Outros administração pública e Instituições financeiras (Tabela 14).

A Tabela 36 (Anexo) apresenta os índices puros para frente e para trás normalizados obtidos para todos os setores das três regiões que compõem o sistema inter-regional. Cabe destacar que esses índices foram calculados de maneira dependente, ou seja, considerando o sistema inter-regional como uma única região, mas levando em conta a importância dos setores para cada umas das regiões individualmente.

Para a identificação dos setores-chave, foi construída a Tabela 15 que trás os cinco setores que mais se destacaram em cada uma das regiões e as Figuras 16 e 17 que trazem, respectivamente, os índices puros para frente e para trás normalizados e calculados para todos os setores de cada uma das regiões do sistema inter-regional. 
Tabela 15. Cinco setores mais importantes, de acordo com os índices puros para trás e para frente normalizados.

\begin{tabular}{|c|c|c|c|c|c|c|}
\hline \multirow[b]{2}{*}{ Setores } & \multicolumn{3}{|c|}{ Para Frente } & \multicolumn{3}{|c|}{ Para Trás } \\
\hline & Acre & $\begin{array}{l}\text { Resto } \\
\text { Norte }\end{array}$ & $\begin{array}{l}\text { Resto } \\
\text { Brasil }\end{array}$ & Acre & $\begin{array}{l}\text { Resto } \\
\text { Norte }\end{array}$ & $\begin{array}{l}\text { Resto } \\
\text { Brasil }\end{array}$ \\
\hline Serviços Prestados às Empresas & 7,390 & 5,219 & 5,559 & & & \\
\hline Comércio & 7,365 & 8,179 & 7,235 & 4,171 & 3,064 & \\
\hline Outros Adm. Pública & 3,781 & 4,083 & 4,226 & 2,910 & & \\
\hline Outros Serv. Prestados às Famílias & 3,739 & & & & & \\
\hline Serv. Alojamento e Alimentação & 2,664 & & & & & \\
\hline Agricultura & & 2,680 & 3,685 & & & \\
\hline Transporte Rodoviário & & 2,659 & & & & \\
\hline Comunicações & & & 2,495 & & & \\
\hline Saúde Pública & & & & 11,120 & & \\
\hline Construção Civil & & & & 6,016 & 5,359 & 4,441 \\
\hline Segurança Pública & & & & 3,330 & & \\
\hline Outros Pecuária & & & & & 3,558 & \\
\hline Indústria de Alimentos & & & & & 3,346 & 4,057 \\
\hline Automóves, Caminhões, Ônibus e Peças & & & & & 3,201 & 3,859 \\
\hline Instituições Financeiras & & & & & & 4,315 \\
\hline Benef. de Produtos Vegetais & & & & & & 4,165 \\
\hline
\end{tabular}

Assim, os dados apresentados na Tabela 15 mostram que o impacto puro da produção total de todos os outros setores (índice para frente) é maior nos setores Serviços prestados às empresas, Comércio e Outros administração pública tanto da economia acreana (Figura 16A), quanto das economias formadas pelo resto do Norte (Figura 16B) resto do Brasil (Figura 16C). Merecem destaque, ainda, os setores Outros Serviços prestados às famílias e Serviços de alojamento e alimentação para a economia acreana; Agricultura para as economias do resto do Norte e do Brasil; Transporte rodoviário para a economia do resto do Norte e Comunicações para o resto do Brasil.

Da Tabela 15 também se obtém os setores cujo valor da produção total tem maior capacidade de impactar a economia como um todo. Nesse caso, os setores acreanos que mais se destacaram foram: Saúde pública, Construção civil, Comércio, Segurança pública e Outros administração pública (Figura 17A). 


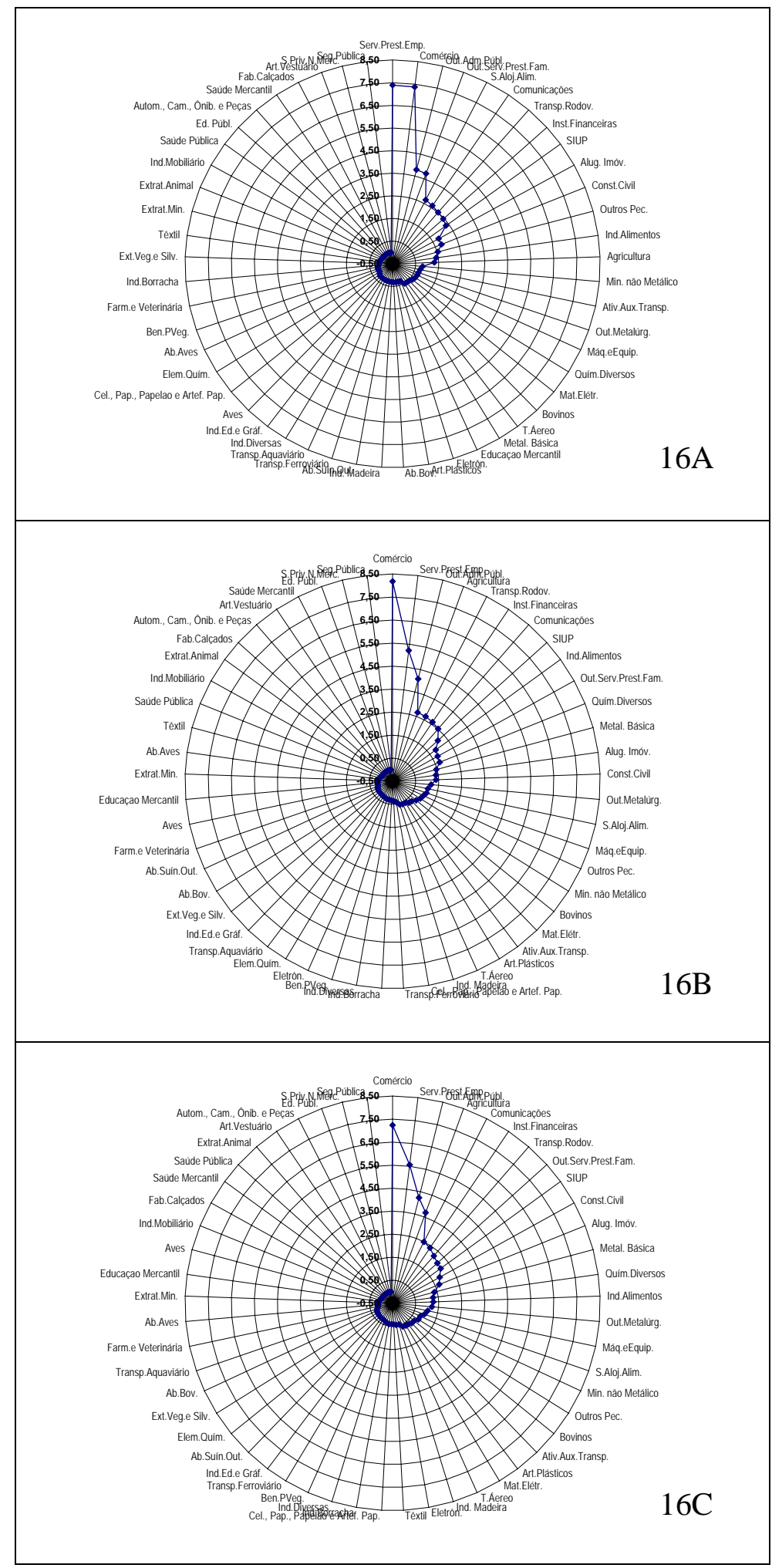

Figura 16 - Indices puros de ligações normalizados para frente para as regiões Acre, resto do Norte e resto do Brasil - índices dependentes. 


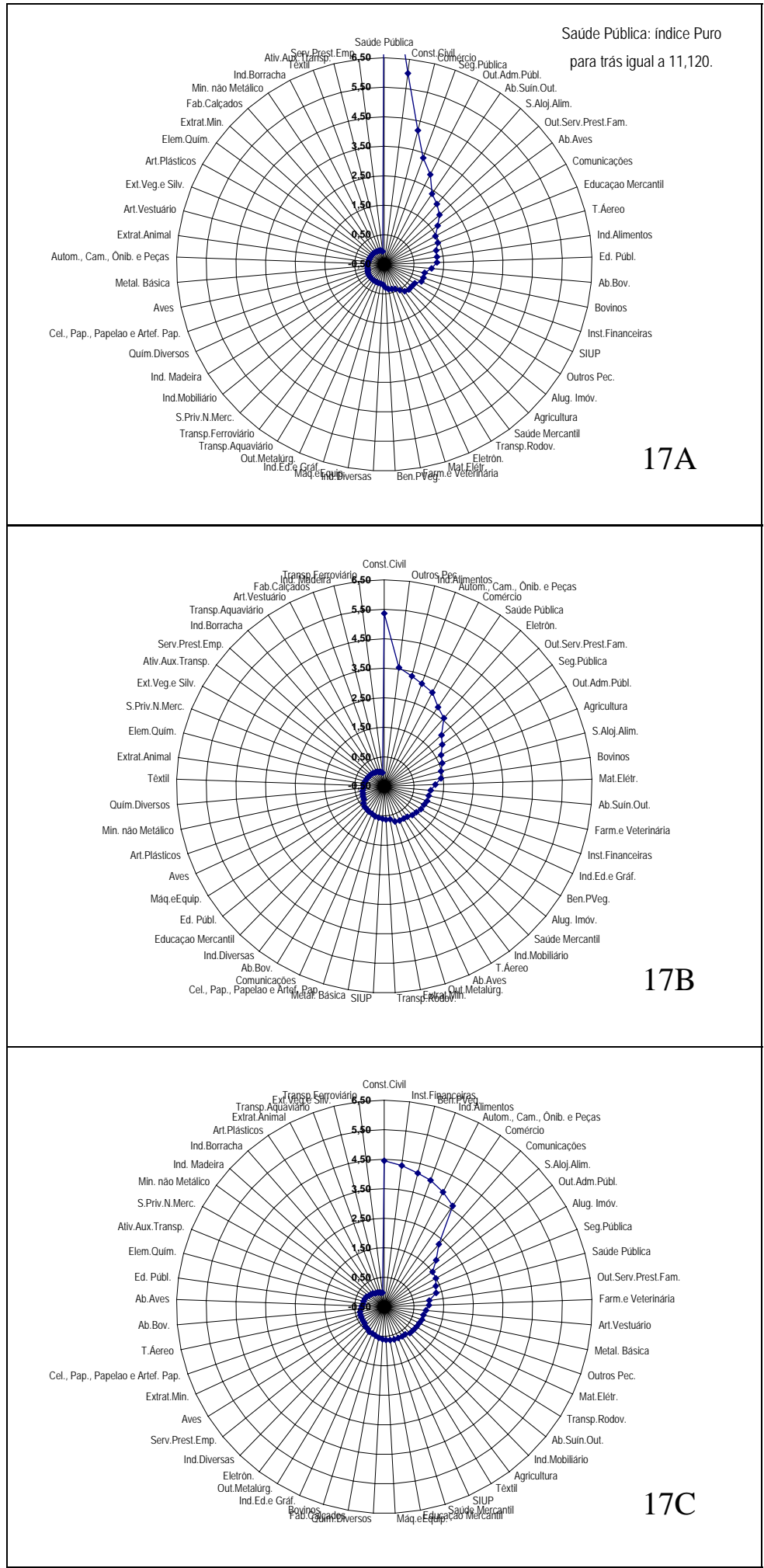

Figura 17 - Indices puros de ligações normalizados para trás para as regiões Acre, resto do Norte e resto do Brasil - índices dependentes. 
No resto do Norte merecem destaque: Construção civil, Outros pecuária, Indústria de alimentos, Automóves, Caminhões, Ônibus e Peças, e Comércio (Figura 17B). Já no resto do Brasil os setores Construção civil, Instituições financeiras, Beneficiamento de produtos vegetais, Indústria de alimentos e Automóves, Caminhões, Ônibus e Peças foram os que se destacaram nos índices puros para trás normalizados (Figura 17C).

Uma vez que os índices de Hirschman-Rasmussen e puros de ligações intersetoriais analisados até então são complementares para a identificação dos setoreschave, a Figura 18 foi elaborado com o intuito de permitir uma análise consolidada desses dois índices de modo que ambos sejam comparados e, assim, sejam determinados os setores efetivamente importantes para cada uma das regiões consideradas no presente estudo.

Da Figura 18 tem-se que o Acre apresentou quatro setores-chave sob os dois enfoques: Indústria de alimentos, SIUP, Comunicações e Instituições Financeiras. Para o resto do Norte temos os seguintes setores-chave: Metalurgia básica, Indústria de alimentos, SIUP e Instituições Financeiras. E, para o resto do Brasil: Metalurgia básica Indústria de alimentos e Transporte rodoviário.

Assim, temos que, de acordo com o critério estabelecido nessa consolidação de índices, apenas o setor Indústria de alimentos pode ser considerado chave para as três regiões, simultaneamente. Os setores Instituições financeiras e SIUP são chave para o Acre e resto do Norte e, o setor Metalurgia básica é chave para o resto do Norte e resto do Brasil.

Se considerarmos aqueles setores que se destacaram nas três regiões estudadas, contudo, levando-se em conta cada índice separadamente, merecem destaque segundo o índice puro de ligação: Agricultura, Indústria de alimentos, SIUP, Construção civil, Comércio, Transporte rodoviário, Comunicações, Instituições financeiras, Serviços de alojamento e alimentação, Outros serviços prestados às famílias, Serviços prestados às empresas, Aluguel de imóveis e Outros administração pública. Segundo o índice de Hirschman-Rasmussen, são comuns às três regiões apenas os setores: Metalurgia básica, Indústria têxtil e Indústria de alimentos. 


\begin{tabular}{|c|c|c|c|c|c|c|c|}
\hline \multirow{2}{*}{\multicolumn{2}{|c|}{ Setores }} & \multicolumn{2}{|c|}{ Acre } & \multicolumn{2}{|c|}{ Resto do Norte } & \multicolumn{2}{|c|}{ Resto do Brasil } \\
\hline & & $\mathrm{H} D$ & & 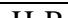 & Dum & $H$ & Dum \\
\hline 1 & Agricultura & & $\mathrm{x}$ & & $\mathrm{x}$ & & $\mathrm{x}$ \\
\hline 3 & Bovinos & & & & $\mathrm{x}$ & $\mathrm{x}$ & \\
\hline 4 & Outros Pecuária & & $\mathrm{x}$ & & $\mathrm{x}$ & & \\
\hline 9 & Metalurgia Básica & $\mathrm{x}$ & & $\mathrm{x}$ & $\mathrm{x}$ & $\mathrm{x}$ & $\mathrm{x}$ \\
\hline 10 & Outros Metalúrgicos & $\mathrm{x}$ & & & & $\mathrm{X}$ & \\
\hline 13 & Equipamentos Eletrônicos & & & & $\mathrm{x}$ & & \\
\hline 14 & Automóveis, Caminhões, Ônibus e Peças & & & & $\mathrm{x}$ & & $\mathrm{x}$ \\
\hline 17 & Celulose, Papel, Papelão e Artefatos de Papel & & & & & $\mathrm{x}$ & \\
\hline 21 & Químicos diversos & $\mathrm{x}$ & & & & $\mathrm{X}$ & \\
\hline 24 & Indústria Têxtil & $\mathrm{x}$ & & $\mathrm{x}$ & & $\mathrm{x}$ & \\
\hline 27 & Beneficiamento de Produtos Vegetais & & & & & & $\mathrm{x}$ \\
\hline 30 & Ab. Suínos e Outros & & $\mathrm{x}$ & & & & \\
\hline 31 & Indústria Alimentos & $\mathrm{x}$ & $\mathrm{x}$ & $\mathrm{X}$ & $\mathrm{x}$ & $\mathrm{X}$ & $\mathrm{x}$ \\
\hline 33 & SIUP & $\mathrm{x}$ & $\mathrm{x}$ & $\mathrm{X}$ & $\mathrm{x}$ & & $\mathrm{x}$ \\
\hline 34 & Construção Civil & & $\mathrm{x}$ & & $\mathrm{x}$ & & $\mathrm{x}$ \\
\hline 35 & Comércio & & $\mathrm{x}$ & & $\mathrm{x}$ & & $\mathrm{x}$ \\
\hline 36 & Transporte Rodoviário & & $\mathrm{x}$ & & $\mathrm{x}$ & $\mathrm{x}$ & $\mathrm{x}$ \\
\hline 41 & Comunicações & $\mathrm{x}$ & $\mathrm{x}$ & & $\mathrm{x}$ & & $\mathrm{x}$ \\
\hline 42 & Instituições Financeiras & $\mathrm{x}$ & $\mathrm{x}$ & $\mathrm{x}$ & $\mathrm{x}$ & & $\mathrm{x}$ \\
\hline 45 & Serviços de Alojamento e Alimentação & & $\mathrm{x}$ & & $\mathrm{x}$ & & $\mathrm{x}$ \\
\hline 46 & Outros Serv. Prestados às Famílias & & $\mathrm{x}$ & & $\mathrm{x}$ & & $\mathrm{x}$ \\
\hline 47 & Serviços Prestados à Empresa & & $\mathrm{x}$ & & $\mathrm{x}$ & & $\mathrm{x}$ \\
\hline 48 & Aluguel de Imóveis & & $\mathrm{x}$ & & $\mathrm{x}$ & & $\mathrm{x}$ \\
\hline 49 & Saúde Pública & & $\mathrm{x}$ & & $\mathrm{x}$ & & \\
\hline 51 & Segurança Pública & & $\mathrm{x}$ & & & & \\
\hline 52 & Outros Administração Pública & & $\mathrm{x}$ & & $\mathrm{x}$ & & $\mathrm{x}$ \\
\hline
\end{tabular}

Figura 18 - Setores-chave consolidados no sistema inter-regional: critério do índice puro total de ligação maior que um e critério mais restritivo dos índices de Hirschman-Rasmussen. 


\subsubsection{Interação entre as regiões do sistema inter-regional}

Através dos resultados obtidos da aplicação do método desenvolvido por Guilhoto, Sonis e Hewings (1996), descrito na seção 3.1.6, é possível analisar a interação entre as regiões Acre, resto do Norte e resto do Brasil.

De acordo com esse método, a produção total de uma região pode ser decomposta em produção induzida pela demanda final da própria região e produção induzida pela demanda final das demais regiões do sistema econômico. Dessa forma, um aumento na demanda final por produtos de determinados setores do Acre, por exemplo, provoca aumentos diretos e indiretos na produção dos setores dessa região e também dos setores das outras regiões com as quais o estado mantém relações comerciais.

Assim, os setores do Acre cuja produção sofreu aumento direto induzem os setores que lhe fornecem insumos, localizados na própria região ou em outras regiões, a também aumentarem suas produções. Dessa forma, os setores localizados em regiões diferentes daquela onde houve o aumento na produção também passam a produzir mais e tem a sua demanda por insumos, da própria região e de outras regiões também aumentada.

A Tabela 16 traz a decomposição da produção total do Acre, resto do Norte e resto do Brasil em produção induzida pela demanda final da própria região e induzida pela demanda final das demais regiões.

Tabela 16. Produção das regiões: Acre, resto do Norte e resto do Brasil induzida pela demanda final da própria região e das outras regiões do sistema interregional, em bilhões de reais de 1999.

\begin{tabular}{|c|c|c|c|c|c|}
\hline \multirow{2}{*}{ Regiões } & \multicolumn{4}{|c|}{ Valor da produção da região induzido pela demanda final } & \multirow{2}{*}{$\begin{array}{c}\text { Produção } \\
\text { Total }\end{array}$} \\
\hline & da própria região & $\%$ & de outras regiões & $\%$ & \\
\hline Acre & 2,20 & 95,95 & 0,09 & 4,05 & 2,30 \\
\hline Resto do Norte & 56,09 & 79,64 & 14,34 & 20,36 & 70,43 \\
\hline Resto do Brasil & $1.617,40$ & 99,09 & 14,90 & 0,91 & $1.632,30$ \\
\hline
\end{tabular}


As informações apresentadas na Tabela 16 mostram que das três regiões, a região resto do Norte é a que apresenta maior integração com as demais regiões do sistema. Isso é evidenciado pelos 14,341 bilhões de reais (20,36\%) de sua produção total que são gerados para atender a demanda final do Acre e resto do Brasil.

No Acre, 95,95\% de sua produção total, de 2,296 bilhões de reais, é induzida pela sua própria demanda final. Assim, temos que um aumento na demanda final do Acre causa maior impacto na produção dos setores localizados dentro da própria região do que na produção dos setores localizados nas regiões resto do Norte e resto do Brasil, o que sugere uma pequena interação desse estado com as demais regiões do sistema. E, 4,05\% da produção do Acre depende da produção que é realizada nas outras regiões (resto do Norte e do Brasil).

Na região resto do Brasil, esse valor chega a 99,09\% o evidencia a pequena influência que as demandas finais das regiões Acre e resto do Norte exercem sobre produção total do resto do Brasil.

Tabela 17. Importância do Acre, resto do Norte e resto do Brasil na indução da produção do sistema inter-regional, valores em bilhões de 1999.

\begin{tabular}{|c|c|c|c|c|c|c|}
\hline \multirow{2}{*}{ Regiões } & \multicolumn{4}{|c|}{$\begin{array}{c}\text { Valor da produção nas regiões induzido pela } \\
\text { demanda final }\end{array}$} & \multirow{2}{*}{$\begin{array}{l}\text { Produção } \\
\text { Total }\end{array}$} & \multirow{2}{*}{$\%$} \\
\hline & $\begin{array}{l}\text { das próprias } \\
\text { regiões }\end{array}$ & $\%$ & da região $j$ & $\%$ & & \\
\hline $\begin{array}{l}\text { Resto do Norte e } \\
\text { Resto do Brasil }\end{array}$ & $1.702,04$ & 99,96 & 0,69 & 0,04 & $1.702,73$ & 49,93 \\
\hline $\begin{array}{l}\text { Acre e } \\
\text { Resto do Brasil }\end{array}$ & $1.620,33$ & 99,13 & 14,27 & 0,87 & $1.634,60$ & 47,93 \\
\hline $\begin{array}{l}\text { Acre e } \\
\text { Resto do Norte }\end{array}$ & 58,35 & 80,23 & 14,38 & 19,77 & 72,73 & 2,13 \\
\hline Total & & & & & $3.410,05$ & 100,00 \\
\hline
\end{tabular}

Na Tabela 17 a produção total é decomposta em outros dois componentes que permitem a identificação: a) do valor da produção total das regiões resto do Norte e resto do Brasil que é devido à demanda final do Acre e à demanda final dessas duas regiões; 
b) do valor da produção do Acre e resto do Brasil que é devido à demanda final do resto do Norte e devido à demanda dessas duas regiões; e c) do valor da produção do Acre e resto do Norte que é decorrente da demanda final do resto do Brasil e da demanda final dessas duas regiões. Tem-se com isso, a importância de cada região como indutora da produção das demais regiões do sistema.

Assim, dos dados apresentados na Tabela 17 tem-se 0,04\% do que acontece de produção no resto do Norte e resto do Brasil depende do Acre; 0,87\% da produção do Acre e resto do Brasil depende do resto do Norte e, 19,77\% do que acontece de produção no Acre e resto do Norte depende do resto do Brasil. O restante da produção gerada nessas regiões visam o atendimento às suas próprias demandas finais.

As informações apresentadas nas Tabelas 16 e 17 apontam uma baixa ligação entre todas as regiões do sistema inter-regional.

\subsection{Multiplicadores tipo I e tipo II}

Os multiplicadores setoriais de produção, de emprego, de renda e de importação calculados no presente trabalho permitem a obtenção de uma resposta para a seguinte pergunta: qual o impacto sobre a economia (em termos de geração de produção, de emprego, de renda e de importação) de uma mudança na demanda por produtos dos diferentes setores? Os multiplicadores respondem a essa pergunta, separando o impacto em direto (sobre o setor que sofreu aumento na demanda) e indireto (sobre os demais setores da economia que fornecem insumos para o setor diretamente afetado pela variação na demanda).

Dois tipos de multiplicadores foram calculados para as regiões Acre, resto do Norte e resto do Brasil: os multiplicadores do tipo I que consideram exogenamente o consumo das famílias no sistema e os multiplicadores do tipo II que endogenizam o consumo das famílias. 


\section{Multiplicador de produção}

O multiplicador de produção mostra quanto cada setor gera de produção no próprio setor e nos demais setores, dado uma unidade de aumento na demanda final.

Tabela 18. Multiplicadores de produção setoriais para o Acre.

\begin{tabular}{|c|c|c|c|c|c|c|c|c|c|}
\hline \multirow{2}{*}{\multicolumn{2}{|c|}{ Setores }} & \multicolumn{4}{|c|}{ Multiplicadores Tipo I } & \multicolumn{4}{|c|}{ Multiplicadores Tipo II } \\
\hline & & Acre & $\begin{array}{c}\text { Resto } \\
\text { do } \\
\text { Norte }\end{array}$ & $\begin{array}{c}\text { Resto } \\
\text { do } \\
\text { Brasil }\end{array}$ & Total & Acre & $\begin{array}{c}\text { Resto } \\
\text { do } \\
\text { Norte }\end{array}$ & $\begin{array}{c}\text { Resto } \\
\text { do } \\
\text { Brasil }\end{array}$ & Total \\
\hline 1 & Agricultura & 1,214 & 0,025 & 0,299 & 1,538 & 1,296 & 0,048 & 0,644 & 1,987 \\
\hline 2 & Aves & 1,784 & 0,017 & 0,415 & 2,216 & 1,988 & 0,051 & 1,008 & 3,047 \\
\hline 3 & Bovinos & 1,302 & 0,041 & 0,552 & 1,894 & 1,362 & 0,072 & 1,042 & 2,476 \\
\hline 4 & Outros Pecuária & 1,309 & 0,034 & 0,521 & 1,864 & 1,382 & 0,064 & 1,026 & 2,472 \\
\hline 5 & Ext. Veg. e Silv. & 1,076 & 0,012 & 0,233 & 1,320 & 1,077 & 0,021 & 0,413 & 1,511 \\
\hline 6 & Ext. Animal & 1,128 & 0,010 & 0,241 & 1,379 & 1,130 & 0,018 & 0,398 & 1,545 \\
\hline 7 & Ext.Mineral & 1,370 & 0,016 & 0,299 & 1,686 & 1,552 & 0,046 & 0,790 & 2,388 \\
\hline 8 & Min. não Metálico & 1,441 & 0,011 & 0,259 & 1,711 & 1,770 & 0,052 & 0,930 & 2,752 \\
\hline 9 & Metal. Básica & 1,964 & 0,021 & 0,397 & 2,382 & 2,063 & 0,045 & 0,822 & 2,930 \\
\hline 10 & Outros Metalúrg. & 1,634 & 0,017 & 0,453 & 2,104 & 1,906 & 0,056 & 1,122 & 3,085 \\
\hline 11 & Máq. e Equip. & 1,174 & 0,008 & 0,158 & 1,341 & 1,342 & 0,030 & 0,508 & 1,879 \\
\hline 12 & Mat. Elétrico & 1,472 & 0,041 & 0,740 & 2,253 & 1,656 & 0,083 & 1,457 & 3,196 \\
\hline 13 & Equip. Eletrôn. & 1,310 & 0,032 & 0,338 & 1,680 & 1,439 & 0,061 & 0,762 & 2,262 \\
\hline 14 & Aut., Cam., Ôn. e Peças & 1,597 & 0,060 & 0,407 & 2,064 & 1,801 & 0,104 & 0,983 & 2,888 \\
\hline 15 & Ind. da Madeira & 1,263 & 0,019 & 0,205 & 1,488 & 1,509 & 0,055 & 0,737 & 2,301 \\
\hline 16 & Ind. do Mobiliário & 1,510 & 0,017 & 0,295 & 1,823 & 1,804 & 0,058 & 0,945 & 2,807 \\
\hline 17 & Cel.,Pap.,Papelão e Art. Pap. & 1,614 & 0,010 & 0,230 & 1,855 & 2,007 & 0,057 & 0,984 & 3,047 \\
\hline 18 & Ind. Ed. e Gráfica & 1,606 & 0,011 & 0,243 & 1,860 & 1,979 & 0,055 & 0,973 & 3,007 \\
\hline 19 & Ind. da Borracha & 1,572 & 0,015 & 0,468 & 2,055 & 1,688 & 0,039 & 0,928 & 2,655 \\
\hline 20 & Elem. Químicos & 1,365 & 0,010 & 0,221 & 1,596 & 1,425 & 0,023 & 0,465 & 1,913 \\
\hline 21 & Quím. diversos & 1,527 & 0,021 & 0,526 & 2,073 & 1,703 & 0,054 & 1,121 & 2,877 \\
\hline 22 & Farm. e Veterin. & 1,350 & 0,013 & 0,266 & 1,629 & 1,499 & 0,037 & 0,665 & 2,201 \\
\hline 23 & Art. Plásticos & 1,293 & 0,016 & 0,666 & 1,976 & 1,520 & 0,055 & 1,406 & 2,981 \\
\hline 24 & Ind. Têxtil & 1,948 & 0,016 & 0,445 & 2,409 & 2,139 & 0,048 & 1,022 & 3,209 \\
\hline 25 & Art. do Vestuário & 1,400 & 0,022 & 0,528 & 1,950 & 1,889 & 0,084 & 1,556 & 3,529 \\
\hline 26 & Fab. Calçados & 1,550 & 0,018 & 0,277 & 1,845 & 1,802 & 0,053 & 0,845 & 2,700 \\
\hline 27 & Benef. de Prod.Veg. & 1,673 & 0,018 & 0,281 & 1,972 & 1,818 & 0,045 & 0,709 & 2,572 \\
\hline 28 & Abate de Aves & 1,201 & 0,073 & 1,093 & 2,367 & 1,291 & 0,124 & 1,948 & 3,362 \\
\hline 29 & Abate de Bovinos & 1,284 & 0,213 & 0,972 & 2,468 & 1,372 & 0,323 & 1,926 & 3,620 \\
\hline 30 & Ab. Suínos e Outros & 1,592 & 0,100 & 0,818 & 2,510 & 1,709 & 0,166 & 1,656 & 3,532 \\
\hline 31 & Ind. Alimentos & 1,536 & 0,023 & 0,534 & 2,093 & 1,712 & 0,059 & 1,178 & 2,950 \\
\hline 32 & Ind. Diversas & 1,386 & 0,027 & 0,344 & 1,758 & 1,626 & 0,066 & 0,928 & 2,620 \\
\hline 33 & SIUP & 1,455 & 0,031 & 0,721 & 2,207 & 1,715 & 0,083 & 1,665 & 3,463 \\
\hline 34 & Constr. Civil & 1,211 & 0,049 & 0,551 & 1,811 & 1,340 & 0,089 & 1,126 & 2,555 \\
\hline 35 & Comércio & 1,265 & 0,015 & 0,537 & 1,817 & 1,739 & 0,077 & 1,605 & 3,422 \\
\hline 36 & Transp. Rodov. & 1,245 & 0,021 & 0,538 & 1,804 & 1,672 & 0,079 & 1,510 & 3,261 \\
\hline 37 & Transp. Aéreo & 1,316 & 0,026 & 0,598 & 1,941 & 1,718 & 0,085 & 1,588 & 3,392 \\
\hline 38 & Transp. Ferrov. & 1,173 & 0,018 & 0,296 & 1,487 & 1,635 & 0,074 & 1,192 & 2,902 \\
\hline 39 & Transp. Aquav. & 1,248 & 0,019 & 0,479 & 1,746 & 1,563 & 0,065 & 1,257 & 2,885 \\
\hline 40 & Ativ. Aux. Transp. & 1,239 & 0,013 & 0,240 & 1,493 & 1,758 & 0,072 & 1,176 & 3,006 \\
\hline 41 & Comunicações & 1,620 & 0,029 & 0,408 & 2,057 & 2,010 & 0,084 & 1,286 & 3,381 \\
\hline 42 & Inst. Financeiras & 1,429 & 0,006 & 0,091 & 1,527 & 1,956 & 0,062 & 0,953 & 2,971 \\
\hline 43 & Saúde Mercantil & 1,341 & 0,024 & 0,373 & 1,739 & 1,958 & 0,101 & 1,575 & 3,634 \\
\hline 44 & Educ.Mercantil & 1,175 & 0,007 & 0,093 & 1,275 & 1,997 & 0,093 & 1,417 & 3,507 \\
\hline 45 & Serv. Aloj.eAlim. & 1,325 & 0,055 & 0,688 & 2,069 & 1,679 & 0,121 & 1,694 & 3,494 \\
\hline 46 & Out.Serv. Prest. a Fam. & 1,255 & 0,060 & 0,771 & 2,085 & 1,576 & 0,123 & 1,748 & 3,446 \\
\hline 47 & Serv. Prest. à Empresa & 1,269 & 0,012 & 0,159 & 1,440 & 1,860 & 0,078 & 1,176 & 3,114 \\
\hline 48 & Aluguel de Imóveis & 1,058 & 0,002 & 0,028 & 1,088 & 1,019 & 0,000 & $-0,012$ & 1,007 \\
\hline 49 & Saúde Pública & 1,297 & 0,028 & 0,345 & 1,671 & 1,957 & 0,110 & 1,604 & 3,671 \\
\hline 50 & Educ. Pública & 1,035 & 0,004 & 0,047 & 1,086 & 1,919 & 0,093 & 1,422 & 3,433 \\
\hline 51 & Seg. Pública & 1,279 & 0,022 & 0,253 & 1,553 & 1,992 & 0,105 & 1,536 & 3,634 \\
\hline 52 & Out.Adm. Pública & 1,070 & 0,004 & 0,054 & 1,129 & 1,940 & 0,092 & 1,416 & 3,448 \\
\hline 53 & Serv. Priv. N. Mercantis & 1,076 & 0,005 & 0,072 & 1,153 & 1,924 & 0,091 & 1,408 & 3,422 \\
\hline
\end{tabular}


As Tabelas 18, 19 e 20 apresentam os multiplicadores de produção, tipo I e II, para as três regiões do sistema inter-regional.

Tabela 19. Multiplicadores de produção para o resto do Norte.

\begin{tabular}{|c|c|c|c|c|c|c|c|c|c|}
\hline \multirow{2}{*}{\multicolumn{2}{|c|}{ Setores }} & \multicolumn{4}{|c|}{ Multiplicadores Tipo I } & \multicolumn{4}{|c|}{ Multiplicadores Tipo II } \\
\hline & & Acre & $\begin{array}{l}\text { Resto } \\
\text { do } \\
\text { Norte }\end{array}$ & $\begin{array}{l}\text { Resto } \\
\text { do } \\
\text { Brasil }\end{array}$ & Total & Acre & $\begin{array}{l}\text { Resto } \\
\text { do } \\
\text { Norte }\end{array}$ & $\begin{array}{l}\text { Resto } \\
\text { do } \\
\text { Brasil }\end{array}$ & Total \\
\hline 1 & Agricultura & 0,000 & 1,181 & 0,313 & 1,494 & 0,001 & 1,751 & 1,287 & 3,038 \\
\hline 2 & Aves & 0,000 & 1,664 & 0,487 & 2,152 & 0,001 & 2,163 & 1,463 & 3,626 \\
\hline 3 & Bovinos & 0,000 & 1,302 & 0,563 & 1,865 & 0,001 & 1,813 & 1,618 & 3,432 \\
\hline 4 & Outros Pecuária & 0,000 & 1,250 & 0,560 & 1,810 & 0,001 & 1,745 & 1,626 & 3,372 \\
\hline 5 & Ext. Veg. e Silv. & 0,000 & 1,065 & 0,213 & 1,278 & 0,001 & 1,647 & 1,152 & 2,799 \\
\hline 6 & Ext. Animal & 0,000 & 1,095 & 0,247 & 1,342 & 0,001 & 1,639 & 1,137 & 2,776 \\
\hline 7 & Ext.Mineral & 0,000 & 1,326 & 0,387 & 1,713 & 0,001 & 1,832 & 1,328 & 3,161 \\
\hline 8 & Min. não Metálico & 0,000 & 1,363 & 0,243 & 1,606 & 0,001 & 1,888 & 1,102 & 2,990 \\
\hline 9 & Metal. Básica & 0,000 & 1,684 & 0,297 & 1,981 & 0,000 & 2,079 & 1,018 & 3,097 \\
\hline 10 & Outros Metalúrg. & 0,000 & 1,347 & 0,692 & 2,039 & 0,001 & 1,780 & 1,615 & 3,396 \\
\hline 11 & Máq. e Equip. & 0,000 & 1,256 & 0,227 & 1,483 & 0,001 & 1,806 & 1,093 & 2,899 \\
\hline 12 & Mat. Elétrico & 0,000 & 1,329 & 0,492 & 1,821 & 0,001 & 1,683 & 1,247 & 2,930 \\
\hline 13 & Equip. Eletrôn. & 0,000 & 1,122 & 0,163 & 1,285 & 0,000 & 1,456 & 0,716 & 2,173 \\
\hline 14 & Aut., Cam., Ôn. e Peças & 0,000 & 1,239 & 0,463 & 1,702 & 0,001 & 1,589 & 1,198 & 2,788 \\
\hline 15 & Ind. da Madeira & 0,000 & 1,359 & 0,352 & 1,711 & 0,001 & 1,952 & 1,412 & 3,365 \\
\hline 16 & Ind. do Mobiliário & 0,000 & 1,442 & 0,374 & 1,816 & 0,001 & 1,960 & 1,328 & 3,289 \\
\hline 17 & Cel.,Pap.,Papelão e Art. Pap. & 0,000 & 1,539 & 0,276 & 1,815 & 0,001 & 2,115 & 1,239 & 3,354 \\
\hline 18 & Ind. Ed. e Gráfica & 0,000 & 1,360 & 0,519 & 1,879 & 0,001 & 1,821 & 1,497 & 3,319 \\
\hline 19 & Ind. da Borracha & 0,000 & 1,395 & 0,383 & 1,778 & 0,000 & 1,735 & 1,064 & 2,800 \\
\hline 20 & Elem. Químicos & 0,000 & 1,278 & 0,191 & 1,469 & 0,000 & 1,729 & 0,914 & 2,643 \\
\hline 21 & Quím. diversos & 0,000 & 1,207 & 0,503 & 1,709 & 0,001 & 1,560 & 1,282 & 2,843 \\
\hline 22 & Farm. e Veterin. & 0,000 & 1,248 & 0,360 & 1,608 & 0,001 & 1,687 & 1,176 & 2,863 \\
\hline 23 & Art. Plásticos & 0,000 & 1,171 & 0,533 & 1,704 & 0,000 & 1,475 & 1,248 & 2,724 \\
\hline 24 & Ind. Têxtil & 0,000 & 1,559 & 0,363 & 1,923 & 0,000 & 1,896 & 1,050 & 2,946 \\
\hline 25 & Art. do Vestuário & 0,000 & 1,476 & 0,329 & 1,805 & 0,001 & 2,144 & 1,405 & 3,550 \\
\hline 26 & Fab. Calçados & 0,000 & 1,394 & 0,200 & 1,594 & 0,001 & 2,012 & 1,153 & 3,166 \\
\hline 27 & Benef. de Prod.Veg. & 0,000 & 1,652 & 0,268 & 1,920 & 0,001 & 2,194 & 1,183 & 3,378 \\
\hline 28 & Abate de Aves & 0,001 & 1,302 & 0,969 & 2,272 & 0,001 & 1,674 & 2,055 & 3,730 \\
\hline 29 & Abate de Bovinos & 0,000 & 1,895 & 0,493 & 2,388 & 0,001 & 2,401 & 1,503 & 3,906 \\
\hline 30 & Ab. Suínos e Outros & 0,002 & 1,791 & 0,652 & 2,445 & 0,002 & 2,238 & 1,718 & 3,959 \\
\hline 31 & Ind. Alimentos & 0,000 & 1,371 & 0,606 & 1,978 & 0,001 & 1,806 & 1,598 & 3,404 \\
\hline 32 & Ind. Diversas & 0,000 & 1,324 & 0,298 & 1,622 & 0,001 & 1,825 & 1,164 & 2,990 \\
\hline 33 & SIUP & 0,000 & 1,667 & 0,369 & 2,036 & 0,001 & 2,181 & 1,300 & 3,482 \\
\hline 34 & Constr. Civil & 0,000 & 1,265 & 0,364 & 1,630 & 0,001 & 1,785 & 1,289 & 3,074 \\
\hline 35 & Comércio & 0,000 & 1,265 & 0,433 & 1,698 & 0,001 & 1,971 & 1,651 & 3,623 \\
\hline 36 & Transp. Rodov. & 0,000 & 1,282 & 0,527 & 1,809 & 0,001 & 1,860 & 1,611 & 3,472 \\
\hline 37 & Transp. Aéreo & 0,000 & 1,356 & 0,590 & 1,946 & 0,001 & 1,893 & 1,664 & 3,557 \\
\hline 38 & Transp. Ferrov. & 0,000 & 1,259 & 0,326 & 1,585 & 0,001 & 1,941 & 1,445 & 3,387 \\
\hline 39 & Transp. Aquav. & 0,000 & 1,302 & 0,503 & 1,805 & 0,001 & 1,884 & 1,584 & 3,469 \\
\hline 40 & Ativ. Aux. Transp. & 0,000 & 1,280 & 0,270 & 1,550 & 0,001 & 1,978 & 1,373 & 3,352 \\
\hline 41 & Comunicações & 0,000 & 1,229 & 0,139 & 1,367 & 0,001 & 1,880 & 1,106 & 2,987 \\
\hline 42 & Inst. Financeiras & 0,000 & 1,353 & 0,059 & 1,413 & 0,001 & 2,211 & 1,255 & 3,466 \\
\hline 43 & Saúde Mercantil & 0,000 & 1,232 & 0,260 & 1,492 & 0,001 & 2,170 & 1,697 & 3,868 \\
\hline 44 & Educ.Mercantil & 0,000 & 1,131 & 0,047 & 1,178 & 0,001 & 2,226 & 1,559 & 3,786 \\
\hline 45 & Serv. Aloj.eAlim. & 0,000 & 1,405 & 0,490 & 1,895 & 0,001 & 2,022 & 1,623 & 3,645 \\
\hline 46 & Out.Serv. Prest. a Fam. & 0,000 & 1,301 & 0,436 & 1,737 & 0,001 & 1,825 & 1,395 & 3,220 \\
\hline 47 & Serv. Prest. à Empresa & 0,000 & 1,208 & 0,139 & 1,347 & 0,001 & 2,013 & 1,324 & 3,338 \\
\hline 48 & Aluguel de Imóveis & 0,000 & 1,060 & 0,019 & 1,079 & 0,001 & 1,691 & 0,882 & 2,574 \\
\hline 49 & Saúde Pública & 0,000 & 1,395 & 0,300 & 1,695 & 0,001 & 2,197 & 1,590 & 3,788 \\
\hline 50 & Educ. Pública & 0,000 & 1,077 & 0,065 & 1,142 & 0,001 & 2,175 & 1,591 & 3,766 \\
\hline 51 & Seg. Pública & 0,000 & 1,369 & 0,245 & 1,614 & 0,001 & 2,235 & 1,592 & 3,828 \\
\hline 52 & Out.Adm. Pública & 0,000 & 1,191 & 0,101 & 1,292 & 0,001 & 2,214 & 1,556 & 3,770 \\
\hline 53 & Serv. Priv. N. Mercantis & 0,000 & 1,055 & 0,044 & 1,099 & 0,001 & 2,167 & 1,573 & 3,742 \\
\hline
\end{tabular}


As informações apresentadas nessas tabelas expressam, respectivamente, o que os setores do Acre, resto do Norte e resto do Brasil induzem de produção na própria região e nas demais regiões devido a uma alteração na demanda final de um determinado setor.

Através dos multiplicadores de produção do tipo I do Acre, apresentados na Tabela 18, pode ser observado que o efeito da variação na demanda final dos setores do Acre afetam mais a produção da economia do resto do Brasil do que do resto do Norte. O que indica que a economia acreana depende mais do resto do Brasil do que do resto do Norte.

Os setores do Acre que têm maior capacidade de estimular a produção nos demais setores da economia são: Abate de suínos e outros, Abate de bovinos, Indústria têxtil, Metalurgia básica e Abate de aves (Tabela 18). Para a região resto do Norte (Tabela 19), além dos setores relacionados a Abate de animais, se destacaram os setores Aves e Outros metalúrgicos. Na região resto do Brasil (Tabela 20), os setores que se destacaram foram os mesmos citados anteriormente para a economia acreana. Houve, no entanto, apenas alteração na ordem de importância dos setores Abate de aves e Indústria têxtil.

A análise dos multiplicadores do tipo II, que tem o consumo das famílias endógeno ao sistema, mostra um aumento no valor dos multiplicadores e, em alguns casos, como o dos setores Abate de aves, Abate de bovinos, Serviços de alojamento e alimentação e Outros serviços prestados às famílias, que um aumento na demanda desses setores do Acre impacta mais a produção do resto do Brasil do que a da própria região ou do resto do Norte.

Quando um setor representando o consumo de famílias é incluído no sistema, os elos são deslocados para segmentos relacionados a serviços. Esse artifício atribui mais realismo ao modelo e permite explicar melhor o que acontece na economia. Ou seja, os setores acreanos que passam a gerar mais produção nos demais setores da economia são: Saúde pública, Saúde mercantil, Segurança pública, Abate de bovinos e Abate de suínos e outros (Tabela 18). 
Tabela 20. Multiplicadores de produção para o resto do Brasil.

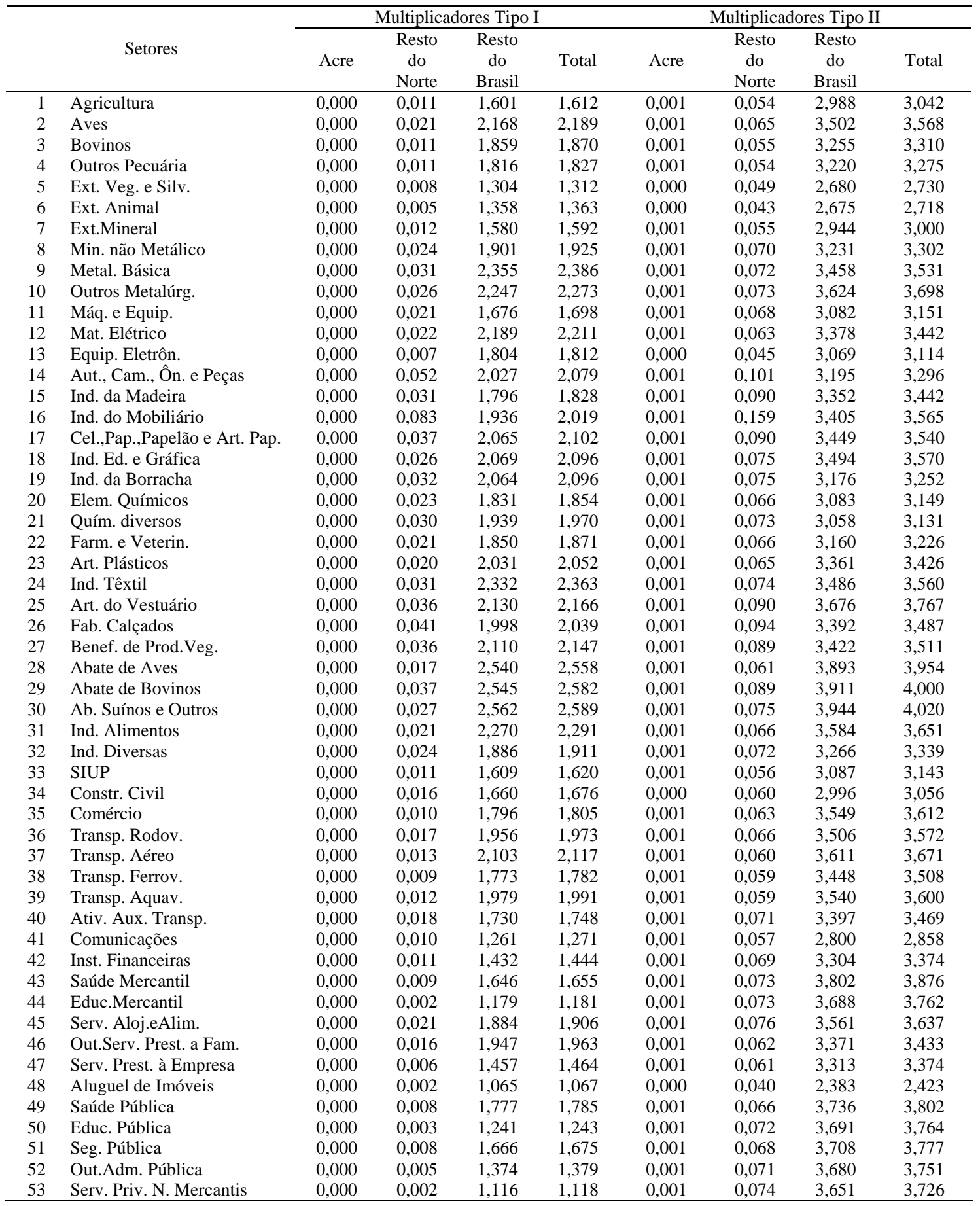

A interpretação dos valores obtidos para os multiplicadores é a seguinte: se houver um aumento de um real na demanda por produtos do setor Saúde pública do 
Acre, por exemplo, isso acarretará um aumento total de produção, em todos os setores da economia acreana, equivalente a 3,67 reais (multiplicador tipo II desse setor) - dos quais um real vai para o atendimento da demanda final e os 2,67 reais restantes representam a produção gerada nos demais setores da economia.

No caso dos setores Saúde mercantil e Segurança pública, a produção gerada nos demais setores é equivalente a 2,63 reais. Já para os setores Abate de bovinos e Abate de suínos e outros, cada um real de aumento na demanda desses setores gera, respectivamente, 2,62 e 2,53 reais nos demais setores da economia acreana (ver coluna total dos multiplicadores tipo II da Tabela 18).

Conforme pode ser observado nas Tabelas 19 e 20, as respostas dos setores do resto do Norte e do resto do Brasil às variações nas suas demanda finais ocorrem de forma muito parecida à resposta dos setores acreanos descrita anteriormente, tanto para os multiplicadores do tipo I quanto para os do tipo II.

Vale destacar, no entanto, que aumentos na demanda final dos setores localizados no resto do Norte ou no resto do Brasil quase não influenciam a produção dos setores localizados no Acre, o que sugere que as produções dos setores dessas regiões são independentes dos insumos produzidos no Acre (ver coluna Acre dos multiplicadores tipo I e II das Tabelas 19 e 20).

Da análise dos multiplicadores tipo II do resto do Norte e resto do Brasil, podese observar que houve alteração na ordem dos setores que se destacaram nessas duas regiões, quando comparado com o Acre. Deve-se observar, entretanto, que na economia formada pela região resto do Brasil, o setor Abate de aves ocupou a terceira posição e, não ficou entre os cinco principais setores das demais regiões. O setor Segurança pública, por sua vez, que se destacou em terceiro e quarto lugar nas economias das regiões Acre e do resto do Norte, respectivamente, foi o sexto colocado no resto do Brasil.

Uma última observação com relação aos multiplicadores de produção tipo I e II diz respeito ao comportamento dos setores componentes do setor florestal: Extrativismo vegetal e silvicultura, Indústria da madeira, Indústria do mobiliário, Fabricação de celulose, pasta mecânica, papel, papelão e artefatos de papel, Indústria editorial e gráfica 
e Indústria da borracha. Esses setores, em nenhuma das três regiões estiveram entre os dez principais setores com maior poder de encadeamento da produção.

\section{Multiplicador de emprego}

A Tabela 21 apresenta os resultados referentes apenas aos multiplicadores de emprego do tipo I e II para os cinco setores mais importantes em cada uma das regiões. As Tabelas 37 e 38 (Anexo) apresentam os resultados completos para cada um dos 53 setores de cada uma das três regiões consideradas no presente trabalho.

Tabela 21. Setores que apresentaram maiores valores de multiplicadores de emprego do tipo I e do tipo II nas regiões: Acre, resto do Norte e resto do Brasil.

\begin{tabular}{llcccccc}
\hline \multirow{2}{*}{ N. Setor/Nome do Setor } & \multicolumn{2}{c}{ Acre } & \multicolumn{2}{c}{ Resto Norte } & \multicolumn{2}{c}{ Resto Brasil } \\
\cline { 3 - 7 } & & Tipo I & Tipo II & Tipo I & Tipo II & Tipo I & Tipo II \\
\hline 28 & Abate de Aves & 120,32 & 153,72 & 49,29 & 70,90 & 19,54 & 25,83 \\
29 & Abate de Bovinos & 31,43 & 54,57 & 11,41 & 25,36 & 9,51 & \\
30 & Abate de Suínos e Outros & 28,47 & 44,91 & 10,50 & & 10,59 & \\
20 & Elementos Químicos & 9,44 & & & & 12,90 & 29,76 \\
41 & Comunicações & 7,38 & 17,52 & & & & \\
52 & Outros Administração Pública & & 18,37 & & & & \\
14 & Automóveis, Caminhões, Ônibus e Peças & & & 9,36 & 39,64 & & \\
21 & Químicos Diversos & & & 6,82 & 28,27 & & 34,35 \\
9 & Metalurgia Básica & & & & & 10,13 & 30,10 \\
48 & Aluguel de Imóveis & & & & 26,76 & & 28,76 \\
\hline
\end{tabular}

A interpretação dos valores apresentados na Tabela 21 para o setor Abate de aves, por exemplo, é a seguinte: para cada emprego direto criado nesse setor, são gerados 119 novos empregos nos demais setores da economia (indiretamente). 
Tabela 22. Número total de empregos gerados no Acre, resto do Norte e resto do Brasil, para a variação de um milhão de reais na demanda final.

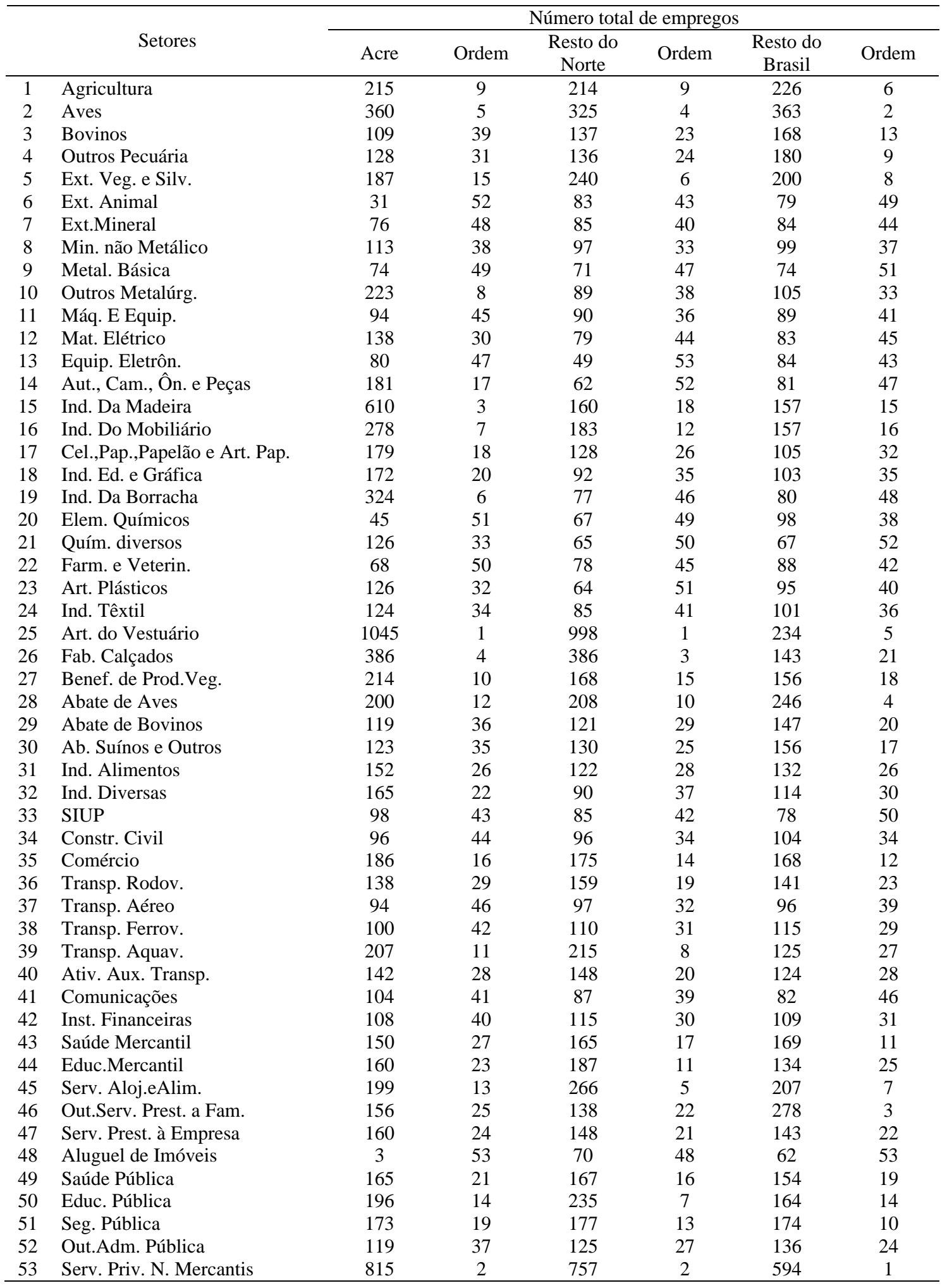


Através das informações dessa tabela, percebe-se que os segmentos mais importantes, em termos de multiplicador de emprego, nas regiões Acre, resto do Norte e resto do Brasil estão relacionados à produção animal (Abates de aves, bovinos e suínos e outros), à Indústria química (Elementos químicos e Químicos diversos), ao setor de Serviços (Outros administração pública, Aluguel de imóveis e Comunicações), à Metalurgia básica e ao setor automobilístico.

Tal como nos multiplicadores de produção, ao endogenizarmos o consumo das famílias, há um aumento nos valores dos multiplicadores de emprego e os setores relacionados a serviços assumem posição de destaque.

Com relação ao número de empregos gerados, as Tabelas 22 e 23 trazem, respectivamente, o número total de empregos e o número de empregos diretos, indiretos e induzidos gerados nos 53 setores de cada uma das regiões consideradas no presente estudo.

Segundo Miller \& Blair (1985), o aumento de produção ocasionado pelo choque na demanda tem como conseqüência, também, o aumento no número de empregos. Se, os empregos forem gerados no setor onde houve aumento de produção, podemos classificar esses empregos como diretamente gerados. Contudo, se os empregos forem gerados nos setores que fornecem insumos para o setor que sofreu o aumento na demanda, esses podem ser classificados como indiretos.

Quando o consumo das famílias é endogenizado ao sistema, surge uma nova categoria de emprego denominada de empregos induzidos. Assim, da soma dessas três categorias de empregos, tem-se o número total de empregos gerados em cada setor da economia.

Nas três regiões consideradas nesse trabalho, os setores Artigos do vestuário, Serviços privados não mercantis e Aves foram os que se destacaram na geração de empregos diretos e, também, no total de empregos gerados. Os setores Aves, Abate de aves e Beneficiamento de produtos vegetais se destacaram na geração de empregos indiretos (nos demais setores da economia) nas três regiões (Tabela 23). 
Tabela 23. Geração de empregos diretos, indiretos, induzidos e total no Acre, resto do Norte e resto do Brasil, para a variação de um milhão de reais na demanda final.

\begin{tabular}{|c|c|c|c|c|c|c|c|c|c|c|}
\hline \multirow{2}{*}{\multicolumn{2}{|c|}{ Setores }} & \multicolumn{3}{|c|}{ Acre } & \multicolumn{3}{|c|}{ Resto do Norte } & \multicolumn{3}{|c|}{ Resto do Brasil } \\
\hline & & \multirow{2}{*}{$\begin{array}{c}\text { Direto } \\
165\end{array}$} & \multirow{2}{*}{$\begin{array}{c}\text { Indireto } \\
30\end{array}$} & \multirow{2}{*}{$\begin{array}{c}\text { Induzido } \\
20\end{array}$} & \multirow{2}{*}{$\begin{array}{c}\text { Direto } \\
124\end{array}$} & \multirow{2}{*}{$\begin{array}{c}\text { Indireto } \\
22\end{array}$} & \multirow{2}{*}{$\begin{array}{c}\text { Induzido } \\
68\end{array}$} & \multirow{2}{*}{$\begin{array}{c}\text { Direto } \\
140\end{array}$} & \multirow{2}{*}{$\begin{array}{c}\text { Indireto } \\
25\end{array}$} & \multirow{2}{*}{$\begin{array}{c}\text { Induzido } \\
61\end{array}$} \\
\hline 1 & Agricultura & & & & & & & & & \\
\hline 2 & Aves & 233 & 89 & 37 & 197 & 63 & 65 & 234 & 70 & 59 \\
\hline 3 & Bovinos & 38 & 46 & 25 & 30 & 38 & 69 & 65 & 41 & 62 \\
\hline 4 & Outros Pecuária & 45 & 57 & 27 & 20 & 48 & 68 & 68 & 50 & 62 \\
\hline 5 & Ext. Veg. e Silv. & 160 & 19 & 8 & 158 & 15 & 67 & 122 & 17 & 61 \\
\hline 6 & Ext. Animal & 11 & 13 & 7 & 11 & 9 & 63 & 11 & 10 & 58 \\
\hline 7 & Ext.Mineral & 21 & 23 & 32 & 7 & 15 & 63 & 10 & 13 & 60 \\
\hline 8 & Min. não Metálico & 41 & 25 & 47 & 22 & 14 & 61 & 20 & 20 & 59 \\
\hline 9 & Metal. Básica & 8 & 41 & 24 & 5 & 17 & 49 & 2 & 22 & 49 \\
\hline 10 & Outros Metalúrg. & 143 & 35 & 44 & 14 & 16 & 59 & 24 & 20 & 61 \\
\hline 11 & Máq. e Equip. & 56 & 13 & 24 & 18 & 9 & 62 & 13 & 14 & 62 \\
\hline 12 & Mat. Elétrico & 57 & 39 & 42 & 15 & 16 & 49 & 7 & 23 & 53 \\
\hline 13 & Equip. Eletrôn. & 28 & 26 & 26 & 4 & 7 & 39 & 9 & 19 & 56 \\
\hline 14 & Aut., Cam., Ôn. e Peças & 97 & 47 & 37 & 2 & 13 & 47 & 7 & 22 & 52 \\
\hline 15 & Ind. da Madeira & 515 & 59 & 37 & 51 & 37 & 73 & 49 & 39 & 69 \\
\hline 16 & Ind. do Mobiliário & 145 & 88 & 45 & 82 & 36 & 65 & 48 & 42 & 66 \\
\hline 17 & Cel.,Pap.,Papelão e Art. Pap. & 96 & 29 & 54 & 29 & 31 & 68 & 14 & 30 & 62 \\
\hline 18 & Ind. Ed. e Gráfica & 87 & 33 & 52 & 9 & 20 & 63 & 14 & 25 & 63 \\
\hline 19 & Ind. da Borracha & 219 & 78 & 27 & 12 & 20 & 45 & 5 & 25 & 50 \\
\hline 20 & Elem. Químicos & 3 & 28 & 14 & 5 & 11 & 52 & 3 & 39 & 56 \\
\hline 21 & Quím. diversos & 56 & 34 & 36 & 2 & 13 & 50 & 2 & 15 & 50 \\
\hline 22 & Farm. e Veterin. & 19 & 23 & 26 & 7 & 16 & 55 & 7 & 23 & 58 \\
\hline 23 & Art. Plásticos & 58 & 23 & 45 & 9 & 10 & 45 & 20 & 16 & 59 \\
\hline 24 & Ind. Têxtil & 26 & 62 & 36 & 13 & 27 & 45 & 11 & 39 & 51 \\
\hline 25 & Art. do Vestuário & 939 & 34 & 72 & 901 & 20 & 77 & 137 & 28 & 69 \\
\hline 26 & Fab. Calçados & 285 & 63 & 39 & 285 & 32 & 69 & 50 & 31 & 62 \\
\hline 27 & Benef. de Prod.Veg. & 95 & 92 & 27 & 33 & 71 & 64 & 10 & 87 & 59 \\
\hline 28 & Abate de Aves & 1 & 155 & 43 & 3 & 142 & 63 & 10 & 176 & 60 \\
\hline 29 & Abate de Bovinos & 2 & 66 & 50 & 5 & 50 & 66 & 9 & 77 & 61 \\
\hline 30 & Ab. Suínos e Outros & 3 & 75 & 45 & 6 & 58 & 66 & 9 & 86 & 61 \\
\hline 31 & Ind. Alimentos & 53 & 62 & 38 & 16 & 44 & 62 & 12 & 62 & 58 \\
\hline 32 & Ind. Diversas & 96 & 30 & 39 & 14 & 15 & 60 & 30 & 23 & 61 \\
\hline
\end{tabular}


Tabela 23. Geração de empregos diretos, indiretos, induzidos e total no Acre, resto do Norte e resto do Brasil, para a variação de um milhão de reais na demanda final.

\begin{tabular}{|c|c|c|c|c|c|c|c|c|c|c|}
\hline \multirow{2}{*}{\multicolumn{2}{|c|}{ Setores }} & \multicolumn{3}{|c|}{ Acre } & \multicolumn{3}{|c|}{ Resto do Norte } & \multicolumn{3}{|c|}{ Resto do Brasil } \\
\hline & & \multirow{2}{*}{$\begin{array}{c}\text { Direto } \\
20\end{array}$} & \multirow{2}{*}{$\begin{array}{c}\text { Indireto } \\
22\end{array}$} & \multirow{2}{*}{$\begin{array}{c}\text { Induzido } \\
56\end{array}$} & \multirow{2}{*}{$\begin{array}{c}\text { Direto } \\
8\end{array}$} & \multirow{2}{*}{$\begin{array}{c}\text { Indireto } \\
14\end{array}$} & \multirow{2}{*}{$\begin{array}{c}\text { Induzido } \\
63\end{array}$} & \multirow{2}{*}{$\begin{array}{c}\text { Direto } \\
4\end{array}$} & \multirow{2}{*}{$\begin{array}{c}\text { Indireto } \\
9\end{array}$} & \multirow{2}{*}{$\begin{array}{c}\text { Induzido } \\
65\end{array}$} \\
\hline 33 & SIUP & & & & & & & & & \\
\hline 34 & Constr. Civil & 37 & 26 & 33 & 18 & 15 & 63 & 28 & 16 & 59 \\
\hline 35 & Comércio & 95 & 18 & 73 & 75 & 15 & 84 & 75 & 16 & 77 \\
\hline 36 & Transp. Rodov. & 53 & 19 & 66 & 69 & 17 & 73 & 52 & 20 & 69 \\
\hline 37 & Transp. Aéreo & 8 & 21 & 66 & 8 & 19 & 71 & 8 & 22 & 67 \\
\hline 38 & Transp. Ferrov. & 23 & 12 & 64 & 18 & 13 & 79 & 23 & 17 & 74 \\
\hline 39 & Transp. Aquav. & 134 & 21 & 51 & 121 & 22 & 73 & 35 & 21 & 69 \\
\hline 40 & Ativ. Aux. Transp. & 57 & 16 & 69 & 54 & 14 & 79 & 31 & 18 & 74 \\
\hline 41 & Comunicações & 6 & 38 & 60 & 5 & 11 & 71 & 6 & 8 & 68 \\
\hline 42 & Inst. Financeiras & 22 & 20 & 66 & 11 & 13 & 90 & 9 & 18 & 83 \\
\hline 43 & Saúde Mercantil & 30 & 34 & 86 & 41 & 20 & 104 & 46 & 28 & 95 \\
\hline 44 & Educ.Mercantil & 47 & 11 & 102 & 66 & 6 & 115 & 17 & 6 & 111 \\
\hline 45 & Serv. Aloj.eAlim. & 87 & 48 & 64 & 154 & 35 & 77 & 95 & 37 & 74 \\
\hline 46 & Out.Serv. Prest. a Fam. & 66 & 28 & 61 & 57 & 16 & 65 & 194 & 21 & 63 \\
\hline 47 & Serv. Prest. à Empresa & 68 & 16 & 77 & 51 & 9 & 88 & 49 & 12 & 82 \\
\hline 48 & Aluguel de Imóveis & 4 & 3 & -4 & 3 & 2 & 66 & 2 & 2 & 58 \\
\hline 49 & Saúde Pública & 45 & 29 & 91 & 44 & 31 & 92 & 27 & 40 & 87 \\
\hline 50 & Educ. Pública & 85 & 3 & 108 & 114 & 5 & 115 & 46 & 10 & 108 \\
\hline 51 & Seg. Pública & 54 & 24 & 95 & 55 & 25 & 97 & 53 & 31 & 90 \\
\hline 52 & Out.Adm. Pública & 6 & 6 & 107 & 5 & 11 & 109 & 18 & 16 & 102 \\
\hline 53 & Serv. Priv. N. Mercantis & 705 & 6 & 104 & 638 & 3 & 116 & 478 & 4 & 112 \\
\hline
\end{tabular}


Da análise dos setores em termos de capacidade de geração de empregos notase que os setores de base primária passam a aparecer entre os setores de destaque. Como é o caso do setor Aves que ficou entre os cinco setores mais importantes nas três regiões em termos de geração de empregos diretos. E, também, o caso do setor Agricultura para a região resto do Brasil e Extrativismo vegetal e silvicultura para a região resto do Norte.

Quando o consumo das famílias é considerado, um choque na demanda ocasiona um aumento no número de empregos gerados, não apenas nos setores relacionados à produção e indústria, mas também naqueles relacionados a Educação, Saúde, Segurança e Outros serviços. Dessa forma, o choque de demanda leva a geração de empregos induzidos nesses setores.

Com relação aos setores Extrativismo vegetal e silvicultura, Indústria da madeira, Indústria do mobiliário, Fabricação de celulose, pasta mecânica, papel, papelão e artefatos de papel, Indústria editorial e gráfica e Indústria da borracha, foco do presente trabalho, temos que, no Acre, todos esses estiveram entre os vinte setores mais importantes em termos de número total de empregos gerados (Tabela 22) e em termos de número de empregos diretos gerados (Tabela 23).

Os setores Indústria do mobiliário, Indústria da borracha e Indústria da Madeira estiveram entre os vinte mais importantes na geração de empregos indiretos e Fabricação de celulose, pasta mecânica, papel, papelão e artefatos de papel se destacou na geração de empregos induzidos (Tabela 23).

A Tabela 24 apresenta o número de empregos diretos, indiretos, induzidos e totais desses seis setores, para cada uma das três regiões separadamente. Esse valor agregado nos permite identificar que o setor florestal acreano gera 1.751 empregos, dos quais 1.222 são diretos (no próprio setor). No resto do Norte, a soma de todos os empregos gerados por esses setores corresponde a 880, dos quais 379 empregos são gerados pelo efeito induzido, decorrente da endogenização do consumo das famílias. Das três regiões em estudo, o resto do Brasil é a que gera menos empregos nesses setores e, dos 802 empregos gerados, cerca de 371 o são pelo efeito induzido. 
Tabela 24. Número de empregos diretos, indiretos, induzidos e total gerados pelos setores Extrativismo vegetal e silvicultura, Indústria da madeira, Indústria do mobiliário, Fabricação de celulose, pasta mecânica, papel, papelão e artefatos de papel, Indústria editorial e gráfica e Indústria da borracha de cada região do sistema inter-regional.

\begin{tabular}{lcccc}
\hline \multirow{2}{*}{ Região } & \multicolumn{4}{c}{ Geração de Empregos } \\
\cline { 2 - 5 } & Diretos & Indiretos & Induzidos & Total \\
\hline Acre & 1.222 & 306 & 223 & 1.751 \\
Resto do Norte & 341 & 160 & 379 & 880 \\
Resto do Brasil & 253 & 179 & 371 & 802 \\
\hline
\end{tabular}

\section{Multiplicador de renda}

Os multiplicadores de renda, tal como foram definidos os multiplicadores de produção e emprego, representa a renda gerada em todos os setores da economia resultante de uma variação de uma unidade monetária na demanda final de um determinado setor.

Da mesma forma que anteriormente, os valores dos multiplicadores para cada um dos 53 setores do sistema inter-regional estão apresentados nos anexos (Tabelas 39 a 41). As Tabelas 25 e 26, apresentadas a seguir, trazem os valores dos multiplicadores I e II de renda, e as rendas direta e indiretamente geradas apenas para os cinco setores considerados mais importantes por esses indicadores em cada região. 
Tabela 25. Setores que apresentaram maiores valores de multiplicadores de renda do tipo I e do tipo II nas regiões: Acre, resto do Norte e resto do Brasil.

\begin{tabular}{llrrrrrr}
\hline \multirow{2}{*}{ N. Setor/Nome do Setor } & \multicolumn{2}{c}{ Acre } & \multicolumn{2}{c}{ Resto Norte } & \multicolumn{2}{c}{ Resto Brasil } \\
\cline { 3 - 7 } & & Tipo I & Tipo II & Tipo I & Tipo II & Tipo I & Tipo II \\
\hline 9 & Metalurgia Básica & 7,720 & 11,502 & 4,700 & 10,923 & 6,669 & 13,687 \\
30 & Abate de Suínos e Outros & 4,463 & 7,960 & 4,437 & 9,314 & 4,681 & 9,234 \\
29 & Abate de Bovinos & 4,461 & 8,187 & 4,298 & & 4,556 & \\
14 & Automóveis, Caminhões, Ônibus e Peças & 4,416 & 6,472 & & & & \\
28 & Abate de Aves & 3,932 & 6,989 & 3,475 & & 4,081 & \\
2 & Aves & & & 5,880 & 14,430 & 6,059 & 14,109 \\
48 & Aluguel de Imóveis & & & & 12,929 & & 14,197 \\
6 & Extrativismo Animal (pesca) & & & & 11,565 & & 11,060 \\
\hline
\end{tabular}

As três regiões do sistema inter-regional apresentaram os setores Metalurgia básica, Abate de suínos e outros, Abate de bovinos e Abate de aves como os setores com maior capacidade de geração de renda nos outros setores da economia, refletido nos altos valores dos seus multiplicadores tipo I (Tabela 25) e, também, nos valores de renda indireta (Tabela 41, Anexo) . Cabe destacar, ainda, que no Acre também merece destaque o setor Automóveis, caminhões, ônibus e peças. Já nas outras duas regiões, o setor Aves se destacou em ambas (Tabela 25).

Os setores Educação mercantil, Educação pública, Segurança pública, Outros serviços da administração pública e Serviços privados não mercantis apresentaram os menores multiplicadores de renda, tanto tipo I quanto II (Tabelas 39 e 40, Anexo). No entanto, esses setores se destacaram na geração de renda direta (Tabela 26). 
Tabela 26. Setores mais importantes na geração de renda direta e indireta em cada uma das regiões do sistema inter-regional.

\begin{tabular}{|c|c|c|c|c|c|c|}
\hline \multirow[b]{2}{*}{ Setor } & \multicolumn{2}{|c|}{ Acre } & \multicolumn{2}{|c|}{ Resto do Norte } & \multicolumn{2}{|c|}{ Resto do Brasil } \\
\hline & $\begin{array}{l}\text { Renda } \\
\text { Direta }\end{array}$ & $\begin{array}{l}\text { Renda } \\
\text { Indireta }\end{array}$ & $\begin{array}{l}\text { Renda } \\
\text { Direta }\end{array}$ & $\begin{array}{l}\text { Renda } \\
\text { Indireta }\end{array}$ & $\begin{array}{l}\text { Renda } \\
\text { Direta }\end{array}$ & $\begin{array}{l}\text { Renda } \\
\text { Indireta }\end{array}$ \\
\hline Educação Pública & 946,52 & & 901,05 & & 833,45 & \\
\hline Outros Adm. Pública & 915,85 & & 784,07 & & 723,94 & \\
\hline Serv. Privados Não Mercantis & 903,14 & & 927,95 & & 915,05 & \\
\hline Segurança Pública & 662,82 & & 567,83 & & 522,93 & \\
\hline Educaçao Mercantil & 619,29 & & 621,41 & & & \\
\hline Celulose, Papel, Papelão e Art. Papel & & 315,40 & & 147,36 & & 191,67 \\
\hline Indústria Editorial e Gráfica & & 283,22 & & 164,04 & & 195,47 \\
\hline Comunicações & & 229,71 & & & & \\
\hline Automóveis, Cam., Ônibus e Peças & & 227,02 & & & & \\
\hline SIUP & & 207,04 & & 174,00 & & \\
\hline Abate de Suínos e Outros & & & & 171,56 & & 184,16 \\
\hline Abate de Bovinos & & & & 163,60 & & 177,79 \\
\hline Saúde Publica & & & & & 475,32 & \\
\hline Transporte Aéreo & & & & & & 166,12 \\
\hline
\end{tabular}

Os setores Fabricação de celulose, pasta mecânica, papel, papelão e artefatos de papel, Indústria da borracha e Indústria editorial e gráfica da economia acreana ocuparam a nona, décima primeira e décima quarta posição, respectivamente, em termos de multiplicador tipo I (Tabela 39, Anexo). E, respectivamente, a décima, nona e décima quinta posição, em termos de multiplicador tipo II (Tabela 40, Anexo).

Os três setores também se destacaram mais como geradores de renda indireta do que direta. Enquanto que, os setores Indústria da madeira e do mobiliário se destacaram na geração de renda no próprio setor. O setor Extrativismo vegetal e silvicultura, no entanto, apresentou equilíbrio tanto na geração de renda no próprio setor (direta) quanto nos demais setores (indireta) (Tabela 41, Anexo e Tabela 26). 


\section{Multiplicador de importação}

O aumento de produção gerado pelo aumento da demanda final em um sistema econômico como o considerado no presente trabalho provoca um aumento no consumo de insumos domésticos e importados. Os multiplicadores de importação nos permitem identificar quais setores tem maior capacidade de estimular as importações.

Os percentuais apresentados na Tabela 27 foram obtidos por meio da divisão do vetor importação dos setores da matriz de insumo-produto pelo valor da produção (VP) desses setores. Dessa forma, foram obtidas as participações dos insumos importados no VP dos setores de cada uma das regiões consideradas nesse trabalho.

As informações apresentadas na Tabela 27 indicam que das três regiões, a região resto do Norte é a mais dependente de outras economias. Nessa região, dezesseis setores se destacaram como demandantes de insumos importados no seu consumo intermediário dos quais, dez apresentaram percentuais acima de 15\% e seis apresentaram percentuais entre $10 \%$ e $15 \%$. Sendo que, merecem destaque os setores Equipamentos eletrônicos, Automóveis, caminhões, ônibus e peças, Material elétrico, Artigos plásticos e Indústria têxtil.

Para o resto do Brasil os setores Automóveis, caminhões, ônibus e peças e Químicos diversos são os setores que mais utilizam insumos importados em seu processo produtivo, com percentuais de $11,78 \%$ e $10,65 \%$, respectivamente. No Acre, esses dois setores também foram os mais expressivos, no entanto, a participação dos insumos importados no VP desses setores não chegou a $0,5 \%$. 
Tabela 27. Participação (\%) das importações no valor da produção das regiões do sistema inter-regional no ano de 1999.

\begin{tabular}{|c|c|c|c|c|}
\hline & Setores & Acre & Resto do Norte & Resto do Brasil \\
\hline 1 & Agricultura & 0,06 & 2,16 & 3,32 \\
\hline 2 & Aves & 0,07 & 2,36 & 3,28 \\
\hline 3 & Bovinos & 0,06 & 1,43 & 3,43 \\
\hline 4 & Outros Pecuária & 0,07 & 1,79 & 3,47 \\
\hline 5 & Ext. Veg. e Silv. & 0,06 & 1,73 & 3,77 \\
\hline 6 & Ext. Animal & 0,06 & 5,19 & 2,86 \\
\hline 7 & Ext.Mineral & 0,08 & 4,37 & 4,18 \\
\hline 8 & Min. não Metálico & 0,07 & 6,15 & 4,60 \\
\hline 9 & Metal. Básica & 0,12 & 13,84 & 7,72 \\
\hline 10 & Outros Metalúrg. & 0,08 & 12,48 & 4,70 \\
\hline 11 & Máquinas e Equipamentos & 0,04 & 10,17 & 4,19 \\
\hline 12 & Material Elétrico & 0,18 & 26,95 & 9,35 \\
\hline 13 & Equipam. Eletrônicos & 0,19 & 34,17 & 8,04 \\
\hline 14 & Autom., Cam., Ônib. e Peças & 0,25 & 29,11 & 11,78 \\
\hline 15 & Ind. da Madeira & 0,01 & 2,66 & 0,78 \\
\hline 16 & Ind. do Mobiliário & 0,07 & 11,24 & 4,18 \\
\hline 17 & Cel.,Pap.,Papelão e Art. Pap. & 0,09 & 4,46 & 5,80 \\
\hline 18 & Ind. Ed. e Gráfica & 0,09 & 12,72 & 5,07 \\
\hline 19 & Ind. da Borracha & 0,13 & 20,38 & 7,58 \\
\hline 20 & Elementos Químicos & 0,09 & 18,88 & 5,04 \\
\hline 21 & Químicos diversos & 0,20 & 21,09 & 10,65 \\
\hline 22 & Farm. e Veterinária & 0,09 & 16,86 & 6,12 \\
\hline 23 & Artigos Plásticos & 0,15 & 24,38 & 8,60 \\
\hline 24 & Indústria Têxtil & 0,17 & 22,98 & 9,32 \\
\hline 25 & Art. do Vestuário & 0,06 & 4,53 & 4,21 \\
\hline 26 & Fabricação de Calçados & 0,08 & 1,78 & 5,15 \\
\hline 27 & Benef. de Prod.Vegetais & 0,10 & 3,33 & 4,14 \\
\hline 28 & Abate de Aves & 0,02 & 0,41 & 1,35 \\
\hline 29 & Abate de Bovinos & 0,02 & 0,60 & 1,29 \\
\hline 30 & Ab. Suínos e Outros & 0,02 & 0,37 & 1,29 \\
\hline 31 & Ind. Alimentos & 0,05 & 3,62 & 3,11 \\
\hline 32 & Ind. Diversas & 0,11 & 15,41 & 7,18 \\
\hline 33 & SIUP & 0,08 & 6,49 & 2,35 \\
\hline 34 & Construção Civil & 0,07 & 3,19 & 2,99 \\
\hline 35 & Comércio & 0,04 & 1,64 & 2,19 \\
\hline 36 & Transp. Rodoviário & 0,11 & 8,67 & 7,14 \\
\hline 37 & Transp. Aéreo & 0,10 & 8,01 & 6,48 \\
\hline 38 & Transp. Ferroviário & 0,07 & 7,53 & 6,53 \\
\hline 39 & Transp. Aquaviário & 0,09 & 7,75 & 6,51 \\
\hline 40 & Ativ. Aux. Transporte & 0,07 & 7,84 & 6,27 \\
\hline 41 & Comunicações & 0,19 & 5,32 & 3,17 \\
\hline 42 & Inst. Financeiras & 0,05 & 2,31 & 2,47 \\
\hline 43 & Saúde Mercantil & 0,02 & 0,32 & 0,69 \\
\hline 44 & Educ.Mercantil & 0,01 & 0,38 & 0,33 \\
\hline 45 & Serv. Aloj.e Alimentação & 0,06 & 2,97 & 2,87 \\
\hline 46 & Out.Serv. Prest. a Família & 0,19 & 14,59 & 9,75 \\
\hline 47 & Serv. Prest. à Empresa & 0,05 & 2,43 & 3,00 \\
\hline 48 & Aluguel de Imóveis & 0,00 & 0,13 & 0,08 \\
\hline 49 & Saúde Pública & 0,06 & 4,11 & 4,07 \\
\hline 50 & Educ. Pública & 0,01 & 0,56 & 1,07 \\
\hline 51 & Seg. Pública & 0,07 & 3,36 & 4,66 \\
\hline 52 & Outros Adm. Pública & 0,02 & 2,20 & 2,85 \\
\hline 53 & Serv. Priv. não Mercantis & 0,01 & 0,26 & 0,44 \\
\hline
\end{tabular}


A Tabela 28 apresenta os setores mais importantes na geração de importação, no próprio setor (direta) e nos demais setores da economia (indireta) para cada unidade monetária de importação diretamente gerada em cada setor. Assim, com relação aos multiplicadores tipo I, os setores relacionados a Abate de animais se destacaram nas três regiões. Os setores Saúde mercantil e Indústria da madeira se destacaram nas regiões Acre e resto do Brasil e, o setor Bovinos se destacou no resto do Norte.

Quando o consumo das famílias é considerado, os setores relacionados a Educação pública e mercantil, Serviços privados não mercantis, Saúde mercantil, Outros administração pública, Aluguel de imóveis, Abate de suínos e outros e Indústria de alimentos foram os que se destacaram nas regiões do sistema inter-regional.

Tabela 28. Setores que apresentaram maiores valores de multiplicadores de importação do tipo I e do tipo II nas regiões: Acre, resto do Norte e resto do Brasil.

\begin{tabular}{|c|c|c|c|c|c|c|c|}
\hline & \multirow{2}{*}{ N. Setor/Nome do Setor } & \multicolumn{2}{|c|}{ Acre } & \multicolumn{2}{|c|}{ Resto Norte } & \multicolumn{2}{|c|}{ Resto Brasil } \\
\hline & & Tipo I & Tipo II & Tipo I & Tipo II & Tipo I & Tipo II \\
\hline 28 & Abate de Aves & 223,954 & & 14,120 & & 5,731 & \\
\hline 29 & Abate de Bovinos & 214,209 & & 9,057 & & 5,998 & \\
\hline 30 & Abate de Suínos e Outros & 185,883 & & 15,762 & 33,968 & 6,102 & \\
\hline 43 & Saúde Mercantil & 146,118 & 557,608 & 8,144 & 42,016 & 5,075 & 18,304 \\
\hline 15 & Indústria da Madeira & 109,755 & & & & 5,636 & 14,183 \\
\hline 50 & Educação Pública & & 1147,203 & & & & \\
\hline 44 & Educaçao Mercantil & & 793,233 & & 34,700 & & 34,706 \\
\hline 53 & Serv. Priv. Não Mercantis & & 735,038 & & 50,267 & & 26,598 \\
\hline 52 & Outros Adm. Pública & & 453,862 & & & & \\
\hline 3 & Bovinos & & & 4,134 & & & \\
\hline 48 & Aluguel de Imóveis & & & & 56,599 & & 72,800 \\
\hline
\end{tabular}


A análise dos setores como geradores de importação direta e indireta (Tabela 42, Anexo) permite-nos identificar se o aumento na produção de um determinado setor, decorrente de um aumento na demanda final, causa maior impacto nas importações feitas diretamente pelo setor ou nas importações feitas indiretamente, ou seja, pelos setores que são fornecedores desses setores ou fornecedores dos fornecedores destes.

A Tabela 29 apresenta os setores que apresentam maior capacidade de estimular as importações do sistema inter-regional. Os setores do Acre que mais se destacam na geração de importação de forma indireta são: Outros serviços prestados à família, Artigos plásticos, Material elétrico, Transporte aéreo e Abate de bovinos.

Tabela 29. Setores mais importantes na geração de importação direta e indireta em cada uma das regiões do sistema inter-regional.

\begin{tabular}{lcccccc}
\hline \multirow{2}{*}{ Setor } & \multicolumn{2}{c}{ Acre } & \multicolumn{2}{c}{ Resto do Norte } & \multicolumn{2}{c}{ Resto do Brasil } \\
\cline { 2 - 6 } & Direta & Indireta & Direta & Indireta & Direta & Indireta \\
\hline Automóves, Caminhões, Ônibus e Peças & 2,47 & & 291,08 & & 117,81 & \\
Químicos diversos & 1,95 & & & & 106,51 & \\
Comunicações & 1,94 & & & & & \\
Outros Serviços Prest. À Família & 1,87 & 65,36 & & & 97,47 & \\
Equipamentos Eletrônicos & 1,87 & & 341,74 & & & \\
Artigos Plásticos & & 57,47 & 243,78 & & & \\
Material Elétrico & & 55,48 & 269,48 & & 93,48 & \\
Transporte Áereo & & 51,05 & & & & \\
Abate de Bovinos & & 50,04 & & & & \\
Ind. Têxtil & & & 229,82 & 116,98 & 93,21 & 98,12 \\
Artigos do Vestuário & & & 102,15 & & 87,82 \\
Metalurgia Básica & & & 92,27 & & 85,46 \\
Indústria da Borracha & & & 83,95 & & \\
Outros Metalúrgicos & & & 81,65 & & 79,18 \\
\hline
\end{tabular}

No resto do Norte, os setores Indústria têxtil, Artigos do vestuário, Metalurgia básica, Indústria da borracha e Outros metalúrgicos foram os que se destacaram na 
geração de importação. No entanto, diferentemente do Acre, os setores se destacaram na geração de importações feitas diretamente pelo setor do que na geração de importações feitas por seus fornecedores (indiretas). Com relação aos cinco setores citados anteriormente, exceção deve ser feita para o setor Artigos do vestuário, que se destacou mais na geração indireta de importações do que direta.

Os setores do resto do Brasil apresentaram equilíbrio nas duas formas de estímulo às importações (Tabela 42, Anexo). Sendo que os setores que têm maior capacidade de estimular as importações da região são: Indústria têxtil, Artigos do vestuário, Metalurgia básica, Artigos plásticos e Outros metalúrgicos. No entanto, com exceção do setor Artigos plásticos, os demais se destacaram por estimular as importações de seus fornecedores diretos e indiretos (geração indireta).

Através das análises feitas até então, pode-se identificar os setores com maior potencial para estimular a economia acreana bem como, quão diversificada é a sua estrutura produtiva, a sua dependência com relação as outras regiões e os setores que mais se destacam na geração de produção, emprego, renda e importação.

\subsection{Produto Interno Bruto florestal acreano}

No Brasil, as informações referentes ao Produto Interno Bruto (PIB) são divulgadas por órgãos oficiais como IBGE e IPEA. Com relação aos PIBs setoriais, não existe uma divulgação para todos os estados brasileiros, nem para todos os setores de atividade. Nesse trabalho foi calculado o PIB Florestal acreano para o ano de 1999, utilizando-se as informações da matriz de insumo-produto.

A Tabela 30 apresenta o PIB das macro regiões brasileiras e do Brasil para o ano 2000. Como se pode observar, a região Sudeste é a que mais contribui para o PIB nacional $(57,79 \%)$ enquanto que a região Norte é a que menos contribui, participando em apenas 4,6\% do PIB nacional. 
Tabela 30. Produto Interno Bruto (R milhão e \%) das macro regiões brasileiras e do Brasil para o ano 2000.

\begin{tabular}{lcc}
\hline \multicolumn{1}{c}{ Região } & R\$ milhão & $\begin{array}{c}\text { Participação (\%) no } \\
\text { PIB Brasil }\end{array}$ \\
\hline Norte & $50.650,00$ & 4,60 \\
Nordeste & $144.135,00$ & 13,09 \\
Centro-Oeste & $76.542,00$ & 6,95 \\
Sudeste & $636.394,00$ & 57,79 \\
Sul & $193.534,00$ & 17,57 \\
Brasil & $1.101 .255,00$ & 100,00 \\
\hline
\end{tabular}

Fonte: IBGE

De acordo com as informações divulgadas pelo Departamento de Contas Nacionais do IBGE a respeito das Contas Regionais do Brasil, temos que o PIB a preço de mercado corrente do estado do Acre vem aumentado ao longo dos anos. Em 1997 o PIB do Acre foi de R\$ 1,31 bilhão, passando para R \$ 1,45 bilhão em 1998, R 1,56 bilhão em 1999 e R\$ 1,70 bilhão em 2000. O PIB acreano calculado neste trabalho, a partir da matriz de insumo-produto, para o ano de 1999 foi de R\$ 1,54 bilhão. A pequena diferença entre esse valor e o divulgado pelo IBGE deve-se a arredondamentos e eventuais erros acumulados ao longo do cálculo.

Levando-se em conta a participação dos estados da Região Norte no valor do PIB dessa região, do ano 2000, temos que o Acre participa com 3,36\% (R\$ 1,7 bilhão) e os estados do Pará e Amazonas participam com, respectivamente, 37,34\% e 37,26\% (Figura 19). 


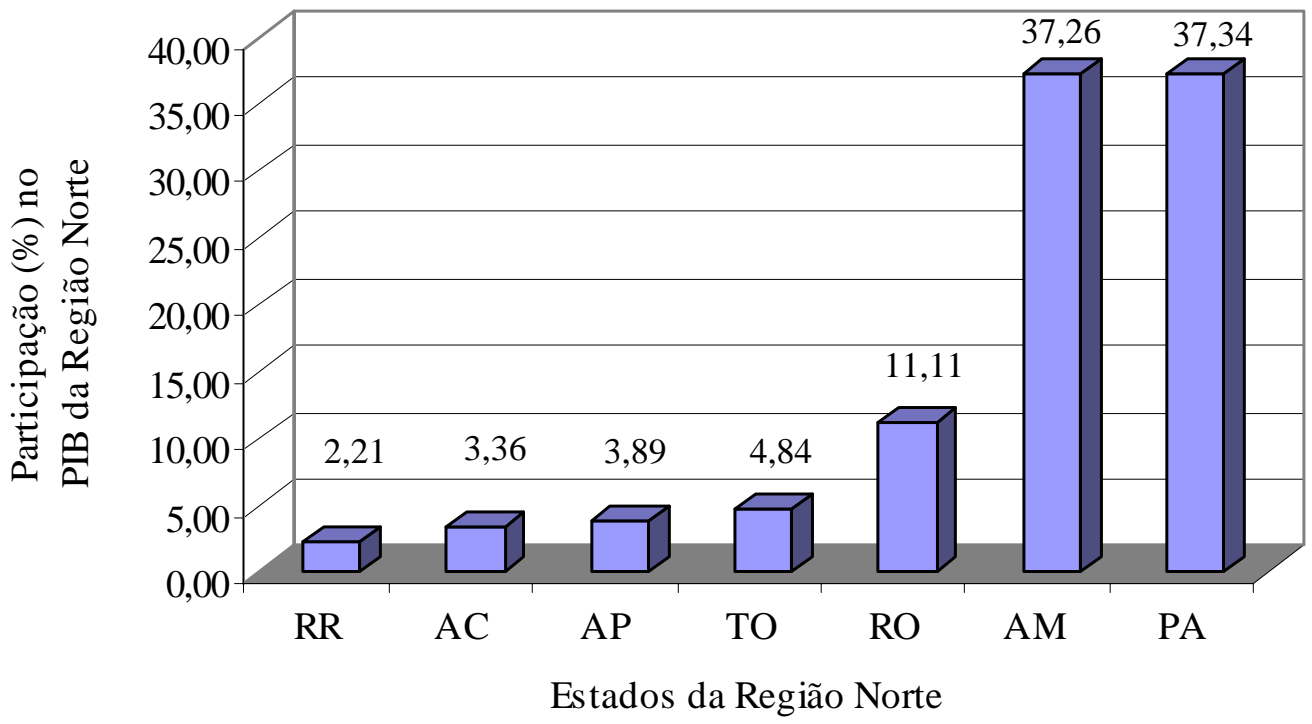

Figura 19 - Participação (\%) dos estados da Região Norte brasileira no PIB da Região, 2000.

O PIB Florestal Acreano também calculado no presente trabalho a partir da matriz de insumo-produto apresentou algumas particularidades com relação a adaptação da metodologia desenvolvida, para o PIB do Agronegócio, por Furtuoso (1998) e aperfeiçoada por Guilhoto, Furtuoso e Silva (2002). Essas particularidades, no entanto, dizem respeito aos setores componentes dos quatro agregados que, quando somados, resultaram no valor do PIB Florestal do Estado do Acre. A seguir é feito um detalhamento desses agregados:

- Agregado I: Indústria para o setor florestal - do qual fazem parte todos os setores que oferecem produtos e serviços para o setor florestal, isto é, dos 53 setores da matriz insumo-produto do estado do Acre, excluiu-se apenas o setor 5 correspondente ao Extrativismo vegetal e silvicultura;

- Agregado II: O próprio setor florestal - considera-se o valor adicionado pelo setor Extrativismo vegetal e silvicultura;

- Agregado III: Indústria de base florestal - do qual fazem parte os setores: Indústria da madeira (15), Indústria do mobiliário (16) e Indústria da Borracha 
(19) que, para o caso da economia acreana configuram-se como os principais setores demandantes de produtos florestais e também como aqueles que efetuam a primeira, segunda e terceira transformação das matérias-primas florestais. Cabe destacar que 79,64\% das vendas do setor Extrativismo vegetal e silvicultura destinam-se a esses setores. Outro ponto importante é que outros setores relacionados direta e indiretamente ao setor florestal tais como Fabricação de celulose, pasta mecânica, papel, papelão e artefatos de papel (17), Indústria editorial e gráfica (18) e Metalurgia básica (9) não se destacaram, no caso da economia acreana, como principais compradores do setor florestal. Por isso, não entraram na composição do PIB do agregado III. O setor Fabricação de celulose, pasta mecânica, papel, papelão e artefatos de papel não se destacou como comprador do setor florestal (Silvicultura) pelo fato de que, no caso específico do estado do Acre, não existem plantios comerciais das espécies geralmente utilizadas na fabricação de celulose e papel (Eucalyptus spp e Pinus spp).

- Agregado IV: Distribuição final - considerou-se o valor adicionado pelos setores: Comércio (35), Transporte rodoviário (36), Transporte aéreo (37), Transporte ferroviário (38), Transporte aquaviário (39), Atividades auxiliares dos transportes (40), Comunicações (41), Instituições financeiras (42), Saúde mercantil (43), Educação mercantil (44), Serviços de alojamento e alimentação (45), Outros serviços prestados à família (46), Serviços prestados à empresa (47), Aluguel de imóveis (48), Saúde pública (49), Educação pública (50), Segurança pública (51), Outros administração pública (52) e Serviços privados não mercantis (53).

Dada essa agregação, temos que o PIB do Agregado I correspondeu a R\$ 0,21 milhão, do Agregado II foi equivalente a R \$ 4,70 milhões, do Agregado III a R 7,63 milhões e do Agregado IV a R\$ 5,23 milhões. Que resulta, pela soma desses quatro valores, em um PIB Florestal de R\$ 17,78 milhões. Esse valor correspondente a 1,15\% do PIB total acreano. 


\subsection{Aplicação dos resultados}

Sempre que se pensa em propor políticas que visem o desenvolvimento dos estados da Amazônia brasileira, surge o dilema entre desenvolvimento vs. degradação ambiental (desmatamento).

Siqueira e Siffert Filho (2001) destacam que a definição de uma política de desenvolvimento regional deve levar em consideração as especificidades de cada uma das regiões em termos de oportunidades de investimento, das restrições ambientais e dos problemas sociais.

O estado do Acre encontra-se em posição de destaque com relação aos demais estados que compõem a Amazônia Brasileira uma vez que apresenta um estudo detalhado dos recursos naturais e meio ambiente; aspectos socioeconômicos e de ocupação territorial e dos indicativos para a sua gestão territorial. Esses estudos fazem parte do Zoneamento Ecológico-Econômico do estado (ZEE-AC), publicado em 2000.

As vantagens comparativas do estado, as restrições ambientais de cada atividade e as questões sociais relacionadas aos povos ribeirinhos e indígenas foram levadas em consideração nesse zoneamento. Dessa forma, foram apontadas como as de maior capacidade de impulsionar o desenvolvimento do estado as seguintes atividades: a madeireira; a consolidação e criação de Reservas Extrativistas e de Projetos de Assentamento Agroextrativistas, de terras indígenas, e de Unidades de Conservação ou Preservação; a agricultura familiar; os empreendimentos agropecuários de médio e grande porte; e o turismo. O volume III do ZEE-AC apresenta uma detalhada descrição dessas atividades (Acre, 2000).

Um dos pontos que mais chamam a atenção nos resultados apresentados por esta pesquisa é o fato de que o setor florestal não se configura entre os setores-chave para o desenvolvimento econômico do Estado do Acre, de acordo com a metodologia e os critérios utilizados.

Entretanto, alguns pontos devem ser levados em consideração com relação ao desempenho do setor florestal no estado do Acre: i) a ausência de políticas de apoio ao setor extrativista acreano fragilizou a atividade nos seringais e levou os extrativistas à 
busca de alternativas econômicas de subsistência tais como a lavoura e a criação de gado (Acre, 2000); ii) estima-se que $80 \%$ da madeira retirada da floresta amazônica são extraídos por meios ilegais, provocando um grande impacto ambiental (Siqueira, 2001). Esses dois pontos ajudam a explicar o porquê do setor florestal não estar entre os chave para o desenvolvimento econômico do estado.

Contudo, constatou-se no presente estudo que setores como Saúde pública, Serviços prestados às empresas, Outros administração pública, Serviços Industriais de Utilidade Pública estiveram entre os setores-chave do estado. Esse resultado vai de encontro com os resultados apresentados no ZEE-AC que estabelece algumas condições para que as atividades descritas anteriormente e identificadas como importantes para gestão territorial do estado permitam sua expansão em bases sustentáveis.

Através do Zoneamento da atividade madeireira no Acre, apresentado no ZEEAC, tem-se que as áreas proibidas à exploração madeireira representariam 19\% do território acreano. Outros 20\% de seu território são áreas que teriam que ser protegidas e onde a atividade madeireira só poderia ocorrer sob regime de manejo. As áreas que apresentam cobertura florestal e não são protegidas representariam 53\% do Acre. E que apenas $8 \%$ do território acreano se encontraria desmatado.

Esses dados reforçam a vocação florestal do estado. No entanto, para que essa vocação se materialize em desenvolvimento econômico para o estado, uma série de políticas públicas seriam necessárias. Dentre essas, destacam-se a melhoria das condições infra-estruturais: transporte, saneamento básico (água e esgoto), energia elétrica; o investimento em capacitação (treinamento e extensão florestal); a regularização fundiária (das reservas extrativistas e dos projetos de assentamento agroextrativistas); o investimento em saúde e educação; a realização de estudos relacionados a cadeias produtivas; a melhoria dos meios de comunicação e a criação de linhas de crédito específicas para as atividades relacionadas ao setor florestal (produtos madeireiros e não madeireiros).

Diante do exposto tem-se que mesmo que no presente estudo o setor florestal não tenha sido considerado chave, os setores dos quais o setor florestal depende para a sua efetiva consolidação o foram. E, dessa forma, tem-se que a matriz insumo-produto 
construída no presente trabalho permite uma análise diferenciada dos setores produtivos acreanos. Pode-se afirmar, portanto, que ao identificar os setores que apresentam fortes interligações com os demais setores do estado sob a ótica de fornecedores e demandantes de insumos, este estudo oferece o instrumental analítico básico para consolidar políticas de desenvolvimento que queiram incluir o setor florestal como um dos alicerces desse processo. 


\section{CONCLUSÕES}

Este trabalho teve o objetivo de analisar o estado do Acre sob duas óticas: das suas relações intersetoriais para assim identificar os setores importantes para o desenvolvimento do estado e, das relações inter-regionais de modo a identificar a dependência do estado com relação as regiões resto do Norte e resto do Brasil, consideradas no presente estudo.

A mensuração das ligações industriais e a identificação de setores-chave com base nos índices de Hirschman-Rasmussen indicam padrões semelhantes para as economias do Acre e resto do Norte no entanto, esse padrão difere do identificado para o resto do Brasil. Para as duas primeiras regiões o padrão identificado sugere que os setores mais interligados nessas economias o são com os setores fornecedores de insumos. Já o resto do Brasil apresenta uma estrutura setorial melhor articulada tanto com relação aos setores demandantes como com relação aos setores ofertantes de insumos.

Através da análise desses índices tem-se que as três economias são bastante diversificadas em termos de número de setores demandantes e ofertantes de insumos. Entretanto, os setores Metalurgia básica, Indústria têxtil e Indústria de alimentos podem ser considerados setores-chave para as três regiões, de acordo com o critério restrito (índices para frente e para trás maiores que um simultaneamente) e, por isso, podem ser considerados os principais estimuladores da atividade econômica dessas regiões.

Considerando os setores com maiores índices de Hirschman-Rasmussen para trás, vinte e um setores merecem destaque dos quais, nove apresentam relação direta com o setor primário acreano, seja ele agropecuário ou florestal. Dessa forma, os setores 
Aves e Abate de suínos e outros possuem relação direta com a pecuária acreana. Os setores Indústria têxtil, Beneficiamento de produtos vegetais e Indústria de alimentos são responsáveis pela transformação dos insumos de base agrícola em produtos de maior valor agregado. Já os setores relacionados ao setor florestal que merecem destaque como demandantes de insumos dos demais setores da economia acreana são: Fabricação de celulose,papel, papelão e artefatos de papel, Indústria editorial e gráfica, Indústria da borracha e Indústria do mobiliário.

Já os setores Agricultura, Indústria de alimentos, Indústria têxtil e Outros pecuária que possuem relação direta com o setor primário do estado destacaram-se como ofertantes de insumos para os demais setores da economia.

A mensuração dos índices puros de ligação permitiu identificar dezessete setores-chave na estrutura produtiva do Acre sendo dois deles atividades primárias (Agricultura e Outros pecuária), outros três relacionam-se ao setor secundário (Construção civil, Indústria de alimentos e Abate de suínos e outros) e doze fazem parte do setor terciário.

Dessas duas constatações, tem-se que, em termos de ligações intersetoriais os setores de base primária acreanos, juntamente com os setores relacionados a comércio e serviços apresentam destaque. O que confirma a hipótese inicial do presente trabalho de que os setores ligados à agricultura juntamente com os setores relacionados ao comércio e serviços constituem a base da economia acreana.

Através da decomposição da produção total em produção induzida pela demanda final da própria região, e produção induzida pela demanda final das demais regiões do sistema econômico, identificou-se que, no Acre, 95,95\% de sua produção total é induzida pela sua própria demanda final. Ou seja, um aumento na demanda final do Acre causa maior impacto na produção dos setores localizados dentro da própria região do que na produção dos setores localizados nas regiões resto do Norte e resto do Brasil, o que sugere uma pequena interação desse estado com as demais regiões do sistema.

Os multiplicadores de produção reforçam a análise de dependência entre as regiões. De acordo com esse indicador, a variação na demanda final dos setores do Acre 
afeta mais a produção da economia do resto do Brasil do que do resto do Norte. Isso indica que a economia acreana depende menos da região Norte e mais do resto do Brasil. Da mesma forma, verificou-se que aumentos na demanda final dos setores localizados no resto do Norte ou no resto do Brasil quase não influenciam a produção dos setores localizados no Acre. Isso .sugere que as produções dos setores dessas duas regiões são independentes dos insumos produzidos no Acre.

Em termos de capacidade de estimular a produção, a geração de empregos, de renda e de importações nos demais setores da economia, os setores acreanos que mais se destacaram, em termos de multiplicadores tipo I, foram os relacionados a Abate de animais (aves, bovinos e suínos e outros), à Metalurgia básica e à Indústria têxtil. Quando o consumo das famílias é considerado no sistema, os setores relacionados a Comércio e Serviços passam a ser mais expressivos.

Em termos de geração de empregos, os setores Extrativismo vegetal e silvicultura, Indústria da madeira, Indústria do mobiliário, Fabricação de celulose, pasta mecânica, papel, papelão e artefatos de papel, Indústria editorial e gráfica e Indústria da borracha da economia acreana estiveram entre os vinte setores mais importantes em termos de número total de empregos gerados e em termos de número de empregos diretos gerados.

Já os setores Indústria do mobiliário, Indústria da borracha e Indústria da Madeira estiveram entre os vinte mais importantes na geração de empregos indiretos e Fabricação de celulose, pasta mecânica, papel, papelão e artefatos de papel se destacou na geração de empregos induzidos.

Com relação aos multiplicadores de renda, os setores Metalurgia Básica (Fundição), Abate de aves, de bovinos e de suínos e outros e Automóveis, caminhões, ônibus e peças merecem destaque. De acordo com os multiplicadores de importação os setores relacionados a Abate de animais, Saúde mercantil e Indústria da madeira merecem destaque pelo fato de que uma variação na demanda final desses setores ocasionam um aumento nas importações de todos os setores da economia.

Os setores Fabricação de celulose, pasta mecânica, papel, papelão e artefatos de papel, Indústria da borracha e Indústria editorial e gráfica da economia acreana 
ocuparam a nona, décima primeira e décima quarta posição, respectivamente, em termos de multiplicador tipo I. E em termos de multiplicador tipo II ocuparam, respectivamente, a décima, nona e décima quinta posição. Os três setores também se destacaram mais como geradores de renda indireta do que direta.

Já os setores Indústria da madeira e do mobiliário se destacaram na geração de renda no próprio setor. O setor Extrativismo vegetal e silvicultura, no entanto, apresentou equilíbrio tanto na geração de renda no próprio setor (direta) quanto nos demais setores (indireta).

Esses setores, no entanto, não apresentaram boas colocações com relação à geração total de importações. Mas, os setores Indústria da borracha, Indústria editorial e gráfica e Fabricação de celulose, papel, papelão e artefatos de papel estiveram entre os vinte principais setores de maior capacidade de geração de importação direta. Com relação a geração de importação indireta, apenas o setor Indústria da borracha ficou entre os vinte primeiros setores.

As análises realizadas no presente trabalho permitiram identificar que o estado do Acre é mais dependente do resto do Brasil do que o resto do Norte. Como sugestão para trabalhos futuros propõem-se a abertura da região resto do Brasil em seus diversos estados componentes e a comparação dessas economias com a do Acre. Com isso, poder-se-á identificar de qual estado do resto do Brasil propriamente dito o Acre é mais dependente bem como será possível inferir sobre a dependência desses estados com relação à economia acreana.

Uma segunda sugestão refere-se às análises de impacto. Este trabalho identifica os setores com maior poder de encadeamento dentro da economia acreana. Seria interessante que um outro estudo identificasee o impacto de variações nas exportações e/ou investimentos nesses setores sobre a geração de produção, de emprego e de valor adicionado nas demais economias de outras regiões.

Este trabalho procurou caracterizar o Acre sob a ótica de suas relações intersetoriais e inter-regionais (com as regiões resto do Norte e resto do Brasil). No entanto, restam ainda algumas lacunas quanto à acuidade dos dados que somente podem ser preenchidas após o efetivo envolvimento de entidades do próprio governo acreano. 
Propõem-se um refinamento, apoiado por uma parceira da Universidade com o Governo Estadual do Acre, das bases de dados usadas neste trabalho, para que o método aqui desenvolvido possa gerar uma ferramenta mais eficaz e precisa de simulações de políticas públicas para o Estado do Acre.

Mesmo sendo um estado florestal por vocação, a efetiva consolidação do desenvolvimento do Acre, com base nesse setor, depende de uma série de estratégias já identificadas no seu Zoneamento Ecológico-Econômico - para que se alcance esse objetivo.

Este trabalho analisa a economia acreana em um importante momento de sua história econômica. O estado vem passando por intensas transformações em sua economia local por conta da integração econômica, comercial e cultural do Estado com os países andinos, através das suas principais vias de acesso rodoviário (BR-364 e BR317) permitindo, assim, o acesso aos portos do Pacífico. A análise insumo-produto utilizada no presente trabalho mostrou-se bastante apropriada para apoiar a discussão de políticas que orientem o desenvolvimento futuro do Acre e as decisões que os seus governantes terão que tomar.

As futuras mudanças na rede de transportes do Acre e a integração que esses investimentos provocarão certamente alterarão as relações intersetoriais e inter-regionais acreanas. É uma expectativa que este trabalho, nesse momento, venha a servir de base para as devidas comparações da estrutura produtiva acreana antes e depois da integração com os países andinos. 
ANEXOS 
Tabela 31. Número de Empresas e Pessoal ocupado segundo categorias de atividades C, D, E e F do Estado do Acre, para o ano 2001.

\begin{tabular}{|c|c|c|c|c|}
\hline Categorias & $\begin{array}{l}\text { Número de } \\
\text { empresas } \\
\text { (Unidade) }\end{array}$ & $\begin{array}{c}\text { Participação no } \\
\text { total de empresas } \\
\text { de cada categoria } \\
(\%)\end{array}$ & $\begin{array}{l}\text { Pessoal ocupado } \\
\text { (PO) total } \\
\text { (Pessoas) }\end{array}$ & $\begin{array}{l}\text { Participação no PO } \\
\text { total de cada } \\
\text { categoria } \\
(\%)\end{array}$ \\
\hline C Indústrias extrativas & 16 & 100,00 & 35 & 100,00 \\
\hline \multicolumn{5}{|l|}{ Extração de minerais não-metálicos } \\
\hline Extração de pedra, areia e argila & 16 & 100,00 & 35 & 100,00 \\
\hline D Indústrias de transformação & 740 & 100,00 & 3.696 & 99,16 \\
\hline Fabricação de produtos alimentícios e bebidas & 190 & 25,68 & 1.223 & 33,09 \\
\hline Fabricação de produtos do fumo & 2 & 0,27 & $\mathrm{X}$ & $\mathrm{X}$ \\
\hline Fabricação de produtos têxteis & 15 & 2,03 & 45 & 1,22 \\
\hline Confecção de artigos do vestuário e acessórios & 34 & 4,59 & 67 & 1,81 \\
\hline Preparação couros, fabricação artefatos de couro, artigos de viagem, calçados & 8 & 1,08 & 12 & 0,32 \\
\hline Fabricação de produtos de madeira & 140 & 18,92 & 940 & 25,43 \\
\hline Fabricação de celulose, papel e produtos de papel & 5 & 0,68 & 15 & 0,41 \\
\hline Edição, impressão e reprodução de gravações & 71 & 9,59 & 330 & 8,93 \\
\hline Fabricação de produtos químicos & 19 & 2,57 & 50 & 1,35 \\
\hline Fabricação de artigos de borracha e plástico & 10 & 1,35 & 73 & 1,98 \\
\hline Fabricação de produtos de minerais não-metálicos & 56 & 7,57 & 434 & 11,74 \\
\hline Metalurgia Básica & 4 & 0,54 & 8 & 0,22 \\
\hline Fabricação de produtos de metal - exclusive máquinas e equipamentos & 38 & 5,14 & 103 & 2,79 \\
\hline Fabricação de máquinas e equipamentos & 15 & 2,03 & 37 & 1,00 \\
\hline Fabricação de máquinas, aparelhos e materiais elétricos & 2 & 0,27 & $\mathrm{X}$ & $\mathrm{X}$ \\
\hline $\begin{array}{l}\text { Fabricação de material eletrônico e de aparelhos e equipamentos de } \\
\text { comunicações }\end{array}$ & 2 & 0,27 & $\mathrm{X}$ & $\mathrm{X}$ \\
\hline Fab. instrumentos médicos, de precisão, ópticos e de relojoaria & 7 & 0,95 & 8 & 0,22 \\
\hline Fabricação e montagem de veículos automotores, reboques e carrocerias & 10 & 1,35 & 30 & 0,81 \\
\hline Fabricação de outros equipamentos de transporte & 3 & 0,41 & 4 & 0,11 \\
\hline Fabricação de móveis e indústrias diversas & 106 & 14,32 & 282 & 7,63 \\
\hline Reciclagem & 3 & 0,41 & 4 & 0,11 \\
\hline
\end{tabular}


Tabela 31. Número de Empresas e Pessoal ocupado segundo categorias de atividades C, D, E e F do Estado do Acre, para o ano 2000.

\begin{tabular}{|c|c|c|c|c|}
\hline Categorias & $\begin{array}{l}\text { Número de } \\
\text { empresas } \\
\text { (Unidade) }\end{array}$ & $\begin{array}{l}\text { Participação no total } \\
\text { de empresas de cada } \\
\text { categoria } \\
(\%)\end{array}$ & $\begin{array}{c}\text { Pessoal ocupado (PO) } \\
\text { total } \\
\text { (Pessoas) }\end{array}$ & $\begin{array}{c}\text { Participação no PO total } \\
\text { de cada categoria } \\
(\%)\end{array}$ \\
\hline E Produção e distribuição de eletricidade, gás e água & 7 & 100,00 & 710 & 69,72 \\
\hline \multicolumn{5}{|l|}{ Eletricidade, gás e água quente } \\
\hline Produção e distribuição de energia elétrica & 2 & 28,57 & $\mathrm{X}$ & $\mathrm{X}$ \\
\hline Captação, tratamento e distribuição de água & 5 & 71,43 & 495 & 69,72 \\
\hline F Construção & 413 & 100,00 & 3.215 & 99,92 \\
\hline \multicolumn{5}{|l|}{ Construção } \\
\hline Preparação do terreno & 24 & 5,81 & 240 & 7,47 \\
\hline Construção de edifícios e obras de engenharia civil & 317 & 76,76 & 2.225 & 69,21 \\
\hline Obras de infra-estrutura para engenharia elétrica e de telecomunicações & 10 & 2,42 & 345 & 10,73 \\
\hline Obras de instalações & 20 & 4,84 & 12 & 9,70 \\
\hline Obras de acabamento & 40 & 9,69 & 88 & 2,74 \\
\hline Aluguel de equipamentos de construção e demolição com operários & 2 & 0,48 & $\mathrm{X}$ & $\mathrm{X}$ \\
\hline
\end{tabular}

Fonte: IBGE (2001)

Nota: os dados com menos de 3 (três) informantes estão desidentificados com o caracter X. 
Tabela 32. Número de empresas e pessoal ocupado segundo categorias de atividades, G até O, para o Estado do Acre, para o ano 2001.

\begin{tabular}{|c|c|c|c|c|}
\hline Categorias & $\begin{array}{l}\text { Número de } \\
\text { empresas } \\
\text { (Unidade) }\end{array}$ & $\begin{array}{c}\text { Participação no } \\
\text { total de empresas } \\
\text { de cada categoria } \\
\text { (\%) }\end{array}$ & $\begin{array}{l}\text { Pessoal ocupado } \\
\text { (PO) total } \\
\text { (Pessoas) }\end{array}$ & $\begin{array}{c}\text { Participação no PO total } \\
\text { de cada categoria } \\
(\%)\end{array}$ \\
\hline G Comércio; reparação de veículos automotores, objetos pessoais e domésticos & 4.901 & 100,00 & 13.104 & 100,00 \\
\hline Comércio,reparação veículos automotores,motocicletas; combustíveis; varejo & 435 & 8,88 & 1.931 & 14,74 \\
\hline Comércio por atacado e representantes comerciais e agentes do comércio & 431 & 8,79 & 1.695 & 12,93 \\
\hline Comércio varejista e reparação de objetos pessoais e domésticos & 4.035 & 82,33 & 9.478 & 72,33 \\
\hline H Alojamento e alimentação & 360 & 100,00 & 1.452 & 100,00 \\
\hline Estabelecimentos hoteleiros e outros tipos de alojamento temporário & 63 & 17,50 & 481 & 33,13 \\
\hline Restaurantes e outros estabelecimentos de serviços de alimentação & 297 & 82,50 & 971 & 66,87 \\
\hline I Transporte, armazenagem e comunicações & 155 & 100,00 & 2.015 & 100,00 \\
\hline Transporte terrestre & 79 & 50,97 & 1.217 & 60,40 \\
\hline Transporte aquaviário & 5 & 3,23 & 23 & 1,14 \\
\hline Transporte aéreo & 10 & 6,45 & 186 & 9,23 \\
\hline Atividades anexas e auxiliares do transporte e agências de viagem & 44 & 28,39 & 501 & 24,86 \\
\hline Correio e telecomunicações & 17 & 10,97 & 88 & 4,37 \\
\hline J Intermediação financeira & 182 & 100,00 & 284 & 100,00 \\
\hline Intermediação financeira, exclusive seguros e previdência privada & 158 & 86,81 & 147 & 51,76 \\
\hline Seguros e previdência privada & 5 & 2,75 & 81 & 28,52 \\
\hline Atividades auxiliares da intermediação financeira & 19 & 10,44 & 56 & 19,72 \\
\hline K Atividades imobiliárias, aluguéis e serviços prestados às empresas & 458 & 100,00 & 2.458 & 100,00 \\
\hline Atividades imobiliárias & 42 & 9,17 & 184 & 7,49 \\
\hline $\begin{array}{l}\text { Aluguel veículos,máquinas,equip s/ condutores,operadores,obj } \\
\text { pessoais,domésticos }\end{array}$ & 44 & 9,61 & 86 & 3,50 \\
\hline Atividades de informática e conexas & 49 & 10,70 & 220 & 8,95 \\
\hline Pesquisa e desenvolvimento & 6 & 1,31 & 309 & 12,57 \\
\hline Serviços prestados principalmente às empresas & 317 & 69,21 & 1.659 & 67,49 \\
\hline
\end{tabular}


Tabela 32. Número de empresas e pessoal ocupado segundo categorias de atividades, G até O, para o Estado do Acre, para o ano 2001.

\begin{tabular}{|c|c|c|c|c|}
\hline Categorias & $\begin{array}{l}\text { Número de } \\
\text { empresas } \\
\text { (Unidade) }\end{array}$ & $\begin{array}{l}\text { Participação no total de } \\
\text { empresas de cada } \\
\text { categoria } \\
(\%)\end{array}$ & $\begin{array}{l}\text { Pessoal ocupado } \\
\text { (PO) total } \\
\text { (Pessoas) }\end{array}$ & $\begin{array}{c}\text { Participação no PO total de } \\
\text { cada categoria } \\
(\%)\end{array}$ \\
\hline L Administração pública, defesa e seguridade social & 74 & 100,00 & 40.936 & 100,00 \\
\hline Administração do estado e da política econômica e social & 69 & 93,24 & 37.963 & 92,74 \\
\hline Serviços coletivos prestados pela administração pública & 5 & 6,76 & 2.973 & 7,26 \\
\hline M Educação & 200 & 100,00 & 1.877 & 100,00 \\
\hline Educação pré-escolar e fundamental & 122 & 61,00 & 534 & 28,45 \\
\hline Educação média de formação geral, profissionalizante ou técnica & 27 & 13,50 & 233 & 12,41 \\
\hline Educação superior & 5 & 2,50 & 901 & 48,00 \\
\hline Formação permanente e outras atividades de ensino & 46 & 23,00 & 209 & 11,13 \\
\hline N Saúde e serviços sociais & 121 & 100,00 & 1.891 & 100,00 \\
\hline Atividades de atenção à saúde & 101 & 83,47 & 1.458 & 77,10 \\
\hline Serviços veterinários & 3 & 2,48 & 8 & 0,42 \\
\hline Serviços sociais & 17 & 14,05 & 425 & 22,47 \\
\hline O Outros serviços coletivos, sociais e pessoais & 955 & 100,00 & 2.397 & 100,00 \\
\hline Limpeza urbana e esgoto; e atividades conexas & 9 & 0,94 & 9 & 0,38 \\
\hline Atividades associativas & 737 & 77,17 & 1.466 & 61,16 \\
\hline Atividades recreativas, culturais e desportivas & 113 & 11,83 & 733 & 30,58 \\
\hline Serviços pessoais & 96 & 10,05 & 189 & 7,88 \\
\hline
\end{tabular}

\section{Fonte: IBGE (2001)}

Nota: os dados com menos de 3 (três) informantes estão desidentificados com o caracter X. 
Tabela 33. Índices de ligação de Hirschman-Rasmussen para trás e para frente para o sistema inter-regional Acre, resto do Norte e resto do Brasil (1999) - índices dependentes* .

\begin{tabular}{|c|c|c|c|c|c|c|c|c|c|c|c|c|c|}
\hline \multirow{2}{*}{\multicolumn{2}{|c|}{ Setores }} & \multicolumn{6}{|c|}{ Índices de Ligações para Frente } & \multicolumn{6}{|c|}{ Índices de Ligações para Trás } \\
\hline & & Acre & Ordem & $\begin{array}{l}\text { Resto } \\
\text { Norte }\end{array}$ & Ordem & $\begin{array}{l}\text { Resto } \\
\text { Brasil }\end{array}$ & Ordem & Acre & Ordem & $\begin{array}{l}\text { Resto } \\
\text { Norte }\end{array}$ & Ordem & $\begin{array}{l}\text { Resto } \\
\text { Brasil }\end{array}$ & Ordem \\
\hline 1 & Agricultura & 1,072 & 35 & 1,142 & 31 & 3,646 & 2 & 0,863 & 121 & 0,839 & 123 & 0,905 & 112 \\
\hline 2 & Aves & 0,660 & 106 & 0,715 & 86 & 1,535 & 18 & 1,244 & 17 & 1,208 & 22 & 1,229 & 20 \\
\hline 3 & Bovinos & 0,675 & 101 & 1,044 & 38 & 1,562 & 17 & 1,063 & 59 & 1,047 & 63 & 1,050 & 62 \\
\hline 4 & Outros Pecuária & 0,780 & 70 & 0,929 & 50 & 1,355 & 24 & 1,046 & 64 & 1,016 & 78 & 1,026 & 70 \\
\hline 5 & Ext. Veg. e Silv. & 0,685 & 96 & 0,748 & 75 & 0,977 & 43 & 0,741 & 141 & 0,717 & 145 & 0,736 & 142 \\
\hline 6 & Ext. Animal & 0,564 & 147 & 0,564 & 146 & 0,564 & 145 & 0,774 & 134 & 0,753 & 139 & 0,765 & 137 \\
\hline 7 & Ext.Mineral & 0,608 & 126 & 0,793 & 67 & 2,368 & 7 & 0,946 & 101 & 0,961 & 92 & 0,894 & 117 \\
\hline 8 & Min. não Metálico & 0,712 & 88 & 0,714 & 87 & 1,254 & 28 & 0,960 & 94 & 0,902 & 114 & 1,081 & 53 \\
\hline 9 & Metal. Básica & 1,188 & 30 & 0,878 & 54 & 3,506 & 4 & 1,337 & 10 & 1,112 & 43 & 1,339 & 9 \\
\hline 10 & Outros Metalúrg. & 0,793 & 66 & 0,767 & 72 & 1,785 & 13 & 1,181 & 25 & 1,145 & 38 & 1,276 & 14 \\
\hline 11 & Máq. E Equip. & 0,798 & 65 & 0,706 & 90 & 1,516 & 19 & 0,752 & 140 & 0,832 & 128 & 0,953 & 99 \\
\hline 12 & Mat. Elétrico & 0,680 & 98 & 0,644 & 113 & 0,837 & 59 & 1,265 & 16 & 1,022 & 72 & 1,241 & 18 \\
\hline 13 & Equip. Eletrôn. & 0,669 & 103 & 0,636 & 116 & 0,668 & 104 & 0,943 & 102 & 0,721 & 144 & 1,017 & 76 \\
\hline 14 & Aut., Cam., Ôn. e Peças & 0,567 & 142 & 0,828 & 60 & 1,392 & 22 & 1,158 & 34 & 0,955 & 97 & 1,167 & 31 \\
\hline 15 & Ind. Da Madeira & 0,691 & 94 & 0,783 & 69 & 0,855 & 57 & 0,835 & 126 & 0,960 & 93 & 1,026 & 69 \\
\hline 16 & Ind. Do Mobiliário & 0,574 & 140 & 0,578 & 137 & 0,654 & 110 & 1,023 & 71 & 1,020 & 74 & 1,133 & 41 \\
\hline 17 & Cel.,Pap.,Papelão e Art. Pap. & 0,705 & 91 & 0,733 & 79 & 1,869 & 11 & 1,041 & 66 & 1,019 & 75 & 1,180 & 26 \\
\hline 18 & Ind. Ed. e Gráfica & 0,621 & 119 & 0,671 & 102 & 1,033 & 40 & 1,044 & 65 & 1,055 & 60 & 1,176 & 28 \\
\hline 19 & Ind. Da Borracha & 0,738 & 77 & 0,715 & 85 & 1,271 & 27 & 1,153 & 36 & 0,998 & 86 & 1,177 & 27 \\
\hline 20 & Elem. Químicos & 0,651 & 111 & 0,611 & 123 & 1,796 & 12 & 0,896 & 115 & 0,825 & 129 & 1,041 & 67 \\
\hline 21 & Quím. diversos & 1,044 & 39 & 1,082 & 34 & 10,613 & 1 & 1,164 & 32 & 0,959 & 95 & 1,106 & 48 \\
\hline 22 & Farm. e Veterin. & 0,609 & 124 & 0,608 & 125 & 0,814 & 63 & 0,914 & 108 & 0,903 & 113 & 1,050 & 61 \\
\hline 23 & Art. Plásticos & 0,728 & 83 & 0,748 & 74 & 1,230 & 29 & 1,109 & 45 & 0,956 & 96 & 1,152 & 37 \\
\hline 24 & Ind. Têxtil & 0,905 & 51 & 0,960 & 48 & 2,042 & 9 & 1,352 & 7 & 1,079 & 54 & 1,326 & 12 \\
\hline 25 & Art. do Vestuário & 0,565 & 143 & 0,562 & 148 & 0,582 & 135 & 1,094 & 50 & 1,013 & 82 & 1,216 & 21 \\
\hline 26 & Fab. Calçados & 0,615 & 122 & 0,598 & 129 & 0,687 & 95 & 1,036 & 68 & 0,894 & 116 & 1,144 & 39 \\
\hline 27 & Benef. de Prod.Veg. & 0,604 & 128 & 0,607 & 127 & 1,047 & 37 & 1,107 & 47 & 1,078 & 55 & 1,205 & 23 \\
\hline 28 & Abate de Aves & 0,577 & 138 & 0,571 & 141 & 0,577 & 139 & 1,329 & 11 & 1,275 & 15 & 1,436 & 3 \\
\hline 29 & Abate de Bovinos & 0,658 & 109 & 0,636 & 117 & 0,676 & 100 & 1,385 & 5 & 1,341 & 8 & 1,449 & 2 \\
\hline 30 & Ab. Suínos e Outros & 0,681 & 97 & 0,660 & 107 & 0,730 & 82 & 1,409 & 4 & 1,372 & 6 & 1,453 & 1 \\
\hline 31 & Ind. Alimentos & 0,970 & 45 & 0,952 & 49 & 2,466 & 6 & 1,175 & 29 & 1,110 & 44 & 1,286 & 13 \\
\hline
\end{tabular}


Tabela 33. Índices de ligação de Hirschman-Rasmussen para trás e para frente para o sistema inter-regional Acre, resto do Norte e resto do Brasil (1999) - índices dependentes* .

\begin{tabular}{|c|c|c|c|c|c|c|c|c|c|c|c|c|c|}
\hline \multirow{2}{*}{\multicolumn{2}{|c|}{ Setores }} & \multicolumn{6}{|c|}{ Índices de Ligações para Frente } & \multicolumn{6}{|c|}{ Índices de Ligações para Trás } \\
\hline & & Acre & Ordem & $\begin{array}{l}\text { Resto } \\
\text { Norte }\end{array}$ & Ordem & $\begin{array}{l}\text { Resto } \\
\text { Brasil }\end{array}$ & Ordem & Acre & Ordem & $\begin{array}{l}\text { Resto } \\
\text { Norte }\end{array}$ & Ordem & $\begin{array}{l}\text { Resto } \\
\text { Brasil }\end{array}$ & Ordem \\
\hline 32 & Ind. Diversas & 0,640 & 115 & 0,633 & 118 & 0,860 & 56 & 0,987 & 87 & 0,910 & 109 & 1,072 & 56 \\
\hline 33 & SIUP & 1,132 & 32 & 1,619 & 15 & 2,990 & 5 & 1,239 & 19 & 1,143 & 40 & 0,910 & 110 \\
\hline 34 & Constr. Civil & 0,738 & 78 & 0,711 & 89 & 0,804 & 64 & 1,017 & 77 & 0,915 & 107 & 0,941 & 103 \\
\hline 35 & Comércio & 1,916 & 10 & 1,738 & 14 & 3,630 & 3 & 1,020 & 73 & 0,953 & 98 & 1,013 & 80 \\
\hline 36 & Transp. Rodov. & 1,002 & 41 & 0,971 & 44 & 1,442 & 20 & 1,012 & 83 & 1,015 & 79 & 1,107 & 46 \\
\hline 37 & Transp. Aéreo & 0,731 & 81 & 0,723 & 84 & 0,840 & 58 & 1,089 & 52 & 1,092 & 51 & 1,188 & 24 \\
\hline 38 & Transp. Ferrov. & 0,644 & 114 & 0,663 & 105 & 0,892 & 53 & 0,834 & 127 & 0,890 & 118 & 1,000 & 85 \\
\hline 39 & Transp. Aquav. & 0,615 & 121 & 0,619 & 120 & 0,649 & 112 & 0,980 & 89 & 1,013 & 81 & 1,117 & 42 \\
\hline 40 & Ativ. Aux. Transp. & 0,698 & 92 & 0,692 & 93 & 0,869 & 55 & 0,838 & 124 & 0,870 & 120 & 0,981 & 88 \\
\hline 41 & Comunicações & 0,991 & 42 & 0,904 & 52 & 1,406 & 21 & 1,155 & 35 & 0,768 & 136 & 0,714 & 147 \\
\hline 42 & Inst. Financeiras & 1,048 & 36 & 0,968 & 46 & 1,594 & 16 & 0,857 & 122 & 0,793 & 133 & 0,810 & 131 \\
\hline 43 & Saúde Mercantil & 0,586 & 132 & 0,580 & 136 & 0,587 & 131 & 0,976 & 90 & 0,838 & 125 & 0,929 & 106 \\
\hline 44 & Educ.Mercantil & 0,586 & 133 & 0,584 & 134 & 0,593 & 130 & 0,716 & 146 & 0,661 & 150 & 0,663 & 149 \\
\hline 45 & Serv. Aloj.eAlim. & 0,678 & 99 & 0,659 & 108 & 0,733 & 80 & 1,161 & 33 & 1,064 & 58 & 1,070 & 57 \\
\hline 46 & Out.Serv. Prest. a Fam. & 0,827 & 61 & 0,759 & 73 & 0,820 & 62 & 1,171 & 30 & 0,975 & 91 & 1,102 & 49 \\
\hline & Serv. Prest. à Empresa & 1,274 & 26 & 1,279 & 25 & 2,137 & 8 & 0,808 & 132 & 0,756 & 138 & 0,822 & 130 \\
\hline 48 & Aluguel de Imóveis & 0,777 & 71 & 0,739 & 76 & 0,964 & 47 & 0,611 & 156 & 0,605 & 158 & 0,599 & 159 \\
\hline 49 & Saúde Pública & 0,565 & 144 & 0,562 & 151 & 0,562 & 152 & 0,938 & 105 & 0,951 & 100 & 1,002 & 84 \\
\hline 50 & Educ. Pública & 0,562 & 149 & 0,562 & 150 & 0,562 & 153 & 0,609 & 157 & 0,641 & 152 & 0,698 & 148 \\
\hline 51 & Seg. Pública & 0,561 & 159 & 0,561 & 157 & 0,561 & 155 & 0,872 & 119 & 0,906 & 111 & 0,940 & 104 \\
\hline 52 & Out.Adm. Pública & 1,364 & 23 & 0,788 & 68 & 1,101 & 33 & 0,634 & 153 & 0,725 & 143 & 0,774 & 135 \\
\hline & Serv. Priv. N.Mercantis & 0,561 & 158 & 0,561 & 156 & 0,561 & 154 & 0,647 & 151 & 0,617 & 155 & 0,627 & 154 \\
\hline & Padrão médio de ligações & 0,771 & & 0,775 & & 1,454 & & 1,010 & & 0,947 & & 1,044 & \\
\hline
\end{tabular}

* índices obtidos a partir da matriz inversa de Leontief para o sistema total (159 x 159) 
Tabela 34. Índices de ligação de Hirschman-Rasmussen para trás e para frente para o sistema inter-regional Acre, resto do Norte e resto do Brasil (1999) - índices dependentes*.

\begin{tabular}{|c|c|c|c|c|c|c|c|c|c|c|c|c|c|}
\hline \multirow{2}{*}{\multicolumn{2}{|c|}{ Setores }} & \multicolumn{6}{|c|}{ Índices de Ligações para Frente } & \multicolumn{6}{|c|}{ Índices de Ligações para Trás } \\
\hline & & Acro & Ordem & Resto & Ordem & Resto & Ordem & Acre & Ordem & Resto & Ordem & Resto & Ordem \\
\hline 1 & Agricultura & 1,389 & 6 & 1,438 & 4 & 2,014 & 3 & 0,884 & 42 & 0,886 & 45 & 0,870 & 42 \\
\hline 2 & Aves & 0,856 & 32 & 0,923 & 27 & 0,971 & 19 & 1,298 & 3 & 1,248 & 5 & 1,179 & 9 \\
\hline 3 & Bovinos & 0,875 & 30 & 1,232 & 8 & 1,071 & 15 & 0,947 & 30 & 0,977 & 28 & 1,010 & 27 \\
\hline 4 & Outros Pecuária & 1,010 & 16 & 1,166 & 12 & 1,003 & 18 & 0,953 & 29 & 0,937 & 37 & 0,987 & 30 \\
\hline 5 & Ext. Veg. e Silv. & 0,888 & 26 & 0,936 & 25 & 0,775 & 27 & 0,783 & 50 & 0,799 & 51 & 0,709 & 48 \\
\hline 6 & Ext. Animal & 0,731 & 50 & 0,753 & 48 & 0,546 & 49 & 0,821 & 48 & 0,821 & 49 & 0,738 & 47 \\
\hline 7 & Ext.Mineral & 0,788 & 41 & 0,920 & 29 & 1,298 & 9 & 0,997 & 22 & 0,994 & 24 & 0,859 & 43 \\
\hline 8 & Min. não Metálico & 0,923 & 22 & 0,936 & 26 & 0,900 & 22 & 1,049 & 18 & 1,022 & 17 & 1,034 & 24 \\
\hline 9 & Metal. Básica & 1,541 & 4 & 1,149 & 13 & 1,955 & 4 & 1,430 & 1 & 1,263 & 3 & 1,281 & 4 \\
\hline 10 & Outros Metalúrg. & 1,028 & 15 & 0,992 & 16 & 1,138 & 13 & 1,189 & 5 & 1,011 & 22 & 1,221 & 7 \\
\hline 11 & Máq. e Equip. & 1,034 & 14 & 0,922 & 28 & 1,008 & 17 & 0,854 & 46 & 0,942 & 36 & 0,911 & 37 \\
\hline 12 & Mat. Elétrico & 0,882 & 28 & 0,844 & 36 & 0,693 & 36 & 1,071 & 16 & 0,997 & 23 & 1,190 & 8 \\
\hline 13 & Equip. Eletrôn. & 0,868 & 31 & 0,822 & 39 & 0,619 & 42 & 0,954 & 28 & 0,841 & 48 & 0,981 & 31 \\
\hline 14 & Aut., Cam., Ôn. e Peças & 0,736 & 47 & 0,982 & 17 & 0,926 & 20 & 1,162 & 9 & 0,929 & 39 & 1,102 & 17 \\
\hline 15 & Ind. da Madeira & 0,896 & 25 & 0,973 & 19 & 0,742 & 31 & 0,919 & 37 & 1,019 & 19 & 0,977 & 32 \\
\hline 16 & Ind. do Mobiliário & 0,745 & 46 & 0,770 & 46 & 0,596 & 44 & 1,099 & 15 & 1,082 & 10 & 1,053 & 23 \\
\hline 17 & Cel.,Pap.,Papelão e Art. Pap. & 0,914 & 23 & 0,970 & 20 & 1,265 & 10 & 1,174 & 7 & 1,154 & 8 & 1,122 & 14 \\
\hline 18 & Ind. Ed. e Gráfica & 0,806 & 37 & 0,878 & 31 & 0,795 & 26 & 1,169 & 8 & 1,020 & 18 & 1,125 & 13 \\
\hline 19 & Ind. da Borracha & 0,957 & 18 & 0,940 & 24 & 0,919 & 21 & 1,144 & 11 & 1,046 & 12 & 1,122 & 15 \\
\hline 20 & Elem. Químicos & 0,845 & 34 & 0,809 & 41 & 1,024 & 16 & 0,993 & 23 & 0,959 & 32 & 0,995 & 29 \\
\hline 21 & Quím. diversos & 1,353 & 8 & 1,221 & 9 & 4,356 & 1 & 1,111 & 14 & 0,905 & 43 & 1,054 & 22 \\
\hline 22 & Farm. e Veterin. & 0,789 & 40 & 0,803 & 42 & 0,664 & 39 & 0,982 & 24 & 0,936 & 38 & 1,005 & 28 \\
\hline 23 & Art. Plásticos & 0,944 & 21 & 0,951 & 22 & 0,893 & 23 & 0,941 & 32 & 0,878 & 46 & 1,104 & 16 \\
\hline 24 & Ind. Têxtil & 1,174 & 12 & 1,256 & 7 & 1,395 & 8 & 1,418 & 2 & 1,170 & 7 & 1,268 & 5 \\
\hline 25 & Art. do Vestuário & 0,733 & 48 & 0,751 & 49 & 0,553 & 48 & 1,019 & 20 & 1,107 & 9 & 1,158 & 10 \\
\hline 26 & Fab. Calçados & 0,797 & 39 & 0,799 & 43 & 0,636 & 40 & 1,128 & 12 & 1,046 & 14 & 1,086 & 18 \\
\hline 27 & Benef. de Prod.Veg. & 0,783 & 42 & 0,809 & 40 & 0,744 & 30 & 1,217 & 4 & 1,239 & 6 & 1,147 & 11 \\
\hline 28 & Abate de Aves & 0,749 & 45 & 0,762 & 47 & 0,554 & 47 & 0,874 & 44 & 0,977 & 27 & 1,381 & 3 \\
\hline 29 & Abate de Bovinos & 0,854 & 33 & 0,847 & 35 & 0,634 & 41 & 0,934 & 33 & 1,421 & 1 & 1,383 & 2 \\
\hline 30 & Ab. Suínos e Outros & 0,882 & 27 & 0,875 & 33 & 0,677 & 37 & 1,159 & 10 & 1,343 & 2 & 1,393 & 1 \\
\hline
\end{tabular}


Tabela 34. Índices de ligação de Hirschman-Rasmussen para trás e para frente para o sistema inter-regional Acre, resto do Norte e resto do Brasil (1999) - índices dependentes*.

\begin{tabular}{|c|c|c|c|c|c|c|c|c|c|c|c|c|c|}
\hline \multirow{2}{*}{\multicolumn{2}{|c|}{ Setores }} & \multicolumn{6}{|c|}{ Índices de Ligações para Frente } & \multicolumn{6}{|c|}{ Índices de Ligações para Trás } \\
\hline & & Acre & Ordem & $\begin{array}{l}\text { Resto } \\
\text { Norte }\end{array}$ & Ordem & $\begin{array}{l}\text { Resto } \\
\text { Brasil }\end{array}$ & Ordem & Acre & Ordem & $\begin{array}{l}\text { Resto } \\
\text { Norte }\end{array}$ & Ordem & $\begin{array}{l}\text { Resto } \\
\text { Brasil }\end{array}$ & Ordem \\
\hline & Ind. Alimentos & 1,256 & 11 & 1,218 & 10 & 1,459 & 7 & 1,118 & 13 & 1,028 & 15 & 1,234 & 6 \\
\hline 32 & Ind. Diversas & 0,829 & 36 & 0,834 & 37 & 0,697 & 35 & 1,009 & 21 & 0,993 & 25 & 1,025 & 25 \\
\hline & SIUP & 1,467 & 5 & 1,991 & 2 & 1,822 & 5 & 1,059 & 17 & 1,250 & 4 & 0,875 & 41 \\
\hline 34 & Constr. Civil & 0,956 & 19 & 0,941 & 23 & 0,725 & 34 & 0,882 & 43 & 0,949 & 33 & 0,903 & 39 \\
\hline 35 & Comércio & 2,483 & 1 & 2,212 & 1 & 2,548 & 2 & 0,920 & 36 & 0,949 & 34 & 0,976 & 33 \\
\hline 36 & Transp. Rodov. & 1,299 & 9 & 1,266 & 6 & 1,158 & 12 & 0,906 & 40 & 0,961 & 30 & 1,063 & 20 \\
\hline 37 & Transp. Aéreo & 0,948 & 20 & 0,951 & 21 & 0,752 & 29 & 0,958 & 27 & 1,017 & 20 & 1,143 & 12 \\
\hline 38 & Transp. Ferrov. & 0,835 & 35 & 0,860 & 34 & 0,728 & 33 & 0,854 & 47 & 0,944 & 35 & 0,964 & 35 \\
\hline 39 & Transp. Aquav. & 0,798 & 38 & 0,824 & 38 & 0,616 & 43 & 0,909 & 39 & 0,977 & 26 & 1,076 & 19 \\
\hline 40 & Ativ. Aux. Transp. & 0,905 & 24 & 0,917 & 30 & 0,757 & 28 & 0,902 & 41 & 0,960 & 31 & 0,940 & 36 \\
\hline & Comunicações & 1,284 & 10 & 1,190 & 11 & 1,118 & 14 & 1,179 & 6 & 0,922 & 41 & 0,685 & 49 \\
\hline 42 & Inst. Financeiras & 1,359 & 7 & 1,270 & 5 & 1,200 & 11 & 1,040 & 19 & 1,015 & 21 & 0,779 & 45 \\
\hline & Saúde Mercantil & 0,760 & 43 & 0,775 & 45 & 0,568 & 46 & 0,976 & 25 & 0,924 & 40 & 0,895 & 40 \\
\hline 44 & Educ.Mercantil & 0,760 & 44 & 0,780 & 44 & 0,572 & 45 & 0,855 & 45 & 0,848 & 47 & 0,641 & 51 \\
\hline & Serv. Aloj.eAlim. & 0,879 & 29 & 0,876 & 32 & 0,672 & 38 & 0,965 & 26 & 1,054 & 11 & 1,024 & 26 \\
\hline 46 & Out.Serv. Prest. a Fam. & 1,072 & 13 & 0,995 & 15 & 0,738 & 32 & 0,913 & 38 & 0,976 & 29 & 1,059 & 21 \\
\hline & Serv. Prest. à Empresa & 1,652 & 3 & 1,664 & 3 & 1,648 & 6 & 0,923 & 35 & 0,906 & 42 & 0,792 & 44 \\
\hline & Aluguel de Imóveis & 1,007 & 17 & 0,976 & 18 & 0,816 & 25 & 0,770 & 52 & 0,795 & 52 & 0,579 & 53 \\
\hline & Saúde Pública & 0,732 & 49 & 0,751 & 51 & 0,544 & 50 & 0,944 & 31 & 1,046 & 13 & 0,966 & 34 \\
\hline & Educ. Pública & 0,729 & 51 & 0,751 & 50 & 0,544 & 51 & 0,753 & 53 & 0,808 & 50 & 0,675 & 50 \\
\hline & Seg. Pública & 0,728 & 53 & 0,750 & 53 & 0,544 & 53 & 0,930 & 34 & 1,027 & 16 & 0,906 & 38 \\
\hline & Out.Adm. Pública & 1,768 & 2 & 1,034 & 14 & 0,871 & 24 & 0,779 & 51 & 0,893 & 44 & 0,747 & 46 \\
\hline & Serv. Priv. N.Mercantis & 0,728 & 52 & 0,750 & 52 & 0,544 & 52 & 0,783 & 49 & 0,791 & 53 & 0,606 & 52 \\
\hline
\end{tabular}

* índices obtidos a partir das sub-matrizes (53 x 53) que ocupam a diagonal principal da inversa de Leontief do sistema total. 
Tabela 35. Índices puros de ligação totais para as regiões Acre, resto do Norte e resto do Brasil (1999) - índices dependentes.

\begin{tabular}{|c|c|c|c|c|c|c|c|}
\hline \multirow{2}{*}{\multicolumn{2}{|c|}{ Setores }} & \multicolumn{6}{|c|}{ Índices Totais } \\
\hline & & Acre & Ordem & $\begin{array}{l}\text { Resto } \\
\text { Norte } \\
\end{array}$ & Ordem & $\begin{array}{l}\text { Resto } \\
\text { Brasil } \\
\end{array}$ & Ordem \\
\hline 1 & Agricultura & 1,001 & 17 & 2,141 & 7 & 2,179 & 9 \\
\hline 2 & Aves & 0,171 & 41 & 0,223 & 42 & 0,213 & 46 \\
\hline 3 & Bovinos & 0,715 & 21 & 1,123 & 18 & 0,611 & 24 \\
\hline 4 & Outros Pecuária & 1,123 & 16 & 2,269 & 6 & 0,832 & 20 \\
\hline 5 & Ext. Veg. e Silv. & 0,061 & 46 & 0,183 & 46 & 0,130 & 49 \\
\hline 6 & Ext. Animal & 0,028 & 51 & 0,101 & 50 & 0,026 & 53 \\
\hline 7 & Ext.Mineral & 0,037 & 49 & 0,378 & 38 & 0,234 & 45 \\
\hline 8 & Min. não Metálico & 0,407 & 27 & 0,583 & 30 & 0,480 & 28 \\
\hline 9 & Metal. Básica & 0,298 & 32 & 1,022 & 19 & 1,110 & 16 \\
\hline 10 & Outros Metalúrg. & 0,420 & 26 & 0,959 & 21 & 0,849 & 18 \\
\hline 11 & Máq. e Equip. & 0,420 & 25 & 0,685 & 24 & 0,839 & 19 \\
\hline 12 & Mat. Elétrico & 0,490 & 24 & 0,962 & 20 & 0,716 & 21 \\
\hline 13 & Equip. Eletrôn. & 0,372 & 29 & 1,429 & 13 & 0,439 & 32 \\
\hline 14 & Aut., Cam., Ôn. e Peças & 0,038 & 48 & 1,606 & 11 & 1,934 & 10 \\
\hline 15 & Ind. da Madeira & 0,216 & 37 & 0,282 & 41 & 0,289 & 41 \\
\hline 16 & Ind. do Mobiliário & 0,075 & 44 & 0,402 & 35 & 0,381 & 35 \\
\hline 17 & Cel.,Pap.,Papelão e Art. Pap. & 0,151 & 42 & 0,492 & 31 & 0,376 & 37 \\
\hline 18 & Ind. Ed. e Gráfica & 0,215 & 39 & 0,608 & 28 & 0,396 & 34 \\
\hline 19 & Ind. da Borracha & 0,045 & 47 & 0,209 & 43 & 0,253 & 43 \\
\hline 20 & Elem. Químicos & 0,096 & 43 & 0,209 & 44 & 0,248 & 44 \\
\hline 21 & Quím. diversos & 0,383 & 28 & 0,956 & 22 & 0,937 & 17 \\
\hline 22 & Farm. e Veterin. & 0,258 & 33 & 0,603 & 29 & 0,571 & 25 \\
\hline 23 & Art. Plásticos & 0,173 & 40 & 0,422 & 34 & 0,343 & 38 \\
\hline 24 & Ind. Têxtil & 0,031 & 50 & 0,141 & 49 & 0,540 & 26 \\
\hline 25 & Art. do Vestuário & 0,020 & 52 & 0,030 & 52 & 0,461 & 30 \\
\hline 26 & Fab. Calçados & 0,011 & 53 & 0,013 & 53 & 0,293 & 40 \\
\hline 27 & Benef. de Prod.Veg. & 0,228 & 35 & 0,632 & 27 & 2,252 & 8 \\
\hline 28 & Abate de Aves & 0,945 & 18 & 0,439 & 32 & 0,190 & 47 \\
\hline 29 & Abate de Bovinos & 0,706 & 22 & 0,363 & 39 & 0,266 & 42 \\
\hline 30 & Ab. Suínos e Outros & 1,340 & 14 & 0,640 & 26 & 0,522 & 27 \\
\hline 31 & Ind. Alimentos & 1,348 & 13 & 2,582 & 5 & 2,661 & 6 \\
\hline 32 & Ind. Diversas & 0,235 & 34 & 0,391 & 36 & 0,397 & 33 \\
\hline 33 & SIUP & 1,622 & 11 & 1,370 & 15 & 1,366 & 15 \\
\hline 34 & Constr. Civil & 3,903 & 3 & 3,374 & 2 & 3,142 & 3 \\
\hline 35 & Comércio & 5,766 & 1 & 5,619 & 1 & 5,427 & 1 \\
\hline 36 & Transp. Rodov. & 1,514 & 12 & 1,642 & 10 & 1,505 & 13 \\
\hline 37 & Transp. Aéreo & 0,920 & 19 & 0,682 & 25 & 0,467 & 29 \\
\hline 38 & Transp. Ferrov. & 0,218 & 36 & 0,162 & 47 & 0,143 & 48 \\
\hline 39 & Transp. Aquav. & 0,215 & 38 & 0,155 & 48 & 0,109 & 51 \\
\hline 40 & Ativ. Aux. Transp. & 0,354 & 30 & 0,388 & 37 & 0,453 & 31 \\
\hline 41 & Comunicações & 2,030 & 8 & 1,514 & 12 & 2,399 & 7 \\
\hline 42 & Inst. Financeiras & 1,674 & 9 & 1,813 & 9 & 3,360 & 2 \\
\hline 43 & Saúde Mercantil & 0,323 & 31 & 0,433 & 33 & 0,335 & 39 \\
\hline 44 & Educ.Mercantil & 0,896 & 20 & 0,300 & 40 & 0,379 & 36 \\
\hline 45 & Serv. Aloj.eAlim. & 2,432 & 7 & 1,272 & 16 & 1,406 & 14 \\
\hline 46 & Out.Serv. Prest. a Fam. & 2,870 & 6 & 1,913 & 8 & 1,569 & 12 \\
\hline 47 & Serv. Prest. à Empresa & 3,662 & 4 & 2,656 & 4 & 2,960 & 4 \\
\hline 48 & Aluguel de Imóveis & 1,240 & 15 & 1,143 & 17 & 1,585 & 11 \\
\hline 49 & Saúde Pública & 5,572 & 2 & 1,377 & 14 & 0,664 & 23 \\
\hline 50 & Educ. Pública & 0,645 & 23 & 0,199 & 45 & 0,114 & 50 \\
\hline 51 & Seg. Pública & 1,667 & 10 & 0,955 & 23 & 0,685 & 22 \\
\hline 52 & Out.Adm. Pública & 3,345 & 5 & 2,884 & 3 & 2,868 & 5 \\
\hline 53 & Serv. Priv. N.Mercantis & 0,072 & 45 & 0,072 & 51 & 0,096 & 52 \\
\hline
\end{tabular}


Tabela 36. Índices puros de ligação para trás e para frente para o sistema inter-regional Acre, resto do Norte e resto do Brasil (1999) - índices dependentes.

\begin{tabular}{|c|c|c|c|c|c|c|c|c|c|c|c|c|c|}
\hline \multirow{2}{*}{\multicolumn{2}{|c|}{ Setores }} & \multicolumn{6}{|c|}{ Índices Puros para Frente } & \multicolumn{6}{|c|}{ Índices Puros para Trás } \\
\hline & & Acre & Ordem & $\begin{array}{l}\text { Resto } \\
\text { Norte }\end{array}$ & Ordem & $\begin{array}{l}\text { Resto } \\
\text { Brasil }\end{array}$ & Ordem & Acre & Ordem & $\begin{array}{l}\text { Resto } \\
\text { Norte }\end{array}$ & Ordem & $\begin{array}{l}\text { Resto } \\
\text { Brasil }\end{array}$ & Ordem \\
\hline 1 & Agricultura & 1,310 & 14 & 2,680 & 4 & 3,685 & 4 & 0,692 & 21 & 1,604 & 11 & 0,674 & 22 \\
\hline 2 & Aves & 0,267 & 34 & 0,153 & 39 & 0,069 & 43 & 0,076 & 39 & 0,294 & 37 & 0,356 & 36 \\
\hline 3 & Bovinos & 0,538 & 21 & 0,819 & 20 & 0,704 & 20 & 0,892 & 16 & 1,426 & 13 & 0,518 & 30 \\
\hline 4 & Outros Pecuária & 1,535 & 12 & 0,978 & 18 & 0,822 & 19 & 0,712 & 19 & 3,558 & 2 & 0,842 & 17 \\
\hline 5 & Ext. Veg. e Silv. & 0,094 & 41 & 0,236 & 35 & 0,269 & 36 & 0,029 & 44 & 0,130 & 45 & $-0,009$ & 52 \\
\hline 6 & Ext. Animal & 0,018 & 44 & 0,014 & 46 & 0,014 & 48 & 0,038 & 42 & 0,187 & 42 & 0,037 & 50 \\
\hline 7 & Ext.Mineral & 0,054 & 43 & 0,117 & 41 & 0,113 & 41 & 0,021 & 47 & 0,639 & 26 & 0,355 & 37 \\
\hline 8 & Min. não Metálico & 0,806 & 15 & 0,915 & 19 & 0,826 & 18 & 0,008 & 49 & 0,251 & 39 & 0,133 & 46 \\
\hline 9 & Metal. Básica & 0,524 & 23 & 1,465 & 12 & 1,372 & 12 & 0,071 & 40 & 0,580 & 29 & 0,849 & 16 \\
\hline 10 & Outros Metalúrg. & 0,684 & 17 & 1,176 & 15 & 1,211 & 15 & 0,156 & 31 & 0,743 & 25 & 0,487 & 32 \\
\hline 11 & Máq. e Equip. & 0,681 & 18 & 1,055 & 17 & 1,054 & 16 & 0,159 & 29 & 0,315 & 36 & 0,624 & 27 \\
\hline 12 & Mat. Elétrico & 0,607 & 20 & 0,704 & 21 & 0,629 & 23 & 0,374 & 25 & 1,220 & 14 & 0,802 & 18 \\
\hline 13 & Equip. Eletrôn. & 0,326 & 25 & 0,294 & 31 & 0,448 & 26 & 0,418 & 24 & 2,562 & 7 & 0,429 & 33 \\
\hline 14 & Aut., Cam., Ôn. e Peças & 0,009 & 48 & 0,008 & 48 & 0,008 & 50 & 0,066 & 41 & 3,201 & 4 & 3,859 & 5 \\
\hline 15 & Ind. da Madeira & 0,302 & 28 & 0,556 & 25 & 0,459 & 25 & 0,130 & 36 & 0,009 & 52 & 0,119 & 47 \\
\hline 16 & Ind. do Mobiliário & 0,017 & 45 & 0,016 & 45 & 0,018 & 44 & 0,133 & 35 & 0,788 & 22 & 0,743 & 21 \\
\hline 17 & Cel.,Pap.,Papelão e Art. Pap. & 0,214 & 35 & 0,424 & 26 & 0,409 & 28 & 0,089 & 38 & 0,559 & 30 & 0,343 & 38 \\
\hline 18 & Ind. Ed. e Gráfica & 0,270 & 33 & 0,237 & 34 & 0,304 & 33 & 0,159 & 30 & 0,979 & 18 & 0,488 & 31 \\
\hline 19 & Ind. da Borracha & 0,095 & 40 & 0,330 & 28 & 0,407 & 29 & $-0,004$ & 50 & 0,088 & 48 & 0,099 & 48 \\
\hline 20 & Elem. Químicos & 0,170 & 36 & 0,253 & 32 & 0,278 & 35 & 0,022 & 46 & 0,165 & 43 & 0,218 & 43 \\
\hline 21 & Quím. diversos & 0,653 & 19 & 1,707 & 11 & 1,272 & 13 & 0,113 & 37 & 0,205 & 40 & 0,603 & 28 \\
\hline 22 & Farm. e Veterin. & 0,157 & 39 & 0,177 & 38 & 0,138 & 39 & 0,359 & 26 & 1,028 & 16 & 1,003 & 14 \\
\hline 23 & Art. Plásticos & 0,321 & 26 & 0,587 & 23 & 0,639 & 22 & 0,026 & 45 & 0,257 & 38 & 0,048 & 49 \\
\hline 24 & Ind. Têxtil & 0,069 & 42 & 0,089 & 43 & 0,410 & 27 & $-0,007$ & 51 & 0,193 & 41 & 0,671 & 23 \\
\hline 25 & Art. do Vestuário & 0,004 & 51 & 0,007 & 49 & 0,011 & 49 & 0,035 & 43 & 0,054 & 50 & 0,910 & 15 \\
\hline 26 & Fab. Calçados & 0,004 & 50 & 0,008 & 47 & 0,018 & 45 & 0,017 & 48 & 0,018 & 51 & 0,569 & 29 \\
\hline 27 & Benef. de Prod.Veg. & 0,164 & 38 & 0,308 & 30 & 0,338 & 31 & 0,293 & 27 & 0,955 & 19 & 4,165 & 3 \\
\hline 28 & Abate de Aves & 0,166 & 37 & 0,110 & 42 & 0,119 & 40 & 1,723 & 9 & 0,767 & 24 & 0,261 & 41 \\
\hline 29 & Abate de Bovinos & 0,319 & 27 & 0,224 & 36 & 0,251 & 37 & 1,093 & 15 & 0,502 & 32 & 0,281 & 40 \\
\hline
\end{tabular}


Tabela 36. Índices puros de ligação para trás e para frente para o sistema inter-regional Acre, resto do Norte e resto do Brasil (1999) - índices dependentes.

\begin{tabular}{|c|c|c|c|c|c|c|c|c|c|c|c|c|c|}
\hline \multirow{2}{*}{\multicolumn{2}{|c|}{ Setores }} & \multicolumn{6}{|c|}{ Índices Puros para Frente } & \multicolumn{6}{|c|}{ Índices Puros para Trás } \\
\hline & & Acre & Ordem & $\begin{array}{l}\text { Resto } \\
\text { Norte }\end{array}$ & Ordem & $\begin{array}{l}\text { Resto } \\
\text { Brasil }\end{array}$ & Ordem & Acre & Ordem & $\begin{array}{l}\text { Resto } \\
\text { Norte }\end{array}$ & Ordem & $\begin{array}{l}\text { Resto } \\
\text { Brasil }\end{array}$ & Ordem \\
\hline 30 & Ab. Suínos e Outros & 0,297 & 29 & 0,212 & 37 & 0,291 & 34 & 2,380 & 6 & 1,066 & 15 & 0,752 & 20 \\
\hline 31 & Ind. Alimentos & 1,406 & 13 & 1,818 & 9 & 1,265 & 14 & 1,290 & 13 & 3,346 & 3 & 4,057 & 4 \\
\hline 32 & Ind. Diversas & 0,273 & 32 & 0,310 & 29 & 0,379 & 30 & 0,197 & 28 & 0,472 & 33 & 0,415 & 34 \\
\hline 33 & SIUP & 2,365 & 9 & 2,142 & 8 & 2,075 & 9 & 0,881 & 18 & 0,599 & 28 & 0,658 & 24 \\
\hline 34 & Constr. Civil & 1,786 & 11 & 1,386 & 14 & 1,842 & 10 & 6,016 & 2 & 5,359 & 1 & 4,441 & 1 \\
\hline 35 & Comércio & 7,365 & 2 & 8,179 & 1 & 7,235 & 1 & 4,171 & 3 & 3,064 & 5 & 3,621 & 6 \\
\hline 36 & Transp. Rodov. & 2,510 & 7 & 2,659 & 5 & 2,228 & 7 & 0,521 & 23 & 0,627 & 27 & 0,782 & 19 \\
\hline 37 & Transp. Aéreo & 0,529 & 22 & 0,586 & 24 & 0,596 & 24 & 1,311 & 12 & 0,777 & 23 & 0,337 & 39 \\
\hline 38 & Transp. Ferrov. & 0,292 & 30 & 0,358 & 27 & 0,305 & 32 & 0,145 & 33 & $-0,035$ & 53 & $-0,018$ & 53 \\
\hline 39 & Transp. Aquav. & 0,279 & 31 & 0,249 & 33 & 0,201 & 38 & 0,151 & 32 & 0,061 & 49 & 0,017 & 51 \\
\hline 40 & Ativ. Aux. Transp. & 0,729 & 16 & 0,665 & 22 & 0,697 & 21 & $-0,021$ & 52 & 0,111 & 46 & 0,210 & 44 \\
\hline & Comunicações & 2,592 & 6 & 2,517 & 7 & 2,495 & 5 & 1,470 & 10 & 0,511 & 31 & 2,304 & 7 \\
\hline 42 & Inst. Financeiras & 2,457 & 8 & 2,601 & 6 & 2,404 & 6 & 0,892 & 17 & 1,026 & 17 & 4,315 & 2 \\
\hline 43 & Saúde Mercantil & 0,006 & 49 & 0,006 & 50 & 0,017 & 46 & 0,640 & 22 & 0,859 & 21 & 0,653 & 25 \\
\hline 44 & Educ.Mercantil & 0,346 & 24 & 0,142 & 40 & 0,112 & 42 & 1,445 & 11 & 0,457 & 34 & 0,646 & 26 \\
\hline 45 & Serv. Aloj.eAlim. & 2,664 & 5 & 1,067 & 16 & 0,960 & 17 & 2,200 & 7 & 1,478 & 12 & 1,852 & 8 \\
\hline & Out.Serv. Prest. a Fam. & 3,739 & 4 & 1,735 & 10 & 2,111 & 8 & 2,004 & 8 & 2,092 & 8 & 1,027 & 13 \\
\hline 47 & Serv. Prest. à Empresa & 7,390 & 1 & 5,219 & 2 & 5,559 & 2 & $-0,059$ & 53 & 0,096 & 47 & 0,364 & 35 \\
\hline & Aluguel de Imóveis & 1,789 & 10 & 1,393 & 13 & 1,684 & 11 & 0,692 & 20 & 0,893 & 20 & 1,485 & 10 \\
\hline 49 & Saúde Pública & 0,014 & 46 & 0,019 & 44 & 0,016 & 47 & 11,120 & 1 & 2,733 & 6 & 1,311 & 12 \\
\hline 50 & Educ. Pública & 0,012 & 47 & 0,005 & 51 & 0,006 & 51 & 1,276 & 14 & 0,393 & 35 & 0,222 & 42 \\
\hline & Seg. Pública & 0,000 & 53 & 0,000 & 53 & 0,000 & 53 & 3,330 & 4 & 1,909 & 9 & 1,369 & 11 \\
\hline & Out.Adm. Pública & 3,781 & 3 & 4,083 & 3 & 4,226 & 3 & 2,910 & 5 & 1,688 & 10 & 1,511 & 9 \\
\hline & Serv. Priv. N.Mercantis & 0,000 & 52 & 0,000 & 52 & 0,000 & 52 & 0,144 & 34 & 0,143 & 44 & 0,192 & 45 \\
\hline
\end{tabular}


Tabela 37. Multiplicador de emprego tipo I para o Acre, resto do Norte e resto do Brasil.

\begin{tabular}{|c|c|c|c|c|c|c|c|}
\hline \multirow{2}{*}{\multicolumn{2}{|c|}{ Setores }} & \multicolumn{6}{|c|}{ Multiplicadores Tipo I } \\
\hline & & Acre & Ordem & Resto do Norte & Ordem & Resto do Brasil & Ordem \\
\hline 1 & Agricultura & 1,183 & 47 & 1,181 & 45 & 1,178 & 50 \\
\hline 2 & Aves & 1,384 & 34 & 1,321 & 39 & 1,300 & 45 \\
\hline 3 & Bovinos & 2,194 & 12 & 2,248 & 21 & 1,620 & 36 \\
\hline 4 & Outros Pecuária & 2,274 & 9 & 3,363 & 10 & 1,734 & 34 \\
\hline 5 & Ext. Veg. e Silv. & 1,116 & 49 & 1,098 & 49 & 1,137 & 51 \\
\hline 6 & Ext. Animal & 2,216 & 11 & 1,885 & 28 & 1,922 & 25 \\
\hline 7 & Ext.Mineral & 2,126 & 14 & 3,020 & 17 & 2,317 & 22 \\
\hline 8 & Min. não Metálico & 1,610 & 26 & 1,605 & 33 & 2,009 & 24 \\
\hline 9 & Metal. Básica & 5,835 & 6 & 4,252 & 6 & 10,128 & 4 \\
\hline 10 & Outros Metalúrg. & 1,248 & 41 & 2,083 & 25 & 1,809 & 28 \\
\hline 11 & Máq. e Equip. & 1,237 & 42 & 1,513 & 35 & 2,099 & 23 \\
\hline 12 & Mat. Elétrico & 1,672 & 23 & 2,062 & 26 & 4,136 & 13 \\
\hline 13 & Equip. Eletrôn. & 1,911 & 19 & 2,907 & 18 & 3,219 & 16 \\
\hline 14 & Aut., Cam., Ôn. e Peças & 1,485 & 30 & 9,358 & 4 & 4,185 & 12 \\
\hline 15 & Ind. da Madeira & 1,114 & 50 & 1,721 & 31 & 1,808 & 29 \\
\hline 16 & Ind. do Mobiliário & 1,609 & 27 & 1,445 & 38 & 1,879 & 27 \\
\hline 17 & Cel.,Pap.,Papelão e Art. Pap. & 1,308 & 38 & 2,060 & 27 & 3,192 & 17 \\
\hline 18 & Ind. Ed. e Gráfica & 1,376 & 35 & 3,367 & 9 & 2,758 & 19 \\
\hline 19 & Ind. da Borracha & 1,358 & 37 & 2,592 & 20 & 5,737 & 9 \\
\hline 20 & Elem. Químicos & 9,440 & 4 & 3,334 & 11 & 12,896 & 2 \\
\hline 21 & Quím. diversos & 1,615 & 25 & 6,818 & 5 & 8,681 & 7 \\
\hline 22 & Farm. e Veterin. & 2,225 & 10 & 3,283 & 12 & 4,499 & 10 \\
\hline 23 & Art. Plásticos & 1,401 & 33 & 2,164 & 22 & 1,788 & 30 \\
\hline 24 & Ind. Têxtil & 3,382 & 8 & 3,052 & 16 & 4,473 & 11 \\
\hline 25 & Art. do Vestuário & 1,037 & 52 & 1,023 & 52 & 1,207 & 49 \\
\hline 26 & Fab. Calçados & 1,221 & 45 & 1,113 & 48 & 1,625 & 35 \\
\hline 27 & Benef. de Prod.Veg. & 1,966 & 17 & 3,155 & 15 & 9,508 & 6 \\
\hline 28 & Abate de Aves & 120,325 & 1 & 49,285 & 1 & 19,537 & 1 \\
\hline 29 & Abate de Bovinos & 31,434 & 2 & 11,410 & 2 & 9,513 & 5 \\
\hline 30 & Ab. Suínos e Outros & 28,468 & 3 & 10,495 & 3 & 10,588 & 3 \\
\hline 31 & Ind. Alimentos & 2,167 & 13 & 3,765 & 7 & 6,334 & 8 \\
\hline 32 & Ind. Diversas & 1,307 & 39 & 2,094 & 24 & 1,776 & 31 \\
\hline 33 & SIUP & 2,087 & 16 & 2,793 & 19 & 3,272 & 15 \\
\hline 34 & Constr. Civil & 1,705 & 22 & 1,806 & 29 & 1,571 & 41 \\
\hline 35 & Comércio & 1,194 & 46 & 1,193 & 44 & 1,214 & 48 \\
\hline 36 & Transp. Rodov. & 1,359 & 36 & 1,248 & 42 & 1,373 & 43 \\
\hline 37 & Transp. Aéreo & 3,782 & 7 & 3,539 & 8 & 3,890 & 14 \\
\hline 38 & Transp. Ferrov. & 1,545 & 29 & 1,730 & 30 & 1,743 & 33 \\
\hline 39 & Transp. Aquav. & 1,161 & 48 & 1,178 & 46 & 1,585 & 39 \\
\hline 40 & Ativ. Aux. Transp. & 1,279 & 40 & 1,266 & 41 & 1,586 & 38 \\
\hline 41 & Comunicações & 7,377 & 5 & 3,192 & 14 & 2,415 & 21 \\
\hline 42 & Inst. Financeiras & 1,940 & 18 & 2,142 & 23 & 3,079 & 18 \\
\hline 43 & Saúde Mercantil & 2,116 & 15 & 1,475 & 36 & 1,612 & 37 \\
\hline 44 & Educ.Mercantil & 1,225 & 44 & 1,095 & 50 & 1,334 & 44 \\
\hline 45 & Serv. Aloj.eAlim. & 1,549 & 28 & 1,229 & 43 & 1,392 & 42 \\
\hline 46 & Out.Serv. Prest. a Fam. & 1,425 & 32 & 1,280 & 40 & 1,108 & 52 \\
\hline 47 & Serv. Prest. à Empresa & 1,229 & 43 & 1,173 & 47 & 1,247 & 46 \\
\hline 48 & Aluguel de Imóveis & 1,716 & 21 & 1,601 & 34 & 1,776 & 32 \\
\hline 49 & Saúde Pública & 1,647 & 24 & 1,699 & 32 & 2,460 & 20 \\
\hline 50 & Educ. Pública & 1,039 & 51 & 1,046 & 51 & 1,217 & 47 \\
\hline 51 & Seg. Pública & 1,449 & 31 & 1,463 & 37 & 1,571 & 40 \\
\hline 52 & Out.Adm. Pública & 1,860 & 20 & 3,242 & 13 & 1,879 & 26 \\
\hline 53 & Serv. Priv. N. Mercantis & 1,009 & 53 & 1,005 & 53 & 1,009 & 53 \\
\hline
\end{tabular}


Tabela 38. Multiplicador de emprego tipo II para o Acre, resto do Norte e resto do Brasil.

\begin{tabular}{|c|c|c|c|c|c|c|c|}
\hline \multirow{2}{*}{\multicolumn{2}{|c|}{ Setores }} & \multicolumn{6}{|c|}{ Multiplicadores Tipo II } \\
\hline & & Acre & Ordem & Resto do Norte & Ordem & Resto do Brasil & Ordem \\
\hline 1 & Agricultura & 1,304 & 48 & 1,726 & 47 & 1,618 & 50 \\
\hline 2 & Aves & 1,544 & 45 & 1,648 & 49 & 1,553 & 51 \\
\hline 3 & Bovinos & 2,861 & 22 & 4,515 & 31 & 2,566 & 45 \\
\hline 4 & Outros Pecuária & 2,873 & 21 & 6,738 & 21 & 2,644 & 44 \\
\hline 5 & Ext. Veg. e Silv. & 1,167 & 50 & 1,521 & 50 & 1,634 & 49 \\
\hline 6 & Ext. Animal & 2,892 & 19 & 7,815 & 18 & 7,398 & 24 \\
\hline 7 & Ext.Mineral & 3,644 & 15 & 11,833 & 13 & 8,284 & 20 \\
\hline 8 & Min. não Metálico & 2,769 & 24 & 4,311 & 33 & 4,976 & 28 \\
\hline 9 & Metal. Básica & 8,711 & 8 & 13,869 & 11 & 30,098 & 2 \\
\hline 10 & Outros Metalúrg. & 1,558 & 43 & 6,201 & 25 & 4,315 & 31 \\
\hline 11 & Máq. e Equip. & 1,672 & 42 & 4,929 & 30 & 7,020 & 26 \\
\hline 12 & Mat. Elétrico & 2,402 & 28 & 5,379 & 27 & 11,443 & 16 \\
\hline 13 & Equip. Eletrôn. & 2,830 & 23 & 14,004 & 10 & 9,643 & 18 \\
\hline 14 & Aut., Cam., Ôn. e Peças & 1,866 & 40 & 39,644 & 2 & 11,908 & 15 \\
\hline 15 & Ind. da Madeira & 1,186 & 49 & 3,143 & 37 & 3,229 & 40 \\
\hline 16 & Ind. do Mobiliário & 1,917 & 38 & 2,232 & 44 & 3,257 & 39 \\
\hline 17 & Cel.,Pap.,Papelão e Art. Pap. & 1,876 & 39 & 4,363 & 32 & 7,692 & 22 \\
\hline 18 & Ind. Ed. e Gráfica & 1,976 & 36 & 10,773 & 16 & 7,197 & 25 \\
\hline 19 & Ind. da Borracha & 1,480 & 46 & 6,203 & 24 & 15,102 & 10 \\
\hline 20 & Elem. Químicos & 13,714 & 6 & 14,757 & 9 & 29,760 & 3 \\
\hline 21 & Quím. diversos & 2,263 & 33 & 28,272 & 3 & 34,346 & 1 \\
\hline 22 & Farm. e Veterin. & 3,572 & 16 & 11,052 & 15 & 13,328 & 12 \\
\hline 23 & Art. Plásticos & 2,176 & 35 & 7,226 & 20 & 4,721 & 30 \\
\hline 24 & Ind. Têxtil & 4,756 & 12 & 6,447 & 22 & 9,076 & 19 \\
\hline 25 & Art. do Vestuário & 1,113 & 52 & 1,108 & 53 & 1,710 & 48 \\
\hline 26 & Fab. Calçados & 1,357 & 47 & 1,356 & 51 & 2,869 & 42 \\
\hline 27 & Benef. de Prod.Veg. & 2,249 & 34 & 5,089 & 29 & 15,235 & 9 \\
\hline 28 & Abate de Aves & 153,721 & 1 & 70,905 & 1 & 25,834 & 5 \\
\hline 29 & Abate de Bovinos & 54,571 & 2 & 25,364 & 5 & 16,225 & 8 \\
\hline 30 & Ab. Suínos e Outros & 44,911 & 3 & 21,307 & 7 & 17,472 & 7 \\
\hline 31 & Ind. Alimentos & 2,892 & 20 & 7,665 & 19 & 11,329 & 17 \\
\hline 32 & Ind. Diversas & 1,712 & 41 & 6,348 & 23 & 3,847 & 33 \\
\hline 33 & SIUP & 4,886 & 11 & 11,107 & 14 & 20,472 & 6 \\
\hline 34 & Constr. Civil & 2,601 & 26 & 5,253 & 28 & 3,664 & 35 \\
\hline 35 & Comércio & 1,960 & 37 & 2,312 & 42 & 2,252 & 46 \\
\hline 36 & Transp. Rodov. & 2,603 & 25 & 2,309 & 43 & 2,681 & 43 \\
\hline 37 & Transp. Aéreo & 12,522 & 7 & 12,935 & 12 & 12,778 & 13 \\
\hline 38 & Transp. Ferrov. & 4,369 & 13 & 6,112 & 26 & 4,925 & 29 \\
\hline 39 & Transp. Aquav. & 1,545 & 44 & 1,782 & 46 & 3,541 & 37 \\
\hline 40 & Ativ. Aux. Transp. & 2,490 & 27 & 2,723 & 40 & 3,942 & 32 \\
\hline 41 & Comunicações & 17,523 & 5 & 17,998 & 8 & 13,880 & 11 \\
\hline 42 & Inst. Financeiras & 5,021 & 9 & 10,133 & 17 & 12,743 & 14 \\
\hline 43 & Saúde Mercantil & 4,968 & 10 & 4,004 & 34 & 3,698 & 34 \\
\hline 44 & Educ.Mercantil & 3,390 & 17 & 2,836 & 39 & 7,710 & 21 \\
\hline 45 & Serv. Aloj.eAlim. & 2,284 & 32 & 1,726 & 48 & 2,172 & 47 \\
\hline 46 & Out.Serv. Prest. a Fam. & 2,345 & 30 & 2,425 & 41 & 1,433 & 52 \\
\hline 47 & Serv. Prest. à Empresa & 2,359 & 29 & 2,885 & 38 & 2,918 & 41 \\
\hline 48 & Aluguel de Imóveis & 0,795 & 53 & 26,760 & 4 & 28,760 & 4 \\
\hline 49 & Saúde Pública & 3,691 & 14 & 3,788 & 35 & 5,630 & 27 \\
\hline 50 & Educ. Pública & 2,308 & 31 & 2,057 & 45 & 3,559 & 36 \\
\hline 51 & Seg. Pública & 3,226 & 18 & 3,246 & 36 & 3,259 & 38 \\
\hline 52 & Out.Adm. Pública & 18,369 & 4 & 24,682 & 6 & 7,433 & 23 \\
\hline 53 & Serv. Priv. N. Mercantis & 1,157 & 51 & 1,187 & 52 & 1,243 & 53 \\
\hline
\end{tabular}


Tabela 39. Multiplicador de renda tipo I para o Acre, resto do Norte e resto do Brasil.

\begin{tabular}{|c|c|c|c|c|c|c|c|}
\hline \multirow{2}{*}{\multicolumn{2}{|c|}{ Setores }} & \multicolumn{6}{|c|}{ Multiplicadores Tipo I } \\
\hline & & Acre & Ordem & Resto do Norte & Ordem & Resto do Brasil & Ordem \\
\hline 1 & Agricultura & 1,959 & 26 & 1,787 & 25 & 1,901 & 25 \\
\hline 2 & Aves & 2,591 & 18 & 5,880 & 1 & 6,059 & 2 \\
\hline 3 & Bovinos & 3,177 & 10 & 2,033 & 15 & 2,176 & 20 \\
\hline 4 & Outros Pecuária & 2,874 & 13 & 2,032 & 16 & 2,135 & 22 \\
\hline 5 & Ext. Veg. e Silv. & 2,012 & 25 & 1,732 & 27 & 1,500 & 40 \\
\hline 6 & Ext. Animal & 3,460 & 8 & 2,926 & 8 & 3,012 & 11 \\
\hline 7 & Ext.Mineral & 2,310 & 21 & 2,951 & 7 & 2,116 & 23 \\
\hline 8 & Min. não Metálico & 1,535 & 38 & 1,933 & 20 & 2,055 & 24 \\
\hline 9 & Metal. Básica & 7,720 & 1 & 4,700 & 2 & 6,669 & 1 \\
\hline 10 & Outros Metalúrg. & 1,765 & 33 & 1,640 & 32 & 1,779 & 30 \\
\hline 11 & Máq. e Equip. & 1,275 & 46 & 1,424 & 41 & 1,556 & 38 \\
\hline 12 & Mat. Elétrico & 2,952 & 12 & 1,680 & 28 & 2,717 & 13 \\
\hline 13 & Equip. Eletrôn. & 2,256 & 23 & 1,980 & 17 & 2,171 & 21 \\
\hline 14 & Aut., Cam., Ôn. e Peças & 4,416 & 4 & 1,653 & 31 & 2,421 & 14 \\
\hline 15 & Ind. da Madeira & 1,498 & 40 & 1,660 & 30 & 1,776 & 31 \\
\hline 16 & Ind. do Mobiliário & 1,805 & 32 & 1,672 & 29 & 1,873 & 26 \\
\hline 17 & Cel.,Pap.,Papelão e Art. Pap. & 3,210 & 9 & 2,148 & 14 & 2,415 & 15 \\
\hline 18 & Ind. Ed. e Gráfica & 2,855 & 14 & 1,923 & 21 & 2,289 & 19 \\
\hline 19 & Ind. da Borracha & 3,107 & 11 & 2,343 & 11 & 2,875 & 12 \\
\hline 20 & Elem. Químicos & 2,833 & 15 & 1,974 & 18 & 3,150 & 10 \\
\hline 21 & Quím. diversos & 2,775 & 16 & 1,914 & 22 & 3,955 & 6 \\
\hline 22 & Farm. e Veterin. & 2,300 & 22 & 1,887 & 23 & 2,300 & 18 \\
\hline 23 & Art. Plásticos & 1,711 & 35 & 2,196 & 13 & 1,622 & 35 \\
\hline 24 & Ind. Têxtil & 3,706 & 6 & 2,334 & 12 & 3,184 & 9 \\
\hline 25 & Art. do Vestuário & 1,827 & 31 & 1,623 & 33 & 1,851 & 29 \\
\hline 26 & Fab. Calçados & 1,850 & 29 & 1,492 & 38 & 1,862 & 28 \\
\hline 27 & Benef. de Prod.Veg. & 3,671 & 7 & 3,170 & 6 & 3,626 & 7 \\
\hline 28 & Abate de Aves & 3,932 & 5 & 3,475 & 5 & 4,081 & 5 \\
\hline 29 & Abate de Bovinos & 4,461 & 3 & 4,298 & 4 & 4,556 & 4 \\
\hline 30 & Ab. Suínos e Outros & 4,643 & 2 & 4,437 & 3 & 4,681 & 3 \\
\hline 31 & Ind. Alimentos & 2,599 & 17 & 2,699 & 9 & 3,297 & 8 \\
\hline 32 & Ind. Diversas & 2,450 & 19 & 1,880 & 24 & 2,325 & 17 \\
\hline 33 & SIUP & 2,105 & 24 & 1,970 & 19 & 1,620 & 36 \\
\hline 34 & Constr. Civil & 2,388 & 20 & 2,561 & 10 & 2,379 & 16 \\
\hline 35 & Comércio & 1,461 & 41 & 1,434 & 39 & 1,505 & 39 \\
\hline 36 & Transp. Rodov. & 1,609 & 37 & 1,554 & 37 & 1,659 & 33 \\
\hline 37 & Transp. Aéreo & 1,864 & 28 & 1,756 & 26 & 1,869 & 27 \\
\hline 38 & Transp. Ferrov. & 1,455 & 42 & 1,599 & 35 & 1,659 & 34 \\
\hline 39 & Transp. Aquav. & 1,615 & 36 & 1,615 & 34 & 1,756 & 32 \\
\hline 40 & Ativ. Aux. Transp. & 1,376 & 44 & 1,420 & 42 & 1,490 & 41 \\
\hline 41 & Comunicações & 1,931 & 27 & 1,310 & 44 & 1,207 & 49 \\
\hline 42 & Inst. Financeiras & 1,452 & 43 & 1,280 & 45 & 1,313 & 46 \\
\hline 43 & Saúde Mercantil & 1,499 & 39 & 1,233 & 48 & 1,372 & 44 \\
\hline 44 & Educ.Mercantil & 1,159 & 50 & 1,085 & 51 & 1,084 & 51 \\
\hline 45 & Serv. Aloj.eAlim. & 1,717 & 34 & 1,562 & 36 & 1,415 & 43 \\
\hline 46 & Out.Serv. Prest. a Fam. & 1,847 & 30 & 1,417 & 43 & 1,587 & 37 \\
\hline 47 & Serv. Prest. à Empresa & 1,275 & 47 & 1,230 & 49 & 1,292 & 47 \\
\hline 48 & Aluguel de Imóveis & 1,368 & 45 & 1,433 & 40 & 1,485 & 42 \\
\hline 49 & Saúde Pública & 1,242 & 48 & 1,265 & 46 & 1,322 & 45 \\
\hline 50 & Educ. Pública & 1,020 & 53 & 1,033 & 52 & 1,060 & 52 \\
\hline 51 & Seg. Pública & 1,214 & 49 & 1,242 & 47 & 1,281 & 48 \\
\hline 52 & Out.Adm. Pública & 1,038 & 51 & 1,087 & 50 & 1,118 & 50 \\
\hline 53 & Serv. Priv. N. Mercantis & 1,029 & 52 & 1,015 & 53 & 1,019 & 53 \\
\hline
\end{tabular}


Tabela 40. Multiplicador de renda tipo II para o Acre, Resto do Norte e Resto do Brasil.

\begin{tabular}{|c|c|c|c|c|c|c|c|}
\hline \multirow{2}{*}{\multicolumn{2}{|c|}{ Setores }} & \multicolumn{6}{|c|}{ Multiplicadores Tipo II } \\
\hline & & Acre & Ordem & Resto do Norte & Ordem & Resto do Brasil & Ordem \\
\hline 1 & Agricultura & 2,792 & 30 & 4,830 & 15 & 4,594 & 18 \\
\hline 2 & Aves & 3,801 & 18 & 14,430 & 1 & 14,109 & 2 \\
\hline 3 & Bovinos & 4,973 & 8 & 4,607 & 19 & 4,877 & 15 \\
\hline 4 & Outros Pecuária & 4,483 & 12 & 4,748 & 16 & 4,846 & 16 \\
\hline 5 & Ext. Veg. e Silv. & 2,651 & 36 & 6,477 & 11 & 4,189 & 22 \\
\hline 6 & Ext. Animal & 4,452 & 13 & 11,565 & 3 & 11,060 & 4 \\
\hline 7 & Ext.Mineral & 3,402 & 22 & 6,568 & 10 & 4,342 & 20 \\
\hline 8 & Min. não Metálico & 2,197 & 43 & 4,357 & 20 & 3,744 & 27 \\
\hline 9 & Metal. Básica & 11,502 & 1 & 10,923 & 4 & 13,687 & 3 \\
\hline 10 & Outros Metalúrg. & 2,672 & 35 & 2,852 & 36 & 3,037 & 35 \\
\hline 11 & Máq. e Equip. & 1,727 & 49 & 2,823 & 38 & 2,866 & 38 \\
\hline 12 & Mat. Elétrico & 4,525 & 11 & 2,754 & 41 & 4,779 & 17 \\
\hline 13 & Equip. Eletrôn. & 3,221 & 24 & 5,104 & 13 & 4,004 & 25 \\
\hline 14 & Aut., Cam., Ôn. e Peças & 6,472 & 5 & 2,786 & 39 & 4,209 & 21 \\
\hline 15 & Ind. da Madeira & 2,334 & 41 & 3,301 & 28 & 3,357 & 29 \\
\hline 16 & Ind. do Mobiliário & 2,768 & 32 & 3,062 & 32 & 3,315 & 30 \\
\hline 17 & Cel.,Pap.,Papelão e Art. Pap. & 4,613 & 10 & 4,082 & 22 & 4,106 & 24 \\
\hline 18 & Ind. Ed. e Gráfica & 4,117 & 15 & 3,228 & 30 & 3,836 & 26 \\
\hline 19 & Ind. da Borracha & 4,638 & 9 & 4,898 & 14 & 5,730 & 13 \\
\hline 20 & Elem. Químicos & 3,837 & 17 & 4,728 & 17 & 7,106 & 10 \\
\hline 21 & Quím. diversos & 4,165 & 14 & 3,861 & 23 & 8,716 & 7 \\
\hline 22 & Farm. e Veterin. & 3,243 & 23 & 3,825 & 24 & 4,440 & 19 \\
\hline 23 & Art. Plásticos & 2,587 & 39 & 4,698 & 18 & 2,735 & 39 \\
\hline 24 & Ind. Têxtil & 5,534 & 6 & 4,281 & 21 & 5,818 & 12 \\
\hline 25 & Art. do Vestuário & 3,458 & 21 & 3,359 & 27 & 3,421 & 28 \\
\hline 26 & Fab. Calçados & 2,676 & 34 & 2,962 & 35 & 3,196 & 31 \\
\hline 27 & Benef. de Prod.Veg. & 5,328 & 7 & 7,753 & 8 & 7,688 & 9 \\
\hline 28 & Abate de Aves & 6,989 & 4 & 7,844 & 7 & 8,317 & 8 \\
\hline 29 & Abate de Bovinos & 8,187 & 2 & 9,225 & 6 & 9,071 & 6 \\
\hline 30 & Ab. Suínos e Outros & 7,960 & 3 & 9,314 & 5 & 9,234 & 5 \\
\hline 31 & Ind. Alimentos & 3,974 & 16 & 5,767 & 12 & 6,370 & 11 \\
\hline 32 & Ind. Diversas & 3,606 & 20 & 3,573 & 25 & 4,159 & 23 \\
\hline 33 & SIUP & 3,208 & 25 & 3,269 & 29 & 2,909 & 36 \\
\hline 34 & Constr. Civil & 3,708 & 19 & 6,662 & 9 & 5,502 & 14 \\
\hline 35 & Comércio & 2,314 & 42 & 2,651 & 42 & 2,702 & 40 \\
\hline 36 & Transp. Rodov. & 2,775 & 31 & 2,838 & 37 & 2,879 & 37 \\
\hline 37 & Transp. Aéreo & 3,130 & 26 & 3,129 & 31 & 3,164 & 32 \\
\hline 38 & Transp. Ferrov. & 2,699 & 33 & 3,425 & 26 & 3,076 & 34 \\
\hline 39 & Transp. Aquav. & 2,608 & 38 & 3,020 & 34 & 3,098 & 33 \\
\hline 40 & Ativ. Aux. Transp. & 2,397 & 40 & 2,763 & 40 & 2,585 & 43 \\
\hline 41 & Comunicações & 2,827 & 29 & 2,454 & 43 & 2,229 & 45 \\
\hline 42 & Inst. Financeiras & 2,080 & 44 & 2,048 & 47 & 2,106 & 47 \\
\hline 43 & Saúde Mercantil & 2,638 & 37 & 2,343 & 45 & 2,654 & 41 \\
\hline 44 & Educ.Mercantil & 1,768 & 47 & 1,764 & 50 & 1,747 & 50 \\
\hline 45 & Serv. Aloj.eAlim. & 2,924 & 28 & 3,035 & 33 & 2,479 & 44 \\
\hline 46 & Out.Serv. Prest. a Fam. & 2,980 & 27 & 2,348 & 44 & 2,594 & 42 \\
\hline 47 & Serv. Prest. à Empresa & 1,854 & 45 & 2,155 & 46 & 2,154 & 46 \\
\hline 48 & Aluguel de Imóveis & 0,968 & 53 & 12,929 & 2 & 14,197 & 1 \\
\hline 49 & Saúde Pública & 1,796 & 46 & 1,920 & 48 & 1,997 & 48 \\
\hline 50 & Educ. Pública & 1,440 & 52 & 1,504 & 52 & 1,542 & 52 \\
\hline 51 & Seg. Pública & 1,743 & 48 & 1,871 & 49 & 1,920 & 49 \\
\hline 52 & Out.Adm. Pública & 1,467 & 50 & 1,598 & 51 & 1,640 & 51 \\
\hline 53 & Serv. Priv. N. Mercantis & 1,454 & 51 & 1,476 & 53 & 1,472 & 53 \\
\hline
\end{tabular}


Tabela 41. Geração de renda direta e indireta no Acre, resto do Norte e resto do Brasil.

\begin{tabular}{|c|c|c|c|c|c|c|c|}
\hline \multirow{3}{*}{\multicolumn{2}{|c|}{ Setores }} & \multicolumn{2}{|c|}{ Acre } & \multicolumn{2}{|c|}{ Resto do Norte } & \multicolumn{2}{|c|}{ Resto do Brasil } \\
\hline & & Renda & Renda & Renda & Renda & Renda & Renda \\
\hline & & Direta & Indireta & Direta & Indireta & Direta & Indireta \\
\hline 1 & Agricultura & 88,47 & 84,88 & 81,85 & 64,42 & 84,53 & 76,18 \\
\hline 2 & Aves & 113,75 & 180,98 & 27,79 & 135,62 & 27,26 & 137,88 \\
\hline 3 & Bovinos & 52,49 & 114,29 & 98,02 & 101,26 & 84,82 & 99,77 \\
\hline 4 & Outros Pecuária & 61,35 & 114,99 & 92,62 & 95,62 & 84,94 & 96,38 \\
\hline 5 & Ext. Veg. e Silv. & 47,54 & 48,12 & 51,73 & 37,86 & 83,87 & 41,91 \\
\hline 6 & Ext. Animal & 26,79 & 65,90 & 26,79 & 51,61 & 26,79 & 53,90 \\
\hline 7 & Ext.Mineral & 106,88 & 140,04 & 64,51 & 125,86 & 100,59 & 112,21 \\
\hline 8 & Min. Não Metálico & 263,54 & 140,92 & 92,09 & 85,90 & 129,63 & 136,69 \\
\hline 9 & Metal. Básica & 23,78 & 159,81 & 28,92 & 107,00 & 25,96 & 147,17 \\
\hline 10 & Outros Metalúrg. & 180,20 & 137,92 & 180,20 & 115,39 & 180,20 & 140,38 \\
\hline 11 & Máq. E Equip. & 199,60 & 54,85 & 163,41 & 69,30 & 176,62 & 98,28 \\
\hline 12 & Mat. Elétrico & 98,54 & 192,35 & 166,28 & 113,15 & 94,96 & 163,04 \\
\hline 13 & Equip. Eletrôn. & 99,52 & 124,95 & 45,84 & 44,90 & 113,06 & 132,39 \\
\hline 14 & Aut., Cam., Ôn. e Peças & 66,46 & 227,02 & 154,22 & 100,64 & 108,34 & 154,01 \\
\hline 15 & Ind. Da Madeira & 162,47 & 80,90 & 162,47 & 107,18 & 162,47 & 126,02 \\
\hline 16 & Ind. Do Mobiliário & 170,73 & 137,36 & 170,73 & 114,71 & 170,73 & 149,04 \\
\hline 17 & Cel.,Pap.,Papelão e Art. Pap. & 142,70 & 315,40 & 128,36 & 147,36 & 135,41 & 191,67 \\
\hline 18 & Ind. Ed. e Gráfica & 152,66 & 283,22 & 177,64 & 164,04 & 151,64 & 195,47 \\
\hline 19 & Ind. Da Borracha & 64,43 & 135,72 & 64,43 & 86,53 & 64,43 & 120,80 \\
\hline 20 & Elem. Químicos & 51,93 & 95,18 & 68,81 & 67,03 & 52,10 & 112,00 \\
\hline 21 & Quím. diversos & 95,44 & 169,43 & 93,71 & 85,67 & 38,83 & 114,75 \\
\hline 22 & Farm. E Veterin. & 100,88 & 131,11 & 104,43 & 92,67 & 100,74 & 130,93 \\
\hline 23 & Art. Plásticos & 189,47 & 134,66 & 65,60 & 78,48 & 196,60 & 122,29 \\
\hline 24 & Ind. Têxtil & 72,49 & 196,16 & 84,62 & 112,85 & 72,32 & 157,94 \\
\hline 25 & Art. Do Vestuário & 162,24 & 134,25 & 162,24 & 101,13 & 162,24 & 138,08 \\
\hline 26 & Fab. Calçados & 172,77 & 146,87 & 172,77 & 85,03 & 172,77 & 149,00 \\
\hline 27 & Benef. de Prod.Veg. & 59,93 & 160,08 & 51,32 & 111,36 & 53,46 & 140,36 \\
\hline 28 & Abate de Aves & 52,59 & 154,18 & 53,60 & 132,65 & 52,47 & 161,64 \\
\hline 29 & Abate de Bovinos & 49,97 & 172,95 & 49,60 & 163,60 & 49,99 & 177,79 \\
\hline 30 & Ab. Suínos e Outros & 50,02 & 182,23 & 49,92 & 171,56 & 50,02 & 184,16 \\
\hline 31 & Ind. Alimentos & 102,62 & 164,11 & 74,82 & 127,13 & 70,42 & 161,78 \\
\hline 32 & Ind. Diversas & 124,19 & 180,06 & 130,37 & 114,73 & 123,95 & 164,26 \\
\hline 33 & SIUP & 187,38 & 207,04 & 179,42 & 174,00 & 187,90 & 116,49 \\
\hline 34 & Constr. Civil & 92,27 & 128,03 & 56,79 & 88,64 & 70,30 & 96,94 \\
\hline 35 & Comércio & 314,32 & 144,88 & 255,25 & 110,83 & 240,14 & 121,33 \\
\hline 36 & Transp. Rodov. & 208,68 & 127,04 & 208,68 & 115,63 & 208,68 & 137,50 \\
\hline 37 & Transp. Aéreo & 190,92 & 165,01 & 188,92 & 142,73 & 191,10 & 166,12 \\
\hline 38 & Transp. Ferrov. & 190,92 & 86,87 & 159,29 & 95,49 & 193,73 & 127,59 \\
\hline 39 & Transp. Aquav. & 190,92 & 117,47 & 190,92 & 117,45 & 190,92 & 144,38 \\
\hline 40 & Ativ. Aux. Transp. & 249,26 & 93,64 & 216,68 & 91,03 & 250,27 & 122,70 \\
\hline 41 & Comunicações & 246,66 & 229,71 & 228,57 & 70,83 & 247,04 & 51,08 \\
\hline 42 & Inst. Financeiras & 387,97 & 175,29 & 432,46 & 121,19 & 387,28 & 121,13 \\
\hline 43 & Saúde Mercantil & 279,20 & 139,27 & 345,70 & 80,72 & 275,59 & 102,53 \\
\hline 44 & Educ.Mercantil & 619,29 & 98,24 & 621,41 & 52,93 & 619,23 & 51,96 \\
\hline 45 & Serv. Aloj.eAlim. & 195,80 & 140,30 & 191,57 & 107,75 & 258,92 & 107,44 \\
\hline 46 & Out.Serv. Prest. a Fam. & 198,62 & 168,14 & 256,49 & 106,89 & 232,12 & 136,16 \\
\hline 47 & Serv. Prest. à Empresa & 486,95 & 133,78 & 347,66 & 79,96 & 352,31 & 102,73 \\
\hline 48 & Aluguel de Imóveis & 34,95 & 12,86 & 21,02 & 9,10 & 16,97 & 8,23 \\
\hline 49 & Saúde Pública & 606,31 & 146,47 & 515,75 & 136,76 & 475,32 & 152,85 \\
\hline 50 & Educ. Pública & 946,52 & 18,99 & 901,05 & 29,95 & 833,45 & 50,35 \\
\hline 51 & Seg. Pública & 662,82 & 142,15 & 567,83 & 137,25 & 522,93 & 146,75 \\
\hline 52 & Out.Adm. Pública & 915,85 & 35,19 & 784,07 & 68,12 & 723,94 & 85,61 \\
\hline 53 & Serv. Priv. N. Mercantis & 903,14 & 26,22 & 927,95 & 14,36 & 915,05 & 16,98 \\
\hline
\end{tabular}


Tabela 42. Geração de importações diretas e indiretas nos setores do Acre, resto do Norte e resto do Brasil.

\begin{tabular}{|c|c|c|c|c|c|c|c|}
\hline & \multirow{3}{*}{ Setores } & \multicolumn{6}{|c|}{ Importações } \\
\hline & & \multicolumn{2}{|c|}{ Acre } & \multicolumn{2}{|c|}{ Resto do Norte } & \multicolumn{2}{|c|}{ Resto do Brasil } \\
\hline & & Diretas & Indiretas & Diretas & Indiretas & Diretas & Indiretas \\
\hline 1 & Agricultura & 0,62 & 22,92 & 21,58 & 33,24 & 33,19 & 39,23 \\
\hline 2 & Aves & 0,66 & 24,89 & 23,63 & 56,41 & 32,83 & 51,81 \\
\hline 3 & Bovinos & 0,65 & 35,06 & 14,28 & 44,76 & 34,26 & 43,90 \\
\hline 4 & Outros Pecuária & 0,65 & 32,14 & 17,94 & 43,49 & 34,65 & 43,05 \\
\hline 5 & Ext. Veg. e Silv. & 0,59 & 15,72 & 17,30 & 16,69 & 37,69 & 18,14 \\
\hline 6 & Ext. Animal & 0,60 & 20,18 & 51,85 & 23,76 & 28,62 & 23,83 \\
\hline 7 & Ext.Mineral & 0,81 & 21,00 & 43,71 & 43,65 & 41,77 & 30,09 \\
\hline 8 & Min. não Metálico & 0,68 & 19,34 & 61,53 & 41,55 & 46,02 & 51,25 \\
\hline 9 & Metal. Básica & 1,22 & 26,82 & 138,44 & 92,27 & 77,25 & 85,46 \\
\hline 10 & Outros Metalúrg. & 0,80 & 32,47 & 124,79 & 81,65 & 46,97 & 79,18 \\
\hline 11 & Máq. e Equip. & 0,40 & 11,77 & 101,65 & 43,17 & 41,95 & 41,65 \\
\hline 12 & Mat. Elétrico & 1,82 & 55,48 & 269,48 & 72,94 & 93,48 & 75,41 \\
\hline 13 & Equip. Eletrôn. & 1,87 & 27,65 & 341,74 & 26,46 & 80,36 & 46,32 \\
\hline 14 & Aut., Cam., Ôn. e Peças & 2,47 & 46,57 & 291,08 & 63,08 & 117,81 & 77,01 \\
\hline 15 & Ind. da Madeira & 0,13 & 14,46 & 26,61 & 36,73 & 7,78 & 36,07 \\
\hline 16 & Ind. do Mobiliário & 0,70 & 22,12 & 112,38 & 57,58 & 41,76 & 53,30 \\
\hline 17 & Cel.,Pap.,Papelão e Art. Pap. & 0,87 & 16,73 & 44,58 & 44,59 & 58,03 & 58,87 \\
\hline 18 & Ind. Ed. e Gráfica & 0,89 & 17,56 & 127,17 & 58,61 & 50,70 & 59,29 \\
\hline 19 & Ind. Da Borracha & 1,33 & 39,75 & 203,83 & 83,95 & 75,79 & 76,93 \\
\hline 20 & Elem. Químicos & 0,88 & 15,95 & 188,81 & 37,50 & 50,39 & 42,71 \\
\hline 21 & Quím. diversos & 1,95 & 41,97 & 210,95 & 58,25 & 106,51 & 64,38 \\
\hline 22 & Farm. E Veterin. & 0,88 & 19,37 & 168,59 & 43,93 & 61,18 & 47,86 \\
\hline 23 & Art. Plásticos & 1,53 & 57,47 & 243,78 & 62,90 & 86,00 & 79,38 \\
\hline 24 & Ind. Têxtil & 1,73 & 35,49 & 229,82 & 116,98 & 93,21 & 98,12 \\
\hline 25 & Art. Do Vestuário & 0,64 & 45,26 & 45,31 & 102,15 & 42,06 & 87,82 \\
\hline 26 & Fab. Calçados & 0,78 & 20,64 & 17,79 & 42,75 & 51,53 & 59,56 \\
\hline 27 & Benef. de Prod.Veg. & 0,96 & 19,57 & 33,31 & 38,95 & 41,36 & 52,50 \\
\hline 28 & Abate de Aves & 0,22 & 49,68 & 4,09 & 53,64 & 13,51 & 63,93 \\
\hline 29 & Abate de Bovinos & 0,23 & 50,04 & 6,00 & 48,34 & 12,92 & 64,60 \\
\hline 30 & Ab. Suínos e Outros & 0,24 & 43,97 & 3,70 & 54,63 & 12,93 & 65,96 \\
\hline 31 & Ind. Alimentos & 0,53 & 30,49 & 36,22 & 48,05 & 31,09 & 58,49 \\
\hline 32 & Ind. Diversas & 1,13 & 27,15 & 154,09 & 43,44 & 71,78 & 50,63 \\
\hline 33 & SIUP & 0,76 & 44,58 & 64,92 & 71,43 & 23,51 & 22,46 \\
\hline 34 & Constr. Civil & 0,66 & 38,56 & 31,93 & 42,26 & 29,92 & 37,34 \\
\hline 35 & Comércio & 0,41 & 40,98 & 16,45 & 44,57 & 21,85 & 48,77 \\
\hline 36 & Transp. Rodov. & 1,06 & 47,87 & 86,75 & 66,50 & 71,43 & 69,94 \\
\hline 37 & Transp. Aéreo & 1,05 & 51,05 & 80,08 & 74,42 & 64,84 & 77,20 \\
\hline 38 & Transp. Ferrov. & 0,73 & 24,75 & 75,26 & 46,83 & 65,27 & 51,35 \\
\hline 39 & Transp. Aquav. & 0,92 & 41,62 & 77,45 & 64,77 & 65,06 & 70,92 \\
\hline 40 & Ativ. Aux. Transp. & 0,72 & 21,44 & 78,40 & 42,15 & 62,75 & 47,64 \\
\hline 41 & Comunicações & 1,94 & 29,83 & 53,24 & 26,95 & 31,72 & 14,96 \\
\hline 42 & Inst. Financeiras & 0,52 & 7,08 & 23,09 & 22,05 & 24,70 & 19,26 \\
\hline 43 & Saúde Mercantil & 0,15 & 22,01 & 3,21 & 22,94 & 6,90 & 28,11 \\
\hline 44 & Educ.Mercantil & 0,10 & 5,84 & 3,80 & 7,75 & 3,34 & 6,73 \\
\hline 45 & Serv. Aloj.eAlim. & 0,62 & 35,39 & 29,73 & 40,51 & 28,73 & 37,52 \\
\hline 46 & Out.Serv. Prest. a Fam. & 1,87 & 65,36 & 145,90 & 64,19 & 97,47 & 63,21 \\
\hline 47 & Serv. Prest. à Empresa & 0,51 & 10,59 & 24,32 & 20,51 & 30,04 & 21,34 \\
\hline 48 & Aluguel de Imóveis & 0,02 & 1,92 & 1,31 & 3,84 & 0,81 & 2,71 \\
\hline 49 & Saúde Pública & 0,63 & 22,61 & 41,13 & 43,57 & 40,71 & 39,60 \\
\hline 50 & Educ. Pública & 0,07 & 2,83 & 5,62 & 8,02 & 10,69 & 11,09 \\
\hline 51 & Seg. Pública & 0,67 & 16,52 & 33,60 & 34,73 & 46,62 & 31,87 \\
\hline 52 & Out.Adm. Pública & 0,17 & 3,54 & 21,96 & 16,28 & 28,54 & 17,23 \\
\hline 53 & Serv. Priv. N. Mercantis & 0,10 & 4,19 & 2,57 & 4,92 & 4,38 & 4,93 \\
\hline
\end{tabular}




\section{REFERÊNCIAS BIBLIOGRÁFICAS}

ACRE. Governo do Estado do Acre. Programa Estadual de Zoneamento EcológicoEconômico do Estado do Acre. Zoneamento ecológico-econômico: aspectos socioeconômicos e ocupação territorial: documento final. Rio Branco: SECTMA, 2000. 3v.

BACHA, C.J.C. Macroeconomia: conceito, mensuração e evolução dos agregados econômicos brasileiros. Piracicaba: ESALQ, Depto. Economia, Administração e Sociologia, 1999. 218p. (Série didática, 83)

BECKER, B.K. Amazônia: mudanças estruturais e tendências na passagem do milênio. In: MENDES, A.D. (Org.). A Amazônia e o seu banco. Manaus: Editora Valer/Banco da Amazônia, 2002. 445p.

BÊRNI, D.A. Matriz de insumo-produto: exposição teórica e desdobramentos empíricos. Porto Alegre: PUC-RS, Depto. Economia, Núcleo de Estudo e Pesquisa (NEP), 2000. 32p. (Textos didáticos, 2)

BRASIL. Superintendência do Plano de Valorização Econômica da Amazônia. Valorização econômica da Amazônia: programa de emergência, artigo 19 da Lei no. 1.806 de 6 de janeiro de 1953. Belém: SPVEA, Setor de Coordenação e Divulgação, 1954. 169p. 
BRASIL, M.C.; SANTOS, C.A.; TEIXEIRA, P. A população da Amazônia (1940 a 2000). In: MENDES, A.D. (Org.). A Amazônia e o seu banco. Manaus: Editora Valer/Banco da Amazônia, 2002. 445p.

BRASIL. Ministério do Desenvolvimento, Indústria e Comércio Exterior. Comércio exterior: indicadores e estatísticas: exportações. http://www.mdic.gov.br. (20 fev. 2004)

CARTER, A.P.; PETRI, P.A. Leontief's contribution to Economics. Journal of Policy Modeling, v.11, n.1, p.7-30, 1989.

CASIMIRO FILHO, F. Contribuições do turismo à economia brasileira. Piracicaba, 2002. 220p. Tese (Doutorado) - Escola Superior de agricultura “Luiz de Queiroz”, Universidade de São Paulo.

CONSIDERA, C.M.; RAMOS, R.L.O.; MAGALHÃES, K.M.M. et al. Matrizes de insumo-produto regionais 1985 e 1992: metodologia e resultados. Rio de Janeiro: IPEA, NEMESIS, 1997. 55p.

FEIJÓ, C.A.; RAMOS, R.L.O.; YOUNG, C.E.F.; LIMA, F.C.G.C.; GALVÃO, O.J.A. Contabilidade social: o novo sistema de contas nacionais do Brasil. Rio de Janeiro: Campus, 2001. cap.2, p.51-116: O novo sistema de contas nacionais do Brasil: as contas econômicas integradas e as tabelas de recursos e usos.

FEIJÓ, C.A.; RAMOS, R.L.O.; YOUNG, C.E.F.; LIMA, F.C.G.C.; GALVÃO, O.J.A. Contabilidade social: o novo sistema de contas nacionais do Brasil. Rio de Janeiro: Campus, 2001. cap.3, p.118-143: O modelo de insumo-produto. 
FEIJÓ, C.A.; RAMOS, R.L.O.; YOUNG, C.E.F.; LIMA, F.C.G.C.; GALVÃO, O.J.A. Contabilidade social: o novo sistema de contas nacionais do Brasil. Rio de Janeiro: Campus, 2001. cap.4, p.144-155: Cálculo efetivo de uma matriz de coeficientes técnicos.

FEIJÓ, C.A.; RAMOS, R.L.O.; YOUNG, C.E.F.; LIMA, F.C.G.C.; GALVÃO, O.J.A. Contabilidade social: o novo sistema de contas nacionais do Brasil. Rio de Janeiro: Campus, 2001. cap.5, p.156-173: Aplicações do modelo de insumo-produto.

FREITAS, A. Os territórios federais e o Banco da Amazônia. In: MENDES, A.D. (Org.). A Amazônia e o seu banco. Manaus: Editora Valer/Banco da Amazônia, 2002. 445p.

GUILHOTO, J.J.M.; SONIS, M.; HEWINGS, G.J.D.; MARTINS, E.B. Índices de ligações e setores-chave na economia brasileira: 1959/80. Pesquisa e Planejamento Econômico, v.2, n.24, p.287-314, ago. 1994.

GUILHOTO, J.J.M.; SONIS, M.; HEWINGS, G.J.D.; MARTINS, E.B. Linkages and multipliers in a multiregional framework: integration of alternative approaches. Urbana: University of Illinois, Regional Economics Applications Laboratory, 1996. 20p. (Discussion Paper, 96-T-8)

GUILHOTO, J.J.M.; FURTUOSO, M.C.O.; BARROS, G.S.C. O agronegócio na economia brasileira (1994-1999). Piracicaba: CNA/CEPEA/ESALQ, 2000. 112p.

GUILHOTO, J.J.M. Leontief e insumo-produto: antecedentes, princípios e evolução. Piracicaba: ESALQ, Depto. Economia, Administração e Sociologia, 2001. 32p. (Série Seminários da Pós-Graduação, 15) 
GUILHOTO, J.J.M.; OLIVEIRA, A.F.; GAMEIRO, A.H. et al. Notas metodológicas de construção da matriz insumo-produto para a economia brasileira para 1999. Piracicaba: ESALQ, Depto. Economia, Administração e Sociologia, 2001b. (Relatório de atividades)

GUILHOTO, J.J.M.; SESSO FILHO, U.A.; LOPES, R.L.; HILGEMBERG, C.M.A.T.; HILGEMBERG, E.M. Nota metodológica: construção da matriz insumo-produto utilizando dados preliminares das contas nacionais (compact disc). In: ENCONTRO BRASILEIRO DE ESTUDOS REGIONAIS E URBANOS, 2., São Paulo, 2002. Anais. São Paulo: Associação Brasileira de Estudos Regionais, 2002. p.1-19.

GUILHOTO, J.J.M.; MAGALHÃES, A.M.; SESSO FILHO, U.A.; HILGEMBERG, C.M.A.T.; HILGEMBERG, E.M.; CAMARGO, F.S.; SILVA, G.S.; MORI, J.S.; CECCHINI, K.; SILVA, L.M.S.; HASEGAWA, M.M.; FIGUEIREDO, M.G.; FURTUOSO, M.C.; LOPES, R.L. Projeto de estimação de matrizes de insumoproduto para a região e os Estados da Amazônia Legal: relatório final. Recife, dez. 2002. 159p.

GUILHOTO, J.J.M. Análise de insumo-produto: teoria e fundamentos. Piracicaba, 2003. 64p. /No prelo/

INSTITUTO BRASILEIRO DE GEOGRAFIA E ESTATÍSTICA (IBGE). Censo demográfico de 2000. http://www.ibge.gov.br (05 maio 2003)

INSTITUTO BRASILEIRO DE GEOGRAFIA E ESTATÍSTICA. Cadastro geral de empresas 1996-2001. http://www.ibge.gov.br (05 jan. 2004a)

INSTITUTO BRASILEIRO DE GEOGRAFIA E ESTATÍSTICA. Produção agrícola municipal 1990-2002. http://www.ibge.gov.br (05 jan. 2004b) 
INSTITUTO BRASILEIRO DE GEOGRAFIA E ESTATÍSTICA. Produção extrativa vegetal 1990-2002. http://www.ibge.gov.br (05 jan. 2004c)

INSTITUTO BRASILEIRO DE GEOGRAFIA E ESTATÍSTICA. Pesquisa da pecuária municipal 1990-2002. http://www.ibge.gov.br (05 jan. 2004d)

LEONTIEF, W. Input-output economics. 2.ed. New York: Oxford University Press, 1986. 257p.

MENDES, A.D. Amazônia: terra e civilização: variações em torno de uma trajetória de 60 anos - 1942-2002. In: MENDES, A.D. (Org.). A Amazônia e o seu banco. Manaus: Editora Valer/Banco da Amazônia, 2002. 445p.

MIERNYK, W.H. Elementos de análise do insumo-produto. Tradução de A. Reis. São Paulo: Atlas, 1974. 164 p.

MILLER, R.E.; BLAIR, P.D. Input-output analysis: foundations and extensions. New Jersey: Prentice Hall, 1985. 463p.

MIRANDA NETO, M. O enigma amazônico: desafio ao futuro. Belém: CEJUP, 1991. 20p.

MORAES, R. $\mathbf{O}$ papel do setor público na Amazônia. http://www.iesam.com.br/03/aceb/doc/A03-Setor-Pblico.pdf (20 abr. 2003)

MONTOYA RODRIGUEZ, M.A. A matriz insumo-produto internacional do Mercosul em 1990: a desigualdade regional e o impacto intersetorial do comércio interregional. Piracicaba, 1998. 217p. Tese (Doutorado) - Escola Superior de Agricultura “Luiz de Queiroz”, Universidade de São Paulo. 
MORETTO, A.C. Relações intersetoriais e inter-regionais na economia paranaense em 1995. Piracicaba, 2000. 161p. Tese (Doutorado) - Escola Superior de Agricultura “Luiz de Queiroz”, Universidade de São Paulo.

NASSER, B. Economia regional, desigualdade regional no Brasil e o estudo dos eixos nacionais de integração e desenvolvimento. Revista do BNDES, n.7, p.145-178, dez. 2000.

SILVEIRA, S. de F.R. Inter-relações econômicas dos estados da bacia do Rio São Francisco: análise de insumo-produto. Piracicaba, 2000. 245p. Tese (Doutorado) Escola Superior de Agricultura “Luiz de Queiroz”, Universidade de São Paulo.

SIQUEIRA, T.V.; SIFFER FILHO, N.F. Desenvolvimento regional no Brasil: tendências e novas perspectivas. Revista do BNDES, v.8, n.16, p.79-118, dez. 2001. 